\title{
EVOLUTION OF ANTHROPOGENIC PB AND PB ISOTOPES IN THE DEEP NORTH ATLANTIC OCEAN AND THE INDIAN OCEAN
}

\author{
By \\ Jong-Mi Lee \\ B.S., Seoul National University, Republic of Korea, 2005 \\ M.S., Seoul National University, Republic of Korea, 2007 \\ Submitted in partial fulfillment of the requirements for the degree of \\ Doctor of Philosophy \\ at the

\begin{abstract}
MASSACHUSETTS INSTITUTE OF TECHNOLOGY
and the

WOODS HOLE OCEANOGRAPHIC INSTITUTION
\end{abstract}

June 2013

C2013 Jong-Mi Lee. All rights reserved.

The author hereby grants to MIT and WHOI permission to reproduce and to distribute publicly paper and electronic copies of this thesis document in whole or in part in any medium now known or hereafter created.

Signature of Author

Joint Program in Oceanography/Applied Ocean Science and Engineering Massachusetts Institute of Technology and Woods Hole Oceanographic Institution May 16, 2013

Certified by

Edward A. Boyle

Professor of Earth, Atmospheric, and Planetary Sciences

Thesis Supervisor

Accepted by

Bernhard Peucker-Ehrenbrink

Chair, Joint Committee for Chemical Oceanography Woods Hole Oceanographic Institution 


\title{
Evolution of Anthropogenic $\mathrm{Pb}$ and $\mathrm{Pb}$ isotopes in the deep North Atlantic Ocean and the Indian Ocean
}

\author{
by \\ Jong-Mi Lee \\ Submitted to the MIT/WHOI Joint Program in Oceanography/Applied Ocean Science \\ and Engineering \\ on May 16th, 2013, in partial fulfillment of the \\ Requirement for the degree of \\ Doctor of Philosophy
}

$\mathrm{Pb}$ and $\mathrm{Pb}$ isotopes in the ocean have varied on decadal to centennial time scales due to anthropogenic $\mathrm{Pb}$ inputs. Thus, tracing the temporal variation of $\mathrm{Pb}$ and $\mathrm{Pb}$ isotopes in the ocean provides information on the major sources of $\mathrm{Pb}$ and the transport of $\mathrm{Pb}$ from sources to the ocean surface and into the ocean interior. In this thesis study, first, a method was developed for the analysis of dissolved $\mathrm{Pb}$ and other trace elements in seawater using single batch nitrilotriacetate resin extraction and isotope dilution ICP-MS, which was applied in analyzing seawater $\mathrm{Pb}$ concentrations in the rest of the study. A $\sim 550$ year history of the $\mathrm{Pb}$ and $\mathrm{Pb}$ isotopes in the deep North Atlantic Ocean is reconstructed using a deep-sea coral, showing the infiltration of anthropogenic $\mathrm{Pb}$ to deep sea. Comparing the results to the surface North Atlantic Ocean $\mathrm{Pb}$ record using a Transit Time Distribution model, the mean transit time of $\mathrm{Pb}$ is estimated to be $\sim 64$ years. This is longer than the transit time estimate assuming simple advection from a source, showing the importance of advective-diffusive mixing in the transport of $\mathrm{Pb}$ to the ocean interior. The later part of the thesis investigates $\mathrm{Pb}$ in the Indian Ocean, where no useful $\mathrm{Pb}$ data have been previously reported. First, using annually-banded surface growing corals, I reconstruct variations of $\mathrm{Pb}$ and isotopes in the surface waters of the central and eastern Indian Oceans during the past half-century. Results of the study show the increase of $\mathrm{Pb}$ concentrations from the mid-1970s, and major sources of the $\mathrm{Pb}$ are discussed, including leaded gasoline and coal burning, based on their emission histories and $\mathrm{Pb}$ isotope signatures. Second, $\mathrm{Pb}$ concentration and isotope profiles are presented from the northern and western Indian Oceans. Higher $\mathrm{Pb}$ concentrations and lower $\mathrm{Pb}$ isotope ratios $\left({ }^{206} \mathrm{~Pb} /{ }^{207} \mathrm{~Pb},{ }^{208} \mathrm{~Pb} /{ }^{207} \mathrm{~Pb}\right)$ are found in the upper water column $(<1500 \mathrm{~m})$ as a result of 
anthropogenic $\mathrm{Pb}$ inputs, and their distributions are largely controlled by the water circulation in the Indian Ocean.

Thesis Supervisor: Edward A. Boyle

Title: Professor of Earth, Atmospheric and Planetary Sciences 


\section{Acknowledgement}

I would like to thank all the people who made this work possible. First, I owe a big thank to my advisor Ed Boyle. He taught me a lot about trace metal techniques, guided me to find right and important scientific questions whenever I was lost, and supported all my work. Not only that, he was also supportive of me having a family, very understanding and patient, which I cannot be grateful enough.

I'd like to thank my committee: Bill Jenkins, Carl Lamborg, Phoebe Lam, and Konrad Hughen. Interests they showed during committee meetings were so inspiring and encouraging. I usually had this magical experience that my work, which looked so boring beforehand, turns into the most interesting one in the world after the committee meeting.

I also would like to thank Jess Adkins and Selene Eltgroth, who provided the deep-sea coral and the radiocarbon data used in Chapter 3, and shared their expertise in deep-sea coral analysis with me. My work in Chapter 4 and 5 could not be completed without these people who helped me to collect corals and seawater samples from the Indian Ocean: Miriam Pfeiffer, Aron Meltzner, Kerry Sieh, Bambang Suwargadi, Danny Natawidjaja, Toshitaka Gamo, Hajime Obata, and Kazuhiro Norisuye. I'd like to send my special thanks to Intan Suci Nurhati for collecting coral and aerosol samples from Singapore, and Mengli Chen for having lengthy discussion with me about the industrial $\mathrm{Pb}$ sources in Singapore.

I also want to thank my lab members. Rick Kayser provided terrific laboratory and field support. Gonzalo Carrasco and Abigail Noble were wonderful friends and also great mentors. Jessica Fitzsimmons was an awesome officemate, who always encouraged me with positive words and a big hug. I'd also like to thank Simone Moos and my former lab colleagues, Ruifeng Zhang and Yolanda Echegoyen-Sanz, for their support and friendship. Yolanda also allowed me to use her $\mathrm{Pb}$ concentration data from the Indian Ocean for my work in Chapter 5.

Lastly, I give heartfelt thanks to my family and friends for their love and infinite support throughout this process. Special thanks to my Mom who came from Korea to Boston twice to help me raising Ihan, and to my Dad who had to live lonely life in Korea while Mom was here. Thank my husband Moonyoung who encouraged me to finish graduate school when I wanted to quit, and thank Ihan for being there.

This research was supported by the US National Science Foundation (NSF Award No. OCE-0926197, OCE-1233749, OCE-0926204), the Singapore National Research Foundation through the Singapore-MIT Alliance for Research and Technology (Award No. WBS 6916070), and Center for Microbial Research and Education (NSF-OIA Award No. EF-0424599). The coral from Singapore was collected with the permit of the National Parks Board (Permit No: NP/RP11-016b). 


\section{Table of contents}

\section{Chapter 1.}

Introduction. $\quad 13$

1.1. The Biogeochemical Cycle of $\mathrm{Pb}$ in the Ocean 13

1.2. Anthropogenic $\mathrm{Pb}$ emissions and historical records 16

1.3. Anthropogenic $\mathrm{Pb}$ in the Ocean 19

1.4. Pb Isotope Geochemistry 21

1.5. Thesis outline 24

\section{Chapter 2.}

Analysis of trace metals $(\mathrm{Cu}, \mathrm{Cd}, \mathrm{Pb}$, and $\mathrm{Fe})$ in seawater using single batch nitrilotriacetate resin extraction and isotope dilution inductively coupled plasma mass spectrometry 39

2.1. Introduction 40

2.2. Experimental 41

2.2.1. Reagents 41

2.2.2. Materials 41

2.2.3. Standards 41

2.2.4. NTA (nitrilotriacetate) resin 42

2.2.5. Seawater for method calibration 42

2.2.6. Instrumentation 42

2.2.7. General procedure 43

2.3. Results and discussion 43

2.3.1. Sample $\mathrm{pH}$

2.3.2. Number of resin beads 43

2.3.3. Sample-resin binding and trace metal elution times 44

2.3.4. Procedural blank, detection limit, and accuracy 45

2.3.5. Multi-element analysis 45 
2.3.6. $\mathrm{Cu}, \mathrm{Cd}, \mathrm{Pb}$, and $\mathrm{Fe}$ concentrations from open ocean (BATS) samples 46

$\begin{array}{ll}\text { 2.4. Conclusions } & 47\end{array}$

\section{Chapter 3.}

$\mathrm{Pb}$ in a deep sea coral: transfer of anthropogenic Pb to the deep North Atlantic Ocean over the last 500 years $\quad 49$

3.1. Introduction $\quad 50$

3.2. Sampling and analytical methods $\quad 52$

3.2.1. Coral sampling 53

3.2.2. Coral cleaning and analysis of $\mathrm{Pb} / \mathrm{Ca}$ and $\mathrm{Pb}$ isotopes 54

3.3. Results 56

3.3.1. Age model using ${ }^{14} \mathrm{C} \quad 56$

3.3.2. $\mathrm{Pb} / \mathrm{Ca}$ and $\mathrm{Pb}$ isotope ratios 56

3.4. Discussion 58

3.4.1. Apparent transit time of $\mathrm{Pb} \quad 58$

3.4.2. Transit time distributions (TTDs) 60

3.4.2.1. Background $\quad 60$

3.4.2.2. Surface and deep ocean tracer concentrations 62

3.4.2.3. Constraining TTDs 65

3.4.2.4. Discrepancies between model-estimated and observed $\mathrm{Pb} 67$

$\begin{array}{ll}\text { 3.5. Conclusions } & 73\end{array}$

\section{Chapter 4.}

History of the $\mathrm{Pb}$ and $\mathrm{Pb}$ isotopes of the surface Indian Ocean over the past $\sim 50$ years reconstructed from corals 91

4.1. Introduction $\quad 92$

4.2. Materials and Methods $\quad 94$

4.2.1. Sample collection and analysis $\quad 94$ 
4.2.2. Regional setting

4.2.3. History of industrial $\mathrm{Pb}$ emissions from countries around the Indian Ocean

4.3. Results 102

4.3.1. $\mathrm{Pb} / \mathrm{Ca}$ ratios of the corals 102

4.3.2. $\mathrm{Pb}$ isotope ratios of the corals

104

4.4. Discussion

106

4.4.1. $\mathrm{Pb}$ in the Chagos coral and its potential sources

106

4.4.2. $\mathrm{Pb}$ in the Western Sumatra coral and its potential sources

109

4.4.3. $\mathrm{Pb}$ in the Jong Island coral and its potential sources

110

4.5. Conclusions

115

\section{Chapter 5.}

Distribution of $\mathbf{P b}$ and $\mathbf{P b}$ isotopes in the Indian Ocean 143

5.1. Introduction 144

5.2. Materials and methods 148

5.3. Results 150

5.3.1. Hydrography 150

5.3.2. Distribution of $\mathrm{Pb}$ concentrations 151

5.3.3. Distribution of $\mathrm{Pb}$ isotopes 152

5.4. Discussion 154

5.4.1. $\mathrm{Pb}$ concentrations and the phase-out of leaded gasoline $\quad 154$

5.4.2. $\mathrm{Pb}$ in the Southern Ocean (station 14) 155

5.4.3. Pb isotopes in the southern Indian Ocean SAMW 156

5.4.4. $\mathrm{Pb}$ isotopes in the northwestern Indian Ocean (Arabian Sea) 159

5.4.5. $\mathrm{Pb}$ isotopes in the Bay of Bengal 161

5.5. Conclusions 166

Appendix I. Pb isotopes measurement via MC-ICP-MS 193 


\section{List of Figures}

\section{Chapter 1.}

1.1 Historical leaded gasoline consumption in US and Western Europe, and the $\mathrm{Pb}$ record from the Pettaquamscutt River sediments 32

1.2 $\mathrm{Pb}$ concentrations from the Dasuopu ice cap, Mt. Xixabangma, Himalaya 33

1.3 Historical $\mathrm{Pb}$ concentrations and ${ }^{206} \mathrm{~Pb} /{ }^{207} \mathrm{~Pb}$ ratios of the surface waters near Bermuda 34

$1.4 \mathrm{~Pb}$ concentration and ${ }^{206} \mathrm{~Pb} /{ }^{207} \mathrm{~Pb}$ profiles in seawaters near Bermuda from 1979 to 201135

$1.5 \mathrm{~Pb}$ contents and ${ }^{206} \mathrm{~Pb} /{ }^{207} \mathrm{~Pb}$ of a coral collected from Ogasawara Island, Japan 36

1.6 Radiogenic growth curves for the bulk Earth $\mathrm{Pb}$ isotopes 37

1.7 Global map of the $\mathrm{Pb}$ isotope composition of city aerosols collected in 1994-1999 38

\section{Chapter 2}

2.1 Relationships between percent recovery of $\mathrm{Cd}$ and $\mathrm{Pb}$ and the sample $\mathrm{pH}$

2.2 Relationships between percent recovery of $\mathrm{Cu}, \mathrm{Cd}$, and $\mathrm{Pb}$ and the number of days allowed for sample-resin binding

2.3 Relationships between percent recovery of $\mathrm{Pb}$ and the number of NTA resin beads added to the sample

2.4 Profiles of $\mathrm{Cu}, \mathrm{Cd}, \mathrm{Pb}$, and $\mathrm{Fe}$ at BATS analyzed by the ID-NTA bead-ICPMS method and comparison with the data from nearby stations in Sargasso Sea

2.5 Cd-P relationship in the GEOTRACES-BATS station compared with that from nearby stations

\section{Chapter 3}

3.1 Enallopsammia rostrata sample ALV-3701-8

$3.2 \mathrm{~Pb} / \mathrm{Ca},{ }^{206} \mathrm{~Pb} /{ }^{207} \mathrm{~Pb}$ and ${ }^{208} \mathrm{~Pb} /{ }^{207} \mathrm{~Pb}$ ratios in the deep sea coral E. rostrata (ALV-3701-8) 82

3.3 Comparison of the $\mathrm{Pb}$ concentrations and isotope ratios in the deep sea with those in the surface North Atlantic Ocean

3.4 Pairs of $\Gamma$ and $\Delta$ constrained by $\mathrm{CFC} 11, \mathrm{CFC} 12, \mathrm{CFC} 113$, and ${ }^{14} \mathrm{C}$

3.5 TTDs with different mean ages, and model-reproduced deep-sea tracer concentrations (CFCs, $\Delta^{14} \mathrm{C}, \mathrm{Pb}$ and $\mathrm{Pb}$ isotope ratios) in comparison with the observed data 
3.6 Model-reproduced $\mathrm{Pb}$ concentrations and isotope ratios with different particle scavenging rates and regeneration efficiencies

\section{Chapter 4}

4.1 Map of the Indian Ocean and sampling locations of the Chagos, Sumatra, and Jong Island corals

4.2 $\mathrm{Pb}$ emissions from gasoline combustion in the countries around the Indian Ocean

4.3 $\mathrm{Pb}$ emissions from coal burning for electricity production in the countries around the Indian Ocean

4.4 Time series of $\mathrm{Pb} / \mathrm{Ca},{ }^{206} \mathrm{~Pb} /{ }^{207} \mathrm{~Pb}$ and ${ }^{208} \mathrm{~Pb} /{ }^{207} \mathrm{~Pb}$ ratios in the Chagos coral

4.5 Time series of $\mathrm{Pb} / \mathrm{Ca},{ }^{206} \mathrm{~Pb} /{ }^{207} \mathrm{~Pb}$ and ${ }^{208} \mathrm{~Pb} /{ }^{207} \mathrm{~Pb}$ ratios in the Sumatra coral

4.6 Time series of $\mathrm{Pb} / \mathrm{Ca},{ }^{206} \mathrm{~Pb} /{ }^{207} \mathrm{~Pb}$ and ${ }^{208} \mathrm{~Pb} /{ }^{207} \mathrm{~Pb}$ ratios in the Jong Island coral

4.7 Total $\mathrm{Pb}$ emissions from India and its relationship with the Chagos coral $\mathrm{Pb} / \mathrm{Ca}$ ratios

4.8 Triple isotope plot for the $\mathrm{Pb}$ in the Chagos and Sumatra corals in comparison with various anthropogenic $\mathrm{Pb}$ sources

4.9 Triple isotope plot for the $\mathrm{Pb}$ in the Jong Island coral in comparison with various anthropogenic $\mathrm{Pb}$ sources

\section{Chapter 5}

5.1 Map of sampling stations in the Japanese Indian GEOTRACES cruise (KH 09-5)

5.2 T-S diagram of the stations in the northern and southern Indian Oceans

5.3 Transect of dissolved $\mathrm{Pb}$ concentrations, ${ }^{206} \mathrm{~Pb} /{ }^{207} \mathrm{~Pb}$, and ${ }^{208} \mathrm{~Pb} /{ }^{207} \mathrm{~Pb}$ ratios from the western Indian Ocean

5.4 Triple isotope plot for the $\mathrm{Pb}$ in the Indian Ocean seawater in comparison with various anthropogenic $\mathrm{Pb}$ sources

$5.5{ }^{206} \mathrm{~Pb} /{ }^{207} \mathrm{~Pb}$, dissolved $\mathrm{O}_{2}$, and density profiles of the southern Indian Ocean

$5.6{ }^{206} \mathrm{~Pb} /{ }^{207} \mathrm{~Pb}$, salinity, and density profiles of the northern Indian Ocean upper waters

5.7 $\mathrm{Pb}$ isotope composition of the aerosols collected near the southern Africa, 1994-2007

5.8 $\mathrm{Pb}$ concentration and isotope profiles in the Arabian Sea and the Bay of Bengal 


\section{List of Tables}

\section{Chapter 2}

2.1 Fe released from various vials with different positions 41

2.2a Typical PQ2+ operating conditions for $\mathrm{Cu}, \mathrm{Cd}$, and $\mathrm{Pb}$ analysis 42

2.2b Typical Isoprobe operating conditions for Fe analysis 42

2.3 Procedural blank and detection limit of the ID-NTA bead-ICPMS method and SAFe consensus $\mathrm{Cu}, \mathrm{Cd}, \mathrm{Pb}$, and $\mathrm{Fe}$ values determined by this method 45

2.4 Concentrations of $\mathrm{Cu}, \mathrm{Cd}$, and $\mathrm{Pb}$ in ${ }^{65} \mathrm{Cu},{ }^{110} \mathrm{Cd}$, and ${ }^{204} \mathrm{~Pb}$ enriched isotope spikes $\quad 46$

\section{Chapter 3}

3.1 $\mathrm{Pb} / \mathrm{Ca},{ }^{206} \mathrm{~Pb} /{ }^{207} \mathrm{~Pb}$, and ${ }^{208} \mathrm{~Pb} /{ }^{207} \mathrm{~Pb}$ ratios in the deep-sea coral ALV-3701-8

\section{Chapter 4}

4.1 $\mathrm{Pb} / \mathrm{Ca},{ }^{206} \mathrm{~Pb} /{ }^{207} \mathrm{~Pb},{ }^{208} \mathrm{~Pb} /{ }^{207} \mathrm{~Pb}$, and ${ }^{206} \mathrm{~Pb} /{ }^{204} \mathrm{~Pb}$ ratios in the Chagos coral

$4.2 \mathrm{~Pb} / \mathrm{Ca},{ }^{206} \mathrm{~Pb} /{ }^{207} \mathrm{~Pb},{ }^{208} \mathrm{~Pb} /{ }^{207} \mathrm{~Pb}$, and ${ }^{206} \mathrm{~Pb} /{ }^{204} \mathrm{~Pb}$ ratios in the Sumatra coral

$4.3 \mathrm{~Pb} / \mathrm{Ca},{ }^{206} \mathrm{~Pb} /{ }^{207} \mathrm{~Pb},{ }^{208} \mathrm{~Pb} /{ }^{207} \mathrm{~Pb}$, and ${ }^{206} \mathrm{~Pb} /{ }^{204} \mathrm{~Pb}$ ratios in the Jong Island coral 136

4.4 $\mathrm{Pb}$ isotope ratios in seawater collected from the South China Sea in March, 2000 138

4.5 $\mathrm{Pb}$ isotope ratios in aerosols collected in Singapore, 2011-2012

4.6 $\mathrm{Pb}$ emissions from leaded gasoline combustions in the South and Southeast Asian countries

4.7 $\mathrm{Pb}$ emissions from coal burning for electricity production in the South and Southeast Asian countries

\section{Chapter 5}

5.1 Hydrographic condition of the stations from the Japanese Indian GEOTRACES cruise 184

5.2 $\mathrm{Pb}$ concentration and $\mathrm{Pb}$ isotope results from the Japanese Indian GEOGRACES cruise 187 


\section{Chapter 1: Introduction}

Lead $(\mathrm{Pb})$ is one of the elements most contaminated by human activities. $\mathrm{Pb}$ in the modern ocean is dominated by anthropogenic $\mathrm{Pb}$, and the distribution of $\mathrm{Pb}$ and $\mathrm{Pb}$ isotopes throughout the ocean provides valuable information on the transport and removal of these anthropogenic inputs and the time scales of those processes in the ocean. This information is critical for proper environmental management as $\mathrm{Pb}$ is highly toxic to human and marine organisms, and it is also useful in predicting the fate of other anthropogenic elements (e.g., $\mathrm{Cu}, \mathrm{Cd}, \mathrm{Zn}$ and $\mathrm{Hg}$ ) that are produced and introduced to the ocean via similar pathways. In addition, anthropogenic $\mathrm{Pb}$ can serve as a transient tracer of oceanic processes (e.g., ventilation) because anthropogenic $\mathrm{Pb}$ fluxes to the ocean and their isotope ratios are temporally and spatially variable depending on major $\mathrm{Pb}$ sources. However, despite this importance, existing data on the $\mathrm{Pb}$ in the ocean are very limited; there are only a few time series data, and direct seawater $\mathrm{Pb}$ observations are from a few locations, spanning only the past three decades. This thesis study presents decadal- to centennial-scale records of $\mathrm{Pb}$ in surface and deep oceans and new water column profiles of $\mathrm{Pb}$ and $\mathrm{Pb}$ isotopes from the areas not previously studied, which will improve our current understanding on the $\mathrm{Pb}$ in the ocean.

\subsection{The Biogeochemical Cycle of $\mathrm{Pb}$ in the Ocean}


Naturally-occurring $\mathrm{Pb}$ in the ocean is supplied from three sources: hydrothermal $\mathrm{Pb}$ derived from mid-ocean ridges, rivers, and aeolian dust deposition. Hydrothermal sources are estimated to supply about 2-6\% (Chen et al, 1986; Peucker-Ehrenbrink et al., 1994) of the total natural $\mathrm{Pb}$ flux $\left(1.3 \times 10^{7} \mathrm{~kg} \mathrm{yr}^{-1}\right)$ to the oceans (Chow and Patterson, 1962). However, most of this hydrothermal $\mathrm{Pb}$ is known to be precipitated close to the vents and ridges with sulphide (Chen et al., 1986, Godfrey et al., 1994) or metalliferous sediments (O’Nions et al., 1978; Peucker-Ehrenbrink et al., 1994), and contribute little to the dissolved $\mathrm{Pb}$ budgets in the ocean. Likewise, most of the dissolved riverine $\mathrm{Pb}$ has been suggested to be scavenged in estuaries (e.g., Rama et al., 1961; Benninger et al., 1975; Danielsson et al., 1983; Windom et al., 1985), although in some rivers, it has been found that $\mathrm{Pb}$ is conservative or released from particles in estuaries (e.g., Benoit et al., 1994; Boutier et al., 1993; Elbaz-Poulichet et al., 1996; Windom et a., 1985). Therefore, the dominant source of naturally occurring $\mathrm{Pb}$ in the open ocean is considered to be aeolian dust deposition. The aeolian $\mathrm{Pb}$ flux is difficult to quantify because of the contamination of modern aerosols with anthropogenic $\mathrm{Pb}$ and large uncertainties in solubilization of aerosol $\mathrm{Pb}$ in seawater. For example, a model assuming $8 \%$ solubility predicts that aeolian $\mathrm{Pb}$ contributes a significant fraction (40-90\%) of the $\mathrm{Pb}$ in most parts of the world ocean (Henderson and Maier-Reimer, 2002).

The dominance of aeolian supply of $\mathrm{Pb}$ is particularly true in the modern ocean, where anthropogenic $\mathrm{Pb}$ fluxes predominate over the natural $\mathrm{Pb}$ fluxes (Nriagu, 1979; 1990; Nriagu and Pacyna, 1988). Anthropogenic Pb is often associated with sub-micron, carbonaceous aerosols derived from high-temperature industrial processes (Rosman et al., 
1990), and thus, it is effectively transported long-distance by winds and removed from the atmosphere to the ocean by wet and dry deposition. The atmospheric $\mathrm{Pb}$ deposition is mostly by precipitation, e.g., accounting for $\sim 85 \%$ of the total deposition (Duce et al., 1991), and the residence time of aerosols in the troposphere is about a week (e.g. (Francis et al., 1970).

In the ocean, $\mathrm{Pb}$ is not utilized in any biological process. Although it is possible that $\mathrm{Pb}$ is inadvertently taken up by organisms, it is likely that $\mathrm{Pb}$ is removed from water column by scavenging onto the surfaces of sinking particles. $\mathrm{Pb}$ scavenged onto particles might be partially released into the dissolved phase in deep ocean as some particles remineralize during sinking (e.g., Wu et al., 2010). However, the net effect is removal of $\mathrm{Pb}$ by scavenging as evidenced by the deficit of ${ }^{210} \mathrm{~Pb}$ compared to ${ }^{226} \mathrm{Ra}$ in the deep sea. Based on ${ }^{210} \mathrm{~Pb}$, the residence time of $\mathrm{Pb}$ has been estimated to be a few years at the surface and 50-200 years in the deep sea (Bacon et al., 1976; Cochran et al., 1983; Craig et al., 1973; Schaule and Patterson, 1981). In addition to scavenging by sinking particles, it has been suggested that $\mathrm{Pb}$ is removed by boundary scavenging near oceanic margins (e.g., Cochran et al., 1983; Bacon et al., 1976), probably because of Fe- and Mn oxidation-reduction cycling occurring in shelf and slope sediments . Therefore, as a result of predominantly aeolian (natural and anthropogenic) $\mathrm{Pb}$ inputs and particle scavenging, $\mathrm{Pb}$ concentrations in the ocean are often high in the surface mixed layer and rapidly decrease with depth, although this pattern is changing in some regions due to decreasing anthropogenic $\mathrm{Pb}$ fluxes (see Figure 1.4a). 
In the marine environment, dissolved lead $(\mathrm{Pb})$ accounts for $\sim 90 \%$ of the total open ocean $\mathrm{Pb}$ concentration (Shen and Boyle, 1987). Among the dissolved Pb, a significant portion appears to be organically complexed, e.g. 50-70\% of the $\mathrm{Pb}$ in surface waters of the Eastern North Pacific (Capodaglio et al., 1990) and 67-94\% in the Narragansett Bay (Wells et al., 1998). The remaining portion of dissolved $\mathrm{Pb}$ is inorganically bound; Whitfield and Turner (1980) estimated $\mathrm{PbCO}_{3}$ accounts for 55\% of the dissolved inorganic fraction, followed by $\mathrm{PbCl}_{2}(11 \%), \mathrm{Pb}\left(\mathrm{CO}_{3}, \mathrm{Cl}_{3}\right)^{-}(10 \%)$, and $\mathrm{PbCl}^{+}(7 \%)$. The remaining $17 \%$ includes other chloride complexes with additional sulphate and hydroxide complexes.

\subsection{Anthropogenic $\mathrm{Pb}$ emissions and historical records}

Modern $\mathrm{Pb}$ emissions are dominated by anthropogenic emissions. For example, global anthropogenic $\mathrm{Pb}$ emissions in 1975 and 1983 were estimated to be $45 \times 10^{7} \mathrm{~kg}$ and $33 \times 10^{7} \mathrm{~kg}$ (Nriagu, 1979, Nriagu and Pacyna, 1988), almost thirty-fold higher than natural $\mathrm{Pb}$ emissions $\left(12 \times 10^{6} \mathrm{~kg}\right.$ ) (Nriagu, 1989). Anthropogenic $\mathrm{Pb}$ production began approximately 5000 yrs ago, when technologies for smelting lead-silver alloys from sulfide ores and cupelling silver from the alloys were developed (Settle and Patterson, 1980). The anthropogenic $\mathrm{Pb}$ emissions then greatly increased with the onset of industrial evolution because $\mathrm{Pb}$ has been used in various products, e.g., cement, paint, lead-acid batteries, weights, solder, etc., as it is highly malleable and ductile. Anthropogenic $\mathrm{Pb}$ emissions in the 20th century were dominated by North America and Europe, particularly by the leaded gasoline combustion in those regions. The use of leaded gasoline began in 
1920s and increased rapidly from 1950s until the late 1970s (Shotyk et al., 1998; Shen and Boyle, 1987; Wu and Boyle, 1997) (Figure 1.1a), when North America and Europe phased out the leaded gasoline in 1970s and early 1980s because of the toxicity of $\mathrm{Pb}$. Since then, the anthropogenic $\mathrm{Pb}$ emissions from North America and Europe rapidly decreased (Figure 1.1a), but during this period, $\mathrm{Pb}$ emissions probably increased in the other continents such as Asia, South America, Africa.

Few studies have quantitatively estimated and investigated temporal variability of the $\mathrm{Pb}$ emissions from Asia, South America, Africa, and Oceania. However, evidence of increased $\mathrm{Pb}$ pollution in these regions has been found in numerous studies, where they found high $\mathrm{Pb}$ concentrations in aerosols and human blood (e.g., Cheng and $\mathrm{Hu}, 2010$; Chester et al., 1991; Nriagu et al., 1996a; Tripathi et al., 2001). Anthropogenic Pb emissions in these regions probably have increased in the past few decades, given that 1) economic development in most of these regions began only a few decades ago, 2) leaded gasoline has been used until 1990s and early 2000s in most countries (UNEP, 2007) and is still used in Afghanistan, Algeria, Iraq, Myanmar, North Korea, and Yemen (as of 2012). Moreover, in these regions, $\mathrm{Pb}$ emissions from other industrial sources such as smelting, coal burning, and waste incineration, may be comparable to leaded gasoline combustion, e.g. Nriagu (1996a, 1996b) estimated more than 50\% of the anthropogenic $\mathrm{Pb}$ emissions from Africa are from smelting and mining.

Knowing the past variability of $\mathrm{Pb}$ emissions is important because then we can interpret the modern $\mathrm{Pb}$ observations within a historical context and assess the relative importance of various anthropogenic $\mathrm{Pb}$ sources and their transport mechanisms. 
Because anthropogenic $\mathrm{Pb}$ is dispersed throughout the environment by atmospheric transport, historical changes of the anthropogenic $\mathrm{Pb}$ emissions have been found over a wide area, including Polar ice and snows (e.g., Boutron et al., 1991; Candelone et al., 1995; Hong et al., 1994; Murozumi et al., 1969; Wolff and Suttie, 1994), peat bogs (e.g., Shotyk et al., 1998; Weiss et al., 1999), remote ponds (e.g., Shirahata et al., 1980), and aquatic sediments (e.g., Graney et al., 1995; Lima et al., 2005). For example, $\mathrm{Pb}$ concentrations in Greenland ice increased 200-fold during the past 3000 years $(<0.001 \mu \mathrm{g}$ $\mathrm{g}^{-1}$ in $800 \mathrm{BC}$ to $>0.200 \mu \mathrm{g} \mathrm{g}^{-1}$ in 1965) (Murozumi et al., 1969), and Pb concentrations in the Pettaquamscutt River sediments (Rhode Island, US) increased almost 10-fold for the past two centuries and decreased threefold after 1979 as a result of the phase-out of leaded gasoline in US (Lima et al., 2005) (Figute 1.1b).

However, most of these historical records are from North America, Western Europe, or from the regions that primarily receive the $\mathrm{Pb}$ originated from those two regions. Only a few studies have documented the historical $\mathrm{Pb}$ fluxes in the other regions, e.g., Asia, South America, and Oceania, on a regional scale. For example, Barbante et al. (1998) estimated that anthropogenic $\mathrm{Pb}$ emissions from South America peaked in early 1970s, whereas those from Oceania peaked around 1985, which are reflected in the $\mathrm{Pb}$ concentrations in Coast Land and Victoria Land snows in Antarctica. Ice cores from Mt. Xixabangma (Huo et al., 1999) and Mt. Everest (Lee et al., 2011) in the central Himalayas showed that $\mathrm{Pb}$ concentrations continuously increased from 1960s to 1990s, reflecting the $\mathrm{Pb}$ emission trends from Central Asia and the Indian Continent (Figure 1.2). 


\subsection{Anthropogenic $\mathrm{Pb}$ in the Ocean}

As the residence time of $\mathrm{Pb}$ in surface seawater is $\sim 2$ years, $\mathrm{Pb}$ in the surface approaches a steady-state level within a few years tracking changes in the $\mathrm{Pb}$ flux into the ocean. Information on the evolution of the surface ocean $\mathrm{Pb}$ has been derived directly from seawater measurement (Boyle et al., 1986; Schaule and Patterson, 1981; 1983; Veron et al., 1993; Wu and Boyle, 1997) or indirectly from $\mathrm{Pb}$ in annually-banded corals (Desenfant et al., 2006; Shen and Boyle, 1987; Reuer, 2002; Kelly et al., 2009; Inoue et al., 2006), whose $\mathrm{Pb}$ and calcium carbonate was derived from ambient seawater. For example, in the western North Atlantic Ocean, $\mathrm{Pb}$ in the surface mixed layer closely follows the Pb emissions from North America and Western Europe (Wu and Boyle, 1997) (Figure 1.3), e.g., Pb concentration rises slowly from $\sim 1850$ due to coal combustion, ore smelting, and other industrial sources, and then increases dramatically from 1950s to mid-1970s as the use of leaded gasoline becomes dominant. Then, surface $\mathrm{Pb}$ concentrations decrease more than 6-fold during the subsequent three decades due to the phase-out of leaded gasoline the US and Western Europe.

$\mathrm{Pb}$ in surface waters is transported to the ocean interior by advection and eddy diffusion, and also by sinking particles. For example, in the western North Atlantic Ocean, given the residence time of $\mathrm{Pb}$ in deep ocean (a few decades) and decadal time scales of the upper thermocline water ventilation (Jenkins, 1980), surface transient $\mathrm{Pb}$ should be ventilated to the deep ocean on a decadal time scale. This is shown by vertical $\mathrm{Pb}$ profiles in the western North Atlantic Ocean from 1979 and 2010, where thermocline Pb concentrations declined following the decrease in the surface $\mathrm{Pb}$ concentrations (Figure 
1.4a). The transport of surface $\mathrm{Pb}$ to the deeper layers in the western North Atlantic Ocean have been modeled by Boyle (1986) and Shen and Boyle (1988), and they concluded that the shape of the vertical profile is dominated by physical ventilation of the surface mixed layer $\mathrm{Pb}$. However, the models did not reproduce the $\mathrm{Pb}$ profiles below $800 \mathrm{~m}$, which implies that there are additional processes controlling the transport of $\mathrm{Pb}$ in the deep ocean.

Our understanding on the effect of anthropogenic $\mathrm{Pb}$ to the ocean and its transport to the ocean interior on a global scale is still very limited due to lack of data. The primary reason is difficulty of sampling and analysis of $\mathrm{Pb}$ in seawater, and reliable seawater $\mathrm{Pb}$ measurements became available only in the late 1970s (Schaule and Patterson, 1981). So far, $\mathrm{Pb}$ has been mostly studied in the North Atlantic Ocean compared to the other oceans, but even in the North Atlantic Ocean, $\mathrm{Pb}$ data from the deep ocean is scarce. Existing studies from the Pacific, South Atlantic, Arctic, and Antarctic Oceans cover only a small area, and there are almost no studies conducted in the South Pacific and Indian Oceans. Data on the temporal variation of $\mathrm{Pb}$ in the Pacific and Indian Oceans are even scarcer. There is only one study that reported a $\mathrm{Pb}$ transient from the Ogasawara coral in the western Pacific Ocean (Inoue et al., 2006; Inoue and Tanimizu, 2008) (Figure 1.5), which shows that $\mathrm{Pb}$ concentrations continuously increased between 1896 and mid-1960s, slightly decrease in 1970s, and then increase rapidly after 1980 again due to the increased $\mathrm{Pb}$ emissions from China. This trend is different from what is observed in the North Atlantic Ocean (Figure 1.4), showing the spatial variability of the anthropogenic $\mathrm{Pb}$ fluxes to the ocean. Moreover, this spatial variability emphasizes that knowing the 
boundary conditions of $\mathrm{Pb}$ for the other areas of the oceans is important to better assess the influence of anthropogenic $\mathrm{Pb}$ in the global ocean.

\subsection{Pb Isotope Geochemistry}

$\mathrm{Pb}$ has four naturally occurring stable isotopes: ${ }^{204} \mathrm{~Pb},{ }^{206} \mathrm{~Pb},{ }^{207} \mathrm{~Pb}$, and ${ }^{208} \mathrm{~Pb}$.

${ }^{204} \mathrm{~Pb}$ is primordial from the solar nebula and serves as a constant reservoir reference isotope. The latter three are partly primordial and also produced from the radioactive decay of ${ }^{238} \mathrm{U},{ }^{235} \mathrm{U}$, and ${ }^{232} \mathrm{Th}$, respectively. The isotopic composition of $\mathrm{Pb}$ in an ore deposit is a function of three parameters:

(1) the decay rate of the parent isotopes: $1.55125 \times 10^{-10} \mathrm{yr}^{-1}$ for ${ }^{238} \mathrm{U}, 9.8485 \times 10^{-10} \mathrm{y}^{-1}$ for ${ }^{235} \mathrm{U}$, and $4.9475 \times 10^{-11} \mathrm{yr}^{-1}$ for ${ }^{232} \mathrm{Th}$ (Steiger and Jäger, 1977).

(2) the initial abundance of parent and $\mathrm{Pb}$ isotopes in the source reservoir (e.g., the mantle or continental crust)

(3) the length of time the reservoir evolved before $\mathrm{Pb}$ was separated by geological processes

The bulk earth is assumed to have started with a primordial $\mathrm{Pb}$ isotopic composition similar to that measured for the Canyon Diablo Fe-meteorite (Tatsumoto et al., 1973), and has become progressively more radiogenic through Earth history to present day values as shown in Figure 1.6 (Stacey and Kramers, 1975; Cumming and Richards, 1975, Sangster et al., 2000). In fact, because the Earth is chemically heterogeneous, an infinite family of growth curves exists, each specific to a particular reservoir. Once the primary $\mathrm{Pb}$ ore is formed, the isotopic composition of $\mathrm{Pb}$ remains 
constant because it contains little $U$ and Th. For this reason, the isotope composition of $\mathrm{Pb}$ in $\mathrm{Pb}$ ore deposits is primarily a function of the geological age of the deposit, with older $\mathrm{Pb}$ ores having less radiogenic compositions (e.g., lower ratios) than more recent deposits.

$\mathrm{Pb}$ isotopic compositions in $\mathrm{Pb}$-containing products, e.g., gasoline, depend on the source ores used for the production. It has been found that ores from different parts of the world often have their own Pb isotope signatures (Chow and Patterson, 1962; Doe, 1970; Sangster et al., 2000), and the $\mathrm{Pb}$ isotope composition of other significant anthropogenic Pb sources, e.g., coals, have been characterized as well (Diaz-Somoano et al., 2007; 2009; Mukai et al., 1993). Unlike light stable isotopes, e.g., oxygen isotopes, mass differences among the $\mathrm{Pb}$ isotopes are small precluding significant fractionation via physicochemical and biologic processes in the environment relative to source variability. Thus, many studies have used $\mathrm{Pb}$ isotope ratios to identify sources and pathways of anthropogenic $\mathrm{Pb}$ in the environment (e.g., Mukai et al., 1993; Lee et al., 2011; Rosman et al., 1994; Planchon et al., 2003; Inoue and Tanimizu, 2008). The utility of Pb isotopes as an anthropogenic tracer was first suggested by Chow and Johnston (1965), where they observed $\mathrm{Pb}$ isotopic variability among gasoline and aerosols from the Los Angeles basin, California. Recent studies on the aerosols collected around the world exhibit a wide range of anthropogenic $\mathrm{Pb}$ isotopes in different regions and countries (Bollhöfer and Rosman, 2000; 2001) depending on main $\mathrm{Pb}$ sources, ranging between $1.06-1.25\left({ }^{206} \mathrm{~Pb} /{ }^{207} \mathrm{~Pb}\right)$ and 2.32-2.46 $\left({ }^{208} \mathrm{~Pb} /{ }^{207} \mathrm{~Pb}\right.$ ) (Figure 1.7). While not necessarily unique, in many cases the isotope ratios of any individual or regional source appear to be sufficiently characteristic 
and can be used to determine the provenance of $\mathrm{Pb}$ with some degree of certainty. One needs caution in $\mathrm{Pb}$ isotopic fingerprinting, however, because 1) the isotope ratios of a single industrial source can change significantly in a short time depending on blending of various $\mathrm{Pb}$ ores during production, 2) $\mathrm{Pb}$ ores and refined products are internationally traded, and 3) production and consumption of recycled and re-smelted $\mathrm{Pb}$ are increasing, particularly in the Western countries (Sangster et al., 2000 and references therein).

As the main sources dominating the anthropogenic $\mathrm{Pb}$ emissions are changing over time, isotope ratios of the anthropogenic $\mathrm{Pb}$ evolve accordingly. For example, the isotope ratios of the $\mathrm{Pb}$ in the surface waters near Bermuda increased after 1960s due to increased use of the $\mathrm{Pb}$ from southeast Missouri district in US, and decreased after 1970s due to the dominance of European $\mathrm{Pb}$ over US $\mathrm{Pb}$ as Europe phased out leaded gasoline later than US (Shen and Boyle, 1987; Kelly et al., 2009) (Figure 1.3). As the anthropogenic $\mathrm{Pb}$ is transported to the deeper layers, the variability of $\mathrm{Pb}$ isotopes in the surface ocean is also transferred to deep layers (Shen and Boyle, 1988; Veron et al., 1998; Reuer et al., 2002) (Figure 1.4b). As for the Pb flux, the anthropogenic Pb isotope flux to the surface ocean is also spatially variable depending on primary $\mathrm{Pb}$ sources and prevailing wind direction. Thus, $\mathrm{Pb}$ isotope ratios in the ocean provide additional information, i.e. time scale and pathways, on the dispersion of the anthropogenic $\mathrm{Pb}$ into the ocean interior (e.g., Alleman et al., 1999; 2001; Boyle et al., 1986; Hamelin et al., 1997; Veron et al., 1994; 1998). 


\subsection{Thesis outline}

This thesis offers several new perspectives on the biogeochemical cycling of $\mathrm{Pb}$ and $\mathrm{Pb}$ isotopes in the marine environment. First, a reliable and accurate method for analyzing various trace elements $(\mathrm{Cu}, \mathrm{Cd}, \mathrm{Fe}$, and $\mathrm{Pb})$ in seawater using Nitrilotriacetate (NTA) resin extraction and isotope dilution ICP-MS is presented in Chapter 2. Chapter 3 presents a $\sim 550 \mathrm{yr}$ history of elemental and isotopic composition of $\mathrm{Pb}$ in the deep North Atlantic Ocean reconstructed from a modern colonial deep-sea coral collected from the Bermuda slope. The results of this study illustrate the intrusion of anthropogenic $\mathrm{Pb}$ into the ocean interior and show the advantages of deep-sea corals as reliable recorders of deep ocean $\mathrm{Pb}$. The reconstructed deep ocean $\mathrm{Pb}$ record is compared to the surface North Atlantic Pb record (Shen and Boyle, 1987; Kelly et al., 2009) to estimate the time scale of $\mathrm{Pb}$ transport from surface to the deep ocean and provide insights into governing processes. The work presented in Chapters 4 and 5 investigates the influence of anthropogenic $\mathrm{Pb}$ inputs to the Indian Ocean where no reliable $\mathrm{Pb}$ data exist. In Chapter 4, we reconstruct the evolution of $\mathrm{Pb}$ and $\mathrm{Pb}$ isotopes in the central and eastern part of the Indian Ocean based on surface growing, annually-banded corals. The records from three corals demonstrate the increase of $\mathrm{Pb}$ in the surface Indian Ocean due to anthropogenic $\mathrm{Pb}$ inputs, but $\mathrm{Pb}$ isotope records are different in each coral, showing that $\mathrm{Pb}$ in each region is governed by different sources and processes. We discuss the major sources of $\mathrm{Pb}$ in each coral by comparing the coral records to the historical anthropogenic $\mathrm{Pb}$ emissions from the nations around the Indian Ocean and their Pb isotope signatures. Chapter 5 presents dissolved $\mathrm{Pb}$ concentration and isotopes profiles from the northern and western 
parts of the Indian Ocean. The observations demonstrate that the distribution of $\mathrm{Pb}$ in the modern Indian Ocean is largely affected by anthropogenic Pb inputs, but hydrographic distribution also plays an important role. 


\section{References for Chapter 1}

Alleman, L. Y., A. J. Veron, T. M. Church, A. R. Flegal, and B. Hamelin (1999), Invasion of the abyssal North Atlantic by modern anthropogenic lead, Geophys. Res. Lett., 26(10), 1477-1480.

Alleman, L. Y., T. M. Church, A. J. Veron, G. Kim, B. Hamelin, and A. R. Flegal (2001), Isotopic evidence of contaminant lead in the South Atlantic troposphere and surface waters, Deep-Sea Res. Pt. II, 48(13), 2811-2827.

Bacon, M. P., D. W. Spencer, and P. G. Brewer (1976), Pb-210-Ra-226 and Po-210-Pb210 Disequilibria in Seawater and Suspended Particulate Matter, Earth Planet. Sc. Lett., 32(2), 277-296.

Barbante, C., C. Turetta, A. Gambaro, G. Capodaglio, and G. Scarponi (1998), Sources and origins of aerosols reaching Antarctica as revealed by lead concentration profiles in shallow snow, Ann. Glaciol., 27, 674-678.

Benninger, L. K., D. M. Lewis, and K. K. Turekian (1975), The use of natural Pb-210 as a heavy metal tracer in the river-estuarine system, in Marine Chemistry in the Coastal Environment, edited by T. M. Church, pp. 202-210, American Chemical Society Symposium Series.

Benoit, G., S. D. Oktaymarshall, A. Cantu, E. M. Hood, C. H. Coleman, M. O. Corapcioglu, and P. H. Santschi (1994), Partitioning of Cu, Pb, Ag, Zn, Fe, Al, and $\mathrm{Mn}$ between Filter-Retained Particles, Colloids, and Solution in 6 Texas Estuaries, Mar. Chem., 45(4), 307-336.

Bollhöfer, A., and K. J. R. Rosman (2000), Isotopic source signatures for atmospheric lead: The Southern Hemisphere, Geochim. Cosmochim. Ac., 64(19), 3251-3262.

Bollhöfer, A., and K. J. R. Rosman (2001), Isotopic source signatures for atmospheric lead: The Northern Hemisphere, Geochim. Cosmochim. Ac., 65(11), 1727-1740.

Boutier, B., J. F. Chiffoleau, D. Auger, and I. Truquet (1993), Influence of the Loire River on Dissolved Lead and Cadmium Concentrations in Coastal Waters of Brittany, Estuar. Coast. Shelf S., 36(2), 133-145.

Boutron, C. F., U. Gorlach, J. P. Candelone, M. A. Bolshov, and R. J. Delmas (1991), Decrease in Anthropogenic Lead, Cadmium and Zinc in Greenland Snows since the Late 1960s, Nature, 353(6340), 153-156.

Boyle, E. A., S. D. Chapnick, G. T. Shen, and M. P. Bacon (1986), Temporal Variability of Lead in the Western North-Atlantic, J. Geophys. Res.-Oceans, 91(C7), 85738593.

Candelone, J. P., S. M. Hong, C. Pellone, and C. F. Boutron (1995), Postindustrial Revolution Changes in Large-Scale Atmospheric-Pollution of the NorthernHemisphere by Heavy-Metals as Documented in Central Greenland Snow and Ice, J. Geophys. Res.-Atmos., 100(D8), 16605-16616.

Capodaglio, G., K. H. Coale, and K. W. Bruland (1990), Lead Speciation in Surface Waters of the Eastern North Pacific, Mar. Chem., 29(2-3), 221-233. 
Chen, J. H., G. J. Wasserburg, K. L. Vondamm, and J. M. Edmond (1986), The U-Th-Pb Systematics in Hot-Springs on the East Pacific Rise at 21-Degrees-N and Guaymas-Basin, Geochim. Cosmochim. Ac., 50(11), 2467-2479.

Cheng, H. F., and Y. A. Hu (2010), Lead (Pb) isotopic fingerprinting and its applications in lead pollution studies in China: A review, Environ. Pollut., 158(5), 1134-1146.

Chester, R., A. S. Berry, and K. J. T. Murphy (1991), The Distributions of Particulate Atmospheric Trace-Metals and Mineral Aerosols over the Indian-Ocean, Mar. Chem., 34(3-4), 261-290.

Chow, T. J., and C. C. Patterson (1962), The Occurrence and Significance of Lead Isotopes in Pelagic Sediments, Geochim. Cosmochim. Ac., 26(Feb), 263-308.

Chow, T. J., and M. S. Johnston (1965), Lead Isotopes in Gasoline and Aerosols of Los Angeles Basin, California, Science, 147, 147-148.

Chung, Y. (1987), Pb-210 in the Western Indian-Ocean - Distribution, Disequilibrium, and Partitioning between Dissolved and Particulate Phases, Earth Planet. Sc. Lett., 85(1-3), 28-40.

Chung, Y., and H. Craig (1983), Pb-210 in the Pacific - the Geosecs Measurements of Particulate and Dissolved Concentrations, Earth Planet. Sc. Lett., 65(2), 406-432.

Cochran, J. K., M. P. Bacon, S. Krishnaswami, and K. K. Turekian (1983), Po-210 and $\mathrm{Pb}-210$ Distributions in the Central and Eastern Indian-Ocean, Earth Planet. Sc. Lett., 65(2), 433-452.

Cochran, J. K., T. Mckibbinvaughan, M. M. Dornblaser, D. Hirschberg, H. D. Livingston, and K. O. Buesseler (1990), Pb-210 Scavenging in the North-Atlantic and North Pacific Oceans, Earth Planet. Sc. Lett., 97(3-4), 332-352.

Craig, H., Krishnas.S, and Somayaju.B1 (1973), Pb-210 - Ra-226 - Radioactive Disequilibrium in Deep-Sea, Earth Planet. Sc. Lett., 17(2), 295-305.

Cumming, G. L., and J. R. Richards (1975), Ore Lead Isotope Ratios in a Continuously Changing Earth, Earth Planet. Sc. Lett., 28(2), 155-171.

Danielsson, L. G., B. Magnusson, S. Westerlund, and K. Zhang (1983), Trace-Metals in the Gota River Estuary, Estuar. Coast. Shelf S., 17(1), 73-85.

Desenfant, F., A. J. Veron, G. F. Camoin, and J. Nyberg (2006), Reconstruction of pollutant lead invasion into the tropical North Atlantic during the twentieth century, Coral Reefs, 25(3), 473-484.

Diaz-Somoano, M., I. Suarez-Ruiz, J. I. G. Alonso, J. R. Encinar, M. A. Lopez-Anton, and M. R. Martinez-Tarazona (2007), Lead isotope ratios in Spanish coals of different characteristics and origin, Int. J. Coal Geol., 71(1), 28-36.

Diaz-Somoano, M., M. E. Kylander, M. A. Lopez-Anton, I. Suarez-Ruiz, M. R. Martinez-Tarazona, M. Ferrat, B. Kober, and D. J. Weiss (2009), Stable Lead Isotope Compositions In Selected Coals From Around The World And Implications For Present Day Aerosol Source Tracing, Environ. Sci. Technol., 43(4), 1078-1085.

Doe, B. R. (1970), Lead isotopes, Springer Verlag, Berlin, Heidelberg, New York. 
Duce, R. A., et al. (1991), The atmospheric input of trace species to the world ocean, Global Biogeochemical Cycle, 5(3), 193-259.

Elbaz-Poulichet, F., J. M. Garnier, D. M. Guan, J. M. Martin, and A. J. Thomas (1996), The conservative behaviour of trace metals $(\mathrm{Cd}, \mathrm{Cu}, \mathrm{Ni}$ and $\mathrm{Pb})$ and $\mathrm{As}$ in the surface plume of stratified estuaries: Example of the Rhone River (France), Est. Coast. Shelf Sci., 42(3), 289-310.

Francis, C. W., G. Chesters, and L. A. Haskin (1970), Determination of Pb-210 Mean Residence Time in Atmosphere, Environ. Sci Technol, 4(7), 586-589.

Godfrey, L. V., R. Mills, H. Elderfield, and E. Gurvich (1994), Lead Behavior at the Tag Hydrothermal Vent Field, 26-Degrees-N, Mid-Atlantic Ridge, Mar. Chem., 46(3), 237-254.

Graney, J. R., A. N. Halliday, G. J. Keeler, J. O. Nriagu, J. A. Robbins, and S. A. Norton (1995), Isotopic Record of Lead Pollution in Lake-Sediments from the Northeastern United-States, Geochim. Cosmochim. Ac., 59(9), 1715-1728.

Hamelin, B., J. L. Ferrand, L. Alleman, E. Nicolas, and A. Veron (1997), Isotopic evidence of pollutant lead transport from North America to the subtropical North Atlantic gyre, Geochim. Cosmochim. Ac., 61(20), 4423-4428.

Henderson, G. M., and E. Maier-Reimer (2002), Advection and removal of Pb-210 and stable Pb isotopes in the oceans: A general circulation model study, Geochim.. Cosmochim. Ac., 66(2), 257-272.

Hong, S. M., J. P. Candelone, C. C. Patterson, and C. F. Boutron (1994), Greenland Ice Evidence of Hemispheric Lead Pollution 2-Millennia Ago by Greek and Roman Civilizations, Science, 265(5180), 1841-1843.

Huo, W. M., T. D. Yao, and Y. F. Li (1999), Increasing atmospheric pollution revealed by $\mathrm{Pb}$ record of a 7 000-m ice core, Chinese Sci. Bull., 44(14), 1309-1312.

Inoue, M., and M. Tanimizu (2008), Anthropogenic lead inputs to the western Pacific during the 20th century, Sci Total Environ, 406(1-2), 123-130.

Inoue, M., A. Hata, A. Suzuki, M. Nohara, N. Shikazono, W. W. S. Yim, W. S. Hantoro, D. H. Sun, and H. Kawahata (2006), Distribution and temporal changes of lead in the surface seawater in the western Pacific and adjacent seas derived from coral skeletons, Environ. Pollut., 144(3), 1045-1052.

Jenkins, W. J. (1980), Tritium and He-3 in the Sargasso Sea, J Mar Res, 38(3), 533-569.

Kelly, A. E., M. K. Reuer, N. F. Goodkin, and E. A. Boyle (2009), Lead concentrations and isotopes in corals and water near Bermuda, 1780-2000, Earth Planet. Sc. Lett., 283(1-4), 93-100.

Lee, K., S. Do Hur, S. Hou, L. J. Burn-Nunes, S. Hong, C. Barbante, C. F. Boutron, and K. J. R. Rosman (2011), Isotopic signatures for natural versus anthropogenic $\mathrm{Pb}$ in high-altitude Mt. Everest ice cores during the past 800 years, Sci. Total Environ., 412, 194-202.

Lima, A. L., B. A. Bergquist, E. A. Boyle, M. K. Reuer, F. O. Dudas, C. M. Reddy, and T. I. Eglinton (2005), High-resolution historical records from Pettaquamscutt River 
basin sediments: 2 . $\mathrm{Pb}$ isotopes reveal a potential new stratigraphic marker, Geochim. Cosmochim. Ac., 69(7), 1813-1824.

Mukai, H., N. Furuta, T. Fujii, Y. Ambe, K. Sakamoto, and Y. Hashimoto (1993), Characterization of Sources of Lead in the Urban Air of Asia Using Ratios of Stable Lead Isotopes, Environ. Sci. Technol., 27(7), 1347-1356.

Murozumi, M., T. J. Chow, and Patterso.C (1969), Chemical Concentrations of Pollutant Lead Aerosols, Terrestrial Dusts and Sea Salts in Greenland and Antarctic Snow Strata, Geochim. Cosmochim. Ac., 33(10), 1247-1294.

Nriagu, J. O. (1979), Global Inventory of Natural and Anthropogenic Emissions of TraceMetals to the Atmosphere, Nature, 279(5712), 409-411.

Nriagu, J. O. (1989), A Global Assessment of Natural Sources of Atmospheric TraceMetals, Nature, 338(6210), 47-49.

Nriagu, J. O. (1990), Human Influence on the Global Cycling of Trace-Metals, Global Planet Change, 82(1-2), 113-120.

Nriagu, J. O., and J. M. Pacyna (1988), Quantitative Assessment of Worldwide Contamination of Air, Water and Soils by Trace-Metals, Nature, 333(6169), 134139.

Nriagu, J. O., M. L. Blankson, and K. Ocran (1996a), Childhood lead poisoning in Africa: A growing public health problem, Sci. Total Environ., 181(2), 93-100.

Nriagu, J. O., C. Jinabhai, R. Naidoo, and A. Coutsoudis (1996b), Atmospheric lead pollution in KwaZulu/Natal, South Africa, Sci. Total Environ., 191(1-2), 69-76.

O'Nions, R. K., S. R. Carter, R. S. Cohen, N. M. Evensen, and P. J. Hamilton (1978), Pb, $\mathrm{Nd}$ and $\mathrm{Sr}$ Isotopes in Oceanic Ferromanganese Deposits and Ocean-Floor Basalts, Nat. Clim. Change, 273(5662), 435-438.

Peucker-Ehrenbrink, B., A. W. Hofmann, and S. R. Hart (1994), Hydrothermal Lead Transfer from Mantle to Continental-Crust - the Role of Metalliferous Sediments, Earth Planet. Sc. Lett., 125(1-4), 129-142.

Planchon, F. A. M., K. van de Velde, K. J. R. Rosman, E. W. Wolff, C. P. Ferrari, and C. F. Boutron (2003), One hundred fifty-year record of lead isotopes in Antarctic snow from Coats Land, Geochim. Cosmochim. Ac., 67(4), 693-708.

Rama, M. Koide, and E. D. Goldberg (1961), Lead-210 in Natural Waters, Science, 134(3472), 98-99.

Reuer, M. K. (2002), Centennial-Scale Elemental and Isotopic Variability in the Tropical and Subtropical North Atlantic Ocean, Massachusetts Institute of Technology.

Rosman, K. J. R., C. C. Patterson, and D. M. Settle (1990), The Distribution of Lead between Sea Salt, Dust, and Lead-Rich Aerosols in the Mid South-Pacific Easterlies at American-Samoa, J. Geophys. Res.-Atmos, 95(D4), 3687-3691.

Rosman, K. J. R., W. Chisholm, C. Boutron, J. P. Candelone, and C. C. Patterson (1994), Anthropogenic lead isotopes in Antarctica, Geophys. Res. Lett., 21(24), 26692672. 
Sangster, D. F., P. M. Outridge, and W. J. Davis (2000), Stable lead isotope characteristics of lead ore deposits of environmental significance, Environmental Reviews, 8(2), 115-147.

Schaule, B. K., and C. C. Patterson (1981), Lead Concentrations in the Northeast Pacific - Evidence for Global Anthropogenic Perturbations, Earth Planet. Sc. Lett., 54(1), 97-116.

Schaule, B. K., and C. C. Patterson (1983), Perturbations of the natural lead profile in the Sargasso Sea by industrial lead, in Trace Metals in Sea Water, edited by C. S. Wong, pp. 487-504, Plenum, New York.

Settle, D. M., and C. C. Patterson (1980), Lead in Albacore - Guide to Lead Pollution in Americans, Science, 207(4436), 1167-1176.

Shen, G. T., and E. A. Boyle (1987), Lead in Corals - Reconstruction of Historical Industrial Fluxes to the Surface Ocean, Earth Planet. Sc. Lett., 82(3-4), 289-304.

Shen, G. T., and E. A. Boyle (1988), Thermocline Ventilation of Anthropogenic Lead in the Western North-Atlantic, J. Geophys. Res.-Oceans, 93(C12), 15715-15732.

Shirahata, H., R. W. Elias, C. C. Patterson, and M. Koide (1980), Chronological Variations in Concentrations and Isotopic Compositions of Anthropogenic Atmospheric Lead in Sediments of a Remote Subalpine Pond, Geochim. Cosmochim. Ac., 44(2), 149-162.

Shotyk, W., D. Weiss, P. G. Appleby, A. K. Cheburkin, R. Frei, M. Gloor, J. D. Kramers, S. Reese, and W. O. Van der Knaap (1998), History of atmospheric lead deposition since 12,370 C-14 yr BP from a peat bog, Jura Mountains, Switzerland, Science, 281(5383), 1635-1640.

Spencer, D. W., M. P. Bacon, and P. G. Brewer (1980), The distribution of $210 \mathrm{~Pb}$ and 210Po in the North Sea, Thalassia Jugoslavica, 16, 125-154.

Stacey, J. S., and J. D. Kramers (1975), Approximation of Terrestrial Lead Isotope Evolution by a 2-Stage Model, Earth Planet. Sc. Lett., 26(2), 207-221.

Steiger, R. H., and E. Jager (1977), Subcommission on Geochronology - Convention on Use of Decay Constants in Geochronology and Cosmochronology, Earth Planet. Sc. Lett., 36(3), 359-362.

Tatsumoto, M., R. J. Knight, and C. J. Allegre (1973), Time Differences in Formation of Meteorites as Determined from Ratio of Pb-207 to Pb-206, Science, 180(4092), 1279-1283.

Tripathi, R. M., R. Raghunath, A. V. Kumar, V. N. Sastry, and S. Sadasivan (2001), Atmospheric and children's blood lead as indicators of vehicular traffic and other emission sources in Mumbai, India, Sci. Total Environ., 267(1-3), 101-108.

UNEP (2007), The global campaign to eliminate leaded gasoline: progress as of January 2007, edited, www.unep.org/pcfv/PDF/LeadReport.pdf.

Veron, A. J., T. M. Church, and A. R. Flegal (1998), Lead isotopes in the western North Atlantic: Transient tracers of pollutant lead inputs, Environ. Res., 78(2), 104-111. 
Veron, A. J., T. M. Church, C. C. Patterson, and A. R. Flegal (1994), Use of Stable Lead Isotopes to Characterize the Sources of Anthropogenic Lead in North-Atlantic Surface Waters, Geochim. Cosmochim. Ac., 58(15), 3199-3206.

Veron, A. J., T. M. Church, A. R. Flegal, C. C. Patterson, and Y. Erel (1993), Response of Lead Cycling in the Surface Sargasso Sea to Changes in Tropospheric Input, J. Geophys. Res.-Oceans, 98(C10), 18269-18276.

Weiss, D., W. Shotyk, P. G. Appleby, I. D. Kramers, and A. K. Cheburkin (1999), Atmospheric $\mathrm{Ph}$ deposition since the industrial revolution recorded by five Swiss peat profiles: Enrichment factors, fluxes, isotopic composition, and sources, Environ. Sci. Technol., 33(9), 1340-1352.

Wells, M. L., P. B. Kozelka, and K. W. Bruland (1998), The complexation of 'dissolved' $\mathrm{Cu}, \mathrm{Zn}, \mathrm{Cd}$ and $\mathrm{Pb}$ by soluble and colloidal organic matter in Narragansett Bay, RI, Mar. Chem., 62(3-4), 203-217.

Whitfield, M., and D. R. Turner (1980), The theoretical studies of the chemical speciation of lead in seawater, in Lead in the Marine Environment, edited by M. Branica and Z. Konrad, Pergamon, New York.

Windom, H. L., R. G. Smith, and M. Maeda (1985), The Geochemistry of Lead in Rivers, Estuaries and the Continental-Shelf of the Southeastern United-States, Mar. Chem., 17(1), 43-56.

Wolff, E. W., and E. D. Suttie (1994), Antarctic Snow Record of Southern-Hemisphere Lead Pollution, Geophys. Res. Lett., 21(9), 781-784.

Wu, J. F., and E. A. Boyle (1997), Lead in the western North Atlantic Ocean: Completed response to leaded gasoline phaseout, Geochim. Cosmochim. Ac., 61(15), 32793283.

Wu, J. F., R. Rember, M. B. Jin, E. A. Boyle, and A. R. Flegal (2010), Isotopic evidence for the source of lead in the North Pacific abyssal water, Geochim. Cosmochim. Ac., 74(16), 4629-4638. 


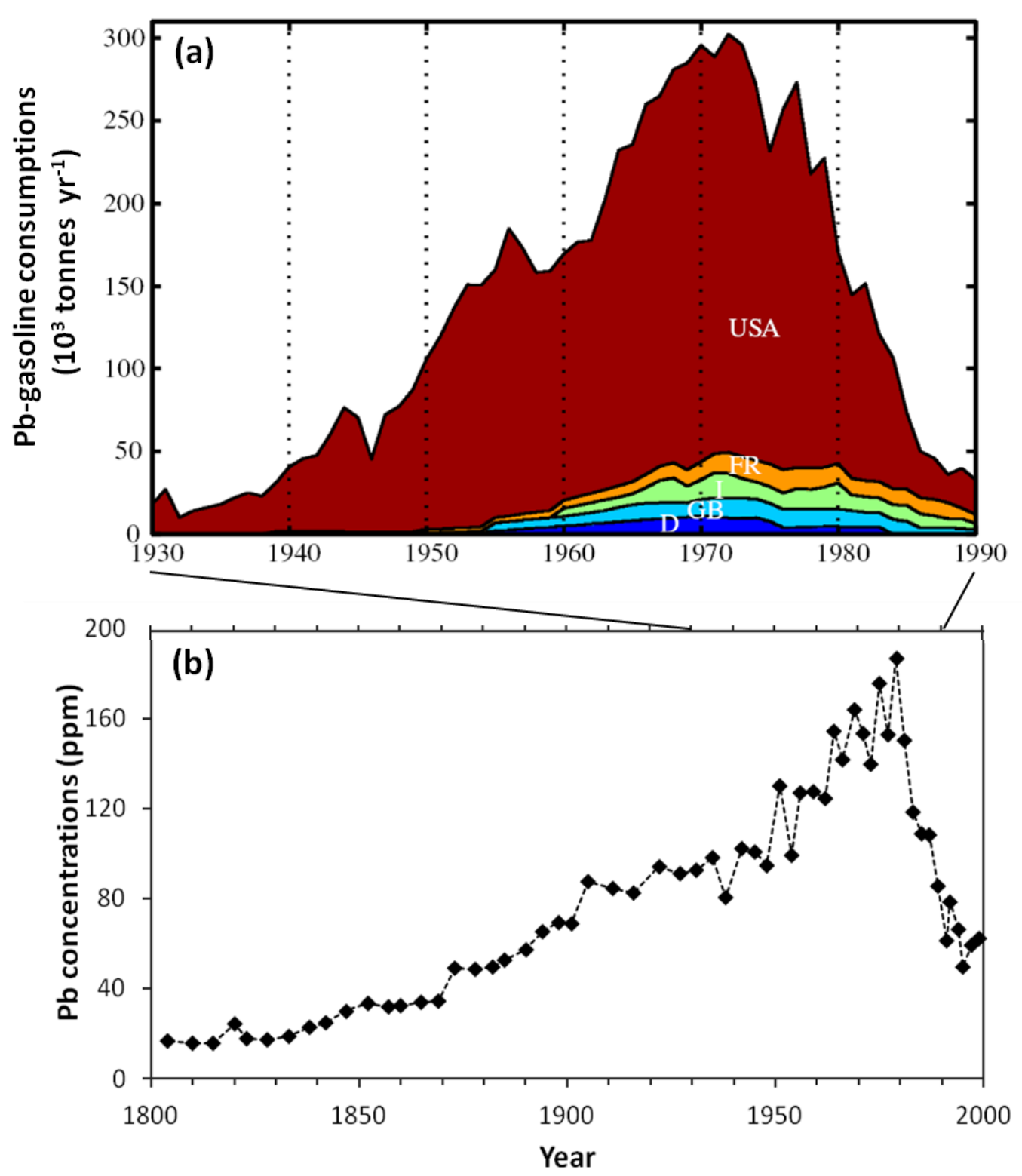

Figure 1.1 (a) Historical leaded gasoline consumption in US and Western Europe between 1930 and 1990 (USA=United States, FR=France, I=Italy, GB=United Kingdom, and $\mathrm{D}=$ Germany) (Wu and Boyle, 1997 and references therein). (b) Pb record from the Pettaquamscutt River sediments, Rhode Island (Lima et al., 2005). 


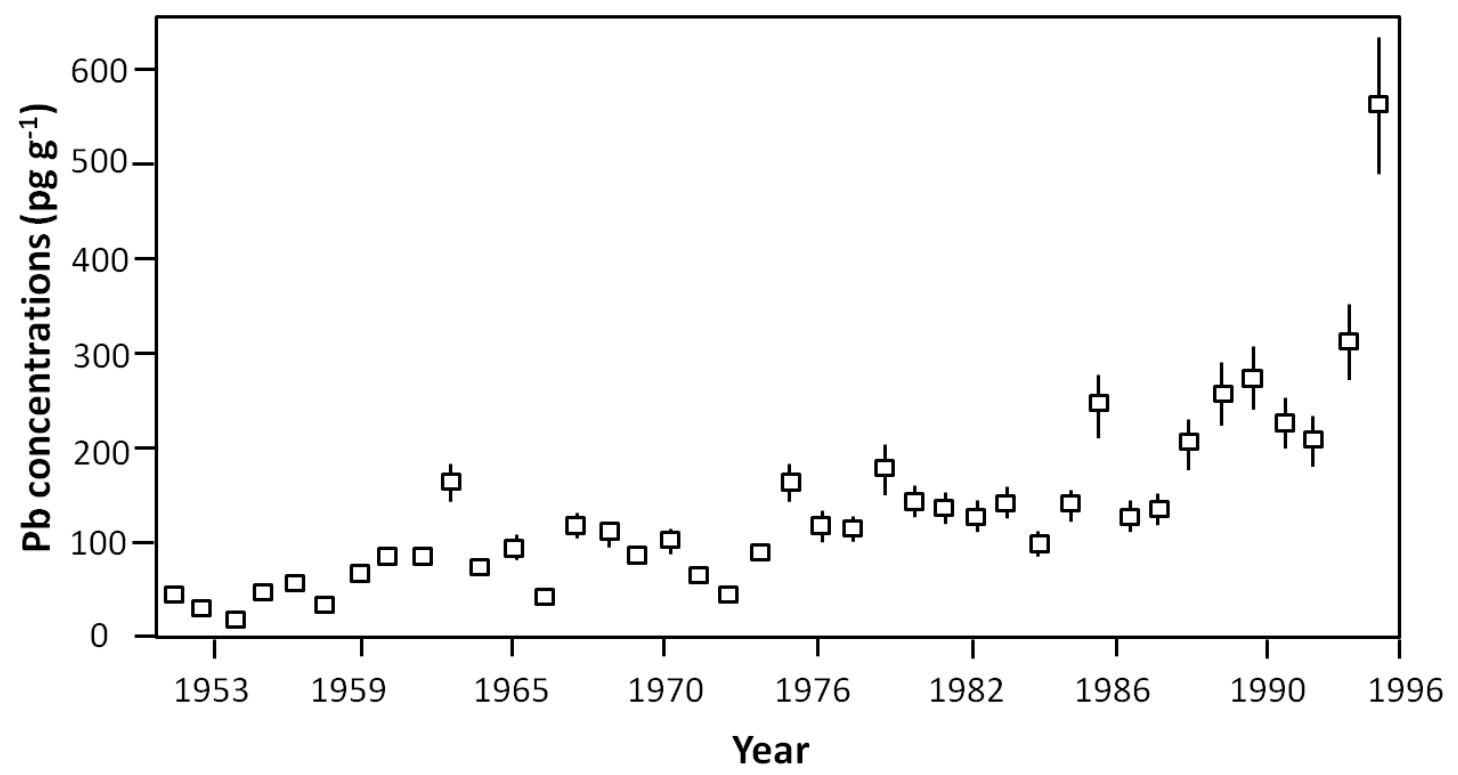

Figure 1.2 $\mathrm{Pb}$ concentrations from the Dasuopu ice cap ( $\left.28^{\circ} 21^{\prime} \mathrm{N}, 85^{\circ} 46^{\prime} \mathrm{E}\right)$ located in the Mt. Xixabangma in the Himalaya (Huo et al., 1999). 

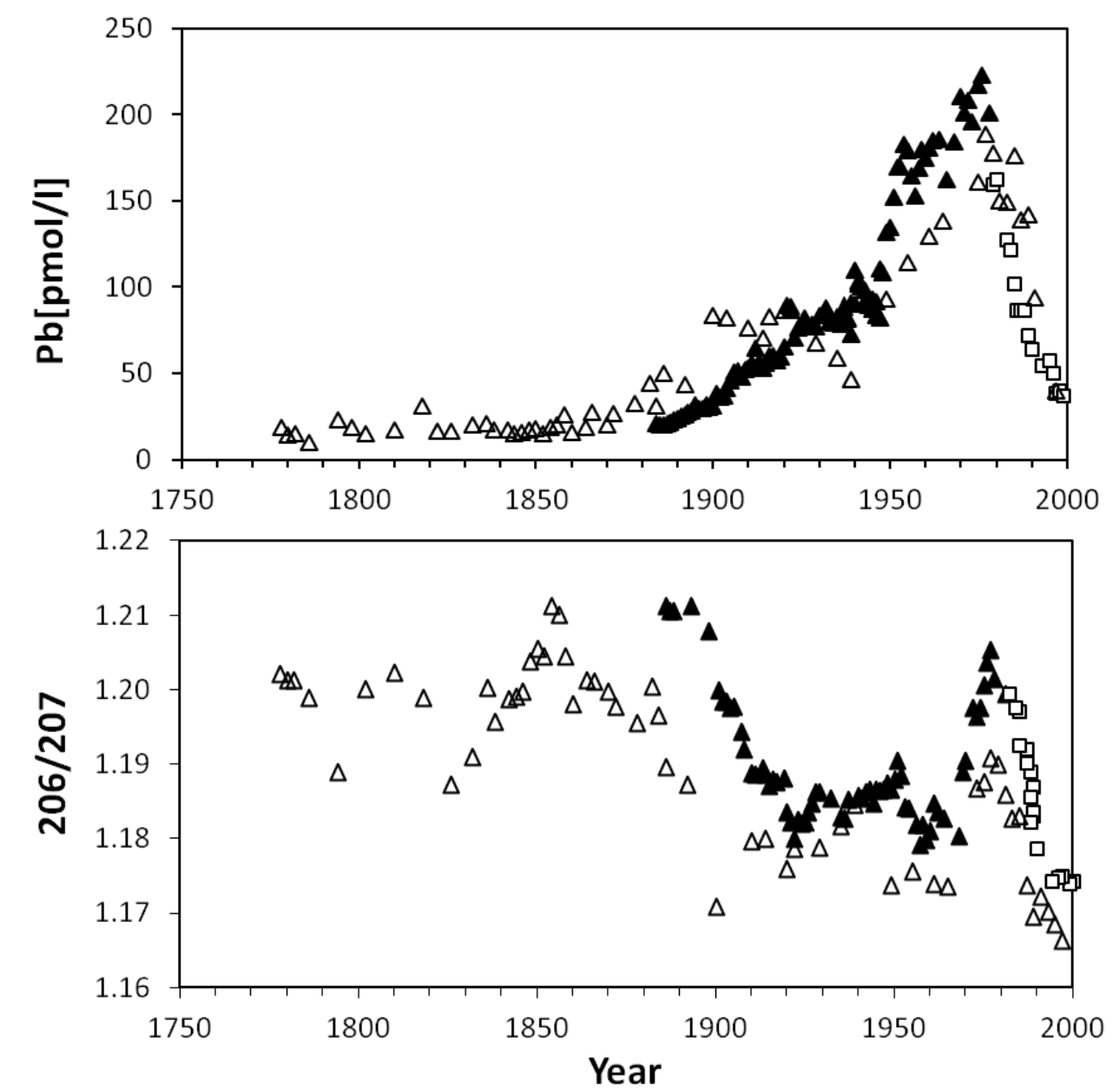

Figure 1.3 Historical $\mathrm{Pb}$ concentrations and ${ }^{206} \mathrm{~Pb} /{ }^{207} \mathrm{~Pb}$ ratios of the surface waters near Bermuda (Kelly et al., 2009; Shen and Boyle, 1986; Reuer, 2002). Data shown with squares (口) are from direct seawater observations, and triangles are reconstructed from annually banded corals collected from North Rock $(\boldsymbol{\Lambda})$ and John Smith's Bay $(\Delta)$ in Bermuda. 


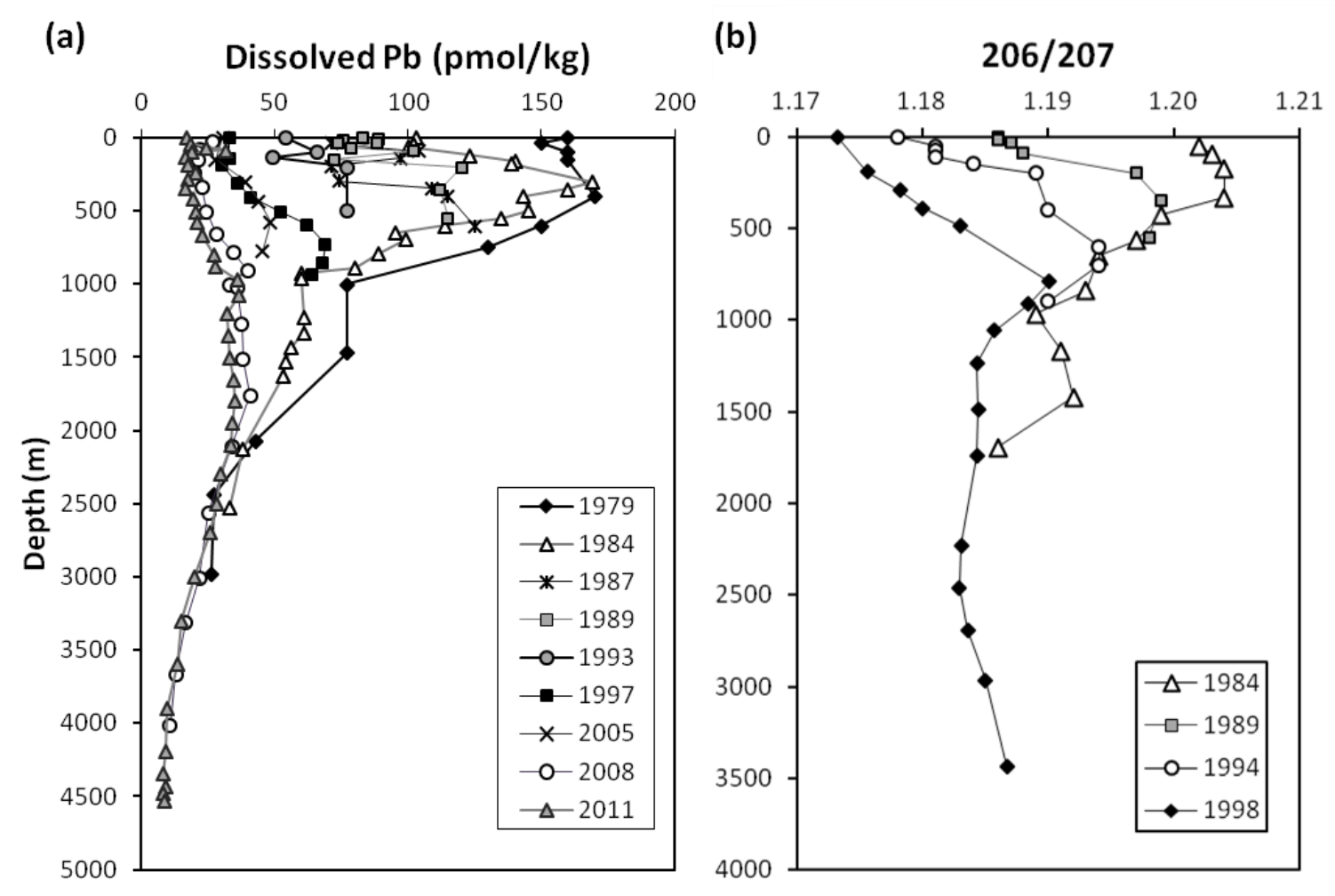

Figure 1.4 (a) $\mathrm{Pb}$ concentration and (b) ${ }^{206} \mathrm{~Pb} /{ }^{207} \mathrm{~Pb}$ profiles in seawaters near Bermuda from 1979 to 2011. The Pb profile data are from Schaule and Patterson, 1983 (sampled in 1979), Boyle et al., 1986 (sampled in 1984), Veron et al., 1993 (sampled in 1989), Wu and Boyle, 1997 (sampled in 1993). The ${ }^{206} \mathrm{~Pb} /{ }^{207} \mathrm{~Pb}$ profiles are from Shen and Boyle, 1988 (sampled in 1984), Veron et al., 1998 (sampled in 1994), and Reuer, 2002 (sampled in 1998). The others are MIT-unpublished data. 

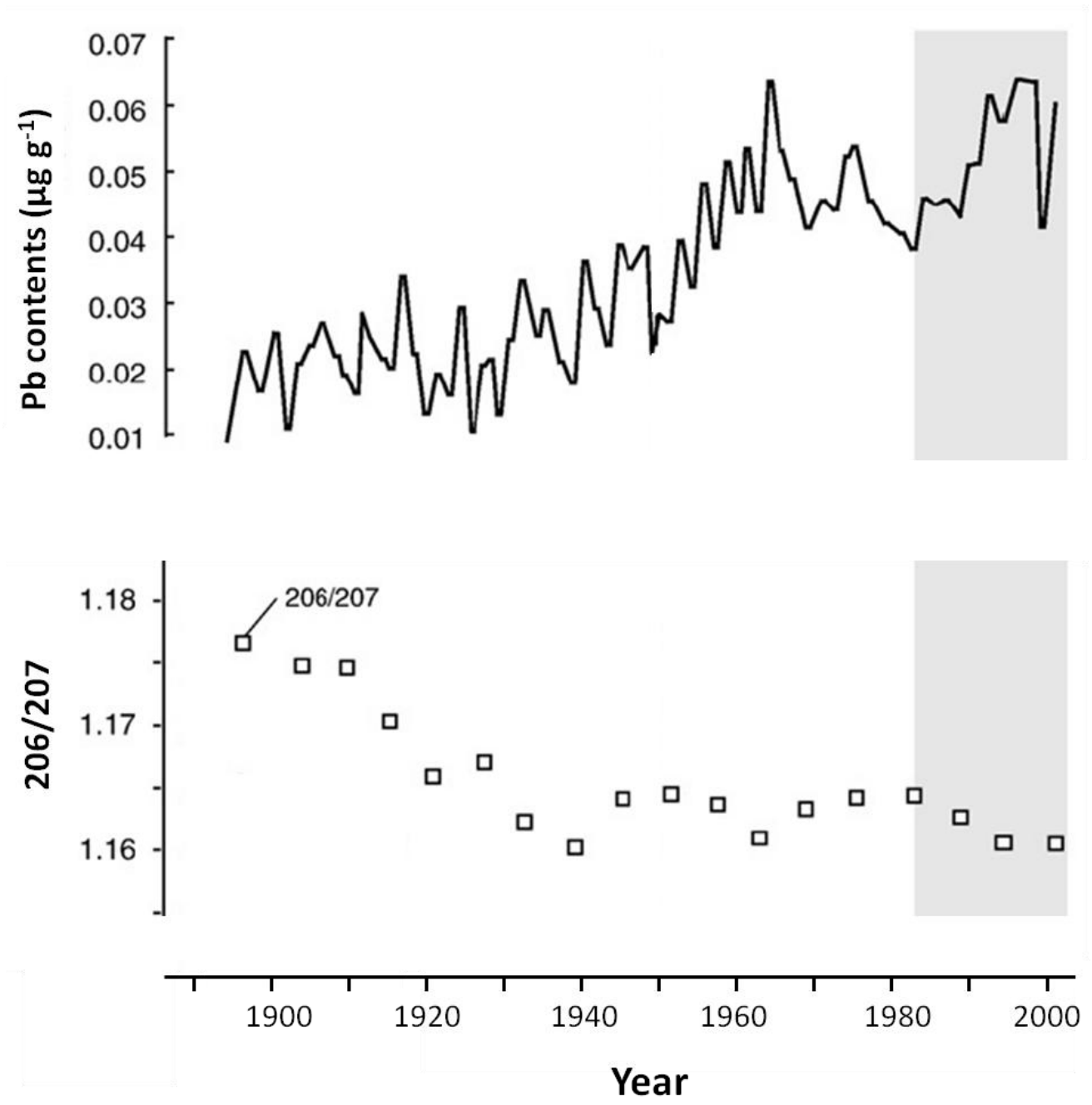

Figure 1.5 $\mathrm{Pb}$ contents and ${ }^{206} \mathrm{~Pb} /{ }^{207} \mathrm{~Pb}$ ratios of an annually-banded coral from Ogasawara Island, Japan, showing the evolution of $\mathrm{Pb}$ in the western Pacific surface waters in the 20th century (Inoue et al., 2006; Inoue and Tanimizu, 2008). Shaded area reflects the influence of anthropogenic $\mathrm{Pb}$ from China. 

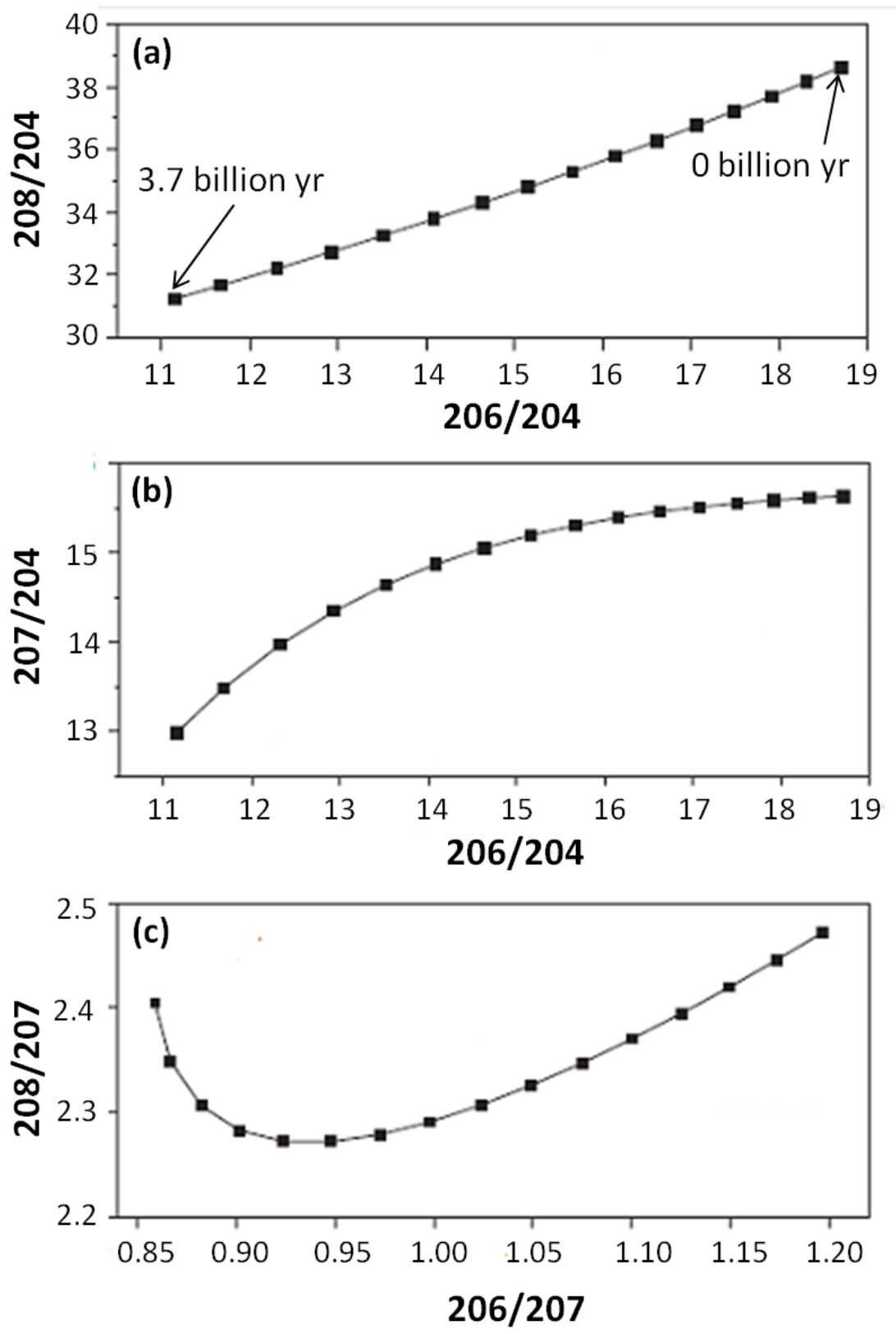

Figure 1.6 Radiogenic growth curves for the bulk Earth $\mathrm{Pb}$ isotopes: (a) ${ }^{208} \mathrm{~Pb} /{ }^{204} \mathrm{~Pb}$ vs. ${ }^{206} \mathrm{~Pb} /{ }^{204} \mathrm{~Pb}$, (b) ${ }^{207} \mathrm{~Pb} /{ }^{204} \mathrm{~Pb}$ vs. ${ }^{206} \mathrm{~Pb} /{ }^{204} \mathrm{~Pb}$ (Stacey and Kramers, 1975), and (c) ${ }^{208} \mathrm{~Pb} /{ }^{207} \mathrm{~Pb}$ vs. ${ }^{206} \mathrm{~Pb} /{ }^{207} \mathrm{~Pb}$ (Sangster et al., 2000). Reference ages on plots are given in years before present. 


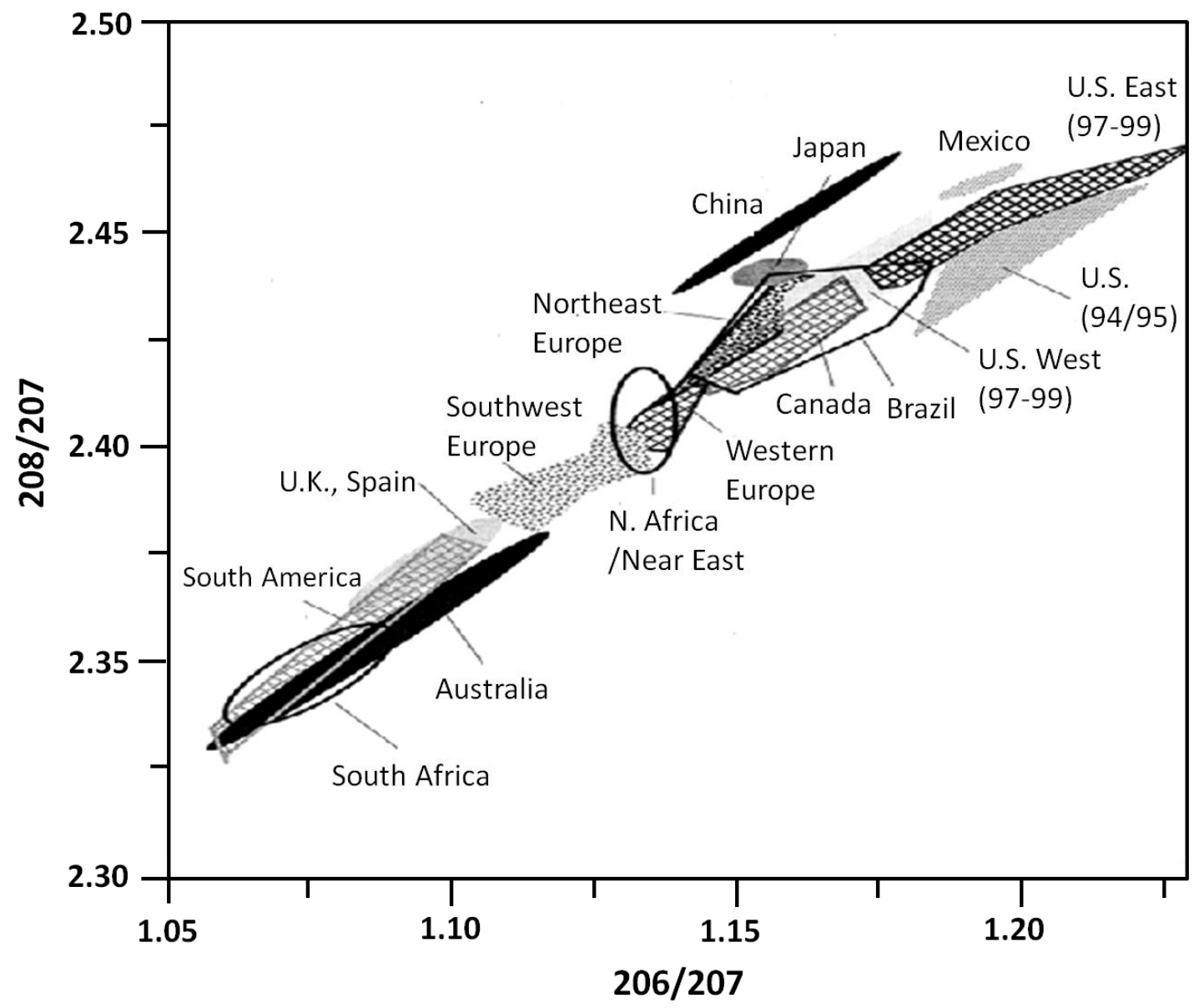

Figure 1.7 A global map of the $\mathrm{Pb}$ isotope composition of the aerosols collected between 1994-1999, modified from Bollhöfer and Rosman (2000). The actual data are from Bollhöfer and Rosman (2000; 2001). 


\title{
Chapter 2
}

\section{Analysis of trace metals $(\mathrm{Cu}, \mathrm{Cd}, \mathrm{Pb}$, and $\mathrm{Fe})$ in seawater using single batch Nitrilotriacetate resin extraction and isotope dilution inductively coupled plasma mass spectrometry}

Reprinted with permission of Analytica Chimica Acta Lee, J.-M., E. A. Boyle, Y. Echegoyen-Sanz, J. N. Fitzsimmons, R, Zhang and R. A. Kayser (2010). Analysis of trace metals $(\mathrm{Cu}, \mathrm{Cd}, \mathrm{Pb}$, and $\mathrm{Fe}$ ) in seawater using single batch Nitrilotriacetate resin extraction and isotope dilution inductively coupled plasma mass spectrometry. Analytica Chimica Acta, 686, 93-101.

\begin{abstract}
A simple and accurate low-blank method has been developed for the analysis of total dissolved copper, cadmium, lead, and iron in a small volume (1.3-1.5ml per element) of seawater. Pre-concentration and salt-separation of a stable isotope spiked sample is achieved by single batch extraction onto nitrilotriacetate (NTA)-type Superflow ${ }^{\circledR}$ chelating resin beads (100-2400 beads depending on the element). Metals are released into $0.1-0.5 \mathrm{M} \mathrm{HNO}_{3}$, and trace metal isotope ratios are determined by ICPMS. The benefit of this method compared to our previous $\mathrm{Mg}(\mathrm{OH})_{2}$ coprecipitation method is that the final matrix is very dilute so cone-clogging and matrix sensitivity suppression are minimal. Recovery efficiencies are sensitive to sample $\mathrm{pH}$, number of resin beads added, and the length of time allowed for sample-resin binding and elution; these factors are optimized for each element to yield the highest recovery. The method has a low procedural blank and high sensitivity sufficient for the analysis of pM-nM open-ocean trace metal concentrations. Application of this method to samples from the Bermuda Atlantic Time-Series Study station provides oceanographically consistent $\mathrm{Cu}, \mathrm{Cd}, \mathrm{Pb}$, and Fe profiles that are in good agreement with other reliable data for this site. In addition, the method can potentially be modified for the simultaneous analysis of multiple elements, which will be beneficial for the analysis of large number of samples.
\end{abstract}




\title{
Analysis of trace metals ( $\mathrm{Cu}, \mathrm{Cd}, \mathrm{Pb}$, and $\mathrm{Fe}$ ) in seawater using single batch nitrilotriacetate resin extraction and isotope dilution inductively coupled plasma mass spectrometry
}

\author{
Jong-Mi Lee ${ }^{a}$, Edward A. Boyle ${ }^{a, *}$, Yolanda Echegoyen-Sanz ${ }^{a}$, Jessica N. Fitzsimmons ${ }^{a}$, \\ Ruifeng Zhang ${ }^{\mathrm{b}}$, Richard A. Kayser ${ }^{\mathrm{a}}$ \\ ${ }^{a}$ Department of Earth, Atmospheric, and Planetary Sciences, Massachusetts institute of Technology, Cambridge, MA 02139, USA \\ ${ }^{b}$ State Key Laboratory of Estuarine and Coastal Research, East China Normal University, Shanghai 200062, China
}

\section{A R T I C L E I N F O}

\section{Articie history:}

Received 9 September 2010

Received in revised form

12 November 2010

Accepted 29 November 2010

Available online 10 December 2010

\section{Keywords:}

Seawater

Trace elements

Isotope dilution inductively coupled

plasma mass spectrometry

$\mathrm{Fe}$

$\mathrm{Pb}$

$\mathrm{Cd}$

$\mathrm{Cu}$

\begin{abstract}
A B S T R A C T
A simple and accurate low-blank method has been developed for the analysis of total dissolved copper, cadmium, lead, and iron in a small volume (1.3-1.5 mL per element) of seawater. Pre-concentration and salt-separation of a stable isotope spiked sample are achieved by single batch extraction onto nitrilotriacetate (NTA)-type Superflow ${ }^{\circledR}$ chelating resin beads (100-2400 beads depending on the element). Metals are released into $0.1-0.5 \mathrm{M} \mathrm{HNO}_{3}$, and trace metal isotope ratios are determined by ICPMS. The benefit of this method compared to our previous $\mathrm{Mg}(\mathrm{OH})_{2}$ coprecipitation method is that the final matrix is very dilute so cone-clogging and matrix sensitivity suppression are minimal, while still retaining the high accuracy of the isotope dilution technique. Recovery efficiencies are sensitive to sample $\mathrm{pH}$, number of resin beads added, and the length of time allowed for sample-resin binding and elution; these factors are optimized for each element to yield the highest recovery. The method has a low procedural blank and high sensitivity sufficient for the analysis of $\mathrm{pM}-\mathrm{nM}$ open-ocean trace metal concentrations. Application of this method to samples from the Bermuda Atlantic Time-Series Study station provides oceanographically consistent $\mathrm{Cu}, \mathrm{Cd}, \mathrm{Pb}$, and Fe profiles that are in good agreement with other reliable data for this site. In addition, the method can potentially be modified for the simultaneous analysis of multiple elements, which will be beneficial for the analysis of large number of samples.
\end{abstract}

(c) 2010 Elsevier B.V. All rights reserved.

\section{Introduction}

It has been widely recognized that trace metals play important roles in the ocean. Trace metals such as iron, copper, and cadmium are essential for the growth of marine phytoplankton [1-5]; for instance, iron is known to be used in chlorophyll production and nitrogen fixation [3,6], thereby regulating primary productivity and marine biogeochemical cycles [7,8], and copper and cadmium can be toxic under some conditions [9,10]. Other trace elements, such as lead, document the impact of anthropogenic trace metal inputs to the ocean for the past two centuries $[11,12]$.

In spite of their importance, however, global-scale trace metal data are sparse because of difficulties in sampling and analysis. Because of their extremely low concentrations $\left(10^{-9}\right.$ to $10^{-12} \mathrm{~mol} \mathrm{~L}^{-1}$ ) compared to the high-salt matrix in seawater, analysis of trace metals requires pre-concentration and purification

\footnotetext{
* Corresponding author. Tel.: +1 6172533388 ; fax: +1 6172538630 E-mail address: eaboyle@mit.edu (E.A. Boyle).
}

0003-2670/\$ - see front matter $\mathcal{C} 2010$ Elsevier B.V. All rights reserved. doi:10.1016/j.aca.2010.11.052 before detection, which includes solvent extraction [13-15] and extraction onto chelating resin columns (e.g. Chelex-100, 8- HQ chelating resin) $[14,16,17]$ followed by trace metal quantification using graphite furnace atomic absorption spectrometry (GFAAS) or inductively coupled plasma mass spectrometry (ICPMS). Trace metal concentrations can be also measured electrochemically (e.g. anodic stripping voltammetry), where pre-concentration is achieved by long deposition times $[18,19]$. However, these methods are relatively labor-intensive (i.e. reagent purification and sample processing) and time-consuming as they require large sample volumes (hundreds of mililiter to liter scale).

In the last decade, various methods have been developed to allow trace metal analysis with a simpler procedure and a smaller sample volume. One of these is the $\mathrm{Mg}(\mathrm{OH})_{2}$ co-precipitation method coupled with isotope dilution ICPMS [20-22]. This method uses small volumes $(1.5-50 \mathrm{~mL})$ of seawater and reagents and has good sensitivity with low procedural blanks. However, the resulting sample matrix contains high $\mathrm{Mg}^{2+}$ and seasalt occluded in the precipitates that can clog the nebulizer and leave deposits on the ICPMS cones, which limits runs to a few hours, suppresses ICPMS 
signal strength, and requires frequent cleaning of the nebulizer and cones. Thus, this method is not ideal for the routine measurement of many samples.

Other approaches that have been employed are on-line column extraction methods using recently developed chelating resins that have higher affinity for metal ions [23-25]. For instance, Lohan et al. [23] used on-line preconcentration by nitrilotriacetate (NTA)type chelating resin columns coupled to flow injection analysis by ICPMS. This study demonstrated that dissolved $\mathrm{Fe}^{3+}$ and $\mathrm{Cu}^{2+}$ can be quantitatively recovered at pH below 2 after oxidization of $\mathrm{Fe}^{2+}$ to $\mathrm{Fe}^{3+}$ by the addition of trace $\mathrm{H}_{2} \mathrm{O}_{2}$, which is extremely advantageous in that samples can be processed without further $\mathrm{pH}$ adjustment (trace metal samples are routinely acidified and stored at $\mathrm{pH}$ 1.7-2.0 to preserve metal ions in soluble inorganic form). However, because these on-line column extraction methods assign trace metal concentrations by external standardization, accuracies are affected by sample matrix and recovery variation during pre-concentration. In cases where the sample $\mathrm{pH}$ needs to be adjusted to a higher $\mathrm{pH}$ (e.g., EDTA-type resin, or NTA resin for other trace metals except $\mathrm{Fe}$ and $\mathrm{Cu}$ ), recovery efficiencies may also vary during $\mathrm{pH}$ adjustment because metal ions may be lost by re-complexation with organic ligands or binding to bottle walls. A very recently developed method tackles this problem by using isotope dilution and standard additions prior to on-line column extraction to analyze multiple elements simultaneously [26]. However, on-line column extraction methods generally have low ICPMS throughput because sample analysis rate is limited by sample uptake and elution times, and they are also relatively sample consuming as large sample volumes are used to rinse the entire system and precondition the resin column.

In this study, we utilized the same resin as in Lohan et al.'s method, but modified the method by using (1) isotope dilution to avoid recovery efficiency and sensitivity issues and (2) offline batch extraction from 100 to 2400 resin beads to keep blanks low and improve ICPMS throughput. This method requires relatively little analyst time and minimal volume of sample (only 1.3-1.5 mL), which is beneficial under circumstances when sample volume is limited. In addition, the use of small amounts of resin lowers the Fe procedural blank in particular by reducing the Fe released from the NTA resin (see Section 3.2). With this method we were able to analyze dissolved $\mathrm{Cu}, \mathrm{Cd}, \mathrm{Pb}$, and $\mathrm{Fe}$ in seawater samples to demonstrate oceanographically consistent profiles near Bermuda.

\section{Experimental}

\subsection{Reagents}

All reagent and sample preparations were carried out in a Class 100 clean laminar flow bench or recirculating fume hood in a positive-pressure clean lab. High purity $\mathrm{H}_{2} \mathrm{O}$ was prepared by redistillation of "ultrapure" deionized water in a Corning "Mega-Pure" Vycor ${ }^{\circledR} /$ borosilicate still. Nitric acid was prepared by distilling reagent-grade $\mathrm{HNO}_{3}$ four times in a Vycor still and diluting with high-purity water to make $0.1 \mathrm{M}$ or $0.5 \mathrm{M} \mathrm{HNO}_{3}$. Clean Suprapur ${ }^{\circledR}$ hydrogen peroxide ( $30 \%$ solution, EMD Chemicals) was diluted to $0.75 \%$ with high purity $\mathrm{H}_{2} \mathrm{O}$. Acetic acid ( $\mathrm{HAc}$ ) was prepared by Vycor-distilling reagent-grade acetic acid, and clean ammonium hydroxide $\left(\mathrm{NH}_{4} \mathrm{OH}\right)$ was purchased (Optima ${ }^{\circledR}$ grade, Fisher Scientific) or alternatively made by purifying reagent-grade $\mathrm{NH}_{4} \mathrm{OH}$ by vapor-distillation.

Ammonium acetate buffer solution was prepared by mixing clean $\mathrm{NH}_{4} \mathrm{OH}$ and $\mathrm{HAc}$. The mixing ratio was determined empirically to keep the $\mathrm{pH}$ of the buffer between 7.9 and 7.98 because at pH higher than 8.0, $\mathrm{Mg}(\mathrm{OH})_{2}$ can be precipitated when buffer meets the sample, potentially resulting in the loss of metals. The buffer
Table 1

Fe released from various vials with different positions. The Fe concentrations were measured in $0.5 \mathrm{M} \mathrm{HNO}_{3}$ after $150 \mu \mathrm{L}$ of the $0.5 \mathrm{M} \mathrm{HNO}_{3}$ was stored in empty vials for five days, which corresponds to the Fe procedural blank coming from the vials. Eppendorf $\mathrm{A}$ and $\mathrm{B}$ are from different lots.

\begin{tabular}{lll}
\hline Vials & Position & $\mathrm{Fe}(\mathrm{nM})$ \\
\hline Eppendorf A & Right-side up & 0.004 \\
& Upside-down & 0.021 \\
Eppendorf B & Right-side up & 0.005 \\
& Upside-down & 0.043 \\
Molecular BioProducts, Inc. & Right-side up & 0.041 \\
& Upside-down & 0.030 \\
\hline
\end{tabular}

was used without further dilution to minimize the volume of buffer added to the samples. Because ammonia gas is lost relatively rapidly through plastic bottle walls, the buffer was refrigerated when not in use to reduce buffer weakening.

\subsection{Materials}

All the $1.5 \mathrm{~mL}$ polyethylene vials (Eppendorf AG or Molecular BioProducts, Inc. with o-rings removed) and bottles were acidleached for one day at $60^{\circ} \mathrm{C}$ with $10 \%$ reagent-grade $\mathrm{HCl}$. The vials and bottles were then rinsed 3-5 times with pure distilled water, filled with high-purity $0.06 \mathrm{M} \mathrm{HCl}$, and then leached for another day at $60^{\circ} \mathrm{C}$. The dilute $\mathrm{HCl}$ was left in the vials until just before use. Pipette tips were rinsed with dilute $\mathrm{HCl}$ and high purity $\mathrm{H}_{2} \mathrm{O}$ immediately before use. Before sample preparation, $1.5 \mathrm{~mL}$-size vials from different companies were tested for their Fe blank by adding $150 \mu \mathrm{L}$ of clean $0.5 \mathrm{M} \mathrm{HNO}_{3}$ to acid-cleaned, empty vials and measuring Fe concentrations in the acid after 5 days of leaching. The Fe detected herein represents the Fe blank coming from the vial walls since during sample preparation Fe is eluted from the resin beads in the same way (i.e., store $150 \mu \mathrm{L}$ of $0.5 \mathrm{M} \mathrm{HNO}_{3}$ in resin-containing vials for five days). We also conducted the same test while the vials were kept upside-down to check for potential contamination from vial caps. Eppendorf vials (no longer commercially available; reused repeatedly) were found to be cleaner for $\mathrm{Fe}$ compared to the other brands tested, so only these vials were used for $\mathrm{Fe}$ analysis, although different lots of vials resulted in variable Fe blanks (Table 1). We also found that vial caps are the largest contributor to Fe blanks even after they are cleaned by the acidleaching steps described above, so vials were kept upright during sample preparation, and every effort was made to avoid contact between acidic sample solution and caps. $\mathrm{Cu}, \mathrm{Cd}$, and $\mathrm{Pb}$ blanks were low regardless of what brand vials were used, and vials from Eppendorf AG and Molecular BioProducts, Inc. were both used for these elements.

\subsection{Standards}

$\mathrm{Cu}, \mathrm{Cd}$, and $\mathrm{Pb}$ standards with natural isotope abundance were prepared by diluting ULTRA grade ICP standards (ULTRA Scientific, North Kingstown, RI) with $0.1 \mathrm{M} \mathrm{HNO}_{3}$. For the natural isotope abundance Fe standard, $99.99 \%$ pure Fe metal was dissolved in $1 \%$ (V/V) $\mathrm{HNO}_{3}$ and further diluted with $0.5 \mathrm{M} \mathrm{HNO}_{3}$. Scarcer-stableisotope-enriched spikes $\left({ }^{65} \mathrm{Cu},{ }^{110} \mathrm{Cd}\right.$, and $\left.{ }^{204} \mathrm{~Pb}\right)$ were made by dissolution of $\mathrm{CuO}, \mathrm{CdO}$ and $\mathrm{PbCO}_{3}$ (Oak Ridge National Laboratories) in $1 \% \mathrm{HNO}_{3}$, and working isotope spikes were made by subsequent dilution with $0.1 \mathrm{M} \mathrm{HNO}_{3}$. A ${ }^{54} \mathrm{Fe}-{ }^{57} \mathrm{Fe}$ enriched isotope spike was shared with us from the laboratory of Dan Schrag (Harvard Univ., Cambridge, MA, USA). The concentrations of these working isotope spikes were adjusted to minimize error propagation of the isotope dilution method, i.e. to match approximately the isotope ratio of the sample-spike mixture with the geometric mean of the isotope ratios of the isotope spike and the natural 
sample, and not too far from 1:1 to minimize blank errors [27,28]. The exact concentrations of $\mathrm{Cu}, \mathrm{Cd}, \mathrm{Pb}$, and $\mathrm{Fe}$ in the isotope spikes were determined by isotope dilution calibration against the natural abundance standard of each element.

\subsection{NTA resin}

We have used NTA Superflow ${ }^{\circledR}$ resin (Qiagen Inc., Valencia, CA) supplied in both $\mathrm{Ni}^{2+}$ and non- $\mathrm{Ni}^{2+}$ forms, although the non- $\mathrm{Ni}^{2+}$ form was preferred. The resin was cleaned by multiple rinsing steps in acid-cleaned polypropylene centrifuge tubes. When not being used or cleaned, the resin was kept refrigerated. The resin was first washed several times with high purity $\mathrm{H}_{2} \mathrm{O}$, then multiple times with high purity $1.5 \mathrm{M} \mathrm{HCl}$, and then again multiple times with high purity $\mathrm{H}_{2} \mathrm{O}$ until the pH was higher than 3 . Then the resin was rinsed several times with high purity $0.5 \mathrm{M} \mathrm{HNO}_{3}$; for the first washes, it was left on a shaker table for several hours, and then left overnight for the final wash. Finally, the resin was rinsed with high purity $\mathrm{H}_{2} \mathrm{O}$ several times until the $\mathrm{pH}$ was higher than 3 . After each wash, the resin was centrifuged down and the supernatant was discarded. Cleaned NTA resin was then diluted with high purity $\mathrm{H}_{2} \mathrm{O}$ so the resin suspension contained $\sim 100-400$ resin beads per $25 \mu \mathrm{L}$, and was stored in a refrigerator. The resin blank was checked by leaching the resin beads in $0.5 \mathrm{M} \mathrm{HNO}_{3}$ and measuring trace metal concentrations (see Section 3.4); if the blank was higher than expected, we repeated the $0.5 \mathrm{M} \mathrm{HNO}_{3}$ and high purity $\mathrm{H}_{2} \mathrm{O}$ rinsing steps. Cleaning the resin is particularly important for Fe. It seems that Fe within the beads diffuses to the surface of the beads where it can be dissolved into the samples, so even after the resin is cleaned once, significant amounts of $\mathrm{Fe}$ are slowly released from the resin beads over time. We found a high resin blank for $\mathrm{Fe}$ (up to $\sim 2.5 \mathrm{nM}$ ) when the resin was stored for a long time (a few months), and it decreased to the normal level $(<0.2 \mathrm{nM})$ after re-cleaning the resin.

\subsection{Seawater for method calibration}

Two seawater samples, SAFe MIT "A" and SAFe D2, were used as reference samples in this study. They were collected from the surface and $1000 \mathrm{~m}$ depth at $30^{\circ} \mathrm{N} 140^{\circ} \mathrm{W}$ in the North Pacific during the SAFe program in 2004 [29]. This program provides reference samples (SAFe S for surface seawater and SAFe D2 for deep water) from a homogenized large volume tank, filtered and acidified ( $\mathrm{pH}$ 1.7.) in a uniform way. The SAFe MIT "A" was taken at the surface at the same station during the same cruise using a towed fish sampler and thus should have comparable concentration to the "official" SAFe S. The SAFe MIT "A" was filtered through clean $0.2 \mu \mathrm{m}$ Osmonics capsule filters and acidified to $\mathrm{pH}$ 2.0.

Samples for an oceanographic profile were collected at the Bermuda Atlantic Time-Series Study station (BATS, $31^{\circ} 40^{\prime} \mathrm{N}$, $64^{\circ} 10^{\prime} \mathrm{W}$ ) in June 2008 during GEOTRACES IC1 intercalibration cruise. The samples used for $\mathrm{Cu}, \mathrm{Cd}$, and $\mathrm{Pb}$ profiles were taken using a Moored In-situ Trace Element Serial Sampler (MITESS) or with a single MITESS “ATE” (Automated Trace Element) [30,31]. Soon after sample collection (within $24 \mathrm{~h}$ ), the samples were filtered through acid-cleaned $0.4 \mu \mathrm{m}$ Nuclepore filters in a class 100 laminar flow bench. The samples used for Fe were collected by the GEOTRACES GOFlo rosette system, filtered through $0.2 \mu \mathrm{m}$ Osmonics capsule filters. All samples were acidified to $\mathrm{pH} 2.0$ with $4 \times$ Vycor-distilled $6 \mathrm{~N}$ $\mathrm{HCl}$ (except SAFe D2 that was acidified to $\mathrm{pH} 1.7$ with sub-boiling distilled $6 \mathrm{~N} \mathrm{HCl}$.

\subsection{Instrumentation}

A Quadrupole ICPMS (VG PlasmaQuad 2+) was used for $\mathrm{Cu}$, $\mathrm{Cd}$, and $\mathrm{Pb}$ analyses. Measured isotopes were ${ }^{63} \mathrm{Cu}$ and ${ }^{65} \mathrm{Cu}$ for $\mathrm{Cu} ;{ }^{95} \mathrm{Mo},{ }^{110} \mathrm{Cd},{ }^{114} \mathrm{Cd}$ and ${ }^{118} \mathrm{Sn}$ for $\mathrm{Cd}$; and ${ }^{202} \mathrm{Hg},{ }^{204} \mathrm{~Pb}$, and
Table 2a

Typical $\mathrm{PQ}^{2+}$ operating conditions for $\mathrm{Cu}, \mathrm{Cd}$, and $\mathrm{Pb}$ analysis.

\begin{tabular}{ll}
\hline Instrumental parameter & Set point \\
\hline Forward power & $1450 \mathrm{~W}$ \\
Reflected power & $<3 \mathrm{~W}$ \\
Plasma Ar gas flow & $15.1 \mathrm{Lmin}^{-1}$ \\
Carrier Ar gas flow & $1.18 \mathrm{Lmin}^{-1}$ \\
Auxiliary Ar gas flow & $1.14 \mathrm{Lmin}^{-1}$ \\
Acquisition method & Peak jump mode \\
Channels per mass & 3 \\
Channel spacing & 0.02 \\
Number of sweeps & 200 \\
Dwell time & $10 \mathrm{~ms} /$ peak \\
Data acquisition time & $73 \mathrm{~s}$ \\
\hline
\end{tabular}

${ }^{208} \mathrm{~Pb}$ for $\mathrm{Pb}$. The sensitivity of the instrument was $\sim 100,000$ counts per second for $1 \mathrm{ppb}$ Indium when a nominal $50 \mu \mathrm{Lmin}^{-1}$ MicroMist ${ }^{\circledR}$ concentric nebulizer (Glass Expansion, measured flow rate of $70 \mu \mathrm{L} \mathrm{min}^{-1}$ ) was used in conjunction with a water-cooled Scott double by-pass spray chamber and a Fassel quartz torch(Glass Expansion). Free-aspiration was used for sample uptake, and a frit filter was used at the tip of the sipper tubing to prevent clogging from the resin beads. The operating details are listed in Table $2 \mathrm{a}$. Isobaric interferences on ${ }^{110} \mathrm{Cd}\left({ }^{94} \mathrm{Mo}^{16} \mathrm{O}\right)$ and ${ }^{114} \mathrm{Cd}\left({ }^{98} \mathrm{Mo}^{16} \mathrm{O}\right)$ were corrected using ${ }^{95} \mathrm{Mo}$ counts of each sample and the MoO/ $/{ }^{95} \mathrm{Mo}$ of a Mo standard, and the magnitude of this correction was negligibly small $\left(<0.1 \%\right.$ ). The ${ }^{114} \mathrm{Sn}$ interference on ${ }^{114} \mathrm{Cd}$ and ${ }^{204} \mathrm{Hg}$ interference on ${ }^{204} \mathrm{~Pb}$ were corrected by monitoring ${ }^{118} \mathrm{Sn}$ and ${ }^{202} \mathrm{Hg}$.

For $\mathrm{Fe}$ analysis, ${ }^{52} \mathrm{Cr},{ }^{54} \mathrm{Fe}$, and ${ }^{56} \mathrm{Fe}$ were determined simultaneously with Faraday cups using static mode on a multi-collector magnetic sector ICPMS (GV/Micromass IsoProbe) with a hexapole collision cell using Ar and $\mathrm{H}_{2}$ collision gases to minimize ${ }^{40} \mathrm{Ar}^{14} \mathrm{~N}^{+}$ and ${ }^{40} \mathrm{Ar}^{16} \mathrm{O}^{+}$interferences and thermalize the ion beam. The same nominal $50 \mu \mathrm{Lmin}^{-1} \mathrm{MicroMist}^{\circledR}$ concentric nebulizer was used along with an APEX Q inlet system (Elemental Scientific, Inc.) with a passive desolvating membrane and a Fassel quartz torch (Glass Expansion). A frit filter was placed on the tip of the sipper tube to avoid clogging by resin beads. This instrument provides very precise Fe data at high sensitivity because ${ }^{40} \mathrm{Ar}^{16} \mathrm{O}^{+}$and ${ }^{40} \mathrm{Ar}^{14} \mathrm{~N}^{+}$ interferences on ${ }^{56} \mathrm{Fe}$ and ${ }^{54} \mathrm{Fe}$ are eliminated by the hexapole collision cell and the instrument can be run in low resolution mode. The $\mathrm{Cr}$ interference on mass 54 was corrected by monitoring ${ }^{52} \mathrm{Cr}$, but was negligibly small because the resin does not take up $\mathrm{Cr}$ at the analytical $\mathrm{pH}$ range. The operating details for the IsoProbe are listed in Table $2 \mathrm{~b}$

Dilute nitric acid (the same acid used as for eluates, i.e. $0.1 \mathrm{M}$ $\mathrm{HNO}_{3}$ for $\mathrm{Cu}, \mathrm{Cd}$, and $\mathrm{Pb}$ and $0.5 \mathrm{M} \mathrm{HNO}_{3}$ for $\mathrm{Fe}$ ) was measured at appropriate intervals ("on-peak zero", OPZ) to correct for changes in instrumental background. Instrumental mass bias was corrected by running the "natural" isotope standards of each element (spiked gravimetric standards for $\mathrm{Pb}$ ) at the beginning and end of the sample run each day. The average of these two values was used for the

Table $2 \mathbf{b}$

Typical is oprobe operating conditions for Fe analysis.

\begin{tabular}{ll}
\hline Instrumental parameter & Set point \\
\hline Forward power & $1350 \mathrm{~W}$ \\
Reflected power & $<1 \mathrm{~W}$ \\
Hexapole Ar gas flow & $1.8 \mathrm{mLmin}^{-1}$ \\
Hexapole $\mathrm{H}_{2}$ gas flow & $2.5 \mathrm{mLmin}^{-1}$ \\
Expansion pressure & $3 \times 10^{-1} \mathrm{mbar}$ \\
Hexapole pressure & $4 \times 10^{-4} \mathrm{mbar}$ \\
Analyzer pressure & $2 \times 10^{-7} \mathrm{mbar}$ \\
Nebulizer gas flow & $0.8 \mathrm{Lmin}^{-1}$ \\
Cool gas flow & $14 \mathrm{Lmin}^{-1}$ \\
Aux. gas flow & $1.0 \mathrm{Lmin}^{-1}$ \\
Data acquisition time & $24 \mathrm{~s}$ \\
\hline
\end{tabular}


correction, and a linear \% per amu model was used to correct for instrumental mass bias.

\subsection{General procedure}

Because we have found that optimal conditions vary slightly for $\mathrm{Cu}-\mathrm{Cd}, \mathrm{Pb}$, and $\mathrm{Fe}$, we generally perform these analyses separately, although because of isotope dilution calibration, it is possible to do all simultaneously at $\mathrm{pH} \sim 5$ so long as the isotope spikes do not have contamination for the other elements.

The samples were prepared by the following procedure. Initially, an acid-leached $1.5 \mathrm{~mL}$ vial was rinsed with a small volume $(\sim 0.5 \mathrm{~mL})$ of the acidified seawater sample ( $\mathrm{pH} 1.7-2.0)$, and then $1.3-1.5 \mathrm{~mL}$ of the sample was poured into the vials. The vial was weighed before and after pouring the sample, and the exact sample volume was determined by converting the weight of sample to volume using the density of seawater. Alternatively, for $\mathrm{Cu}, \mathrm{Cd}$, and $\mathrm{Pb}$ analyses where constant volume of sample is desirable for easier $\mathrm{pH}$ adjustment (because the volume of buffer added to samples can be fixed), we poured the sample into the vial and pipetted out exactly $1.3 \mathrm{~mL}$ of the sample using a clean pipette tip. The $1.3 \mathrm{~mL}$ sample in the pipette tip was pipetted back into the same vial after quickly emptying the vial. Then, the sample was spiked with $25 \mu \mathrm{L}$ of stable isotope spikes (enriched in ${ }^{65} \mathrm{Cu},{ }^{110} \mathrm{Cd},{ }^{204} \mathrm{~Pb}$, and ${ }^{54} \mathrm{Fe}$ ) and left for a few minutes after vortex mixing to establish isotopic equilibrium. At this $\mathrm{pH}(<1.7), 2$ min were proven to be sufficient to reach isotope equilibrium [20]. Then, for $\mathrm{Cu}, \mathrm{Cd}$, and $\mathrm{Pb}$ analyses, the $\mathrm{pH}$ of the sample was adjusted to $\mathrm{pH}>5$ using ammonium acetate solution ( $80-200 \mu \mathrm{L}$, depending on the initial sample $\mathrm{pH}$ and target $\mathrm{pH}$ ). Buffer was not added for Fe analysis samples, but $10 \mu \mathrm{L}$ of $0.75 \% \mathrm{H}_{2} \mathrm{O}_{2}$ was added to oxidize $\mathrm{Fe}(\mathrm{II})$ to $\mathrm{Fe}$ (III). After the addition of buffer or $\mathrm{H}_{2} \mathrm{O}_{2}$, sample vials were vortexed again for a few seconds. Finally, 25-150 $\mu \mathrm{L}$ of the NTA resin suspension (100-2400 beads) was added to the vial, vortexed again, and then the sample vial was shaken on an orbital table for $>24 \mathrm{~h}$ to allow the trace metals and resin to bind. After 1-4 days, the sample vial was centrifuged (for $45 \mathrm{~s}$ at $14,500 \mathrm{rpm}$ ) and the overlying seawater was siphoned off carefully, leaving the resin beads at the bottom. The resin beads were then rinsed three times with high purity $\mathrm{H}_{2} \mathrm{O}$ to remove seasalt; in each rinse, the vial was filled with high purity $\mathrm{H}_{2} \mathrm{O}$, centrifuged down, and the supernatant was siphoned off. After rinsing, the $150 \mu \mathrm{L}$ of $0.5 \mathrm{M} \mathrm{HNO}_{3}(\mathrm{Fe})$ or $0.1 \mathrm{M} \mathrm{HNO}_{3}(\mathrm{Cu}, \mathrm{Cd}, \mathrm{Pb})$ was added to the vial, and the trace metals were allowed one to five days (five days for $\mathrm{Fe}$ ) to be released into solution. The final solution was then brought to the ICPMS, and the isotope ratios $\left({ }^{56} \mathrm{Fe}\right)^{54} \mathrm{Fe}$, ${ }^{63} \mathrm{Cu} /{ }^{65} \mathrm{Cu},{ }^{114} \mathrm{Cd} /{ }^{110} \mathrm{Cd}$, and ${ }^{208} \mathrm{~Pb} /{ }^{204} \mathrm{~Pb}$ ) of this solution (after OPZ blank correction) were measured to calculate the concentration of each element.

Procedural blanks for $\mathrm{Cu}, \mathrm{Cd}$, and Fe were determined by processing small volumes $(0.1-0.3 \mathrm{~mL})$ of the SAFe MIT "A" seawater in the same way as samples because their concentrations in this water is small (although a correction for this contribution is made nonetheless). For $\mathrm{Pb}, 0.3 \mathrm{~mL}$ of low- $\mathrm{Pb}$ seawater was used to determine $\mathrm{Pb}$ procedure blank, made by the removal of $\mathrm{Pb}$ in seawater (taken from BATS, 1997) using $\mathrm{Mg}(\mathrm{OH})_{2}$ coprecipitation followed by filtration through clean $0.4 \mu \mathrm{m}$ Nuclepore filters. In order to estimate accurate procedural blanks, the trace metal contents that were initially included in the SAFe MIT "A" seawater or low-Pb seawater were established by running 3-6 replicates of this seawater as a sample in every sample run.

\section{Results and discussion}

Because this method uses isotope dilution, recovery efficiency is not as critical as in flow-injection methods or other methods based on external standardization. However, a sufficient amount of trace metals should be recovered from the resin to ensure that the ICPMS signals from the sample are well above (order of magnitude at least) instrumental background, especially when trace metal concentrations are very low. The sample preparation procedure was optimized by testing various factors that may affect recovery efficiencies of $\mathrm{Cu}, \mathrm{Cd}, \mathrm{Pb}$, and Fe from NTA resin beads, such as sample $\mathrm{pH}$, resin volume, and the length of time allowed for sample-resin binding and elution from the resin. The accuracy of the method was evaluated by measuring SAFe seawaters, and the method was applied to determine vertical profiles of total dissolved $\mathrm{Cu}, \mathrm{Cd}, \mathrm{Pb}$, and Fe concentrations in samples collected from the BATS station.

\subsection{Sample $p H$}

A previous study showed that $\mathrm{pH}$ is critical for trace metal recoveries from the NTA resin [23]. In Lohan et al.'s study, where a resin column and flow-injection system were used, recovery efficiency of Cu was $\sim 50 \%$ at $\mathrm{pH}<2, \sim 90 \%$ at $\mathrm{pH} 2-3$, and near $100 \%$ at $\mathrm{pH}>3.5$. $\mathrm{Cd}$ was recovered only at a $\mathrm{pH}$ higher than 5.5 , with $\sim 80 \%$ recovery efficiency. In the case of $\mathrm{Fe}(\mathrm{III}), \sim 80 \%$ of $\mathrm{Fe}(\mathrm{III})$ was recovered at $\mathrm{pH}$ 1.5 and $\mathrm{Fe}$ (III) was almost fully recovered at $\mathrm{pH}$ higher than 2 . The relationship between $\mathrm{pH}$ and $\mathrm{Pb}$ recovery from NTA resin was not investigated in Lohan et al.'s study.

Based on this previous study, we tested the effect of $\mathrm{pH}$ on recovery efficiencies of $\mathrm{Cu}, \mathrm{Cd}$, and $\mathrm{Pb}$ in our batch-extraction method. Fe was not studied here because Fe is recovered well (50-75\%) at a typical sample $\mathrm{pH}(1.7-2.0)$ without $\mathrm{pH}$ adjustment. We added $50 \mu \mathrm{L}$ of isotope spike to $1.3 \mathrm{~mL}$ of the acidified seawater samples (pH 1.7-2.0), and then adjusted the $\mathrm{pH}$ of samples using ammonium acetate buffer. The $\mathrm{Cu}$ and $\mathrm{Cd}$ recoveries were tested for $\mathrm{pH}$ values ranging from 5.0 to 6.7, and $\mathrm{Pb}$ was tested from $\mathrm{pH} 2.0$ to 6.7. The amount of buffer added to the sample was empirically determined in each test depending on the target pH. Finally, $50 \mu \mathrm{L}$ of NTA resin ( $\sim 200$ beads) was added to the samples, and the samples were processed following the general procedure described in Section 2.4. The recovery efficiency of each element was calculated by comparing the count rates of ${ }^{65} \mathrm{Cu},{ }^{110} \mathrm{Cd}$, and ${ }^{204} \mathrm{~Pb}$ in the enriched isotope spike to those in the final sample solution.

Under our batch-extraction conditions, $70-100 \%$ of $\mathrm{Cu}$ was recovered in the $\mathrm{pH}$ range $5.0-6.7 . \mathrm{Cd}$ recoveries were very low (1-2\%) at pH below 6.0 and higher at pH 6.5 (Fig. 1a), but even the highest recovery at $\mathrm{pH} 6.5$ was only $\sim 5 \%$. The low recovery of $\mathrm{Cd}$ compared to the other elements is probably because of its low binding ability with nitrilotriacetate (NTA) ligands [32]. Also, the much lower recovery of $\mathrm{Cd}$ at the same $\mathrm{pH}$ compared to Lohan et al.'s study is likely because we used only $\sim 200$ resin beads, whereas Lohan et al. used a column packed with $\sim 10^{5}$ resin beads (inner volume of the $1 \mathrm{~cm}$-column: $85 \mu \mathrm{L}$; bead size: $60-160 \mu \mathrm{m}$ ). $\mathrm{Pb}$ recoveries were low at $\mathrm{pH}<4.5$, highest at $\mathrm{pH} \sim 5.0$, and they decreased as $\mathrm{pH}$ increased above 5.0 (Fig. 1b). In a more detailed study using a different seawater sample, the optimal $\mathrm{pH}$ for $\mathrm{Pb}$ appeared to be $5.0-5.4$ (Fig. 1b). Another thing we noticed was that recovery efficiencies seem to be different for different samples, presumably depending on the strength of natural ligands in each sample relative to that of NTA resin. The low overall recovery efficiency of the later experiment (experiment for $\mathrm{pH}$ 5.0-5.6) compared to the others seems to be caused by this natural variability of the samples, and it emphasizes the importance of using the isotope dilution technique.

\subsection{Number of resin beads}

In order to test our hypothesis that the low $\mathrm{Cd}$ recovery is due to the low number of resin beads used for extraction, we prepared 


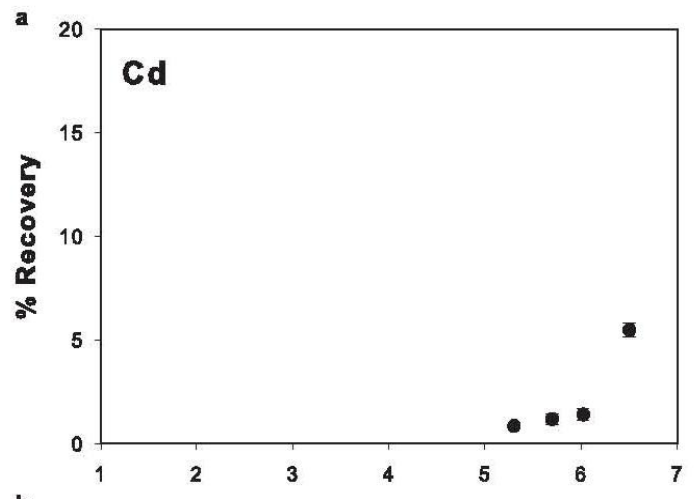

b

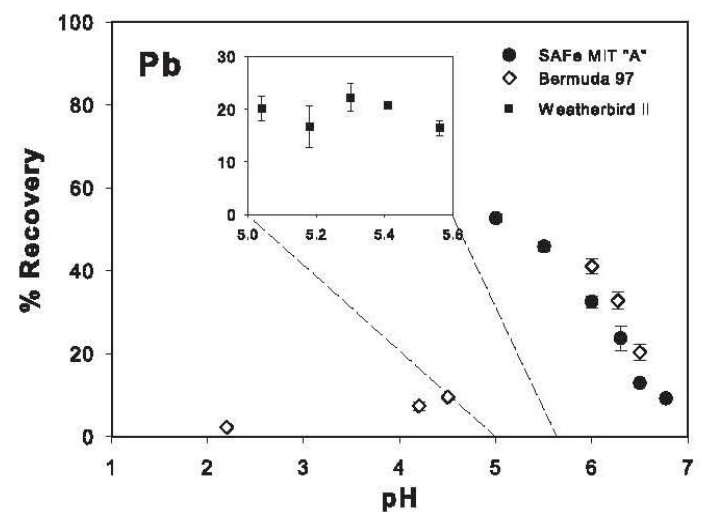

Fig. 1. Relationships between the percent recovery of $\mathrm{Cd}$ and $\mathrm{Pb}$ and the sample $\mathrm{pH}$ when $\sim 200$ resin beads were added to $1.3 \mathrm{~mL}$ of sample. Notice the difference in scales on the vertical axes. Various seawater samples were used for Pb experiments; $\mathrm{Pb}$ recovery efficiencies also varied with the nature of the samples.

samples by adding larger numbers of beads. Recovery efficiencies of $\mathrm{Cu}$ and $\mathrm{Cd}$ increased by $\sim 20 \%$ and $\sim 100 \%$ by doubling the resin volume ( 400 beads) (Fig. 2, white squares), and $\mathrm{Pb}$ recovery also increased as a function of the number of resin beads added to the samples (Fig. 3). Higher recovery efficiencies were achieved by further increasing the number of resin beads; for instance, we could achieve up to $80-90 \% \mathrm{~Pb}$ recovery when 2400 beads were added to the sample. Because the volume of vial is limited to $1.5 \mathrm{~mL}$, in that experiment we made a more concentrated NTA resin suspension ( 400 beads per $25 \mu \mathrm{L}$ ) and added $150 \mu \mathrm{L}$ of resin suspension to the sample.

The concern with using larger volume of resin beads is that adding more beads may increase the procedure blank. When the resin blank was checked for each element (details in Section 3.4), it was negligibly low for $\mathrm{Cu}, \mathrm{Cd}$, and $\mathrm{Pb}$, but was significant for $\mathrm{Fe}$. Thus, for Fe analysis, we did not increase the resin volume (we continued to use $\sim 100$ resin beads) to keep the procedural blank low.

\subsection{Sample-resin binding and trace metal elution times}

The influences of sample-resin binding time and elution time on recovery efficiency were tested with the SAFe MIT "A" seawater. In the first experiment, the samples were allowed to bind to the resin beads on a shaker table for one to four days while the rest of the procedure was kept the same. Cu recovery efficiency increased slightly when a longer time was allowed for sample-resin binding (Fig. 2a), whereas $\mathrm{Cd}$ recovery efficiency showed no detectable
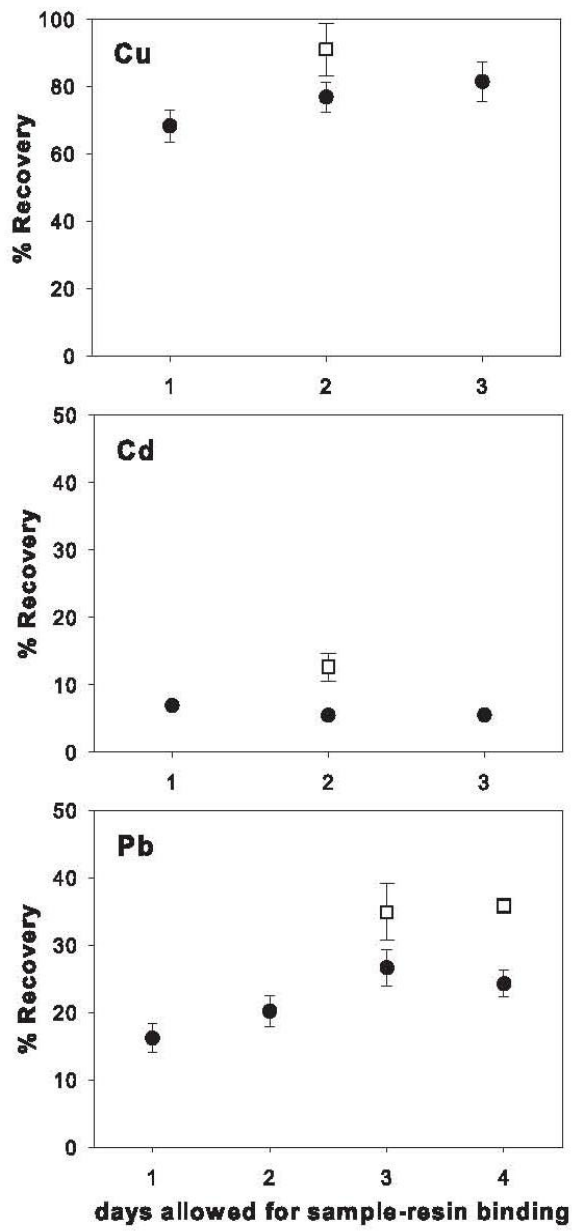

Fig. 2. Relationships between percent recovery of $\mathrm{Cu}, \mathrm{Cd}$, and $\mathrm{Pb}$ and the number of days allowed for sample-resin binding. Samples were prepared at $\mathrm{pH} 6.5$ for $\mathrm{Cu}$ and $\mathrm{Cd}$ and at $\mathrm{pH} 5.3$ for $\mathrm{Pb}$, and $\sim 200$ beads were added to the samples $(\boldsymbol{\square})$. The percent recoveries shown as white squares ( $\square$ ) are when $\sim 400$ resin beads were added to the samples.

difference (Fig. $2 \mathrm{~b}$ ) depending on the binding time. In case of $\mathrm{Pb}$, higher recovery efficiency was achieved when the samples were left with resin beads for longer than 2 days (Fig. $2 \mathrm{c}$ ). The Fe recovery was tested for 24-48 h, and Fe recovery efficiency increased by $\sim 25 \%$ when the samples were left for a longer time. The Fe could be optimally recovered $(>75 \%)$ when the samples were left for about $36-48 \mathrm{~h}$ with the resin; if left longer, chance of contamination from the vial walls/caps increased.

For the sample-resin binding, speed of the shaker table also affects the binding efficiency because a certain speed is necessary to keep the resin beads suspended in the sample. John and Adkins [33] showed that Fe binding to the resin is achieved within a shorter time if samples are shaken vigorously. The optimal speed we found for $\mathrm{Cu}, \mathrm{Cd}$, and $\mathrm{Pb}$ was $\sim 2000 \mathrm{rpm}$. For $\mathrm{Fe}$, shaking samples too vigorously increased the chance of contamination from contact of the sample with the vial caps. The most favorable speed we found to minimize the Fe procedural blank was $1200-1300 \mathrm{rpm}$.

In the second experiment, the samples were allowed to bind to the resin for the same length of time, but different amounts of time (1-5 days) were provided after the addition of nitric acid, 


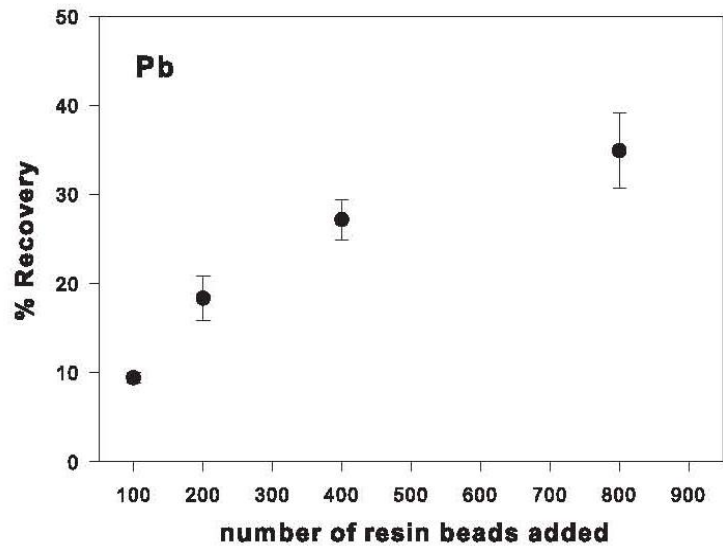

Fig. 3. Relationships between percent recovery of $\mathrm{Pb}$ and the number of NTA resin beads added to the sample. The samples were prepared in $\mathrm{pH} 5.0-5.3$ and three days were allowed for sample-resin binding. Pb was released from the resin for 2-3 days. In another study using different seawater, $\mathrm{Pb}$ recovery up to $80-90 \%$ could be achieved by adding 2400 beads to the samples.

and before the ICPMS run. A longer elution time did not increase $\mathrm{Cu}, \mathrm{Cd}$, or $\mathrm{Pb}$ recoveries between 1 and 5 days, so these elements were clearly released from the resin in a relatively short time. The recovery of Fe increased significantly when a longer time was allowed for elution. However, five days was chosen as the optimal length of time for Fe elution because procedural blank also increases with time, likely because of the slow release of $\mathrm{Fe}$ from the NTA resin beads. When samples could not be run on the ICPMS on schedule, they were refrigerated $\left(<4^{\circ} \mathrm{C}\right)$ to slow down the release of Fe from the resin beads.

According to our investigation, several days to a week for sample preparation yield the highest recovery efficiencies. However, because most of this process time does not involve analyst's work, actual analyst time for sample preparation is relatively small, e.g., several hours for $\sim 100$ samples. In addition, when high recovery efficiency is not critical (i.e., for samples with moderate to high trace metal concentrations), samples can be processed and run on the ICPMS within 3 days.

\subsection{Procedural blank, detection limit, and accuracy}

The procedural blanks and detection limits of this method are shown in Table 3. The detection limits are considered as three times the standard deviations of the procedural blanks. The potential sources of the procedural blank of this batch-extraction method are ammonium acetate buffer or $\mathrm{H}_{2} \mathrm{O}_{2}$, resin beads, dilute nitric acid, sample vials and contamination during handling. Here we examine the contribution of these sources to the procedural blank.

The Fe blank for $\mathrm{H}_{2} \mathrm{O}_{2}$ was measured by adding $10 \mu \mathrm{L}$ of $\mathrm{H}_{2} \mathrm{O}_{2}$ to $100 \mu \mathrm{L}$ of $0.5 \mathrm{M} \mathrm{HNO}_{3}$ and comparing the Fe counts of this solution to those of the Fe standard. The contribution of $\mathrm{H}_{2} \mathrm{O}_{2}$ to the $\mathrm{Fe}$ procedural blank was small, less than $0.004 \mathrm{nM}$.

Table 3

Procedural blank and detection limit of this method $( \pm 1 \sigma)$ and comparison of the SAFe consensus $\mathrm{Cu}, \mathrm{Cd}, \mathrm{Pb}$, and $\mathrm{Fe}$ values with those determined by this method.

\begin{tabular}{llrcl}
\hline & $\mathrm{Cu}(\mathrm{nM})$ & $\mathrm{Cd}(\mathrm{pM})$ & $\mathrm{Pb}(\mathrm{pM})$ & $\mathrm{Fe}(\mathrm{nM})$ \\
\hline Blank & $0.06 \pm 0.04$ & $0 \pm 2$ & $1.3 \pm 0.2$ & $0.05-0.25$ \\
Detect. lim. & 0.12 & 6 & 0.5 & 0.07 \\
SAFe S concensus & $0.55 \pm 0.04$ & 1 & $47.0 \pm 3.4$ & $0.094 \pm 0.008$ \\
SAFe MIT "A" & $0.58 \pm 0.05$ & $1 \pm 2$ & $47.2 \pm 2.3$ & $0.10 \pm 0.05$ \\
SAFe D2 consensus & $2.35 \pm 0.19$ & $992 \pm 35$ & $27.6 \pm 1.9$ & $0.923 \pm 0.029$ \\
SAFe D2 & $2.49 \pm 0.10$ & $977 \pm 25$ & $26.5 \pm 2.0$ & $0.99 \pm .05$ \\
\hline
\end{tabular}

The $\mathrm{Cu}, \mathrm{Cd}$, and $\mathrm{Pb}$ concentrations of ammonium acetate buffer were determined as follows. Because organic solvents cannot be analyzed by ICPMS directly (without addition of oxygen to the nebulizer gas), $2 \mathrm{~mL}$ of buffer solution was evaporated on a hotplate in a V-shaped clean Teflon vial, and the remaining material was redissolved in $200 \mu \mathrm{L}$ of $0.1 \mathrm{M} \mathrm{HNO}_{3} .10 \mu \mathrm{L}$ of enriched isotope spike was then added to the vial followed by a thorough mixing, and $\mathrm{Cu}, \mathrm{Cd}$, and $\mathrm{Pb}$ concentrations in this solution were determined by isotope dilution ICPMS. The metal content was measured in every new batch of buffer to check for contamination. In general, when $150 \mu \mathrm{L}$ of buffer was added to $1.3 \mathrm{~mL}$ sample (buffer to sample ratio used for most of our samples), it added $\sim 0.001 \mathrm{nM}$ of $\mathrm{Cu}$ and $0.26-0.71 \mathrm{pM}$ of $\mathrm{Pb}$ to the procedural blanks. The contribution of buffer to the Cd blank was negligible $(<$ d.l.). The trace metal concentrations in $\mathrm{HAc}$ and $\mathrm{NH}_{4} \mathrm{OH}$ were also measured separately in the same manner, and HAc was found to be the dominant source of trace metals in the buffer. Purifying HAc by further distillation will lower the present buffer blank, and consequently lower the procedural blank.

In order to assess the trace metals coming from the resin suspension, $50 \mu \mathrm{L}$ of resin suspension ( $\sim 200$ beads) was added to $1.5 \mathrm{~mL}$ Eppendorf vials. After the addition of $150 \mu \mathrm{L} 0.1 \mathrm{M} \mathrm{HNO}_{3}$ the resin was left for 1-5 days so any trace metals in the resin could be released. Following the addition of $10 \mu \mathrm{L}$ isotopically enriched standard, the metal concentration in this solution was determined by isotope dilution ICPMS. The $\mathrm{Cu}, \mathrm{Cd}$, and $\mathrm{Pb}$ contents in the resin suspension were negligible ( $<$ d.l.), and the procedural blanks were almost the same even though the number of resin beads was increased. The resin blank for Fe was equivalent to $0.05-0.25 \mathrm{nM}$ for samples depending on the time since the resin was cleaned, which means that the resin is the major source of the Fe procedural blank.

The accuracy of the NTA resin batch-extraction method was tested in several ways. The $\mathrm{Cu}, \mathrm{Cd}, \mathrm{Pb}$, and $\mathrm{Fe}$ concentrations in SAFe seawaters analyzed by this method were compared with the SAFe consensus values (www.geotraces.org/Intercalibration.html\#Standards)(Table 3), and they agreed well. The surface $\mathrm{Cd}$ concentrations are below detection limit for the sample size of $1.3 \mathrm{~mL}$; if lower detection limits are desired, they could be attained by increasing recovery efficiency using more resin beads and concentrating $\mathrm{Cd}$ from a larger sample volume. In addition, the fact that the $\mathrm{Cu}, \mathrm{Cd}$ and $\mathrm{Fe}$ data at BATS station generated by this method match those from previous studies (see Section 3.6) demonstrates that the ID-NTA bead-ICPMS method can provide accurate data.

\subsection{Multi-element analysis}

This method has the potential to detect multi-element concentrations from a single $1.3 \mathrm{~mL}$-size sample. The sample can be spiked with a multi-isotope standard (a mixture of the enriched isotope standard of each element), and the isotope ratios of the multiple elements in the sample can be detected concurrently on the ICPMS. In order to achieve this goal, each scarcer-isotope-enriched spike should be clean with respect to the other elements to yield low procedural blank for all analyzed elements. When ${ }^{65} \mathrm{Cu}-,{ }^{110} \mathrm{Cd}-$, and ${ }^{204} \mathrm{~Pb}$-enriched isotope spikes were checked for $\mathrm{Cu}, \mathrm{Cd}$, and $\mathrm{Pb}$ concentrations (Table 4 ), they were relatively clean for each other except the ${ }^{65} \mathrm{Cu}$ isotope spike, which was slightly contaminated with $\mathrm{Pb}$ probably during storage and handling (this ${ }^{65} \mathrm{Cu}$ spike solution was more than 10 years old). Spiking $25 \mu \mathrm{L}$ of this ${ }^{65} \mathrm{Cu}$ spike to samples will increase the Pb procedural blank by $0.28 \mathrm{pM}$; however, this is still acceptable considering typical $\mathrm{Pb}$ concentrations in the ocean. Cross-contamination was not investigated for Fe because we measure Fe on a different instrument (IsoProbe) from the other elements (PQ2+). Because mixing the ${ }^{65} \mathrm{Cu}$, ${ }^{114} \mathrm{Cd}$, and ${ }^{204} \mathrm{~Pb}$ isotope spikes will slightly change the fraction of each isotope 

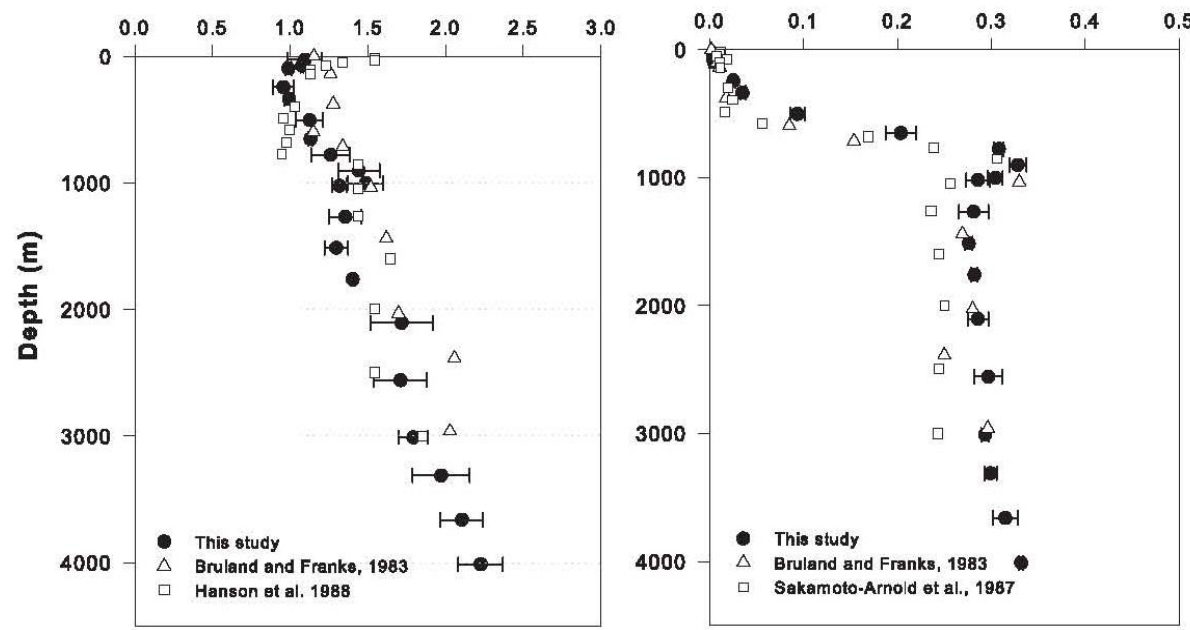

c

Dissolved Pb (nM)

d

Dissolved $\mathrm{Fe}(\mathrm{nM})$
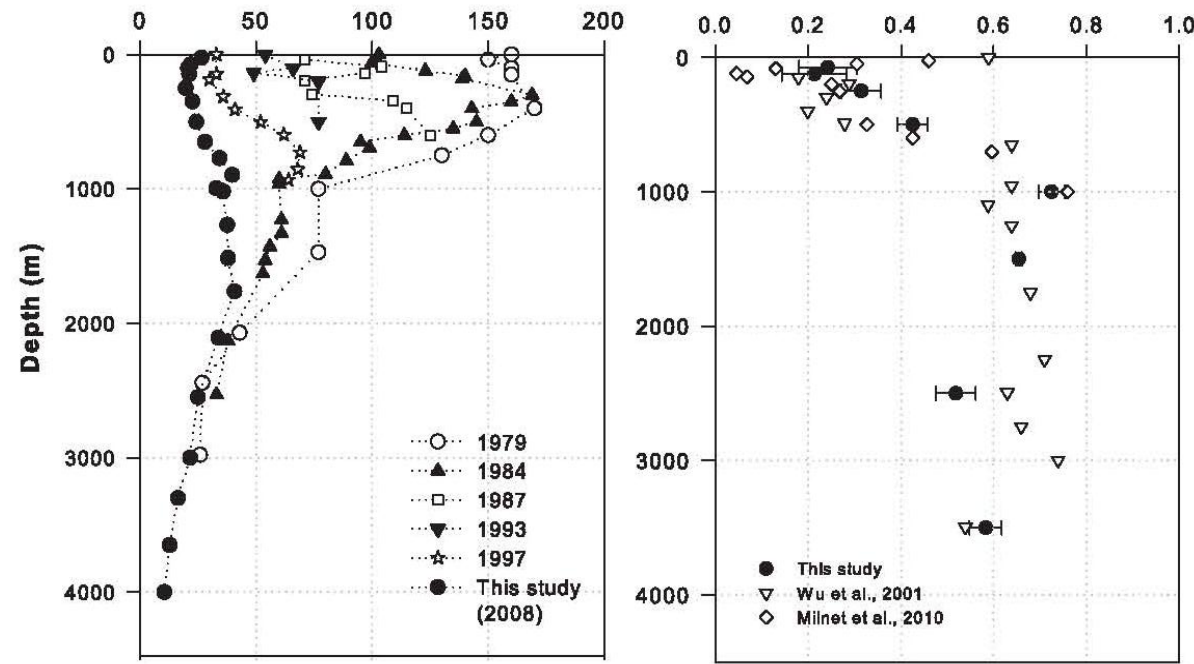

Fig. 4. Profiles of $\mathrm{Cu}, \mathrm{Cd}, \mathrm{Pb}$, and Fe at BATS analyzed by the ID-NTA bead-ICPMS method and comparison with the data from nearby stations in Sargasso Sea. The Cu and Cd profiles are from Bruland and Franks, $1987\left(34^{\circ} 06^{\prime} \mathrm{N}, 66^{\circ} 07^{\prime} \mathrm{W}\right.$ ), Hanson et al. [34] and Sakamoto-Arnold et al. [39] ( $35^{\circ} 40^{\prime} \mathrm{N}, 71^{\circ} 53^{\prime} \mathrm{W}$ ). The Pb profiles are from Schaule and Patterson [40] (sampled in 1979), Boyle et al. [11] (sampled in 1984), Wu and Boyle [12] (sampled in 1993), and others are unpublished data. The Fe profiles are from Wu et al. [41] (34.8 N, 57.8 W) and Milne et al. [26] (same cruise, different cast with different sampling device).

and isotope ratios (contamination from the other isotope spikes), they should be precisely measured before use. Also, the accuracy of this multi-element analysis can be improved by adjusting the mixing ratio and concentrations of each isotope standard to minimize

Table 4

Concentrations of $\mathrm{Cu}, \mathrm{Cd}$, and $\mathrm{Pb}$ in ${ }^{65} \mathrm{Cu},{ }^{110} \mathrm{Cd}$, and ${ }^{204} \mathrm{~Pb}$ enriched is otope spikes. When $25 \mu \mathrm{L}$ of each isotope spike is added to $1.3 \mathrm{~mL}$ sample, it increases the procedural blank of the other elements as much as the numbers in parenthesis.

\begin{tabular}{lllr}
\hline & $\mathrm{Cu}(\mathrm{nM})$ & $\mathrm{Cd}(\mathrm{nM})$ & $\mathrm{Pb}(\mathrm{nM})$ \\
\hline${ }^{65} \mathrm{Cu}$ spike & & $0.031(<0.001)$ & $47.15(0.28)$ \\
${ }^{110} \mathrm{Cd}$ spike & $0.306(0.002)$ & & $8.07(0.05)$ \\
${ }^{204} \mathrm{~Pb}$ spike & $0.976(0.006)$ & $0.048(<0.001)$ & \\
\hline
\end{tabular}

error propagation. The $\mathrm{Cu}$ and $\mathrm{Cd}$ concentrations in SAFe seawaters were assessed simultaneously by spiking the samples with ${ }^{65} \mathrm{Cu}$ and ${ }^{114} \mathrm{Cd}$-enriched isotope spike, and the result agreed well with the SAFe consensus values, affirming that multiple elements can be analyzed simultaneously using this method.

3.6. $\mathrm{Cu}, \mathrm{Cd}, \mathrm{Pb}$, and $\mathrm{Fe}$ concentrations from open ocean (BATS) samples

This new method was applied to the open ocean seawater samples taken from the BATS site during June 2008 GEOTRACES IC1 cruise (Fig. 4). The $\mathrm{Cu}, \mathrm{Cd}$, and $\mathrm{Pb}$ data shown here are from the samples collected by MITESS samplers, and Fe is from GEOTRACES GOFlo samplers (GPrI Isotope cast). 


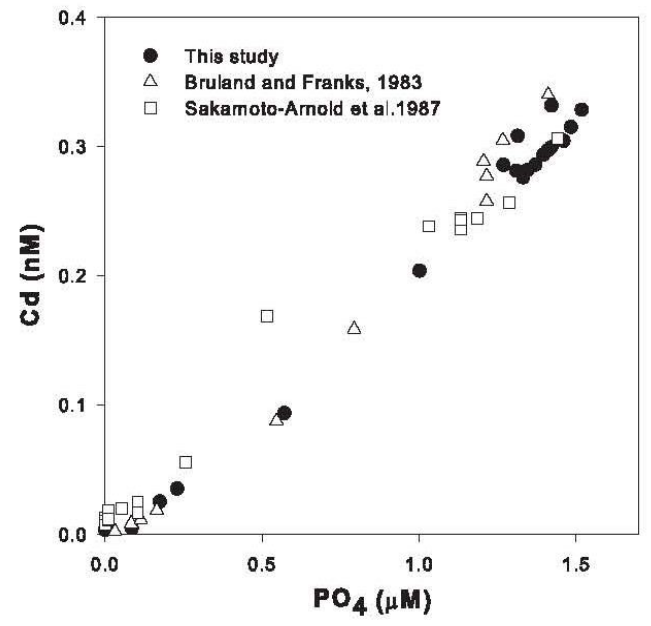

Fig. 5. Cd-P relationship in the GEOTRACES-BATS station (this study) compared with that from nearby stations. The phosphate data weregenerated using an AstoriaPacific rapid flow analyzer and standard chemistry based on molybdenum blue method.

The $\mathrm{Cu}$ profile generated by this method agrees well with the previous data obtained in the Sargasso Sea (Fig. 4a) [34,35]. Dissolved $\mathrm{Cu}$ is low in the upper layer and it increases almost linearly with increasing depth. This characteristic feature of $\mathrm{Cu}$ has been observed in other studies [20,34-37], and is attributed to the combination of biological uptake and remineralization, scavenging onto particles, and the release of $\mathrm{Cu}$ from surface sediments. Otherwise, the profile might be maintained by a relatively uniform supply of $\mathrm{Cu}$ from decomposing organic particles at depth combined with a rapid exchange of dissolved $\mathrm{Cu}$ with sinking particulate $\mathrm{Cu}$ by analogy to ${ }^{230} \mathrm{Th}$ and ${ }^{231} \mathrm{~Pa}$ profiles [38].

The vertical distribution of $\mathrm{Cd}$ is characterized by extremely low values in the surface waters and an intermediate maximum at $\sim 1000 \mathrm{~m}$ (Fig. $4 \mathrm{~b}$ ), the result of biological removal at the surface and regeneration at depth. The concentrations of $\mathrm{Cd}$ are close to the results of the previous studies carried out in the similar region $[35,39]$. The station lying at the northwest of the BATS $\left(35^{\circ} 40^{\prime} \mathrm{N}\right.$, $71^{\circ} 53^{\prime} \mathrm{W}$; BATS: $31^{\circ} 40^{\prime} \mathrm{N}, 64^{\circ} 10^{\prime} \mathrm{W}$ ) has slightly lower Cd concentrations in deep sea, but all these stations show a consistent $\mathrm{Cd}-\mathrm{P}$ relationship (Fig. 5).

The comparison of this Pb data with the previous data in the NW Atlantic $[11,20,40]$ shows the continuing decline in oceanic $\mathrm{Pb}$ due to the phase-out of leaded gasoline in the United States and Europe (Fig. 4c). The Fe data show low values below the seasonal mixed layer increasing to a maximum in deep waters because of biological uptake at surface and regeneration at depth (Fig. $4 \mathrm{~d}$ ). These data are consistent with published Fe data from the same cruise [26] although there is an offset in the upper ocean $(<500 \mathrm{~m})$. The samples used for Milne et al.'s work are from a different sampling system (CLIVAR rosette) on a different day, and the offset in the shallow water could be caused by a natural variation in Fe with time. Strong eddy activity observed in T-S profiles supports this possibility. The Fe profile also shows a similar trend to that from a nearby station $\left(34.8^{\circ} \mathrm{N}, 57.8^{\circ} \mathrm{W}\right)[41]$.

\section{Conclusion}

This paper describes a simple analytical method for measuring total dissolved $\mathrm{Cu}, \mathrm{Cd}, \mathrm{Pb}$, and Fe in seawater using batch-extraction of metals onto NTA Superflow ${ }^{\circledR}$ resin beads and isotope dilution
ICPMS. The method uses only $1.3-1.5 \mathrm{~mL}$ of seawater per element and small volume of reagents that can be purified easily, removes salt effectively, and has low procedural blanks and a low detection limit. In addition, accuracy and precision is ensured regardless of sample matrix (e.g. organic ligands in samples) because isotope dilution is used. This study also demonstrates the potential of the simultaneous analysis of multi-elements by spiking a sample witha multi-isotope enriched standard. The method was applied to measure total dissolved $\mathrm{Cu}, \mathrm{Cd}, \mathrm{Pb}$, and $\mathrm{Fe}$ in open ocean seawaters and the results showed excellent agreement with SAFe reference values and the data from previous studies. This method will be beneficial for the analysis of a large number of samples, as planned in GEOTRACES program, because multiple elements can be measured from a small volume of sample, which will make sample collection, storage and handling much easier.

\section{Acknowledgements}

We thank the officers and crew of the R/V Melville and R/V Knorr, and Bridget Bergquist and Seth John for their assistance in obtaining seawater samples; Ken Bruland and Geoff Smith for collecting bottling, distributing and compiling data for the SAFe reference samples; and SAFe chief scientist Ken Johnson and GEOTRACES IC chief scientist Greg Cutter. This research was supported by NSF Grants OCE-0751409, OCE-0751409, and OCE-0926197 (to University of Hawaii, C-MORE subcontract) and by the Kuwait/MIT Center for Resources and the Environment at MIT with funding provided by the Kuwait Foundation of Science.

\section{References}

11] W.G. Sunda, S.A. Huntsman, Limnol. Oceanogr. 40 (1995) 132

[2] F.M.M. Morel, N.M. Price, Science 300 (2003) 944

[3] F.M.M. Morel, A.J. Milligan, M.A. Saito, in: H. Elderfield (Ed.), Treatise on Geochemistry, Elsevier-Pergamon, Oxford, 2003, p. 113.

[4] T.W. Lane, M.A. Saito, G.N. George, I.J. Pickering, R.C. Prince, F.M.M. Morel, Nature 435 (2005) 42

[5] J. Cranger B. Ward Limnol Oceanogr 48 (2002) 313.

[6] J.G. Rueter, D.R. Ades, J. Phycol. 23 (1987) 452.

[7] J.K. Moore, S.C. Doney, K. Lindsay, Global Biogeochem. Cycle 18 (2004)

[8] K.H. Coale, S.E. Fitzwater, R.M. Gordon, K.S. Johnson, R.T. Barber, Nature 379 (1996) 621.

[9] L.E. Brand, W.G. Sunda, R.R.L. Guillard, J. Exp. Mar. Biol. Ecol. 96 (1986) 225

[10] P.D. Tortell, N.M. Price, Mar. Ecol. Prog. Ser. 138 (1996) 245.

[11] E.A. Boyle, S.D. Chapnick, G.T. Shen, M.P. Bacon, J. Geophys. Res.: Oceans 91 (1986) 8573

[12] J.F. Wu, E.A. Boyle, Geochim. Cosmochim. Acta 61 (1997) 3279

[13] J.H. Martin, R.M. Gordon, Deep-Sea Res. 35 (1988) 177.

[14] K.W. Bruland, R.P. Franks, G.A. Knauer, J.H. Martin, Anal. Chim. Acta 105 (1979) 233

15] W.M. Landing K.W. Bruland, Geochim. Cosmochim. Acta 51 (1987)29.

[16] J.W. Mclaren, A.P. Mykytiuk, S.N. Willie, S.S. Berman, Anal. Chem. 57 (1985) 2907.

17] H. Obata, H. Karatani, E. Nakayama, Anal. Chem. 65 (1993) 1524

18] K.W. Bruland, K.H. Coale, L. Mart, Mar. Chem. 17 (1985) 285

[19] K.W. Bruland, Limnol. Oceanogr. 37 (1992) 1008.

20] J.F. Wu, E.A. Boyle, Anal. Chem. 69 (1997) 2464.

21] M.A. Saito, D.L. Schneider, Anal. Chim. Acta 565 (2006) 222

22] J.F. Wu, Mar. Chem. 103 (2007) 370.

23] M.C. Lohan, A.M. Aguilar-Islas, R.P. Franks, K.W. Bruland, Anal. Chim. Acta 530 (2005) 121.

[24] Y. Sohrin, S. Urushihara, S. Nakatsuka, T. Kono, E. Higo, T. Minami, K. Norisuye, S. Umetani, Anal. Chem. 80 (2008) 6267.

[25] M.C. Lohan, A.M. Aguilar-Islas, K.W. Bruland, Limnol. Oceanogr: Methods 4 (2006) 164 .

W. Landing M Bizimis, P. Morton, Anal Chim. Acta 665(2010) 200

[27] K.Y. Patterson, C. Veillon, T.C. Ohaver, Anal. Chem. 66 (1994) 2829.

[28] A.G. Adriaens, W.R. Kelly, F.C. Adams, Anal. Chem. 65 (1993) 660.

[29] K.S. Johnson, E.A. Boyle, K.W. Bruland, K.H. Coale, C. Measures, J.W. Moffett, A.M Aguilar-Islas, K. Barbeau, B. Bergquist, A.R. Bowie, K. Buck, Y. Cai, Z. Chase, J.T Cullen, T. Doi, V.A. Elrod, S.E. Fitzwater, M. Gordon, A. King, P. Laan, L. LagleraBaquer, W.M. Landing, M.C. Lohan, J. Mendez, A. Milne, H. Obata, L. Ossiander J. Plant, G. Serthou, P.N. Sedwick, G.J. Smith, B. Sohst, S. Tanner, C.M.G. van den Berg. J. Wu, EOS 88 (2007) 131.

[30] E.A. Boyle, B.A. Bergquist, R.A. Kayser, N. Mahowald, Geochim. Cosmochim. Acta $69(2005) 5165$. 
[31] J. Bell, J. Betts, E.A. Boyle, Deep-Sea Res. I 49 (2002) 2103

[32] R.J. Motekaitis, A.E. Martell, Mar. Chem. 21 (1987) 101

[33] S.G. John, J.F. Adkins, Mar. Chem. 119 (2010) 65.

[34] A.K. Hanson, C.M. Sakamoto-Arnold, D.L. Huizenga, D.R. Kester, Mar. Chem. 23

[35] K.W. Bruland, R.P. Franks, in: C.S. Wang, E.A. Boyle, K.W. Bruland, J.D. Burton,
[1981) E.D. Goldberg (Eds.), Trace Metals in Seawater, Plenum Press, New York, 1983,

[36] P.A. Yeats, S. Westerlund, A.R. Flegal, Mar. Chem. 49 (1995) 283.
[37] R.M. Moore, Earth Planet Sci. Lett. 41 (1978) 461.

[38] J.-M. Lee, E.A. Boyle, R. Kayser, Ocean Sciences Meeting, Eos Trans. AGU, 2010 p. CO25B.

[39] C.M. Sakamoto-Arnold, A.K. Hanson, D.L. Huizenga, D.R. Kester, J. Mar. Res. 45 (1987) 201.

40] B.K. Schaule, C.C. Patterson, in: C.S. Wong (Ed.), Trace Metals in Sea Water, Plenum, New York, 1983, p. 487

[41] J.F. Wu, E. Boyle, W. Sunda, L.S. Wen, Science 293 (2001) 847. 


\title{
Chapter 3
}

\section{$\mathrm{Pb}$ in a deep sea coral: transfer of anthropogenic $\mathrm{Pb}$ to the deep North Atlantic Ocean over the last 500 years}

\begin{abstract}
A 550 year history of the $\mathrm{Pb}$ concentration and isotope ratios in the deep North Atlantic Ocean was reconstructed from a deep-sea coral. This coral is found to be a reliable proxy of the deep-sea $\mathrm{Pb}$ variability given that $\mathrm{Pb} / \mathrm{Ca}$ ratios (with a partition coefficient in a reasonable range) and $\mathrm{Pb}$ isotope ratios of the coral correspond to seawater values. $\mathrm{Pb} / \mathrm{Ca}$ ratios of the coral range between $1.1-4.5 \mathrm{nmol} / \mathrm{mol}$ during the 16 th and 17 th centuries, and $\mathrm{Pb}$ isotope ratios $\left({ }^{206} \mathrm{~Pb} /{ }^{207} \mathrm{~Pb}=1.21,{ }^{208} \mathrm{~Pb} /{ }^{207} \mathrm{~Pb}=2.495\right)$ in this period agree with the pre-anthropogenic ratios found in the pelagic sediments of this basin. The $\mathrm{Pb} / \mathrm{Ca}$ ratios are slightly elevated $(\sim 7 \mathrm{nmol} \mathrm{Pb} / \mathrm{mol} \mathrm{Ca})$ between $1740 \mathrm{~s}$ and 1860 s, and the ratio rapidly increases by a factor of four between 1860s and 1997, probably due to the penetration of anthropogenic $\mathrm{Pb}$ into the deep sea. Both ${ }^{206} \mathrm{~Pb} /{ }^{207} \mathrm{~Pb}$ and ${ }^{208} \mathrm{~Pb} /{ }^{207} \mathrm{~Pb}$ ratios decrease from the mid-18th century as the $\mathrm{Pb} / \mathrm{Ca}$ increases because anthropogenic $\mathrm{Pb}$ has lower isotopic ratios than natural $\mathrm{Pb}$ in this period. Comparison of this data to the $200-\mathrm{yr}-$
\end{abstract}


record of the surface $\mathrm{Pb}$ in the western North Atlantic Ocean shows that transit time of $\mathrm{Pb}$ from the surface to the coral growth site is approximately 25 years when weak mixing is assumed. However, using multiple tracers (CFCs, $\Delta^{14} \mathrm{C}$, and $\mathrm{Pb}$ ) with a more sophisticated transit time distributions (TTDs) approach, mean transit time is estimated to be 64 years, which shows the importance of advective-diffusive mixing during the transport.

\subsection{Introduction}

Over the last two centuries, the distribution of $\mathrm{Pb}$ in the surface waters of the North Atlantic Ocean changed significantly because of the industrial $\mathrm{Pb}$ emissions from North America and western Europe (Boyle et al., 1986; Kelly et al., 2009; Reuer and Weiss, 2002; Schaule and Patterson, 1983; Shen and Boyle, 1988a; Veron et al., 1998; Veron et al., 1993; Wu and Boyle, 1997) (see Figure 1.3). For instance, Pb concentrations in surface waters increased more than 10-fold between the 1920s and 1970s mainly due to leaded gasoline utilization in US and decreased rapidly after phase-out of leaded gasoline began in mid-1970s (Wu and Boyle, 1997). Not only $\mathrm{Pb}$ concentrations, but $\mathrm{Pb}$ isotope ratios of the surface North Atlantic Ocean have been also changed over time, depending on the main sources of $\mathrm{Pb}$ (e.g., Kelly et al., 2009). Evidence of these changes have been found from direct measurement of $\mathrm{Pb}$ in seawater (Boyle et al., 1986; Schaule and Patterson, 1983; Veron et al., 1993; Wu and Boyle, 1997) and from annually-banded

corals that grew in coastal seawaters near Bermuda (Kelly et al., 2009; Reuer, 2002; Shen 
and Boyle, 1987), which shows the history of $\mathrm{Pb}$ concentration and isotopic ratios of the surface North Atlantic Ocean since 1780.

Because of the transient characteristics of $\mathrm{Pb}$ and $\mathrm{Pb}$ isotopes in the surface ocean, they have been used to trace the transport of anthropogenic $\mathrm{Pb}$ to the ocean interior, and to estimate the time scale of those processes. For instance, using $\mathrm{Pb}$ isotopes, transport of American $\mathrm{Pb}$ to the eastern North Atlantic Ocean by the Subtropical North Atlantic gyre was inferred from Pb isotopes (Hamelin et al.,1997; Helmers, 1996; Veron et al., 1994), and the intrusion of anthropogenic $\mathrm{Pb}$ by the North Atlantic Deep Water (NADW) was also revealed in the subarctic and abyssal North Atlantic Ocean (Alleman et al., 1999; Veron et al., 1998; Veron et al., 1999) and its subsequent flow to the western equatorial and south Atlantic Ocean (Alleman et al., 2001a; 2001b). Furthermore, using the surface $\mathrm{Pb}$ and $\mathrm{Pb}$ isotope transient, Boyle et al. (1986) and Shen and Boyle (1988) modeled the penetration of $\mathrm{Pb}$ into the deep North Atlantic Ocean, assessing the importance of ventilation and particle reactions in the transport of $\mathrm{Pb}$.

However, in spite of these efforts, our understanding on the penetration of anthropogenic $\mathrm{Pb}$ to the deep ocean is still limited. The primary reason for this is the lack of data on $\mathrm{Pb}$ and $\mathrm{Pb}$ isotopes in the deep sea. Given the long history of anthropogenic $\mathrm{Pb}$ inputs to the surface ocean and the relatively short water ventilation time scale (10-50yrs) compared to the residence time of $\mathrm{Pb}$ in deep sea (a few decades to a century or so), both $\mathrm{Pb}$ concentration and isotope ratios in deep ocean must have changed substantially over the last few centuries. However, no seawater data exist for $\mathrm{Pb}$ concentrations in the deep 
Atlantic Ocean prior to 1979 (Schaule and Patterson, 1983), and there is no Pb isotope data prior to 1984 (Shen and Boyle, 1988).

In this chapter, we reconstructed $\mathrm{Pb}$ concentrations and isotope ratios of the deep western North Atlantic Ocean at 1410 m over the past 550 years using a deep sea coral recently collected from the northern slope of Bermuda. $\mathrm{Pb}$ has not been measured from deep-sea corals before, but given the success of surface corals for reconstructing past surface ocean $\mathrm{Pb}$ and $\mathrm{Pb}$ isotopes variability, deep-sea corals might also be able to generate time series of $\mathrm{Pb}$ in deep sea. Although deep-sea corals have been developed only recently as a paleo proxy, they have been successfully used to reconstruct past ocean circulation (Adkins et al., 1997; 1998), and their potential use as deep sea nutrient and temperature proxies are also being investigated (Cohen and Gaetani, 2006; Shirai et al., 2005). In addition, Adkins et al. (2002) showed that modern deep-sea corals preserve the record of $\Delta^{14} \mathrm{C}$ of dissolved inorganic carbon in the ambient seawater, and a prior study on the same deep sea coral used for this study showed that this coral faithfully records penetration of the bomb radiocarbon signal (Eltgroth, 2006).

We have estimated ventilation time scales based on the $\mathrm{Pb}$ found in this coral together with the radiocarbon record from Eltgroth (2006). We first compared the deepsea coral data to the surface $\mathrm{Pb}$ and radiocarbon time series reconstructed from Bermuda surface corals. Then, we applied a more sophisticated approach called Transit Time Distributions (TTDs) to calculate ventilation time scales.

\subsection{Sampling and analytical methods}




\subsubsection{Coral sampling}

An Enallopsammia rostrata specimen (ALV-3701-8) (Figure 3.1) was collected alive in September 2001 with the DSV Alvin from a depth of 1410m on the north slope of Bermuda $\left(64^{\circ} \mathrm{W} 32^{\circ} \mathrm{N}\right)$. The coral is $55 \mathrm{~cm}$ long, and because of this long vertical length and wide radial cross section (as wide as $3 \mathrm{~cm}$ ), this coral offers advantages for time series reconstructions over other deep sea coral species like Desmophyllum dianthus (Adkins et al., 2004).

Eltgroth (2006) measured ${ }^{14} \mathrm{C}$ ages in 5 different corallite tips to find a branch with the longest history, and Tip 1 at the apex of the largest branch was found to be the youngest one. The excess ${ }^{210} \mathrm{~Pb}$ results of Adkins et al. (2004) likewise showed that the corallite tip at the end of the same branch, adjacent to Tip 1, was the most recently precipitated. Based on these results, we focused our time series analysis on the branch that terminates at Tip 1 (Figure 3.1) since it is most likely to contain the deep ocean interval recording bomb radiocarbon and anthropogenic $\mathrm{Pb}$ infiltration.

From this branch, radial discs were cut perpendicular to the direction of coral growth, in 3-5 mm intervals. From each radial disc, concentric bands were identified under UV light, and we observed that banding in the radial sections is asymmetric with the center of the concentric bands located at a corallite remnant close to the corallite face of the coral. A previous study by Eltgroth (2006) reported ${ }^{14} \mathrm{C}$ ages from transects of three radial sections, from the center to the edge of each section along the longest possible transect $(10-16 \mathrm{~mm})$. The maximum ${ }^{14} \mathrm{C}$ age was found within $1-4 \mathrm{~mm}$ of the section center, and the radial growth rate was linear $(20-30 \mu \mathrm{m} / \mathrm{yr})$ outside of this central 
area (Table 2.2 in Eltgroth, 2006). Therefore for the time series construction, we took samples as close as possible to the center of each radial section.

\subsubsection{Coral cleaning and analysis of $\mathrm{Pb} / \mathrm{Ca}$ and $\mathrm{Pb}$ isotopes}

Coral masses of 100-200 mg were cut from the center of each coral disc. Surface contaminants and organic materials of the corals were removed using a cleaning method described in Reuer (2002) which is slightly modified from Shen and Boyle (1988a). Briefly, cut corals were coarsely crushed to $2-5 \mathrm{~mm}$ size and were cleaned using distilled water, $\mathrm{H}_{2} \mathrm{O}_{2}-\mathrm{NaOH}$, and $\mathrm{HNO}_{3}$. Then, dried samples were further crushed to $280-700 \mu \mathrm{m}$ size and divided into three subsamples. Each subsample went through another round of chemical cleaning using distilled water, $\mathrm{H}_{2} \mathrm{O}_{2}-\mathrm{NaOH}, \mathrm{HNO}_{3}$, and the reducing agent that is a mixture of ammonia, hydrazine, and citric acid. Approximately 30-50 mg of coral was left in each subsample after the final cleaning and was dissolved in strong $\mathrm{HNO}_{3}$.

$\mathrm{Pb} / \mathrm{Ca}$ ratios were analyzed from an aliquot of each dissolved-coral sample. $\mathrm{Pb}$ concentrations were analyzed by isotope dilution ICP-MS (VG PlasmaQuad 2+) after spiking the samples with a ${ }^{204} \mathrm{~Pb}$ enriched spike (Oak Ridge National Laboratory; calibrated with a gravimetric $\mathrm{Pb}$ concentration standard). Ca concentrations were measured by flame AAS (Perkin-Elmer 403) for $\mathrm{Pb} / \mathrm{Ca}$ ratios. The mean standard deviation for $\mathrm{Pb} / \mathrm{Ca}$ coral replicates was $\sim 10 \%$, including analytical and cleaning uncertainties and coral inhomogeneity. The relatively large standard deviation is mainly due to the natural variability of $\mathrm{Pb} / \mathrm{Ca}$ within samples rather than analytical errors. Because of the slow vertical and radial growth rate of the deep sea coral, a coral disc cut 
in a few-mm size contains coral that grew for several years to a decade. Therefore, despite the effort to homogenize samples by crushing and mixing before chemical analysis, a subsample could contain more coral pieces from a certain year and increase the standard deviation.

The rest of the dissolved coral samples were used to determine $\mathrm{Pb}$ isotope ratios. Samples were first purified by $\mathrm{HBr}-\mathrm{HCl}$ anion exchange chromatography (Kraus and Moore, 1953; Strelow, 1978). The sample solutions that ran through columns were dried down on a clean hot plate and re-dissolved in $500 \mu 1$ dilute $(0.5 \mathrm{M})$ nitric acid. After

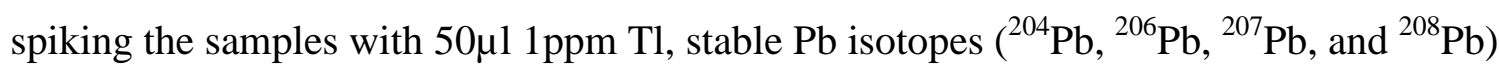
in the samples were determined by multiple collector ICP-MS (Micromass/GV IsoProbe). The $\mathrm{Pb}$ isotope measurement standards (NBS981 and an independent internal lab standard - Reuer $\mathrm{Pb}$ iso standard and/or $\mathrm{BAB} \mathrm{Pb}$ iso standard - or dilutions of these) were also prepared by adding $\mathrm{Tl}$, and were measured at the beginning and the end of each session. Data processing and corrections were performed as in Boyle et al. (2012), which is the method modified from Reuer et al. (2003), including elimination of the isobaric interferences of ${ }^{204} \mathrm{Hg}$, exponential "beta" mass fractionation correction normalized with $\mathrm{a}^{205} \mathrm{Tl} /{ }^{203} \mathrm{Tl}$ spike and with renormalization to NIST SRM-981 (Baker et al., 2004), and a tailing correction derived from a curve fit to ${ }^{209} \mathrm{Bi}$ at half-mass intervals. Modifications made to the Reuer et al.'s method are discussed in detail in Appendix I. Here we will interpret ${ }^{206} \mathrm{~Pb} /{ }^{207} \mathrm{~Pb}$ and ${ }^{208} \mathrm{~Pb} /{ }^{207} \mathrm{~Pb}$ (data in table 3.1); the ${ }^{206} \mathrm{~Pb} /{ }^{207} \mathrm{~Pb}$ ratio has been a traditional measure since the early days of environmental $\mathrm{Pb}$ studies by Patterson and coworkers, and we use ${ }^{208} \mathrm{~Pb} /{ }^{207} \mathrm{~Pb}$ because its signal range is larger than ${ }^{208} \mathrm{~Pb} /{ }^{206} \mathrm{~Pb}$. 


\subsection{Results}

\subsubsection{Age model using ${ }^{14} \mathrm{C}$}

In order to estimate the calendar age of each sample cut from the coral branch, we used the age model established by Eltgroth (2006). Eltgroth (2006) measured radiocarbon from the bottom to the top of the same coral branch that was used for this study. The study found that before the invasion of bomb radiocarbon, the conventional ${ }^{14} \mathrm{C}$ age of the coral sections increased linearly with the distance of each coral section from the bottom, which indicates that this coral grew at a constant rate. Using a linear least-squares fit, the vertical growth rate of this coral was determined to be $0.99 \mathrm{~mm} \mathrm{yr}^{-1}$. Note that Eltgroth (2006) estimated $0.95 \mathrm{~mm} \mathrm{yr}^{-1}$ because she averaged ${ }^{14} \mathrm{C}$ values of the 2-3 subsamples in each coral sample before the linear least-squares fitting, but we made the estimate without averaging the data. Based on the growth rate of $0.99 \mathrm{~mm} \mathrm{yr}^{-1}$, the coral lived for $556 \mathrm{yr}$ given its length $(\sim 55 \mathrm{~cm})$. Following Eltgroth $(2006)$, we set the age at the top end of the branch (youngest tip) to September 2001, the date that the coral was collected, and calculated the calendar ages of the other coral samples based on the distance of each sample from the top end of the branch and the estimated growth rate.

\subsection{2. $\mathrm{Pb} / \mathrm{Ca}$ and $\mathrm{Pb}$ isotope ratios}

$\mathrm{Pb} / \mathrm{Ca}$ and $\mathrm{Pb}$ isotope ratios analyzed from the deep-sea coral are presented in Figure 3.2. Low $\mathrm{Pb} / \mathrm{Ca}$ ratios ranging $1.1-4.5 \mathrm{nmol} / \mathrm{mol}$ are found between $1500 \mathrm{~s}$ and mid-1700s, and during this time period, relatively high ${ }^{206} \mathrm{~Pb} /{ }^{207} \mathrm{~Pb}$ and ${ }^{208} \mathrm{~Pb} /{ }^{207} \mathrm{~Pb}$ ratios appear between 1.207-1.210 and 2.495-2.508, respectively. These older high $\mathrm{Pb}$ isotope 
ratios fall in the range of those found in the Quaternary marine sediments and ferromanganese nodules in this basin (average of 16 samples excluding one anomalous sample are ${ }^{206} \mathrm{~Pb} /{ }^{207} \mathrm{~Pb}=1.210 \pm 0.072,{ }^{208} \mathrm{~Pb} /{ }^{207} \mathrm{~Pb}=2.509 \pm 0.014$ ) (Chow and Patterson, 1962), and thus, we consider the $\mathrm{Pb}$ in this period as pre-anthropogenic. A slightly increased $\mathrm{Pb} / \mathrm{Ca}$ ratio is found in the mid-1700s, and the ratio of $\sim 6 \mathrm{nmol} / \mathrm{mol}$ remains relatively constant until 1860 . From 1860 , the $\mathrm{Pb} / \mathrm{Ca}$ ratio increases rapidly until it reaches a peak $(28.7 \mathrm{nmol} / \mathrm{mol})$ around 1980 , and then slowly decreases afterward. Lower $\mathrm{Pb}$ isotope ratios compared to the pre-anthropogenic values are found in the mid1700 s, and as $\mathrm{Pb} / \mathrm{Ca}$ ratio increases, the isotope ratios further decrease to ${ }^{206} \mathrm{~Pb} /{ }^{207} \mathrm{~Pb}=$ $1.19,{ }^{208} \mathrm{~Pb} /{ }^{207} \mathrm{~Pb}=2.46$ in 1920 . The isotope ratios remain rather constant for the following $\sim 50$ years, and then rapidly drop to ${ }^{206} \mathrm{~Pb} /{ }^{207} \mathrm{~Pb}=1.185$ and ${ }^{208} \mathrm{~Pb} /{ }^{207} \mathrm{~Pb}=2.450$ in 1997. The $\mathrm{Pb}$ isotope ratios found in 1997 coral sample are very close to the $\mathrm{Pb}$ isotope ratios $\left({ }^{206} \mathrm{~Pb} /{ }^{207} \mathrm{~Pb}=1.184 \pm 0.002,{ }^{208} \mathrm{~Pb} /{ }^{207} \mathrm{~Pb}=2.451 \pm 0.005\right)$ measured in seawater samples collected in 1998 from $1490 \mathrm{~m}$ depth at a nearby station $\left(33^{\circ} \mathrm{N}, 57^{\circ} \mathrm{W}\right)$ (Reuer, 2002), which indicates that the $\mathrm{Pb}$ in this deep sea coral was precipitated from ambient seawater without significant isotope fractionation.

The seawater $\mathrm{Pb}$ concentration measured at a depth and location near the coral growth site in 1984 was $53 \mathrm{pmol} \mathrm{kg}^{-1}$ (Boyle et al., 1986). Using this seawater $\mathrm{Pb}$ concentration and the $\mathrm{Pb} / \mathrm{Ca}$ ratio of the coral from 1984 (26.85 nmol/mol), the partition coefficient $\left(D_{p}=(\mathrm{Pb} / \mathrm{Ca})_{\text {coral }} /(\mathrm{Pb} / \mathrm{Ca})_{\text {seawater }}\right)$ of $\mathrm{Pb}$ for this coral is calculated to be $\sim 5.2$ assuming seawater Ca concentration is $10.3 \mathrm{mmol} / \mathrm{kg}$. This $D_{p}$ estimate has uncertainties because it was derived from a single seawater-coral comparison and a single seawater $\mathrm{Pb}$ 
measurement does not represent a long-term averaged $\mathrm{Pb}$ value, whereas the measured coral $\mathrm{Pb} / \mathrm{Ca}$ ratio is an average of several years. Nevertheless, our $D_{p}$ value falls in the range of $D_{p}$ measured in other deep sea corals using ${ }^{210} \mathrm{~Pb}$, e.g., 3-20 in Desmophyllum cristagalli (Adkins et al., 2004) and maximum 8 in Corrallium niobe (Druffel et al., 1990). Applying this $D_{p}$ to the $\mathrm{Pb} / \mathrm{Ca}$ ratios earlier than 1700 s assuming $D_{p}$ was constant during growth of coral, pre-anthropogenic seawater Pb concentrations in deep sea is estimated to be approximately $3-11 \mathrm{pmol} \mathrm{kg}^{-1}$. This value is lower than the preanthropogenic $\mathrm{Pb}$ concentration estimated for the surface North Atlantic Ocean (15 pmol $\mathrm{kg}^{-1}$ ) based on Bermuda coral $\mathrm{Pb} / \mathrm{Ca}$ (Kelly et al., 2009), with the reduction probably the result of particle scavenging of $\mathrm{Pb}$ at depth.

\subsection{Discussion}

\subsubsection{Apparent transit time of $\mathrm{Pb}$}

The coral growth site (1410m, Bermuda slope) is on the pathway of the upper North Atlantic Deep Water, which is mainly formed by the ventilation of Labrador Sea water (LSW) (Dickson et al., 1996; Lazier, 1995; Wallace and Lazier, 1988). We do not have sufficient data on the surface time series of $\mathrm{Pb}$ in LSW, but a couple of seawater measurements conducted during the TTO cruise in 1981 (Weiss et al., 2003) showed that Labrador surface seawater has $\mathrm{Pb}$ isotope ratios similar to those in Bermuda surface corals for the corresponding year, because both places are under influence of the Westerlies and receive most of the $\mathrm{Pb}$ from aerosols transported from North America. Thus, assuming that $\mathrm{Pb}$ in the Labrador Sea surface water has varied as $\mathrm{Pb}$ in Bermuda 
surface seawater, we can estimate the transit time of $\mathrm{Pb}$ from surface to the deep sea by comparing the deep-sea coral $\mathrm{Pb}$ data to the surface ocean $\mathrm{Pb}$ time series reconstructed from Bermuda corals (data from Kelly et al., 2009).

Time series of $\mathrm{Pb}$ and $\mathrm{Pb}$ isotope ratios in Bermuda surface seawater and the data from this study are shown in Figure 3.3. The most noticeable similarity between the two data sets is a decrease in $\mathrm{Pb}$ isotope ratios appearing in 1952 in surface water and in 1975-1979 in deep water, which occurs after relatively constant $\mathrm{Pb}$ isotope ratios (at around 1.19 for ${ }^{206} \mathrm{~Pb} /{ }^{207} \mathrm{~Pb}$ and 2.46 for ${ }^{208} \mathrm{~Pb} /{ }^{207} \mathrm{~Pb}$ ) are maintained for many decades. It seems that the changes in the surface water $\mathrm{Pb}$ isotope ratios that occurred prior to $\sim 1950$ (e.g. a large decrease between 1880 and 1930) do not appear clearly in the deep sea because of the low concentrations of the surface $\mathrm{Pb}$. However, as surface $\mathrm{Pb}$ concentration rapidly increases after $\sim 1950$, the decreasing surface $\mathrm{Pb}$ isotope ratios seem to have resulted in the decrease of the $\mathrm{Pb}$ isotope ratios in the deep sea in 1975-1979. If the decrease in deep sea $\mathrm{Pb}$ isotope ratios in 1975-1979 was caused by the input of the $\mathrm{Pb}$ that was at the surface in $\sim 1952$, our results show that it takes $\sim 25$ years for $\mathrm{Pb}$ to be transported from surface to the deep sea. Since dissolved $\mathrm{Pb}$ is carried to the deep sea mainly by advection (Boyle et al., 1986; Shen and Boyle, 1988), this implies that $~ 25$ years takes for the ventilated LSW spreading to this site.

This $\sim 25$ years of transit time estimate agrees with that observed from the time series of radiocarbon from the same deep sea coral (Figure 2.5 in Eltgroth, 2006). The $\Delta{ }^{14} \mathrm{C}$ at the surface ocean (Druffel, 1989) increases from -50\%o to a plateau at $150 \%$, starting in $1955-1958$. The $\Delta{ }^{14} \mathrm{C}$ of the deep ocean begins to increase in $\sim 1979$, which is 
21-25 years later than the surface. In both tracer records, the rise of $\Delta^{14} \mathrm{C}$ and $\mathrm{Pb}$ concentration is not as rapid (and the amplitude is smaller) in the deep sea as it is in the surface, showing the importance of mixing in the tracer movement from the surface to the deep North Atlantic Ocean.

\subsubsection{Transit time distributions (TTDs)}

\subsubsection{Background}

The transit time estimated in the previous section assumes a weak mixing, so that $\mathrm{Pb}$ and radiocarbon appearing at the surface ocean are transported to the ocean interior with a single transit time, which will be referred to as a "tracer age" in this chapter. This approach has been traditionally made to estimate ventilation time scales using various tracers such as chlorofluorocarbons (CFCs), tritium-helium, and other radioactive elements (e.g. Doney et al., 1997; Fine et al., 2002), but the estimated tracer ages often vary with different tracers. Recent studies on tracer transport have pointed out that in the ocean, where advective-diffusive mixing is prevalent, water masses in the ocean interior have a continuous distribution of transit times since its last contact with a surface, rather than a single transit time (Haine and Hall, 2002; Holzer and Hall, 2000; Waugh et al., 2003). They have shown that tracer ages are differently weighted averages over the transit times that vary from tracer to tracer (Holzer and Hall, 2000; Khatiwala et al., 2001; Wunsch and Heimbach, 2008), and do not represent the age distribution of the water mass. 
According to Transit time distributions (TTDs) theory, assuming steady transport, the concentration of a tracer $\mathrm{c}(\mathrm{r}, \mathrm{t})$ in the ocean interior at location $\mathrm{r}$ and time $\mathrm{t}$ is given by

$$
c(r, t)=\int_{0}^{\infty} c_{0}\left(t-t^{\prime}\right) e^{-\lambda t^{\prime}} G\left(r, t^{\prime}\right) d t^{\prime}
$$

where $c_{0}$ is spatially uniform, time-varying surface concentration of the tracer, $\mathrm{G}(\mathrm{r}, \mathrm{t})$ is the TTDs at location $r$ and $\mathrm{e}^{-\lambda \mathrm{t}^{\prime}}$ is a radioactive decay term for tracers with decay rate $\lambda$ (Haine and Hall, 2002; Hall and Plumb, 1994; Waugh et al., 2004). Following Waugh et al. (2004), we further assume that the G(t) (TTDs) at a certain location can be modelled as an Inverse Gaussian function (Chhikara and Folks, 1989; Seshadri, 1999), i.e. has a broad, asymmetric distribution with a long tail, as

$$
\mathrm{G}(\mathrm{t})=\sqrt{\frac{\Gamma^{3}}{4 \pi \Delta^{2} \mathrm{t}^{3}}} \exp \left(\frac{-\Gamma(\mathrm{t}-\Gamma)^{2}}{4 \Delta^{2} \mathrm{t}}\right)
$$

where

$$
\Gamma=\int_{0}^{\infty} t \mathrm{G}(t) \mathrm{d} t
$$

is the mean transit time ("mean age") and

$$
\Delta^{2}=\frac{1}{2} \int_{0}^{\infty}(t-\Gamma)^{2} \mathrm{G}(t) \mathrm{d} t
$$

defines the width $\Delta$ of the TTDs. Since TTDs provide a fundamental description of the transport in a flow, it is independent of the characteristics of any particular tracer. Instead, the TTDs are dependent on the roles of advection and mixing during transport, and thus appear different depending on the location in the ocean interior. Thus, for a certain location, when the interior concentration of a particular tracer is given with its surface time series, $\Gamma$ and $\Delta$ of the TTDs for that location can be constrained from equation (1), 
and when multiple tracers are used together, $\Gamma$ and $\Delta$ can be further constrained to a narrow range of values.

In the following sections, we have attempted to estimate the transit time distributions (TTDs) for the location where our deep sea coral was collected $(\sim 1410 \mathrm{~m}$ at north of the Bermuda slope, referred to as "DSC site" hereafter), using multiple transient tracers: CFCs, radiocarbon, and $\mathrm{Pb}$. We generated a wide range of TTDs by varying $\Gamma$ and $\Delta$ from 1 to 150 years, and convoluted these TTDs with the known surface time series of tracers to simulate the concentrations of tracers in the deep sea. Then, by comparing the model simulations to observed tracer data from the deep sea, we determined TTDs for the DSC site.

\subsubsection{Surface and deep ocean tracer concentrations}

To simulate the tracer concentrations at an interior location using equation (1), it is necessary to know the surface time series of the tracers, $c_{0}$. In principle, a water parcel in the ocean interior can be originated from any surface area of the ocean. However, here we consider the surface time series, $\mathrm{c}_{0}$, follows that of the Labrador Sea, the main source region of the water reaching the DSC site. For CFCs (CFC11, CFC12, CFC113), the surface time series was calculated from the known atmospheric time series of CFCs (Walker et al., 2000) and solubility functions from Warner and Weiss (1985) and Bu and Warner (1995), assuming that average salinity and temperature of the Labrador Sea surface are $35 \%$ (pss) and $5^{\circ} \mathrm{C}$, and assumed that halocarbons are fully saturated in the surface waters. We should note that a wide range of surface saturation has been observed 
for CFCs. Low saturations can occur depending on the strength of vertical mixing and the changes in gas solubility that depend on mixed-layer temperature and salinity (e.g. Wallace, 1994), which varies between tracers, water masses, and years. Furthermore, biochemical degradation of the tracers may occur in warm $\left(>5^{\circ} \mathrm{C}\right)$ waters, especially for CFC113 (e.g. Roether et al., 2001). However, as we cannot quantify these factors, we simply assume saturation equilibrium.

For the surface time series of radiocarbon, we used the Labrador Sea surface $\Delta{ }^{14} \mathrm{C}$ history estimated based on the quahog shell ${ }^{14} \mathrm{C}$ record from Georges Bank (Weidman and Jones, 1993). Although the high-latitude North Atlantic region may have lower $\Delta{ }^{14} \mathrm{C}$ than Labrador Sea estimates due to deeper mixing with old waters, these estimates agree with direct surface seawater $\Delta^{14} \mathrm{C}$ measurements from TTO and GEOSECS cruises at high latitude stations near the Labrador Sea region (Weidman and Jones, 1993). The $\Delta^{14} \mathrm{C}$ time series estimate exists only for 1938-1989. For the years prior to 1938, we assume that $\Delta^{14} \mathrm{C}$ in the northern North Atlantic Ocean was constant at $-65 \%$ for the past $\sim 250$ years. When calculating the deep sea $\Delta{ }^{14} \mathrm{C}$ evolution, the source function was decaycorrected for the targeted year (half life $=5730$ years).

The surface time series of $\mathrm{Pb}$ and $\mathrm{Pb}$ isotope ratios for the Labrador Sea were calculated from the Bermuda surface coral record (Figure 1.3) (Kelly et al., 2009). Pb concentrations in the Labrador Sea surface water measured in 1981 (TTO cruise) showed that they are about 50\% lower than those in Bermuda surface waters (Weiss et al., 2003) because of the longer distance from North America, the main source region of the anthropogenic $\mathrm{Pb}$. To account for this difference, we first calculated anthropogenic 
fraction of $\mathrm{Pb}$ and its isotope ratios from the Bermuda coral $\mathrm{Pb}$ record assuming that natural (background) $\mathrm{Pb}$ was constant at $\sim 15 \mathrm{pmol} \mathrm{kg}{ }^{-1}$ with isotope ratios of ${ }^{206} \mathrm{~Pb} /{ }^{207} \mathrm{~Pb}$ $=1.21$ and ${ }^{208} \mathrm{~Pb} /{ }^{207} \mathrm{~Pb}=2.49$. Then, time series of the Labrador Sea $\mathrm{Pb}$ concentrations and isotope ratios were re-calculated assuming that the anthropogenic $\mathrm{Pb}$ deposited on the Labrador Sea is $50 \%$ of that deposited on the Bermuda region.

Several $\mathrm{Pb}$ records exist for the Bermuda corals (Figure 1.3). For the post-1880 record, we used the data from North Rock coral (NR), as it is considered to be more representative of the open ocean $\mathrm{Pb}$ values (Kelly et al., 2009), but for the years prior to 1880 (up to 1778) where no North Rock coral data exist, we used the data from John Smith's Bay coral (JSB). However, the JSB coral is suspected to have an influence of local $\mathrm{Pb}$ inputs, particularly in 1860-1880 where $\mathrm{Pb} / \mathrm{Ca}$ ratios are slightly elevated above the natural level. Therefore, for this period, we interpolated the data between JSB-derived 1860 data and NR-derived 1880 data. The re-calculated $\mathrm{Pb}$ isotope ratios time series for the northern North Atlantic Ocean are similar to the natural $\mathrm{Pb}$ isotope ratios when anthropogenic $\mathrm{Pb}$ was low (before 1850) and become close to those of the NR coral after anthropogenic $\mathrm{Pb}$ became predominant over the natural $\mathrm{Pb}$.

For the time series of the tracers at the DSC site (c(t) in equation (1)), we used the $\Delta^{14} \mathrm{C}, \mathrm{Pb}$ concentrations, and $\mathrm{Pb}$ isotope ratios measured from the deep sea coral (Eltgroth, 2006 and this study). No time-series data exist for CFCs at the DSC site; we used two CFC concentrations data measured during the WOCE '97 cruise (section A22, $32.74^{\circ} \mathrm{N}$, $\left.65.99^{\circ} \mathrm{W}, 1400 \mathrm{~m}\right)$ (http://cchdo.ucsd.edu/) and the CLIVAR '03 cruise (repeat section A22, $32.22^{\circ} \mathrm{N}, 65.99^{\circ} \mathrm{W}, 1300 \mathrm{~m}$ and $\left.1500 \mathrm{~m}\right)$ (http://cdiac.ornl.gov/). 


\subsubsection{Constraining TTDs}

The pairs of $\Gamma$ and $\Delta$ that make the model estimated tracer concentrations best fit the observed values are given in Figure 3.4. CFC11, CFC12, and CFC113 constrain $\Gamma$ and $\Delta$ to a wide range of values. CFC11 and CFC12 constrain $\Gamma$ and $\Delta$ almost to the same range because of their similar surface histories. The $\Gamma$ and $\Delta$ constrained by $\mathrm{CFC} 11$ and CFC12 have higher slope ( 1.5) than what constrained by CFC113 ( 1.3), implying that CFC11 and CFC12 tend to capture the effect of mixing better than CFC113, and thus giving higher $\Delta$. The pair of $\Gamma$ and $\Delta$ that best fit to all three halocarbons are chosen to be $\Gamma=42$ and $\Delta=20$ years.

However, when deep sea $\mathrm{Pb}$ and $\Delta^{14} \mathrm{C}$ are reproduced using this $\Gamma$ and $\Delta$ pair, they do not well agree with the observed data (Figures 3.5(e) and (f)). The model-reproduced $\mathrm{Pb}$ concentrations follow the general trend of low and relatively constant values between 1820 until the early 1900s and the following increase from around 1910, but the model estimates too high concentrations for the Pb after 1970s. Similarly, the model can reproduce a broad feature of the decreasing $\mathrm{Pb}$ isotope ratios with a magnitude of $\sim 0.015$ $\left({ }^{206} \mathrm{~Pb} /{ }^{207} \mathrm{~Pb}\right)$ and $\sim 0.02\left({ }^{208} \mathrm{~Pb} /{ }^{207} \mathrm{~Pb}\right)$. However, the timing of the decrease and the exact values are not consistent with the observed data.

The model-reproduced deep sea $\Delta^{14} \mathrm{C}$ values for the pre-1970s are approximately 10\% higher than the deep sea coral-derived values (Figure 3.5(e)), which indicates that the estimated TTDs are too young. Otherwise, this offset might be explained by the mixing with the water originated from the Subantarctic Ocean that has low $\Delta^{14} \mathrm{C}$. Our model assumes that the surface source function of radiocarbon follows that of the 
Labrador Sea, i.e. all of the water originated from this region. However, Broecker et al.(1991) estimated 5-8\% of the water at $2000 \mathrm{~m}$ depth in the subtropical North Atlantic Ocean is southern origin, and using a more advanced TTDs model that incorporates spatial variance of surface tracer concentrations, $\sim 10 \%$ of the water mass at this depth was estimated to be from the south (Khatiwala et al., 2012). Assuming $\Delta{ }^{14} \mathrm{C}$ value of the southern component water is $-158 \%$ as assumed in Broecker et al. (1991), mixing with the southern component water can lower the model-estimated $\Delta{ }^{14} \mathrm{C}$ values by $4.5-9 \%$ (5$10 \%$ mixing). However, even if this mixing effect is taken into account, this TTDs estimates a too rapid increase of the $\Delta{ }^{14} \mathrm{C}$ after 1970 compared to the observed data. Therefore, this pair of $\Gamma$ and $\Delta$ (42 and 20 years) seems to be inappropriate for the DSC site.

Pairs of $\Gamma$ and $\Delta$ that can best reproduce the deep sea $\Delta^{14} \mathrm{C}$ are constrained to a very narrow range, $\Gamma$ between $60-75$ years and $\Delta$ between $40-50$ years (Figure 3.4). These tight constraints on $\Gamma$ and $\Delta$ are possible because we have a long, continuous deep sea $\Delta{ }^{14} \mathrm{C}$ record, because the model-reproduced deep sea $\Delta{ }^{14} \mathrm{C}$ time series has to fit to the entire data: pre-bomb $\Delta{ }^{14} \mathrm{C}$ values, timing of the post-bomb $\Delta{ }^{14} \mathrm{C}$ increase as well as the rate of the increase. In contrast, $\Gamma$ and $\Delta$ cannot be tightly constrained from CFCs because deep sea CFCs data were available only for 1997 and 2003.

Given uncertainties in the deep sea tracer data and the assumed source functions, $\Gamma=64$ years and $\Delta=46$ years are chosen that fit to all CFCs and $\Delta{ }^{14} \mathrm{C}$ in a reasonable range (Figure 3.4). The reproduced tracer concentrations from this TTDs are compared to the observations in Figure 3.5. This new TTDs integrates more old waters than the TTDs 
driven by CFCs only (Figure 3.5(a)), and the reason for the difference between the two TTD estimates is due to the length of surface histories of each tracer. For instance, CFC113 existed for $\sim 30$ years and CFC11 and CFC12 for 50-60 years. Thus, these tracers cannot properly assess the effect of old (>100 yrs) water parcels in TTDs because they have not yet penetrated into the old waters. The $\Delta / \Gamma$ ratio of this new TTDs is $\sim 0.72$, which is lower (less mixing) than the range of $\Delta / \Gamma$ between $0.9-1.25$ found for the upper $500 \mathrm{~m}$ of the Bermuda Time Series Station using tritium and helium-3 profiles (Stanley et al., 2012), but is close to the range of 0.75-1.25 suggested by the studies of CFCs and Tritium from the entire sections of the North Atlantic Ocean (Waugh et al., 2004; 2006).

With this new TTDs, the model-estimated $\mathrm{Pb}$ concentrations fit more closely to the observed data, but little improvement is found in the Pb isotope fits (Figure 3.5(f)). Actually, with the shape of TTDs given in equation (2) and the source function assumed as in section 4.2.2., there were no pairs of $\Gamma$ and $\Delta$ that can perfectly reproduce the observed $\mathrm{Pb}$ isotope data. There are many factors that can cause this misfit, which will be discussed in the following section.

\subsubsection{Discrepancies between model estimate and observation}

Discrepancies between the model-reproduced and observed deep sea $\mathrm{Pb}$ and $\mathrm{Pb}$ isotopes can be explained in many ways as follows:

(1) The deep sea $\mathrm{Pb}$ concentrations were calculated from $\mathrm{Pb} / \mathrm{Ca}$ ratios of the coral using the partition coefficient $D_{p}=5.2$, assuming that $D_{p}$ was constant during coral growth. However, this distribution coefficient has uncertainties as discussed in section 
3.2., and using lower (higher) distribution coefficient would increase (decrease) the $\mathrm{Pb}$ concentrations. In surface growing corals, it was found that $D_{p}$ of trace elements can be variable in a single coral due to kinetic artifacts (Cohen et al., 2001; Devilliers et al., 1994; 1995). Moreover, fine-scale fluctuations have been found within a skeletal structure both in surface and deep sea corals (Cohen and McConnaughey, 2003; Gagnon et al., 2007; Robinson et al., 2006; Sinclair, 2005). These artifacts are expected to be small in our data because 1) the deep sea coral used in this study is considered to have grown at a constant rate, and 2) we tried to collect coral samples from the same location of the coral discs (close to the calcification center), but they cannot be completely ruled out.

(2) In addition to the $\mathrm{Pb}$ transported by advection and mixing, dissolved $\mathrm{Pb}$ can be added to or removed from the water column by sinking particles. For instance, the residence time of $\mathrm{Pb}$ was estimated from ${ }^{210} \mathrm{~Pb}$ to be a few years in the surface and 50200 years in the deep sea, which indicates that $0.5-2 \%$ of deep sea $\mathrm{Pb}$ (higher in surface) is removed by scavenging every year (Bacon et al., 1976; Cochran et al., 1990; Craig et al., 1973; Schaule and Patterson, 1981). Although net scavenging of Pb occurs in the ocean, isotope equilibrium between dissolved and particulate $\mathrm{Pb}$ found in the North Atlantic Ocean suggests that reversible reaction may occur for $\mathrm{Pb}$ (Sherrell and Boyle, 1992). Moreover, Wu et al. (2010) also suggested that the dominant source of $\mathrm{Pb}$ in the North Pacific abyssal water is the $\mathrm{Pb}$ regenerated from sinking particles. We tested the effect of these particle processes by adding particle scavenging and regeneration terms to the equation (1) for $\mathrm{Pb}$ as below. 


$$
c(r, t)=\int_{0}^{\infty} c_{0}\left(t-t^{\prime}\right) e^{-k_{s c v} * t^{\prime}} G\left(r, t^{\prime}\right) d t^{\prime}+f_{r e g} * c_{0}(t)
$$

$\mathrm{Pb}$ removal by particle scavenging was assumed to be the first order reaction with respect to concentration, $\partial \mathrm{C} / \partial \mathrm{t}=-k_{-s c v} \mathrm{C}$, with particle scavenging rate constant, $k_{-s c v}$. As this removal term $\left(\mathrm{e}^{-\mathrm{k}_{\mathrm{scv}} * \mathrm{t}^{\prime}}\right)$ is a function of time, the older a water parcel is, the more $\mathrm{Pb}$ is removed. We tested $k_{-s c v}=0.006-0.01$, which corresponds to the residence time of $100-$ 150 years for $\mathrm{Pb}$ in deep ocean. For particle regeneration, we assumed that regenerated $\mathrm{Pb}$ bears the isotopic signature of the surface $\mathrm{Pb}$ (Figure 3.3) in the year that the model is calculating for, and the fraction of surface $\mathrm{Pb}$ regenerated at $\sim 1410 \mathrm{~m}$ is expressed in particle regeneration efficiency, f_reg. On the basis of ${ }^{210} \mathrm{Po}$ and ${ }^{210} \mathrm{~Pb}$ profiles from the north equatorial Atlantic, Bacon et al. (1976) estimated a recycling efficiency of about $8 \%$ for ${ }^{210} \mathrm{~Pb}$ between 50 and $400 \mathrm{~m}$ depth, and Shen and Boyle (1998) estimated at least $10 \%$ of the surface $\mathrm{Pb}$ is regenerated between surface and $1700 \mathrm{~m}$ based on $\mathrm{Pb}$ and $\mathrm{Pb}$ isotope profiles from the station $\mathrm{S}$ near Bermuda. Thus, we tested particle regeneration efficiencies of $2-4 \%$.

Adding particle scavenging term lowers the overall $\mathrm{Pb}$ concentrations and slows down the increase of $\mathrm{Pb}$ after 1900s (Figure 3.6). On the other hand, adding particle regeneration terms increases the model-estimated $\mathrm{Pb}$ concentrations, particularly for the $\mathrm{Pb}$ between 1920 and late 1970s because of high surface $\mathrm{Pb}$ concentrations during that period. As surface $\mathrm{Pb}$ isotope ratios were low during this period (Figure 3.6), adding particle regeneration slightly lowers the $\mathrm{Pb}$ isotope ratios in 1920-late 1970s, but in overall, $\mathrm{Pb}$ isotopes are less sensitive to the particle processes. When we further tested wide range of k_scv and f_reg, the best fit between the model estimated $\mathrm{Pb}$ 
concentrations and the data was found when $\mathrm{k} \_s c v=0.01$ and $\mathrm{f} \_r e g=0.15$. Such high particle regeneration efficiency is unreasonable at 1410m depth, but even with this extreme assumption, deep sea $\mathrm{Pb}$ isotope ratios are not well reproduced by the TTDs model (Figure 3.6). Therefore, particle reactions cannot solely account for the discrepancies found between model estimates and the observed data, although we cannot really quantify the effect of particles using equation (5) as water parcels arriving at the DSC site spend different amount of times at different depths and locations, and the particle effect cannot be modeled with a single k_scv and f_reg.

(3) The TTDs model used in this study assumes spatially uniform tracer concentrations at the ocean surface that only vary as a function of time. However, in reality, surface $\mathrm{Pb}$ and $\mathrm{Pb}$ isotope distribution exhibit spatial variance depending on prevailing wind direction, distance from main sources, and surface ocean currents (e.g. Gulf Stream and Subtropical North Atlantic Gyre) (Hamelin et al., 1997; Helmers and Vanderloeff, 1993; Veron et al., 1994; Weiss et al., 2003). For instance, the eastern part of the North Atlantic Ocean receives anthropogenic $\mathrm{Pb}$ largely from Europe, which has lower isotope ratios than US and Canada $\mathrm{Pb}$ (Bollhöfer and Rosman, 2001; Grousset et al., 1994; Hamelin et al., 1989). Moreover, the spatial gradient of $\mathrm{Pb}$ and $\mathrm{Pb}$ isotopes evolves with time depending on the relative amount of anthropogenic $\mathrm{Pb}$ emissions from North America and Europe (Weiss et al., 2003 and MIT unpublished data). The other tracers used in this study, CFCs and $\Delta^{14} \mathrm{C}$, also have spatial variance (mostly latitudinal gradient) in surface distributions (Broecker et al., 1985; Doney and Jenkins, 1988; Stuiver and Ostlund, 1980), but they are not as variable as in $\mathrm{Pb}$ and $\mathrm{Pb}$ isotopes. 
(4) As discussed earlier, the DSC site contains water originated from the south. The south-origin water probably had low $\mathrm{Pb}$ concentrations, thus having a negligible effect on the $\mathrm{Pb}$ at the DSC site, because industrial development (and anthropogenic $\mathrm{Pb}$ emissions) in the South American and African countries began only a few decades ago. However, mixing with the south-origin water might cause the lower $\mathrm{Pb}$ isotope ratios than the model estimates in the late 1990s. The anthropogenic Pb emitted from the South America and Africa in 1990s had low isotope ratios (Bollhöfer and Rosman,2000), and the Pb found in the AAIW in the South Atlantic Ocean in 1996 had isotope ratios of ${ }^{206} \mathrm{~Pb} /{ }^{207} \mathrm{~Pb}=1.159 \pm 0.002$ (Alleman et al., 2001a; 2001b). However, the $\mathrm{Pb}$ concentration of this water (AAIW) was still relatively low at $20 \mathrm{pM}$, so even if mixing with the south-origin water lowers the $\mathrm{Pb}$ isotope ratios of the DSC site, the effect would be small compared to the observed discrepancies.

(5) Our TTDs assume that the transport was steady over the last $~ 300$ years, and the TTDs have a shape of the Inverse Gaussian as in equation (2). However, time scales of the ventilation could have been varied over time, particularly during the Little Ice Age (e.g. Broecker, 2000). We have also tested bimodal TTDs to allow a more freedom to the shape of TTDs, as shown in some flow simulations (e.g. Haine and Hall, 2002; Waugh et al., 2003). We assumed that TTDs are a linear combination of two inverse Gaussian distributions and found the optimal TTDs by changing $\Gamma \mathrm{s}$ and $\Delta \mathrm{s}$. For the tracers used in this study and for the DSC site, the optimal bimodal TTDs model were found to be almost identical to the unimodal TTDs, and did not improve the fit between model 
estimates and the observations. However, true TTDs can be multidimensional and may have a different shape from the Inverse Gaussian distributions.

(6) The age estimates for the deep sea coral may need to be re-calibrated. The age model in section 3.3.1 is valid when the samples were measured from the center, i.e., the oldest part of the radial disc, which is only $1-3 \mathrm{~mm}$ wide in diameter (Figure 2.3. in Eltgroth, 2006). However, because of the relatively large amount of sample needed for $\mathrm{Pb}$ analysis, samples were sometimes cut from a wider area, incorporating a younger part of the corals than what was estimated by the age model. The coral has a very slow radial growth rate, 20-30 $\mu \mathrm{m} / \mathrm{yr}$ (Eltgroth, 2006). Thus, for example, if a coral sample used for the analysis was cut within $4 \mathrm{~mm}$ from the center and the true central part is only $2 \mathrm{~mm}$ wide in that radial disc, this sample would be $\sim 50$ years younger than the estimated. This error would be larger for the older samples than the younger samples, as recently formed corals are narrow and have a small age gradient along the radial distance. If we assume that true ages of the coral samples in the 1800 s are $\sim 50$ years younger (i.e. coral data points shifting to the right in Figure 3.5(f)), the fit between the model-reproduced and observed $\mathrm{Pb}$ and $\mathrm{Pb}$ isotopes will improve. The age errors will vary for each data depending on the size of sample cut for each analysis, and they could be corrected by measuring radiocarbon in the stored dissolved coral solutions and determining the true ages of each sample. 


\subsection{Conclusions}

This study shows that deep-sea corals can be utilized as a reliable proxy of the temporal variation of $\mathrm{Pb}$ in deep sea. Using a dee-sea coral, $~ 550$ year history of the $\mathrm{Pb}$ and $\mathrm{Pb}$ isotopes in the deep North Atlantic Ocean was reconstructed, and the results of the study are summarized below.

1. The pre-anthropogenic $\mathrm{Pb}$ concentrations are estimated to be $3-11 \mathrm{pmol} \mathrm{kg}^{-1}$ in deep sea based on the coral $\mathrm{Pb} / \mathrm{Ca}$ ratios. The $\mathrm{Pb}$ concentrations in coral increase from the mid-1800s until $\sim 1980$ due to the intrusion of anthropogenic $\mathrm{Pb}$. The $\mathrm{Pb}$ isotope ratios are more variable than $\mathrm{Pb} / \mathrm{Ca}$, but the infiltration of anthropogenic $\mathrm{Pb}$ lowers the $\mathrm{Pb}$ isotope ratios in the deep sea, particularly after $\sim 1980$.

2. By comparing $\mathrm{Pb}$ and $\Delta^{14} \mathrm{C}$ of the deep-sea coral to those of the surface Bermuda coral, we obtained 20-25 years of transit times (tracer ages). However, water mass ages determined from TTDs are longer than the tracer ages (mean age $=64$ years), representing the importance of turbulent mixing in the transport. The longer TTDs were better constrained by using $\Delta^{14} \mathrm{C}, \mathrm{Pb}$, and CFCs together than using CFCs only because of longer surface time series of $\Delta^{14} \mathrm{C}$ and $\mathrm{Pb}$. Moreover, having a long and continuous record for the deep sea $\Delta^{14} \mathrm{C}$ and $\mathrm{Pb}$ can constrain TTDs to a very narrow range for a single station, showing the advantage of using deep-sea corals for this type of study.

3. The residual inconsistencies between modeled and observed $\mathrm{Pb}$ concentration and isotopic distribution may be partly attributed to the effect of particle scavenging and regeneration processes, but could be also due to the assumptions on the TTDs (shape and non-evolving characteristics). There are also uncertainties in $D_{p}$ and the assumed surface 
$\mathrm{Pb}$ time series, particularly in the spatial distribution of the $\mathrm{Pb}$ in the North Atlantic Ocean and its temporal evolution. However, these cannot be specified until more historical information on the spatial distribution of $\mathrm{Pb}$ becomes available. The offset between model and observation could be also due to the errors in the age estimates of the deep-sea coral samples. 


\section{References for Chapter 3}

Adkins, J. F., E. A. Boyle, L. Keigwin, and E. Cortijo (1997), Variability of the North Atlantic thermohaline circulation during the last interglacial period, Nature, 390(6656), 154-156.

Adkins, J. F., H. Cheng, E. A. Boyle, E. R. M. Druffel, and R. L. Edwards (1998), Deepsea coral evidence for rapid change in ventilation of the deep North Atlantic 15,400 years ago, Science, 280(5364), 725-728.

Adkins, J. F., G. M. Henderson, S. L. Wang, S. O'Shea, and F. Mokadem (2004), Growth rates of the deep-sea scleractinia Desmophyllum cristagalli and Enallopsammia rostrata, Earth Planet. Sc. Lett., 227(3-4), 481-490.

Adkins, J. F., S. Griffin, M. Kashgarian, H. Cheng, E. R. M. Druffel, E. A. Boyle, R. L. Edwards, and C. C. Shen (2002), Radiocarbon dating of deep-sea corals, Radiocarbon, 44(2), 567-580.

Alleman, L. Y., A. J. Veron, T. M. Church, A. R. Flegal, and B. Hamelin (1999), Invasion of the abyssal North Atlantic by modern anthropogenic lead, Geophys. Res. Lett., 26(10), 1477-1480.

Alleman, L. Y., T. M. Church, P. Ganguli, A. J. Veron, B. Hamelin, and A. R. Flegal (2001a), Role of oceanic circulation on contaminant lead distribution in the South Atlantic, Deep-Sea Res. Pt. II, 48(13), 2855-2876.

Alleman, L. Y., T. M. Church, A. J. Veron, G. Kim, B. Hamelin, and A. R. Flegal (2001b), Isotopic evidence of contaminant lead in the South Atlantic troposphere and surface waters, Deep-Sea Res. Pt. II, 48(13), 2811-2827.

Bacon, M. P., D. W. Spencer, and P. G. Brewer (1976), Pb-210-Ra-226 and Po-210-Pb210 Disequilibria in Seawater and Suspended Particulate Matter, Earth Planet. Sc. Lett., 32(2), 277-296.

Baker, J., D. Peate, T. Waight and C. Meyzen (2004), Pb isotopic analysis of standards and samples using a $\mathrm{Pb}-207-\mathrm{Pb}-204$ double spike and thallium to correct for mass bias with a double-focusing MC-ICP-MS, Chem. Geol., 211(3-4), 275-303.

Bollhofer, A., and K. J. R. Rosman (2000), Isotopic source signatures for atmospheric lead: The Southern Hemisphere, Geochim. Cosmochim. Ac., 64(19), 3251-3262.

Bollhofer, A., and K. J. R. Rosman (2001), Isotopic source signatures for atmospheric lead: The Northern Hemisphere, Geochim. Cosmochim. Ac., 65(11), 1727-1740.

Boyle, E. A., S. D. Chapnick, G. T. Shen, and M. P. Bacon (1986), Temporal Variability of Lead in the Western North-Atlantic, J. Geophys. Res.-Oceans, 91(C7), 85738593.

Boyle, E. A., S. John, W. Abouchami, J. F. Adkins, Y. Echegoyen-Sanz, M. Ellwood, A. R. Flegal, K. Fornace, C. Gallon, S. Galer, M. Gault-Ringold, F. Lacan, A. Radic, M. Rehkamper, O. Rouxel, Y. Sohrin, C. Stirling, C. Thompson, D. Vance, Z. Xue, and Y. Zhao (2012), GEOTRACES IC1(BATS) contamination-prone trace element isotopes $\mathrm{Cd}, \mathrm{Fe}, \mathrm{Pb}, \mathrm{Zn}, \mathrm{Cu}$, and Mo Intercalibration, Lim. Ocanogr.Methods, 10, 653-665. 
Broecker, W. S. (2000), Was a change in thermohaline circulation responsible for the Little Ice Age?, P. Natl. Acad. Sci. USA, 97(4), 1339-1342.

Broecker, W. S., A. Virgilio, and T. H. Peng (1991), Radiocarbon Age of Waters in the Deep Atlantic Revisited, Geophys. Res. Lett., 18(1), 1-3.

Broecker, W. S., T. H. Peng, G. Ostlund, and M. Stuiver (1985), The Distribution of Bomb Radiocarbon in the Ocean, J. Geophys. Res.-Oceans, 90(C4), 6953-6970.

Bu, X., and M. J. Warner (1995), Solubility of Chlorofluorocarbon-113 in Water and Seawater, Deep-Sea Res. P.t I, 42(7), 1151-1161.

Chhikara, R. S., and J. L. Folks (1989), The Inverse Gaussian Distributions: theory, Methodology and Applications, Marcel Dekker, New York.

Chow, T. J., and C. C. Patterson (1962), The Occurrence and Significance of Lead Isotopes in Pelagic Sediments, Geochim. Cosmochim. Ac., 26, 263-308.

Cochran, J. K., T. Mckibbinvaughan, M. M. Dornblaser, D. Hirschberg, H. D. Livingston, and K. O. Buesseler (1990), Pb-210 Scavenging in the North-Atlantic and North Pacific Oceans, Earth Planet. Sc. Lett., 97(3-4), 332-352.

Cohen, A. L., and T. A. McConnaughey (2003), Geochemical perspectives on coral mineralization, Rev. Mineral Geochem., 54, 151-187.

Cohen, A. L., and G. A. Gaetani (2006), Compositional variability in the cold-water coral Lophelia pertusa is driven by temperature and aragonite precipitation "efficiency", Geochim. Cosmochim. Ac., 70(18), A107-A107.

Cohen, A. L., G. D. Layne, S. R. Hart, and P. S. Lobel (2001), Kinetic control of skeletal $\mathrm{Sr} / \mathrm{Ca}$ in a symbiotic coral: Implications for the paleotemperature proxy, Paleoceanography, 16(1), 20-26.

Craig, H., Krishnas.S, and Somayaju.Bl (1973), Pb-210 - Ra-226 - Radioactive Disequilibrium in Deep-Sea, Earth Planet. Sc. Lett., 17(2), 295-305.

Devilliers, S., G. T. Shen, and B. K. Nelson (1994), The Sr/Ca-Temperature Relationship in Coralline Aragonite - Influence of Variability in $(\mathrm{Sr} / \mathrm{Ca})$ Seawater and Skeletal Growth-Parameters, Geochim. Cosmochim. Ac., 58(1), 197-208.

Devilliers, S., B. K. Nelson, and A. R. Chivas (1995), Biological-Controls on Coral Sr/Ca and Delta-O-18 Reconstructions of Sea-Surface Temperatures, Science, 269(5228), 1247-1249.

Dickson, R., J. Lazier, J. Meincke, P. Rhines, and J. Swift (1996), Long-term coordinated changes in the convective activity of the North Atlantic, Prog. Oceanogr., 38(3), 241-295.

Doney, S. C., and W. J. Jenkins (1988), The Effect of Boundary-Conditions on Tracer Estimates of Thermocline Ventilation Rates, J. Ma.r Res., 46(4), 947-965.

Doney, S. C., W. J. Jenkins, and J. L. Bullister (1997), A comparison of ocean tracer dating techniques on a meridional section in the eastern North Atlantic, Deep-Sea Res. Pt. I, 44(4), 603-626. 
Druffel, E. R. M. (1989), Decade Time Scale Variability of Ventilation in the NorthAtlantic - High-Precision Measurements of Bomb Radiocarbon in Banded Corals, J. Geophys. Res.-Oceans, 94(C3), 3271-3285.

Druffel, E. R. M., L. L. King, R. A. Belastock, and K. O. Buesseler (1990), Growth-Rate of a Deep-Sea Coral Using Pb-210 and Other Isotopes, Geochim. Cosmochim. Ac., 54(5), 1493-1500.

Eltgroth, S. (2006), Unraveling Deep-Ocean Connections to Climate with Deep-Sea Coral Records of Radiocarbon and $\mathrm{Cd} / \mathrm{Ca}$, California Institute of Technology.

Fine, R. A., M. Rhein, and C. Andrie (2002), Using a CFC effective age to estimate propagation and storage of climate anomalies in the deep western North Atlantic Ocean, Geophys. Res. Lett., 29(24).

Gagnon, A. C., J. F. Adkins, D. P. Fernandez, and L. F. Robinson (2007), Sr/Ca and $\mathrm{Mg} / \mathrm{Ca}$ vital effects correlated with skeletal architecture in a scleractinian deepsea coral and the role of Rayleigh fractionation, Earth Planet. Sc. Lett., 261(1-2), 280-295.

Grousset, F. E., C. R. Quetel, B. Thomas, P. Buatmenard, O. F. X. Donard, and A. Bucher (1994), Transient Pb Isotopic Signatures in the Western-European Atmosphere, Environ. Sci. Technol., 28(9), 1605-1608.

Haine, T. W. N., and T. M. Hall (2002), A generalized transport theory: Water-mass composition and age, J. Phys. Oceanogr., 32(6), 1932-1946.

Hall, T. M., and R. A. Plumb (1994), Age as a Diagnostic of Stratospheric Transport, J. Geophys. Res.-Atmos., 99(D1), 1059-1070.

Hamelin, B., F. E. Grousset, P. E. Biscaye, A. Zindler, and J. M. Prospero (1989), Lead Isotopes in Trade-Wind Aerosols at Barbados - the Influence of European Emissions over the North-Atlantic, J. Geophys. Res.-Oceans, 94(C11), 1624316250.

Hamelin, B., J. L. Ferrand, L. Alleman, E. Nicolas, and A. Veron (1997), Isotopic evidence of pollutant lead transport from North America to the subtropical North Atlantic gyre, Geochim. Cosmochim. Ac., 61(20), 4423-4428.

Helmers, E. (1996), Trace metals in suspended particulate matter of Atlantic Ocean surface water (40 degrees $\mathrm{N}$ to 20 degrees $\mathrm{S}$ ), Mar. Chem., 53(1-2), 51-67.

Helmers, E., and M. M. R. Vanderloeff (1993), Lead and Aluminum in Atlantic Surface Waters (50-Degrees-N to 50-Degrees-S) Reflecting Anthropogenic and Natural Sources in the Eolian Transport, J. Geophys. Res.-Oceans, 98(C11), 20261-20273.

Holzer, M., and T. M. Hall (2000), Transit-time and tracer-age distributions in geophysical flows, J. Atmos. Sci., 57(21), 3539-3558.

Kelly, A. E., M. K. Reuer, N. F. Goodkin, and E. A. Boyle (2009), Lead concentrations and isotopes in corals and water near Bermuda, 1780-2000, Earth Planet. Sc. Lett., 283(1-4), 93-100.

Khatiwala, S., M. Visbeck, and P. Schlosser (2001), Age tracers in an ocean GCM, DeepSea Res. Pt. I, 48(6), 1423-1441. 
Khatiwala, S., F. Primeau, and M. Holzer (2012), Ventilation of the deep ocean constrained with tracer observations and implications for radiocarbon estimates of ideal mean age, Earth Planet. Sc. Lett., 325, 116-125.

Kraus, K. A., and G. E. Moore (1953), Anion Exchange Studies .6. The Divalent Transition Elements Manganese to Zinc in Hydrochloric Acid, J. Am. Chem. Soc., 75(6), 1460-1462.

Lazier, J. R. N. (1995), The salinity decrease in the Labrador Sea over the past thirty years., in Natural Climate Variability on Decade-to-Century Time Scales, edited by D. G. Martinson, pp. 295-304, National Academy Press, Washington, D.C.

Reuer, M. K. (2002), Centennial-Scale Elemental and Isotopic Variability in the Tropical and Subtropical North Atlantic Ocean, Massachusetts Institute of Technology.

Reuer, M. K., and D. J. Weiss (2002), Anthropogenic lead dynamics in the terrestrial and marine environment, Philosophical Transactions of the Royal Society of London Series a-Mathematical Physical and Engineering Sciences, 360(1801), 2889-2904.

Reuer, M. K., E. A. Boyle, and B. C. Grant (2003), Lead isotope analysis of marine carbonates and seawater by multiple collector ICP-MS, Chem. Geol., 200(1-2), 137-153.

Robinson, L. F., J. F. Adkins, D. P. Fernandez, D. S. Burnett, S. L. Wang, A. C. Gagnon, and N. Krakauer (2006), Primary U distribution in scleractinian corals and its implications for U series dating, Geochem. Geophy. Geosy., 7(5), Q05022, ISSN: 1525-2027.

Roether, W., B. Klein, and K. Bulsiewicz (2001), Apparent loss of CFC-113 in the upper ocean, J. Geophys. Res.-Oceans, 106(C2), 2679-2688.

Schaule, B. K., and C. C. Patterson (1981), Lead Concentrations in the Northeast Pacific - Evidence for Global Anthropogenic Perturbations, Earth Planet. Sc. Lett., 54(1), 97-116.

Schaule, B. K., and C. C. Patterson (1983), Perturbations of the natural lead profile in the Sargasso Sea by industrial lead, in Trace Metals in Sea Water, edited by C. S. Wong, pp. 487-504, Plenum, New York.

Seshadri, V. (1999), The Inverse Gaussian Ditributions, Springer, New York.

Shen, G. T., and E. A. Boyle (1987), Lead in Corals - Reconstruction of Historical Industrial Fluxes to the Surface Ocean, Earth Planet. Sc. Lett., 82(3-4), 289-304.

Shen, G. T., and E. A. Boyle (1988a), Determination of Lead, Cadmium and Other TraceMetals in Annually-Banded Corals, Chem. Geol., 67(1-2), 47-62.

Shen, G. T., and E. A. Boyle (1988b), Thermocline Ventilation of Anthropogenic Lead in the Western North-Atlantic, J. Geophys. Res.-Oceans, 93(C12), 15715-15732.

Sherrell, R. M., and E. A. Boyle (1992), Isotopic Equilibration between Dissolved and Suspended Particulate Lead in the Atlantic-Ocean - Evidence from Pb-210 and Stable Pb Isotopes, J. Geophys. Res.-Oceans, 97(C7), 11257-11268. 
Shirai, K., M. Kusakabe, S. Nakai, T. Ishii, T. Watanabe, H. Hiyagon, and Y. Sano (2005), Deep-sea coral geochemistry: Implication for the vital effect, Chem. Geol., 224(4), 212-222.

Sinclair, D. J. (2005), Correlated trace element "vital effects" in tropical corals: A new geochemical tool for probing biomineralization, Geochim. Cosmochim. Ac., 69(13), 3265-3284.

Stanley, R. H. R., S. C. Doney, W. J. Jenkins, and D. E. Lott (2012), Apparent oxygen utilization rates calculated from tritium and helium-3 profiles at the Bermuda Atlantic Time-series Study site, Biogeosciences, 9(6), 1969-1983.

Strelow, F. W. E. (1978), Distribution Coefficients and Anion-Exchange Behavior of Some Elements in Hydrobromic Nitric Acid Mixtures, Anal. Chem., 50(9), 13591361.

Stuiver, M., and H. G. Ostlund (1980), Geosecs Atlantic Radiocarbon, Radiocarbon, 22(1), 1-24.

Veron, A., T. M. Church, and A. R. Flegal (1998), Lead isotopes in the western North Atlantic: Transient tracers of pollutant lead inputs, Environ. Res., 78(2), 104-111.

Veron, A., P. Flament, M. L. Bertho, L. Alleman, R. Flegal, and B. Hamelin (1999), Isotopic evidence of pollutant lead sources in Northwestern France, Atmos. Environ., 33(20), 3377-3388.

Veron, A. J., T. M. Church, C. C. Patterson, and A. R. Flegal (1994), Use of Stable Lead Isotopes to Characterize the Sources of Anthropogenic Lead in North-Atlantic Surface Waters, Geochim. Cosmochim. Ac., 58(15), 3199-3206.

Veron, A. J., T. M. Church, A. R. Flegal, C. C. Patterson, and Y. Erel (1993), Response of Lead Cycling in the Surface Sargasso Sea to Changes in Tropospheric Input, J. Geophys. Res.-Oceans, 98(C10), 18269-18276.

Walker, S. J., R. F. Weiss, and P. K. Salameh (2000), Reconstructed histories of the annual mean atmospheric mole fractions for the halocarbons CFC-11, CFC-12, CFC-113, and carbon tetrachloride, J. Geophys. Res.-Oceans, 105(C6), 1428514296.

Wallace, D. W. R. (1994), Anthropogenic Chlorofluoromethanes and Seasonal Mixing Rates in the Middle Atlantic Bight, Deep-Sea Res Pt Ii, 41(2-3), 307-324.

Wallace, D. W. R., and J. R. N. Lazier (1988), Anthropogenic Chlorofluoromethanes in Newly Formed Labrador Sea-Water, Nature, 332(6159), 61-63.

Warner, M. J., and R. F. Weiss (1985), Solubilities of Chlorofluorocarbon-11 and Chlorofluorocarbon-12 in Water and Seawater, Deep-Sea Res, 32(12), 1485-1497.

Waugh, D. W., T. M. Hall, and T. W. N. Haine (2003), Relationships among tracer ages, J. Geophys. Res.-Oceans, 108(C5) doi: 10.1029/2002JC001325.

Waugh, D. W., T. W. N. Haine, and T. M. Hall (2004), Transport times and anthropogenic carbon in the subpolar North Atlantic Ocean, Deep-Sea Res Pt I, 51(11), 1475-1491. 
Waugh, D. W., T. M. Hall, B. I. McNeil, R. Key, and R. J. Matear (2006), Anthropogenic $\mathrm{CO} 2$ in the oceans estimated using transit time distributions, Tellus B, 58(5), 376389.

Weidman, C. R., and G. A. Jones (1993), A Shell-Derived Time History of Bomb C-14 on Georges Bank and Its Labrador Sea Implications, J. Geophys. Res.-Oceans, 98(C8), 14577-14588.

Weiss, D., E. A. Boyle, J. F. Wu, V. Chavagnac, A. Michel, and M. K. Reuer (2003), Spatial and temporal evolution of lead isotope ratios in the North Atlantic Ocean between 1981 and 1989, J. Geophys. Res.-Oceans, 108(C10), doi: 10.1029/2000JC000762.

Wu, J. F., and E. A. Boyle (1997), Lead in the western North Atlantic Ocean: Completed response to leaded gasoline phaseout, Geochim. Cosmochim. Ac., 61(15), 32793283.

Wu, J. F., R. Rember, M. B. Jin, E. A. Boyle, and A. R. Flegal (2010), Isotopic evidence for the source of lead in the North Pacific abyssal water, Geochim. Cosmochim. Ac., 74(16), 4629-4638.

Wunsch, C., and P. Heimbach (2008), How long to oceanic tracer and proxy equilibrium?, Quaternary Sci. Rev., 27(7-8), 637-651. 


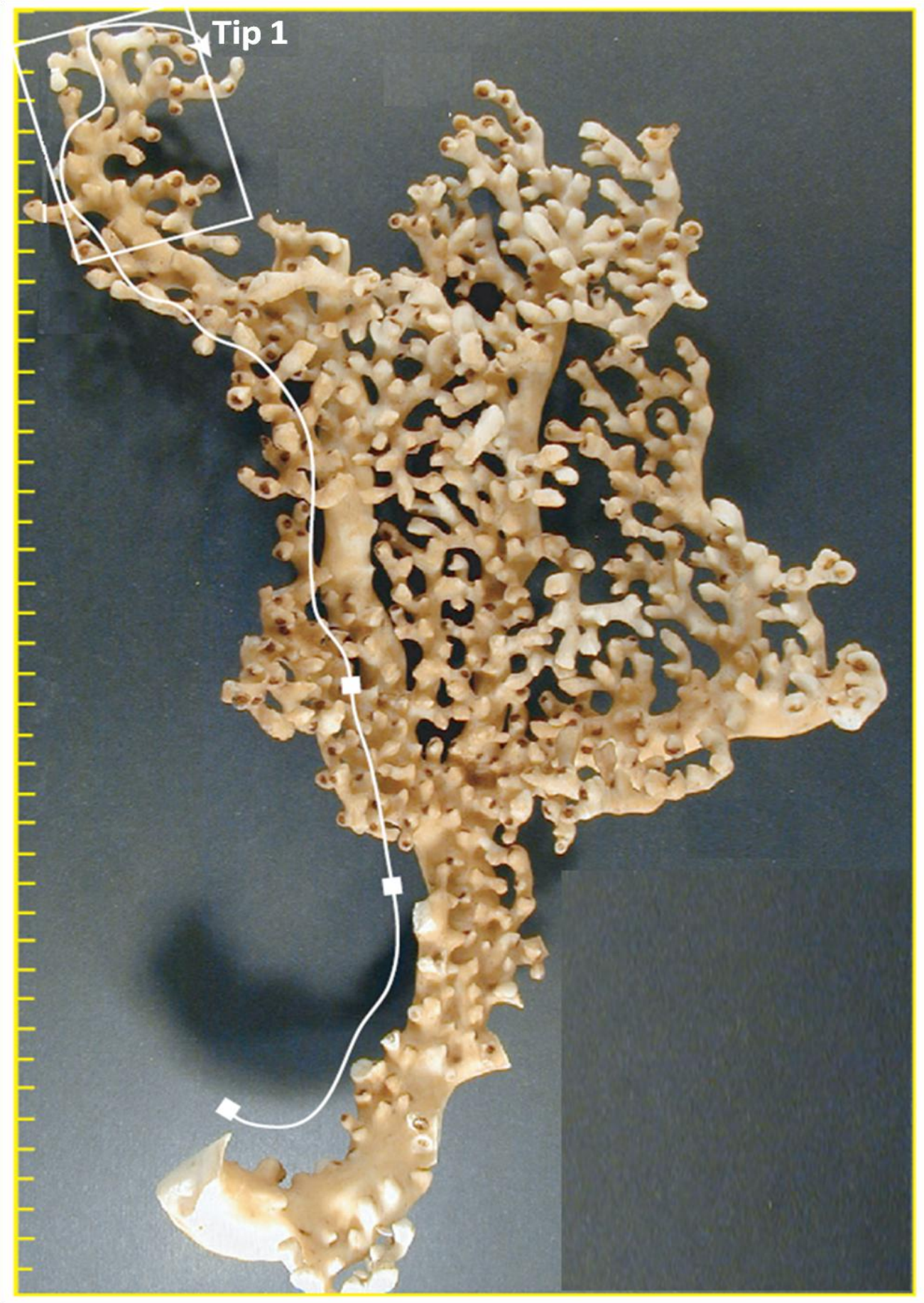

Figure 3.1 Enallopsammia rostrata sample ALV-3701-8, modified from Figure 2.1 in Eltgroth (2006). The line traces the branch and the Tip 1 that were selected for the time series. Scale at left shows $1 \mathrm{~cm}$ divisions. 

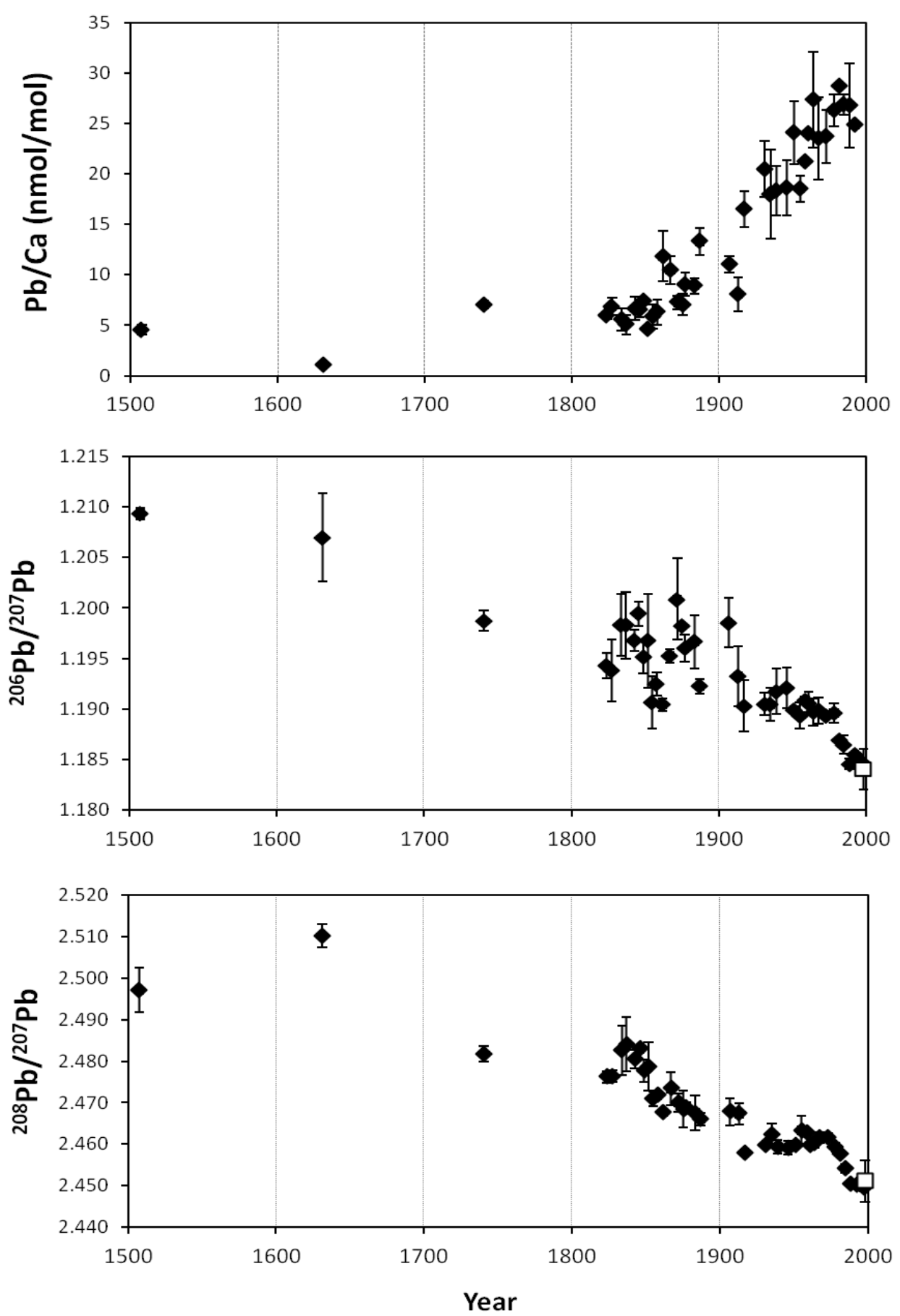

Figure 3.2 Temporal variation of $\mathrm{Pb} / \mathrm{Ca},{ }^{206} \mathrm{~Pb} /{ }^{207} \mathrm{~Pb}$ and ${ }^{208} \mathrm{~Pb} /{ }^{207} \mathrm{~Pb}$ ratios in the deep sea coral E. rostrata (ALV-3701-8). Error bars are standard deviation of the duplicate or triplicate samples. White squares indicate the $\mathrm{Pb}$ isotope ratios measured in seawater collected from a nearby station $\left(33^{\circ} \mathrm{N}, 59^{\circ} \mathrm{W} ; 1490 \mathrm{~m}\right.$ depth) in 1998 (Reuer, 2002). 

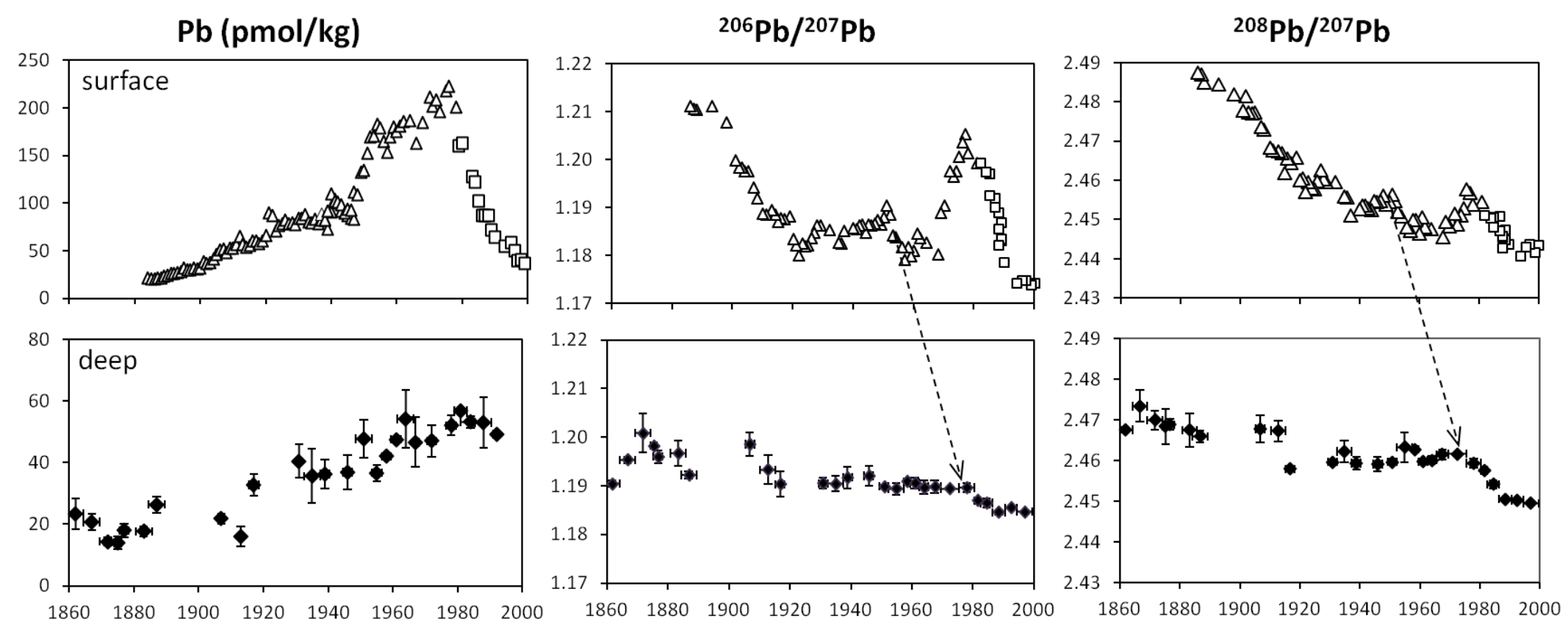

Figure 3.3 $\mathrm{Pb}$ concentrations and $\mathrm{Pb}$ isotope ratios in the deep sea (reconstructed from E. rostrata, bottom plots) in comparison with those in the surface North Atlantic Ocean (top plots). The temporal variation of the surface ocean $\mathrm{Pb}$ is from Bermuda North Rock corals $(\Delta)$ and seawater ( $\square$ ) (Kelly et al., 2009). Dotted arrows show the decrease of the Pb isotope ratios appearing in the deep sea $\sim 25$ years later than its appearance in the surface ocean. 


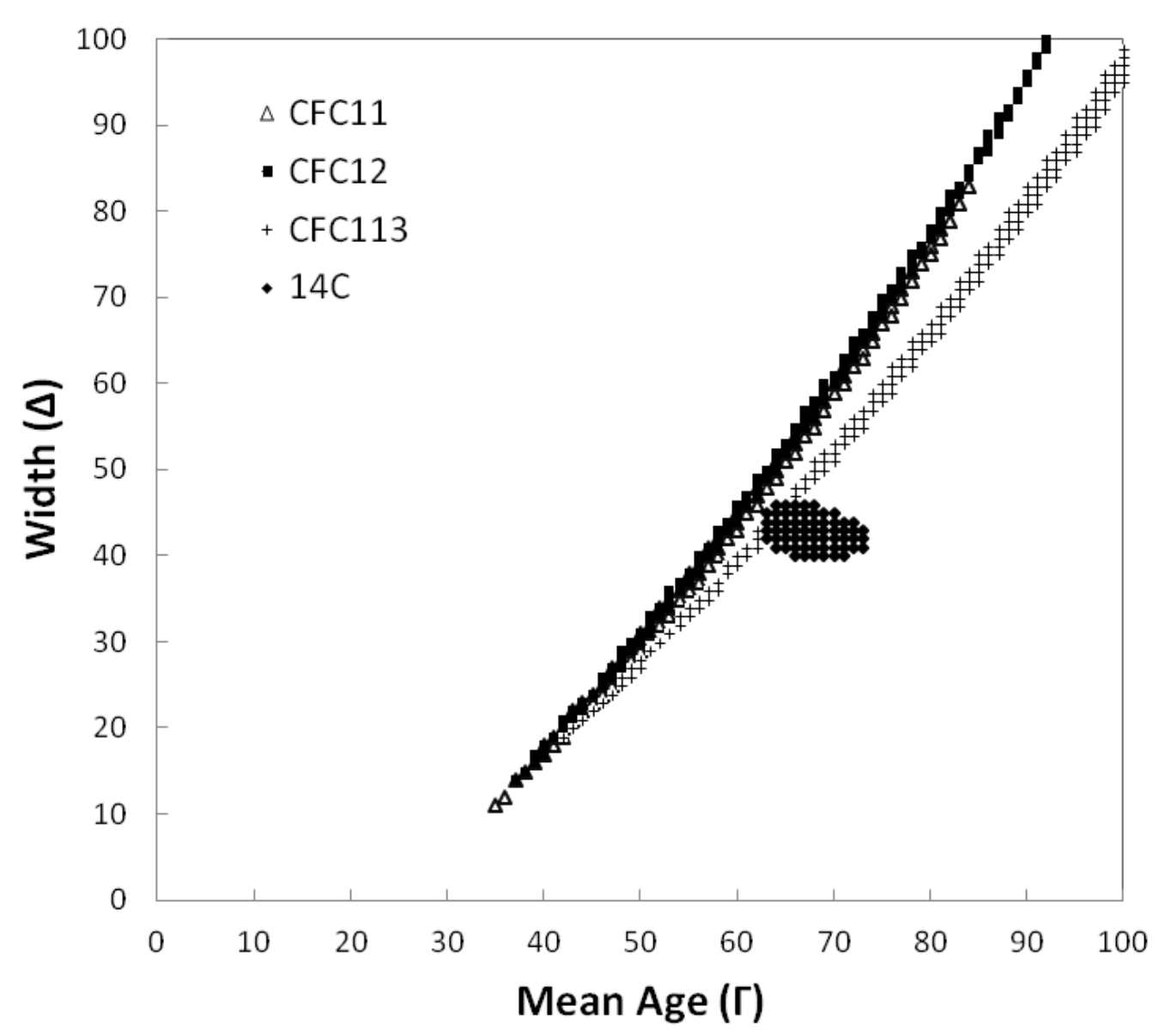

Figure 3.4 Pairs of $\Gamma$ and $\Delta$ constrained by $\mathrm{CFC} 11, \mathrm{CFC} 12, \mathrm{CFC} 113$, and ${ }^{14} \mathrm{C}$ 


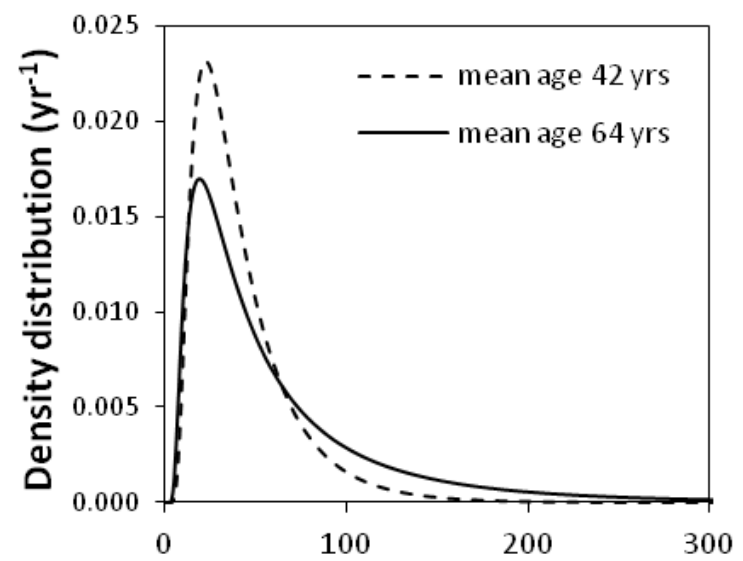

(a)

Time (yrs)
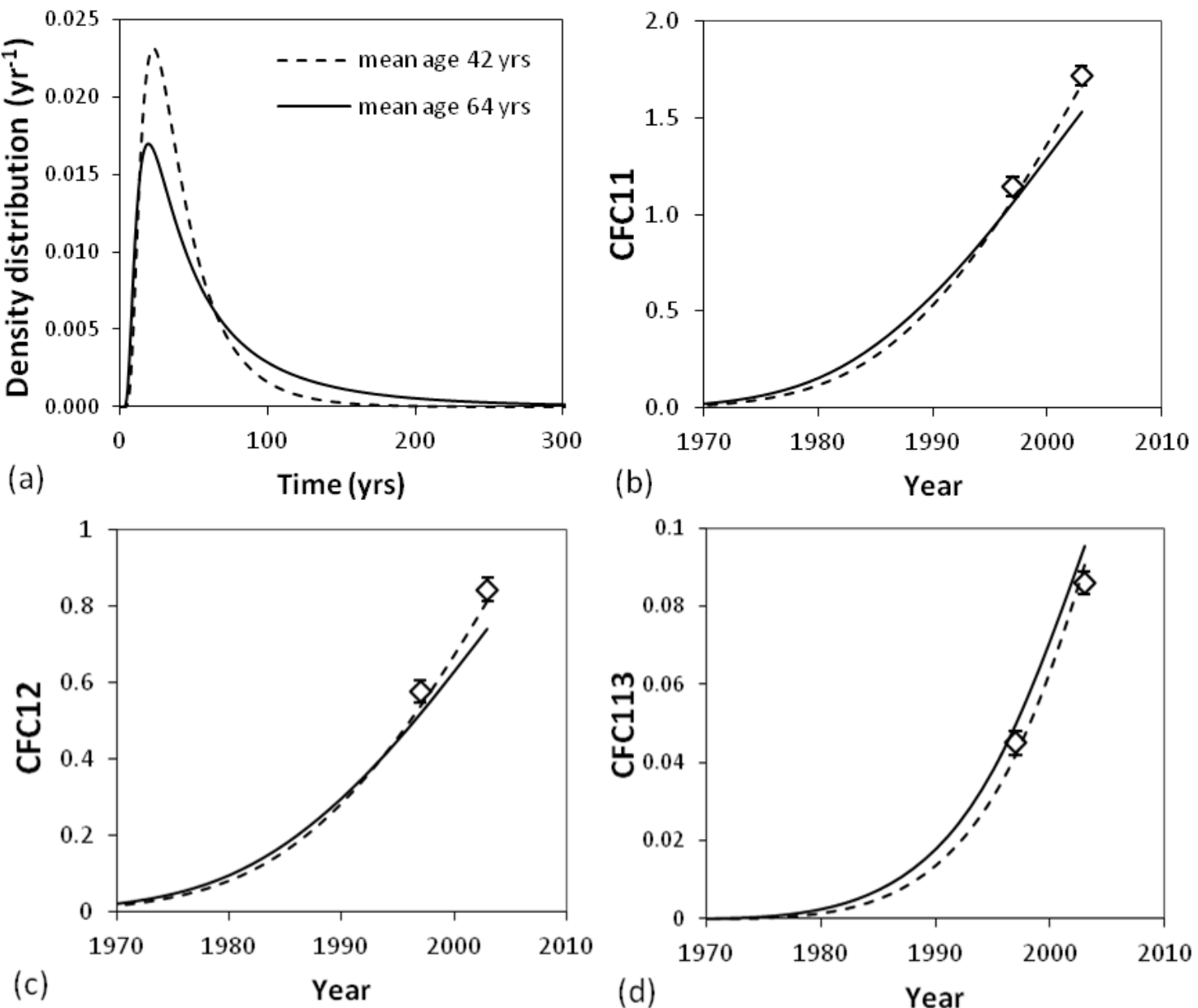

(b)

Year

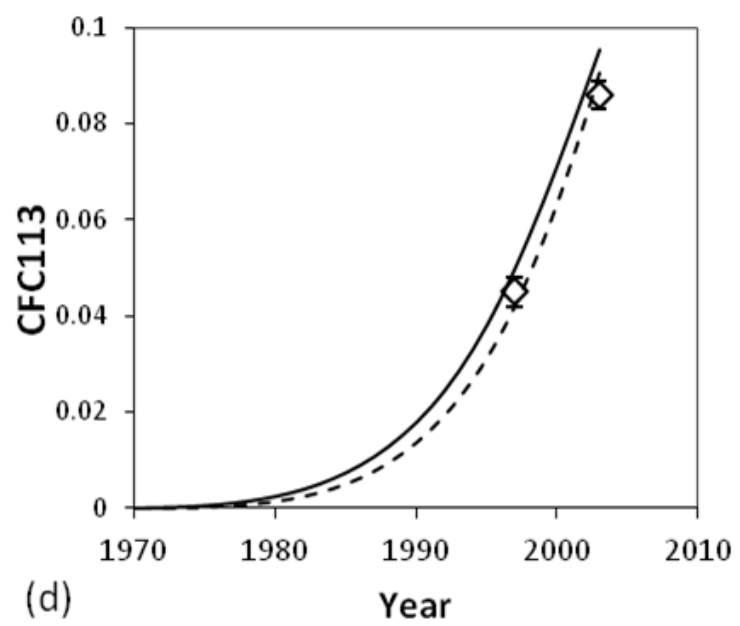

Figure 3.5 (a) TTDs with mean age $(\Gamma)$ of 42 years $(\Delta=20$ years) and 64 years $(\Delta=46$ years), and comparison of tracer concentrations estimated from the two TTDs with what measured from seawater or a deep sea coral for (b) CFC11, (c) CFC12, (d) CFC113, (e) $\Delta^{14} \mathrm{C}$, and (f) $\mathrm{Pb}$ concentration and $\mathrm{Pb}$ isotope ratios. 


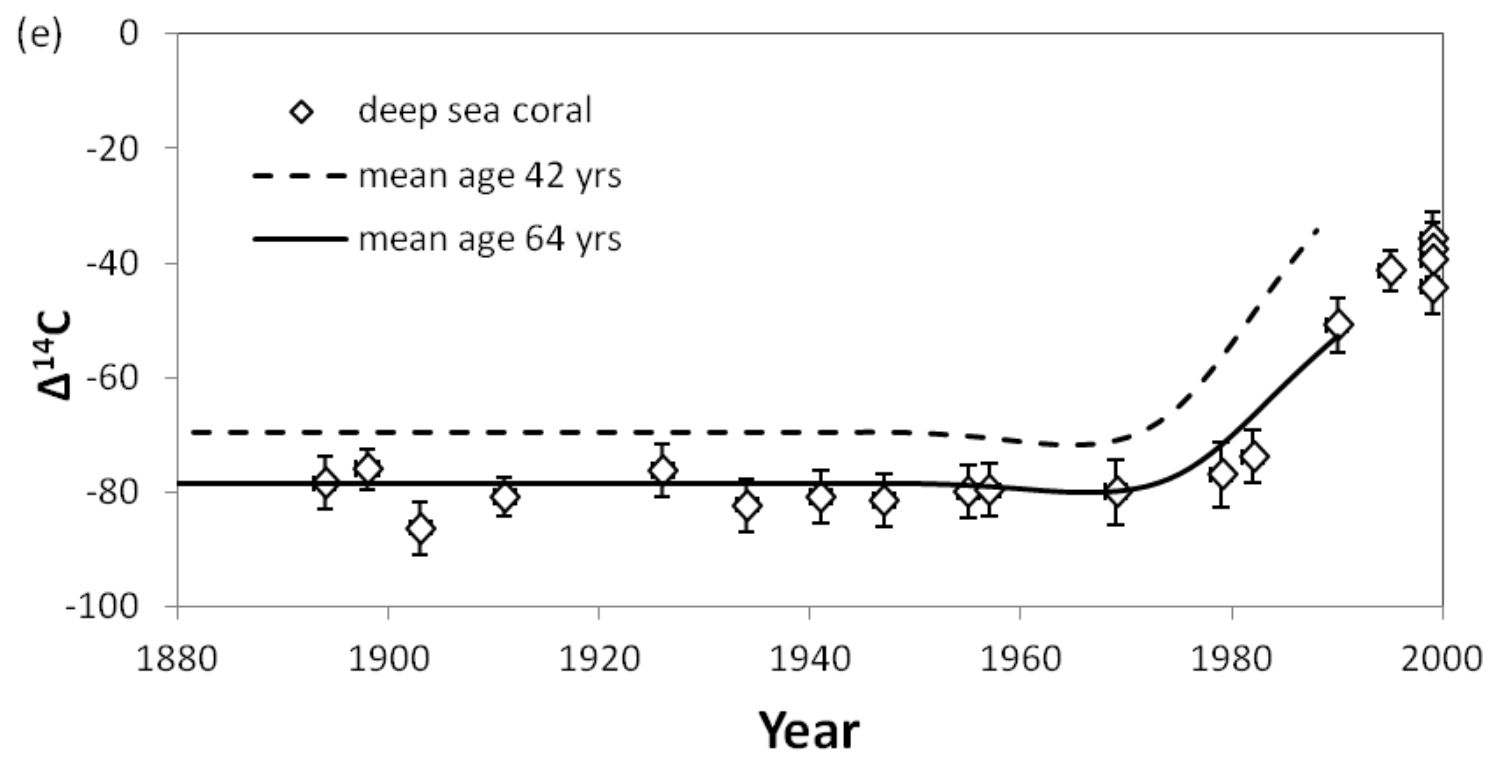

Figure 3.5 (continued) 

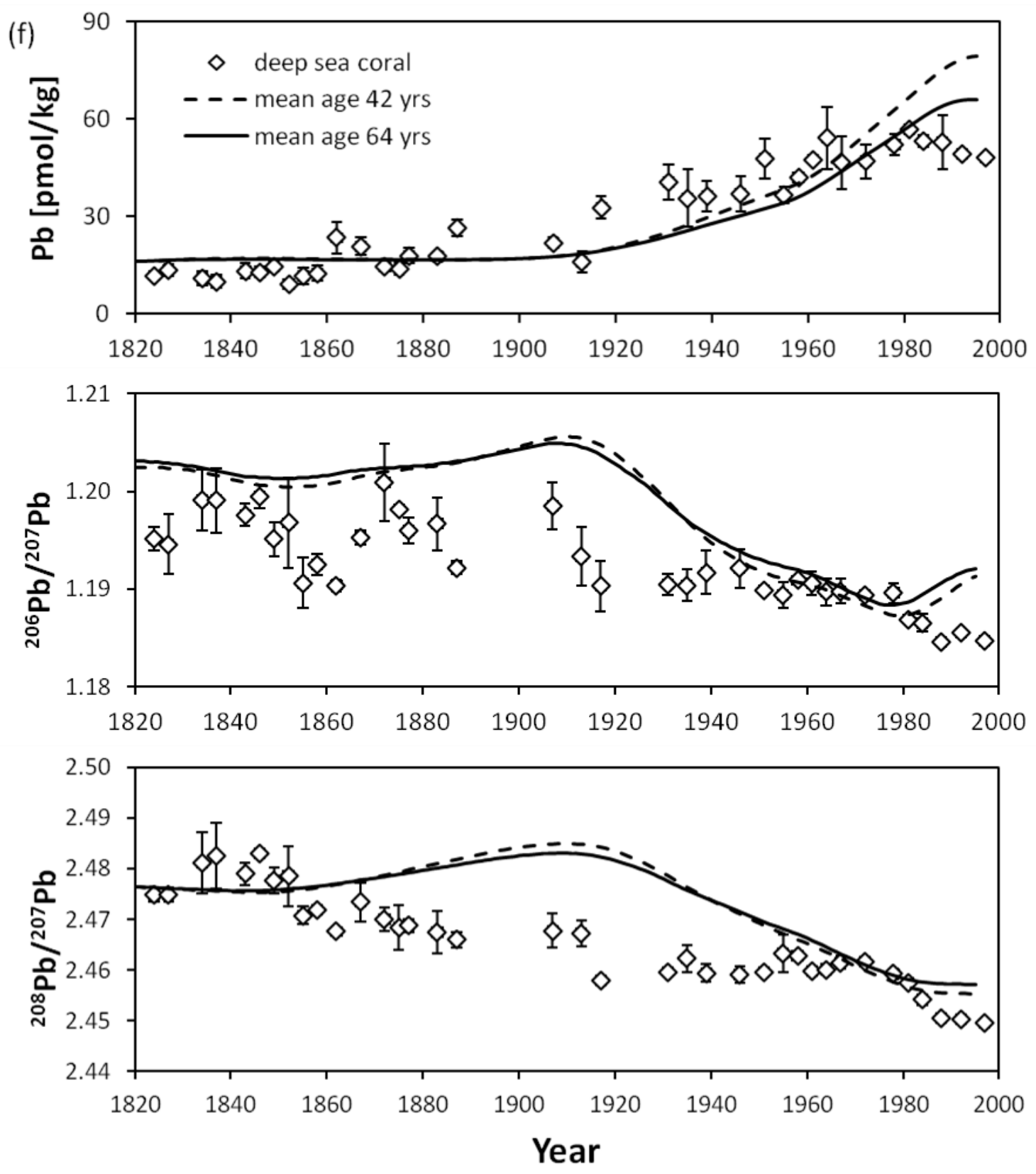

Figure 3.5 (continued) 

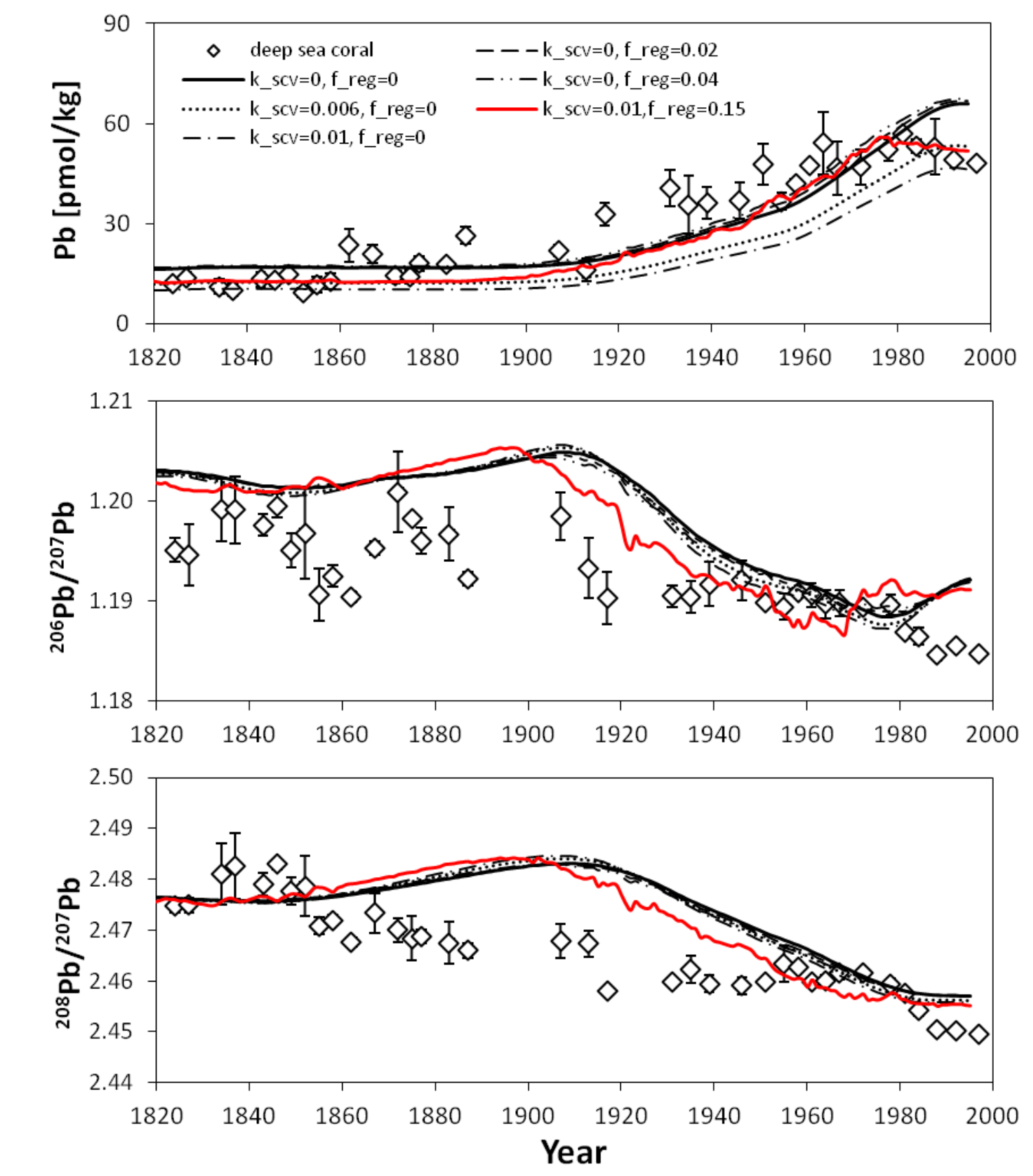

Figure 3.6 Predictions for $\mathrm{Pb}$ concentrations and $\mathrm{Pb}$ isotope ratios using TTDs of mean age $=64$ years and width $=46$ years, with different particle scavenging rates (k_scv) and regeneration efficiencies (f_reg). 
Table 3.1 $\mathrm{Pb} / \mathrm{Ca}(\mathrm{nmol} / \mathrm{mol}),{ }^{206} \mathrm{~Pb} /{ }^{207} \mathrm{~Pb}$, and ${ }^{208} \mathrm{~Pb} /{ }^{207} \mathrm{~Pb}$ ratios in the deep-sea coral ALV-3701-8. The $2 \sigma$ for $\mathrm{Pb} / \mathrm{Ca}$ represents the triplicates standard deviation, and $2 \sigma$ for $\mathrm{Pb}$ isotope ratios represents internal statistics for 20 , ten second integrations via MC-ICPMS. Sample position is the distance $(\mathrm{cm})$ from the coral base to the sample.

\begin{tabular}{|c|c|c|c|c|c|c|c|c|}
\hline \multicolumn{2}{|c|}{ Sample position } & \multirow{2}{*}{ Year } & \multirow{2}{*}{$\mathrm{Pb} / \mathrm{Ca}$} & \multirow{2}{*}{$2 \sigma$} & \multirow{2}{*}{$206 / 207$} & \multirow{2}{*}{$2 \sigma$} & \multirow{2}{*}{$208 / 207$} & \multirow{2}{*}{$2 \sigma$} \\
\hline lower & upper & & & & & & & \\
\hline 5.7 & 6.1 & 1508 & 4.56 & 0.47 & 1.2093 & 0.0006 & 2.4971 & 0.0053 \\
\hline 18.1 & 18.4 & 1631 & 1.11 & 0.19 & 1.2070 & 0.0044 & 2.5102 & 0.0027 \\
\hline 29.0 & 29.3 & 1740 & 7.04 & 0.39 & 1.1987 & 0.0010 & 2.4818 & 0.0018 \\
\hline 37.3 & 37.6 & 1824 & 5.96 & 0.30 & 1.1943 & 0.0012 & 2.4762 & 0.0014 \\
\hline 37.6 & 38.0 & 1827 & 6.83 & 0.86 & 1.1938 & 0.0031 & 2.4763 & 0.0014 \\
\hline 38.3 & 38.6 & 1834 & 5.55 & 1.10 & 1.1983 & 0.0031 & 2.4825 & 0.0060 \\
\hline 38.6 & 38.9 & 1837 & 5.06 & 0.95 & 1.1983 & 0.0033 & 2.4840 & 0.0065 \\
\hline 39.2 & 39.5 & 1843 & 6.66 & 1.17 & 1.1968 & 0.0011 & 2.4805 & 0.0022 \\
\hline 39.5 & 39.8 & 1846 & 6.52 & 0.75 & 1.1995 & 0.0012 & 2.4830 & 0.0010 \\
\hline 39.8 & 40.1 & 1849 & 7.37 & 0.12 & 1.1951 & 0.0017 & 2.4777 & 0.0026 \\
\hline 40.1 & 40.4 & 1852 & 4.63 & 0.29 & 1.1968 & 0.0046 & 2.4786 & 0.0059 \\
\hline 40.4 & 40.7 & 1855 & 5.89 & 1.19 & 1.1906 & 0.0026 & 2.4708 & 0.0017 \\
\hline 40.7 & 41.0 & 1858 & 6.33 & 1.24 & 1.1925 & 0.0011 & 2.4719 & 0.0010 \\
\hline 41.0 & 41.5 & 1862 & 11.82 & 2.48 & 1.1904 & 0.0006 & 2.4676 & 0.0007 \\
\hline 41.5 & 42.0 & 1867 & 10.46 & 1.37 & 1.1953 & 0.0007 & 2.4734 & 0.0039 \\
\hline 42.0 & 42.5 & 1872 & 7.26 & 0.64 & 1.2009 & 0.0040 & 2.4700 & 0.0023 \\
\hline 42.5 & 42.7 & 1875 & 7.06 & 1.04 & 1.1982 & 0.0001 & 2.4684 & 0.0044 \\
\hline 42.7 & 43.0 & 1877 & 9.05 & 1.17 & 1.1960 & 0.0013 & 2.4688 & 0.0013 \\
\hline 43.0 & 43.5 & 1883 & 8.90 & 0.79 & 1.1967 & 0.0027 & 2.4675 & 0.0041 \\
\hline 43.5 & 44.0 & 1887 & 13.30 & 1.31 & 1.1922 & 0.0007 & 2.4660 & 0.0015 \\
\hline 45.0 & 45.4 & 1901 & 17.61 & 0.62 & 1.1908 & 0.0001 & 2.4596 & 0.0003 \\
\hline 45.4 & 45.6 & 1904 & 14.32 & 0.62 & 1.1945 & 0.0029 & 2.4607 & 0.0011 \\
\hline 45.6 & 45.9 & 1907 & 11.01 & 0.82 & 1.1985 & 0.0024 & 2.4678 & 0.0033 \\
\hline 45.9 & 46.1 & 1909 & 17.34 & 1.57 & 1.1901 & 0.0008 & 2.4591 & 0.0010 \\
\hline 46.1 & 46.6 & 1913 & 8.09 & 1.66 & 1.1933 & 0.0030 & 2.4673 & 0.0026 \\
\hline 46.6 & 46.9 & 1917 & 16.53 & 1.78 & 1.1903 & 0.0026 & 2.4580 & 0.0007 \\
\hline 48.0 & 48.3 & 1931 & 20.44 & 2.79 & 1.1905 & 0.0011 & 2.4597 & 0.0005 \\
\hline 48.3 & 48.8 & 1935 & 17.97 & 4.41 & 1.1904 & 0.0016 & 2.4623 & 0.0027 \\
\hline 48.8 & 49.1 & 1939 & 18.32 & 2.40 & 1.1917 & 0.0022 & 2.4594 & 0.0017 \\
\hline 49.5 & 49.8 & 1946 & 18.61 & 2.76 & 1.1921 & 0.0020 & 2.4591 & 0.0017 \\
\hline 50.0 & 50.3 & 1951 & 24.10 & 3.10 & 1.1899 & 0.0004 & 2.4597 & 0.0007 \\
\hline 50.3 & 50.8 & 1955 & 18.49 & 1.31 & 1.1894 & 0.0013 & 2.4633 & 0.0036 \\
\hline
\end{tabular}


Table 3.1 (continued)

\begin{tabular}{|c|c|c|c|c|c|c|c|c|}
\hline \multicolumn{2}{|c|}{ Sample position } & \multirow{2}{*}{ Year } & $\mathrm{Pb} / \mathrm{Ca}$ & $2 \sigma$ & $206 / 207$ & $2 \sigma$ & $208 / 207$ & $2 \sigma$ \\
\cline { 1 - 2 } lower & upper & & & & & & & \\
\hline \hline 50.8 & 51.0 & 1958 & 21.21 & - & 1.1909 & 0.0004 & 2.4628 & 0.0008 \\
51.0 & 51.3 & 1961 & 24.01 & - & 1.1906 & 0.0012 & 2.4598 & 0.0007 \\
51.3 & 51.6 & 1964 & 27.32 & 4.76 & 1.1897 & 0.0014 & 2.4601 & 0.0010 \\
51.6 & 52.0 & 1967 & 23.52 & 4.07 & 1.1898 & 0.0013 & 2.4615 & 0.0013 \\
52.0 & 52.6 & 1972 & 23.72 & 2.64 & 1.1894 & 0.0001 & 2.4617 & 0.0003 \\
52.6 & 53.1 & 1978 & 26.28 & 1.59 & 1.1896 & 0.0010 & 2.4593 & 0.0011 \\
53.1 & 53.3 & 1981 & 28.70 & - & 1.1869 & 0.0002 & 2.4576 & 0.0004 \\
53.3 & 53.7 & 1984 & 26.85 & 0.97 & 1.1865 & 0.0009 & 2.4542 & 0.0010 \\
53.7 & 54.1 & 1988 & 26.74 & 4.20 & 1.1846 & 0.0005 & 2.4505 & 0.0000 \\
54.1 & 54.5 & 1992 & 24.85 & - & 1.1855 & 0.0002 & 2.4503 & 0.0003 \\
54.5 & 55.0 & 1997 & 25.32 & - & 1.1847 & 0.0001 & 2.4495 & 0.0002 \\
\hline
\end{tabular}




\title{
Chapter 4
}

\section{History of the $\mathrm{Pb}$ and $\mathrm{Pb}$ isotopes of the surface Indian Ocean over the past $\sim 50$ years reconstructed from corals.}

\begin{abstract}
Although anthropogenic $\mathrm{Pb}$ emissions around the Indian Ocean have increased over past decades, no continuous record exists showing how they have changed the $\mathrm{Pb}$ in the Indian Ocean. In this chapter, $\mathrm{Pb}$ and $\mathrm{Pb}$ isotope ratios of the surface Indian Ocean were reconstructed for the last $\sim 50$ years using annually-banded corals collected from Chagos Archipelago, West Sumatra, and Strait of Singapore. In general, $\mathrm{Pb} / \mathrm{Ca}$ ratios in all corals increase in mid-1970s, but $\mathrm{Pb}$ isotope ratios in each coral evolve differently, showing that each region is affected by the $\mathrm{Pb}$ from different sources. In the Chagos region, a major source of $\mathrm{Pb}$ appears to be India's $\mathrm{Pb}$ emissions from vehicle gasoline combustion and coal burning. $\mathrm{Pb}$ in the Sumatra region seems to be largely affected by Indonesia's vehicle $\mathrm{Pb}$ emissions, but there are additional $\mathrm{Pb}$ inputs from other sources that could not be identified. The Strait of Singapore has complex sources of $\mathrm{Pb}$, and vehicle $\mathrm{Pb}$ emissions appear to have little impact compared to other industrial sources that probably
\end{abstract}


use coals and $\mathrm{Pb}$ ores from southern China, Indonesia, Malaysia, and Australia. High $\mathrm{Pb}$ isotope ratios found in this region might be caused by the isotope exchange between seawater and riverine particles, and local $\mathrm{Pb}$ sources in the Strait of Singapore may have considerable impact as well.

\subsection{Introduction}

There is a growing concern about pollution in the region of the Indian Ocean and adjacent countries, due to rapid population growth and urbanization in these regions. Pollutant emissions from fossil fuel burning and industrial processes (as well as biofuel and biomass burning) are increasing drastically, causing serious environmental degradation of these regions in many ways (e.g. Balasubramanian et al., 1999; 2011; Ramanathan et al., 2005). For example, South Asian emissions of fossil fuel $\mathrm{SO}_{2}$ and black carbon (BC) increased $\sim 6$-fold since 1930 (Ramanathan et al., 2005), resulting in

thick $(\sim 3 \mathrm{~km})$ layers of aerosols extending from South and Southeast Asia to the northern Indian Ocean, known as Atmospheric Brown Clouds (ABCs) (Lelieveld et al., 2001; Ramanathan et al., 2001b). The ABCs are known to absorb and scatter solar radiation effectively primarily because of the high $\mathrm{BC}$ content, contributing to the changes in the climate and hydrological cycle of this region (e.g. surface cooling, reduction of evaporation and rainfall) (Hulme et al., 1998; Liepert et al., 2004; Ramanathan et al., 2001a; 2005; Rosenfeld, 2000). 
Lead $(\mathrm{Pb})$ is one of the most hazardous heavy metals because of its toxic effects upon human's health and environment. Pb emissions have been dramatically increased as a result of human activities, particularly since the 1920s because of its use as an antiknocking agent in gasoline (Nriagu, 1979; Nriagu and Pacyna, 1988). Although leaded gasoline was phased out three decades ago in most of the developed countries, many developing countries around the Indian Ocean have used leaded gasoline until recently. In addition, there are other $\mathrm{Pb}$ emission sources that are growing with economic development, such as smelting, mining, coal burning, and waste incineration (Nriagu and Pacyna, 1988). Therefore, $\mathrm{Pb}$ pollution is a serious problem in this region, e.g., it was found that in India more than 50\% of the children aged below 12 in Delhi and Kolkata had blood-Pb concentrations higher than the World Health Organization standard $(10 \mu \mathrm{g}$ $\left.\mathrm{dl}^{-1}\right)$ in 1999 (George, 1999).

The increased anthropogenic $\mathrm{Pb}$ emissions probably contaminated the Indian Ocean, as suggested by high $\mathrm{Pb}$ concentrations found in coastal seawaters off India (Rejomon et al., 2010) and marine aerosols collected over the Indian Ocean (Balasubramanian et al., 2011; Chester et al., 1991; Witt et al., 2006). However, no data exist showing how the anthropogenic $\mathrm{Pb}$ inputs have changed the $\mathrm{Pb}$ and $\mathrm{Pb}$ isotopes in the surface Indian Ocean over time. Knowing the surface boundary condition is essential to understand the distribution of $\mathrm{Pb}$ and $\mathrm{Pb}$ isotopes in the water column and to assess the impact of anthropogenic $\mathrm{Pb}$ upon the ocean. Moreover, understanding major sources and processes controlling $\mathrm{Pb}$ in the ocean is critical for environmental pollution management and modeling the behaviors of other pollutants similar to $\mathrm{Pb}$. 
The goal of this study is to reconstruct the history of $\mathrm{Pb}$ concentrations and isotope ratios of the surface Indian Ocean, and determine how they have responded to the increased anthropogenic $\mathrm{Pb}$ emissions from various sources. For the purpose of this study, we used annually-banded corals collected from three locations in the Indian Ocean: Chagos Archipelago, Western Sumatra, and Strait of Singapore. The Chagos Archipelago is in the central Indian Ocean, and Sumatra and Strait of Singapore are on the eastern margin of the Indian Ocean (Figure 4.1). Annually-banded corals have been previously utilized for Pb reconstructions in the western North Atlantic (Kelly et al., 2009; Reuer, 2002; Shen and Boyle, 1987), Caribbean (Desenfant et al., 2006; Dodge and Gilbert, 1984), and western Pacific (Inoue and Tanimizu, 2008; Inoue et al., 2006), and the inferred $\mathrm{Pb}$ trends were found to agree with historical emission estimates and terrestrial proxy records.

\subsection{Materials and Methods}

\subsubsection{Sample collection and analysis}

The first coral core (core GIM) was collected in February 1996 in the lagoon of Peros Banhos Atoll (Figure 4.1A, $71.5^{\circ} \mathrm{E}, 5.2^{\circ} \mathrm{S}$ ) by Miriam Pfeiffer's group (RWTH Aachen University, Aachen, Germany). The Peros Banhos Atoll is the most northwesterly located atoll comprising the Chagos Archpelago, and this sample will be referred as Chagos coral hereafter. The coral core was derived from a Porites solida colony living in a water depth of $3 \mathrm{~m}$ in a channel between Lle Diamant and Grand Ile Mapou, where tidal currents afford good water exchange with the open ocean (Pfeiffer et 
al., 2009). After collection, the core was washed with freshwater, air dried, and then cut into $5 \mathrm{~mm}$ thick slabs. The slabs were cleaned in an ultrasonic bath with de-ionized water for $15 \mathrm{~min}$ and then oven dried at $40^{\circ} \mathrm{C}$. After the initial analysis by Pfeiffer's group, the sample was stored in a plastic wrap in a dry condition until being shipped to MIT. The Xray image of the core shows very distinct annual density bands, and the coral chronologies were assigned by Pfeiffer's group based on these density bands and the seasonal cycle in $\mathrm{Sr} / \mathrm{Ca}$ ratios measured in the coral (Pfeiffer et al., 2009). This coral is relatively short $(\sim 30 \mathrm{~cm})$ and covers the time period of 1973-1996. The top layer (from 1996) was not analyzed for $\mathrm{Pb}$ to avoid a possible contamination by the remnant of organic coral tissues living on the top.

The second coral was collected from the northwest coast of Pulau Simeulue (Figure 4.1B, site LKP-A located at $97.76^{\circ} \mathrm{E}, 2.86^{\circ} \mathrm{N}$ ), which is located on the west of Sumatra, Indonesia, by Aron Meltzner's and Kerry Sieh's group at California Institute of Technology (Joint group with LIPI, Indonesia). The coral core was collected from a Porites sp. microatoll, which died in 2004 because of the Sumatra-Andaman earthquake. After cutting the coral into slabs, the annual bands of the coral were X-rayed and the chronologies were determined by analyzing ${ }^{230} \mathrm{Th}$ in critical points (Meltzner et al., 2010) and counting bands between those critical points. The coral used for this research (LKP1; referred to Sumatra coral hearafter) spans from 1945 to 2004.

The third coral was collected from a Porites lutea colony near the Pulau Jong (Jong Island) that is located in the south of Singapore (Figure $4.1 \mathrm{C} ; 103^{\circ} 47^{\prime} \mathrm{E}, 1^{\circ} 12^{\prime} \mathrm{N}$ ), in December 2010. After collection, the coral was cut into slabs and cleaned with de- 
ionized water, and then dried in a clean bench. The coral has visible brown bands that coincide with high luminescence bands when examined under UV light. It has been known that bright luminescent bands are due to incorporation of terrestrial humic acids into the coral skeleton (Isdale, 1984; Lough, 2011a; b; Nyberg et al., 2007, Scoffin et al., 1989), and thus, the brown bands of the Jong Island coral seem to be formed in summer when high river runoff delivers a large amount of organic materials into the ocean. The coral chronologies were determined based on these bands, spanning from 1960 to 2010. The top layer of the core (from 2010) was not analyzed due to potential contamination from organic tissues.

At MIT, all the corals were physically cleaned, and then approximately 100mg of samples were cut from each band of the corals using a diamond-coated cutting wheel and a Dremel tool. Then, the samples were chemically cleaned and analyzed for $\mathrm{Pb}, \mathrm{Ca}$, and $\mathrm{Pb}$ isotopes $\left({ }^{204} \mathrm{~Pb},{ }^{206} \mathrm{~Pb},{ }^{207} \mathrm{~Pb},{ }^{208} \mathrm{~Pb}\right)$. Chemical cleaning and analytical methods are same as the methods described in the Chapter 3. $\mathrm{Pb} / \mathrm{Ca}$ ratios were measured in triplicate, and samples with the lowest $\mathrm{Pb} / \mathrm{Ca}$ ratios among the triplicates were chosen to measure the $\mathrm{Pb}$ isotopes because these are likely to be least contaminated during sample processing.

\subsubsection{Regional setting}

All corals used in this study lie in the tropical Indian Ocean, near the equator. The equatorial regime of the Indian Ocean lacks the sustained equatorial easterly winds that are observed in the Atlantic and Pacific Oceans (Tomczak and Godfrey, 2003). Instead, 
winds and circulation of the tropical Indian Ocean vary seasonally and inter-annually due to the influence of seasonal monsoons and El Niño-Southern Oscillation (ENSO) (Godfrey, 1996; Potemra and Lukas, 1999; Schott et al., 2009).

Winds over the Chagos Archipelago are weak and generally from the north to northwest during boreal winter monsoon (October to April) (Schott et al., 2009; Sheppard et al., 1999). The Chagos then lies in the intertropical convergence zone (ITCZ) and precipitation is high. During the rest of the year, the southeast trade winds blow strongly. The current system of the equatorial Indian Ocean also changes semiannually. During the boreal summer monsoon, the westward flowing South Equatorial current (SEC) becomes strong centering around $10^{\circ} \mathrm{S}$, and the eastward flowing South Equatorial Countercurrent (SECC) develops during the winter monsoon (Schott et al., 2009).

The semiannually reversing equatorial flows also affect the currents off Sumatra. During winter monsoon, the South Java Current (SJC) flows southeastward and this flow becomes strong in May and November when westerly wind bursts formed during the monsoon transition (Quadfasel and Cresswell, 1992; Sprintall et al., 1999). On the other hand, the SJC flows as a westward current along the coast of Java during the summer monsoon (May-October). During this season, upwelling occurs along the coast off Sumatra, when winds blow northwestward parallel to the coast and Ekman transports are directed offshore (Schott et al., 2002).

In the Strait of Singapore, where the Jong Island coral was collected, winds blow from northeast to southeast in the winter (Nov-Mar) and from south-southwest to northnortheast in the summer. Geographically, the Strait of Singapore is connected to the 
South China Sea on the east, Java Sea and the northeastern Indian Ocean through the Malacca Strait on the west. Its current system is controlled by seasonal monsoons as the hydrodynamic pressure gradient between the two ends of the strait reverse seasonally; the net drift in the Strait of Singapore flows westward during winter monsoon and eastward during summer monsoon (Chen et al., 2005).

\subsubsection{History of $\mathrm{Pb}$ emissions from countries around the Indian Ocean}

In order to find out the major sources contributed to the anthropogenic $\mathrm{Pb}$ in the Indian Ocean, we examined the $\mathrm{Pb}$ emission histories from the countries around the Indian Ocean. In the North Atlantic Ocean, the dominant source of anthropogenic $\mathrm{Pb}$ was found to be automobile exhausts (use of leaded gasoline), and the $\mathrm{Pb} / \mathrm{Ca}$ ratios analyzed in Bermuda corals closely follow the trend of $\mathrm{Pb}$ emissions from leaded gasoline consumption in North America and Europe (Kelly et al., 2009; Reuer, 2002; Shen and Boyle, 1987). On the other hand, coal combustion has been suggested as an important source of $\mathrm{Pb}$ to the Pacific region (Inoue and Tanimizu, 2008), and the same may be true for the Indian Ocean. Therefore, we estimated the amount of $\mathrm{Pb}$ emitted from automobile exhausts and coal burning in the countries around the Indian Ocean, particularly those which have high GDP and/or are close to the sample collection area.

Historical $\mathrm{Pb}$ emissions from automobile exhausts (Figure 4.2) were estimated using the following formula:

$$
\mathrm{E}_{\text {gasoline }}=\mathrm{Q}_{\text {gasoline }} \mathrm{x} \mathrm{K}_{\mathrm{Pb}} \mathrm{x}(\mathrm{Pb})_{\text {gasoline }} \mathrm{x} \mathrm{EF}
$$


where $\mathrm{E}_{\text {gasoline }}$ is the $\mathrm{Pb}$ emissions from gasoline ( $\mathrm{t}$ ), $\mathrm{Q}_{\text {gasoline }}$ is the road sector gasoline consumption (kilotons of oil), $\mathrm{K}_{\mathrm{Pb}}$ is the $\mathrm{Pb}$ content in gasoline used in corresponding years ( $\mathrm{g} \mathrm{Pb} /$ liter of oil), and $\mathrm{EF}$ is the emission factor, which is the proportion of $\mathrm{Pb}$ in petrol emitted to the air. EF was assumed to be $76 \%$ (Li et al., 2012), and for the unit conversion, $0.74 \mathrm{~kg} \mathrm{l}^{-1}$ was used for the density of gasoline (usually ranging $0.71-0.77 \mathrm{~kg}$ $\left.1^{-1}\right)$. Q gasoline data for the years 1971-2009 were available from World Bank database (http://data.worldbank.org), and (Pb) gasoline was taken from literature (e.g. Hilton, 2006) or assumed based on the environmental regulations implemented in each country. If both leaded and unleaded gasoline were in use, market share of the leaded gasoline was taken into account. For India and Indonesia, where leaded gasoline was phased out on a cityscale, market share of the leaded gasoline was calculated based on the number of cars (India) or the population (Indonesia) of the cities that were using leaded gasoline. The changes of the gasoline $\mathrm{Pb}$ content in each country are listed below. Note that some are listed for the maximum allowable lead content in gasoline, and the average $\mathrm{Pb}$ content of the gasoline that was actually used might be lower. Also, Figure 4.2 (data in Table 4.6) was generated assuming no transition time although some time may have taken until $\mathrm{Pb}$ emissions actually decrease after low or unleaded gasoline was introduced in a certain year.

(a) Australia: $\mathrm{Pb}$ content in petrol was $0.84 \mathrm{~g} / \mathrm{l}$ until 1984 , and it was continuously decreased to $0.10 \mathrm{~g} / \mathrm{l}$ in 1994 (Hilton, 2006). Leaded gasoline was completely phased out in 2002, but the data for the lead content in petrol during 1995-2001 is unavailable. 
(b) China: Gasoline with $\mathrm{Pb}$ content $0.7 \mathrm{~g} / \mathrm{l}$ was used in China until the phase-out of leaded gasoline started in the 1990s in several major cities (Xu et al., 2012). The Chinese government says that the entire country stopped using leaded gasoline on July 1 , 2000. Vehicle Pb emission data for 1990-2009 are from Li et al. (2012).

(c) India: Before 1994, the $\mathrm{Pb}$ content in petrol in India reached $0.56 \mathrm{~g} / \mathrm{l}$. Leaded gasoline phaseout was initiated in June 1994, when low-leaded petrol (0.15 g/l) was introduced to four metropolitan cities (Delhi, Mumbai, Kolkata, Chennai). Next year, unleaded petrol $(0.013 \mathrm{~g} / \mathrm{l})$ was introduced in these four cities, and then by state capitals and other major cities from June 1998, with coverage of the entire country by April 2000 (Singh and Singh, 2006).

(d) Indonesia: The lead content in gasoline was 0.7 or $0.84 \mathrm{~g} / \mathrm{l}$ in 1987 (Mukai et al., 1993), and it was between 0.36-0.6 g/l in 1993-1995 (UNEP Chemical, 1998), but it is unknown when they reduced the lead content in gasoline between 1987 and 1993. Gasoline with $\mathrm{Pb}$ content of $\sim 0.15 \mathrm{~g} / \mathrm{l}$ was in use in 2000 , but it is also unknown when Indonesia decreased the gasoline $\mathrm{Pb}$ content between 1995 and 2000. In Jakarta, a leadphase out program was inaugurated in July 2001, replacing low-leaded gasoline $(0.15 \mathrm{~g} / \mathrm{l})$ with unleaded $(0.016 \mathrm{~g} / \mathrm{l})$ gasoline. Until 2005, the phase-out program was implemented only in several cities (e.g. Bali in 2002 and Batam in 2003), and Indonesia finally implemented complete lead phase out in late 2006 (Hirota, 2006; Hosono et al., 2011, Kondo et al., 2007).

(e) Malaysia: In 1984, the lead content in gasoline was reduced from $0.84 \mathrm{~g} / 1$ to $0.4 \mathrm{~g} / \mathrm{l}$, and then to $0.15 \mathrm{~g} / \mathrm{l}$ in 1990 . Unleaded gasoline was first introduced in Malaysia 
in 1992, but both leaded and unleaded gasoline were used in 1990s until leaded gasoline was completely phased out in 2000 (Afroz et al., 2003; Hilton, 2006).

(f) Saudi Arabia: Pb content in petrol used in Saudi Arabia was 0.84 g/l until 1984, and it was reduced to $0.6 \mathrm{~g} / \mathrm{l}$ in 1996 and to $0.4 \mathrm{~g} / \mathrm{l}$ in 1994 (Hilton, 2006). Leaded gasoline was phased out in 2003, but the data for the lead content in petrol during 19952003 is unavailable.

(g) Singapore: Before 1980, Singapore's Pb content in gasoline was $0.8 \mathrm{~g} / \mathrm{l}$ and was reduced to $0.6 \mathrm{~g} / \mathrm{l}$ in 1981 . Another reduction took place in 1983 , where the $\mathrm{Pb}$ content was reduced to $0.4 \mathrm{~g} / \mathrm{l}$. In 1987 , the $\mathrm{Pb}$ content was further reduced to $0.15 \mathrm{~g} / \mathrm{l}$, and leaded gasoline was finally phased out in 1997 (Singapore Ministry of Environment and Water Resources, 1987-2000).

(h) South Africa: Before 1986, South Africa permitted high concentrations of lead in petrol $(0.836 \mathrm{~g} / \mathrm{l})$. In 1986 , the maximum permissible concentration of lead in petrol was reduced to $0.6 \mathrm{~g} / \mathrm{l}$, and further reduced to $0.4 \mathrm{~g} / \mathrm{l}$ in 1989 . In 1996 , unleaded petrol was introduced in the country for the first time, but unleaded petrol constituted only around $30 \%$ of the market share until 2002. Leaded petrol was eventually taken off the market in 2006 (Grobler et al., 1992; Mathee et al., 2006).

(i) Thailand: In 1992, the maximum lead content in gasoline was reduced from $0.84 \mathrm{~g} / \mathrm{l}$ to $0.4 \mathrm{~g} / \mathrm{l}$. Unleaded gasoline was sold from 1991, which comprised about $30 \%$ of the market share in 1993. The lead content in petrol was further reduced to $0.013 \mathrm{~g} / \mathrm{l}$ in 1996, which is categorized as unleaded gasoline (Gerstein et al., 2006). 
Coals are used in various industries and also domestically for cooking and heating, but most of the coals are used to generate electricity (e.g. Nriagu and Pacyna, 1988). In this study, the amount of $\mathrm{Pb}$ emitted from coals used in power plants were estimated based on the following equation:

$$
\mathrm{E}_{\text {coals }}=\mathrm{P}_{\text {coals }} \times \mathrm{C} \mathrm{x}(\mathrm{Pb})_{\text {coals }} \times \mathrm{EF}
$$

where $\mathrm{E}_{\text {coals }}$ is $\mathrm{Pb}$ emissions from coal combustion ( $\left.\mathrm{t}\right), \mathrm{P}_{\text {coals }}$ is the electricity produced from coal sources ( $\mathrm{kWh}$, data available from WorldBank database), $\mathrm{C}$ is the amount of coals used to generate $1 \mathrm{kWh}$ electricity $(\mathrm{kg}),(\mathrm{Pb})_{\text {coals }}$ is $\mathrm{Pb}$ content in coals $(\mathrm{g} \mathrm{Pb} / \mathrm{kg}$ coal), and $\mathrm{EF}$ is the emission factor. C was assumed to be $0.472 \mathrm{~kg}$ per $\mathrm{kWh}$ (U.S. Energy Information Administration, www.eia.gov), although it may vary depending on $\mathrm{Pb}$ content in coals and the efficiency of the power plant. The $\mathrm{Pb}$ content of coals also has a large range ( 3 to over $300 \mathrm{mg} \mathrm{kg}^{-1}$ ) depending on source region, but in this study, $15 \mathrm{mg}$ $\mathrm{kg}^{-1}$ was used for $(\mathrm{Pb})_{\text {coals, }}$ which is an average of the coals from Australia, India, Indonesia, and China (Diaz-Somoano et al., 2009; Li et al., 2012; Masto et al., 2007). EF also varies depending on the types of coal-burning stoves used at the power plants, and was assumed to be $80 \%$ in this study (Li et al., 2012). Coal combustion devices used for other industrial purposes or domestic use have no lead removal devices (i.e. dust removal and flue gas desulfurization devices), and the emission efficiencies will be higher. Historical $\mathrm{Pb}$ emissions due to coal burning are shown in Figure 4.3 (data in Table 4.7).

\subsection{Results}

4.3.1. $\mathrm{Pb} / \mathrm{Ca}$ ratios of the corals 
$\mathrm{Pb} / \mathrm{Ca}$ ratios are lowest in the Sumatra coral and highest in the Jong coral (Figures 4.4-4.6). $\mathrm{Pb} / \mathrm{Ca}$ ratios of the Chagos coral were similar to the Sumatra coral until $\sim 1975$, but became similar to the Jong coral in 1990s. We cannot infer the seawater $\mathrm{Pb}$ concentrations directly from the coral $\mathrm{Pb} / \mathrm{Ca}$ ratios because each coral may have a different partition coefficient $\left(\mathrm{D}_{\mathrm{p}}=(\mathrm{Pb} / \mathrm{Ca})_{\text {coral }}(\mathrm{Pb} / \mathrm{Ca})_{\text {seawater }}\right)$. A range of $2.4-3.7$ has been reported for the $\mathrm{D}_{\mathrm{p}}$ of $\mathrm{Pb}$ for various genus and species of corals (Shen and Boyle, 1987; Kelly et al., 2009). All the corals analyzed in this study are Porites species, but $\mathrm{D}_{\mathrm{p}}$ can also vary within one genus (Shen and Boyle, 1987). However, $\mathrm{Pb} / \mathrm{Ca}$ ratios of the Jong coral is more than 5-fold higher than those in Sumatra and early Chagos data, which is larger than the difference that we expect for variable $D_{p}$ only. Thus, it seems that the Jong Island region has higher $\mathrm{Pb}$ concentrations than the other two regions, probably because it is closer to the land.

A seawater sample was collected near the Jong Island in 2010 during coral sampling, and its $\mathrm{Pb}$ concentration was measured to be $67.2 \mathrm{pmol} \mathrm{kg}^{-1}$. Comparing this to the coral $\mathrm{Pb} / \mathrm{Ca}$ ratio in 2009 (no coral data from 2010), the partition coefficient $\left(\mathrm{D}_{\mathrm{p}}\right)$ of $\mathrm{Pb}$ in Jong Island coral is calculated as 3.8. Based on this $\mathrm{D}_{\mathrm{p}}$, the highest seawater $\mathrm{Pb}$ concentration appeared in the Jong Island region in 2002-2003 is estimated to be $\sim 120$ pmol kg-1 . For the Sumatra and Chagos coral regions, no comparable seawater $\mathrm{Pb}$ concentration data are available.

Interestingly, $\mathrm{Pb} / \mathrm{Ca}$ ratios in all corals start to increase in the mid-1970s. The $\mathrm{Pb} / \mathrm{Ca}$ ratio in the Chagos coral starts to rise in $\sim 1975(\sim 5 \mathrm{nmol} / \mathrm{mol})$ until it reaches $\sim 11$ $\mathrm{nmol} / \mathrm{mol}$ in 1979 , and after a slight decrease in 1980-1984, the ratio increases drastically 
after 1985, with 3.5-fold increase between 1985 and 1994 (Figure 4.3). In the Sumatra coral, $\mathrm{Pb} / \mathrm{Ca}$ ratios stay relatively constant at $4.3 \pm 0.3 \mathrm{nmol} / \mathrm{mol}$ between 1950 and 1975 , and then the ratio starts to increase after 1977. There is a slight decrease in 1984-1997, and the ratio increases to $\sim 9 \mathrm{nmol} / \mathrm{mol}$ in 2004 (Figure 4.4). For the Jong Island coral, it is difficult to pinpoint the year the $\mathrm{Pb} / \mathrm{Ca}$ starts to increase because the ratio fluctuates a lot (Figure 4.5). Nevertheless, $\mathrm{Pb} / \mathrm{Ca}$ ratios of the Jong Island coral between 1980 and 2000 are higher (avg. 32.3 \pm 3.8 ) than those in 1963-1980 (avg. 23.4 \pm 2.6 ), and excluding the low $\mathrm{Pb} / \mathrm{Ca}$ in 1979, one may conclude that the $\mathrm{Pb} / \mathrm{Ca}$ ratios increased from 1974.

These results indicate that $\mathrm{Pb}$ contamination of the surface Indian Ocean began to occur at a significant level from the mid-1970s in the Indian Ocean. The contamination effect seems to be most prominent in the Chagos coral region where $\mathrm{Pb} / \mathrm{Ca}$ ratios increased most dramatically, probably because of the low background $\mathrm{Pb}$ in that region due to its remote location. A similar result has been found in a preliminary study by Shen and Boyle (1987), where they measured $\mathrm{Pb} / \mathrm{Ca}$ ratios in a coral from Mauritius. They reported only 6 data points spanning from 1968-1978, and increased $\mathrm{Pb} / \mathrm{Ca}$ ratios are found in the samples from 1974 and 1978 . However, because of the unusually high $\mathrm{Pb} / \mathrm{Ca}$ values of these two samples ( 3.5 fold higher than the samples from 1968-1972), the authors cautioned us to be aware of the possible influence of refractory phase contaminant $\mathrm{Pb}$ that was not removed during cleaning.

\subsection{2. $\mathrm{Pb}$ isotope ratios of the corals}


The evolution of $\mathrm{Pb}$ isotope ratios in three corals appears different from each other. This difference in $\mathrm{Pb}$ isotope ratios points out that the three sampling regions were influenced by different sources of $\mathrm{Pb}$, and the isotope composition of the $\mathrm{Pb}$ affecting each location also changed over time.

$\mathrm{Pb}$ isotope ratios of the Chagos coral are lower than those in the Sumatra and Jong corals, ranging from $1.138-1.154$ for ${ }^{206} \mathrm{~Pb} /{ }^{207} \mathrm{~Pb}$ and $2.414-2.429$ for ${ }^{208} \mathrm{~Pb} /{ }^{207} \mathrm{~Pb}$ (Figure 4.4). Both isotope ratios decrease from 1973 to 1985 , and increase after 1985 to $\sim 1.153$ for ${ }^{206} \mathrm{~Pb} /{ }^{207} \mathrm{~Pb}$ and 2.415 for ${ }^{208} \mathrm{~Pb} /{ }^{207} \mathrm{~Pb}$ in 1990 and retain relatively high isotope ratios until 1994. This change in the $\mathrm{Pb}$ isotope ratios around 1985 coincides with the rapid increase in $\mathrm{Pb} / \mathrm{Ca}$ of the Chagos coral after 1985. This indicates that the main source of anthropogenic $\mathrm{Pb}$ affecting this region changed around 1985, from sources with low isotope ratios to the ones with higher isotope ratios.

In the western Sumatra coral, rather constant isotope ratios are found between 1950 and $1973,{ }^{206} \mathrm{~Pb} /{ }^{207} \mathrm{~Pb}$ around 1.18 and ${ }^{208} \mathrm{~Pb} /{ }^{207} \mathrm{~Pb}$ around 2.47 , (Figure 4.5). After 1973 , both isotope ratios generally decrease to $1.147\left({ }^{206} \mathrm{~Pb} /{ }^{207} \mathrm{~Pb}\right)$ and $2.440\left({ }^{208} \mathrm{~Pb} /{ }^{207} \mathrm{~Pb}\right)$ in 2004. The timing of the isotope decrease leads the $\mathrm{Pb} / \mathrm{Ca}$ increase by a few years $(\sim 4$ yrs). Thus, it seems that the western Sumatra region was affected by $\mathrm{Pb}$ with low isotope ratios from 1973, but the amount of the $\mathrm{Pb}$ input became significant enough to increase the $\mathrm{Pb} / \mathrm{Ca}$ ratios $\sim 4$ years later.

As seen in the $\mathrm{Pb} / \mathrm{Ca}$ ratios, $\mathrm{Pb}$ isotope ratios of the Jong Island coral also exhibit high variability (Figure 4.6). The $\mathrm{Pb}$ isotope ratios between the 1960s and early 1970s are similar to those in the Sumatra coral during the same period. Then, both isotope ratios 
generally increase in the late 1980s, which implies that the anthropogenic $\mathrm{Pb}$ affecting this area contain relatively high isotopic ratios. However, the year of the highest $\mathrm{Pb} / \mathrm{Ca}$ ratio (2002-2003) does not correspond to the year when the highest $\mathrm{Pb}$ isotope ratios appear (1997), although it matches the year when the second highest Pb isotopes peak appears. This implies that there are multiple sources of $\mathrm{Pb}$ contaminating this region and their isotope composition probably has changed over time.

\subsection{Discussion}

4.4.1. $\mathrm{Pb}$ in the Chagos coral and its potential sources

Chagos coral $\mathrm{Pb} / \mathrm{Ca}$ ratios increase rapidly from 1984-1985. Given the prevailing wind direction, it is most likely that anthropogenic $\mathrm{Pb}$ in this area originated from South Asia. The largest Pb-emitting country in South Asia is India (Figures 4.2 and 4.3), which has the largest population and GDP in South Asia. The number of vehicles in India started to increase from the early-1980s, and $\mathrm{Pb}$ emissions from the automobile exhausts also increased rapidly from then (Figure 4.2). In addition, coal-based power generation in India has grown much over the past three decades (Figure 4.3), burning millions of tons of coal annually (Lelieveld et al., 2001; Ramanathan et al., 2001b). Moreover, Indian coals are known to have high ash content (24-45\%) and higher $\mathrm{Pb}$ concentration than other coals, e.g. Australian coals (Masto et al., 2007), and the amount of $\mathrm{Pb}$ emitted from coal burning is comparable to that from leaded gasoline exhausts in India.

Chagos coral $\mathrm{Pb} / \mathrm{Ca}$ seems to be well correlated $\left(\mathrm{r}^{2}=0.87\right)$ with the total $\mathrm{Pb}$ emissions (sum of vehicle $\mathrm{Pb}$ emissions and coal $\mathrm{Pb}$ emissions) from India when a $1.5 \mathrm{yr}$ 
lag time is assumed between $\mathrm{Pb}$ emission and the coral calcification (Figure 4.7), which agrees with the residence time of $\mathrm{Pb}$ in the oligotrophic ocean surface (e.g. Bacon et al., 1976; Nozaki et al., 1976). Thus, the increase in the Chagos coral $\mathrm{Pb} / \mathrm{Ca}$ appears to be mostly affected by gasoline- $\mathrm{Pb}$ emissions and coal burning from India. Total $\mathrm{Pb}$ emission from India shows a peak around 1993, but unfortunately, we cannot see this peak in the Chagos coral $\mathrm{Pb} / \mathrm{Ca}$ data as it terminates in 1994 (Figure 4.2). We should note that there are other $\mathrm{Pb}$ sources that have been identified in India: $\mathrm{Pb}$ mining and smelting, effluents from $\mathrm{Pb}$ battery-recycling plants, $\mathrm{Pb}$-based paints and pigments, ceramic pottery glazes and $\mathrm{Pb}$-containing cosmetics and folk medicines (Tandon, 1999) and there could be additional supply of $\mathrm{Pb}$ to the Chagos region from other countries in South Asia and Southeast Asia, and also possibly from Australia (during summer monsoon).

The $\mathrm{Pb}$ isotope ratios in the Chagos coral are in the same range as the $\mathrm{Pb}$ in aerosols collected from India in 1995 (Bollhöfer and Rosman, 2001), but are higher than the aerosols from Sri Lanka, Thailand, Indonesia, and in Australia in 1990s (Bollhöfer and Rosman, 2000; 2001; Mukai et al., 1993), supporting that the Pb emitted from India is a main contributor of the $\mathrm{Pb}$ in the Chagos region (Figure 4.8). The $\mathrm{Pb}$ isotope ratios of the Chagos coral appear close to the mixing line of Broken Hill type $\mathrm{Pb}$ ores and Mississippi Valley type $\mathrm{Pb}$ ores (Figure 4.8), which are the $\mathrm{Pb}$ ores that the world's two largest alkyllead suppliers, Associated Octel (BH type $\mathrm{Pb}$ ) and Ethyl Corp. (MV type $\mathrm{Pb}$ ) used mainly to make their products (Bollhöfer and Rosman, 2000). This implies that leaded gasoline combustion is probably the major source of $\mathrm{Pb}$ in this region. However, the Chagos coral $\mathrm{Pb}$ isotopes have slightly higher ${ }^{208} \mathrm{~Pb} /{ }^{206} \mathrm{~Pb}$ ratios than this mixing line, 
which may reflect the coal- $\mathrm{Pb}$ inputs as coals generally have high $\mathrm{Pb}$ (both ${ }^{208} \mathrm{~Pb} /{ }^{206} \mathrm{~Pb}$ and ${ }^{206} \mathrm{~Pb} /{ }^{207} \mathrm{~Pb}$ ) isotope ratios (Diaz-Somoano et al., 2009) (Figure 4.8). The Pb isotopic signatures of Indian coals are unknown, but the coals imported by India between 1988 and 2000 were mainly from Australia (69\%) and Indonesia (10\%) (COMTRADE, 2009), and mixing with the $\mathrm{Pb}$ from these coals can increase the $\mathrm{Pb}$ isotope ratios to the desired direction (Figure 4.8).

The drastic change in the $\mathrm{Pb}$ isotope ratios of the Chagos coral around 1985 could possibly be attributed to the increased use of the alkyllead supplied by Ethyl Corp. after 1985 compared to those supplied by Associate Octel. However, we do not have information on the market share of these companies in India then. The increased $\mathrm{Pb}$ isotope ratios after 1985 could be also due to the increased coal burning in India (and other countries), or could be the combined effect of the two.

Despite the remote location of the Chagos coral, there could be local $\mathrm{Pb}$ sources. For example, Diego Garcia, the largest island of the Chagos Archipelago on the south of the Banhos Atoll, contains a large joint UK-US naval support facility. The construction of the naval facilities in the island started in early 1970s, and now there are about 1500 military personnel and 2000 civilian contractors. Wurl et al. (2006) suggested that high atmospheric PCBs found at the Chagos Archipelago is probably due to the activities on Diego Garcia, and this could be a source of $\mathrm{Pb}$ as well. We cannot assess the influence of $\mathrm{Pb}$ from Diego Garcia because the amount and isotope ratios of the $\mathrm{Pb}$ used in the island are unknown. However, its influence may be minimal considering that North Rock corals at Bermuda, inhabited by more than 60,000 people and a US military base existing until 
1995, did not appear to be significantly affected by local sources (e.g. Shen and Boyle, 1987).

4.4.2. $\mathrm{Pb}$ in Western Sumatra coral and its potential sources

Based on the increased $\mathrm{Pb} / \mathrm{Ca}$ ratios and the decreased $\mathrm{Pb}$ isotope ratios (Figure 4.5), it is clear that significant $\mathrm{Pb}$ contamination began to occur in the western Sumatra region around the mid-1970s. Assuming that the "background $\mathrm{Pb}$ " (i.e. before significant contamination started, not necessarily pristine $\mathrm{Pb}$ values) of this region is the average of the $\mathrm{Pb}$ values in $1950-1970$, when $\mathrm{Pb} / \mathrm{Ca}$ and $\mathrm{Pb}$ isotope ratios were relatively invariable, we can calculate the isotope ratios of the $\mathrm{Pb}$ that contaminated the Sumatra region after 1970s using an equation suggested by Shirahata et al. (1980). The calculated isotope ratios of the contaminant $\mathrm{Pb}$ are almost uniform around ${ }^{206} \mathrm{~Pb} /{ }^{207} \mathrm{~Pb}=1.12$ and ${ }^{208} \mathrm{~Pb} /{ }^{207} \mathrm{~Pb}$ $=2.41\left({ }^{208} \mathrm{~Pb} /{ }^{206} \mathrm{~Pb}=2.15\right)$ except for the years around $1990(1987-1993)$. On the tripleisotope plot (Figure 4.8), this contaminant $\mathrm{Pb}$ falls onto the range of Indian $\mathrm{Pb}$ ores (Sangster et al., 2000) and the aerosols found in Indonesia and Thailand in 1987-89 (Mukai et al., 1993) and 1995-98 (Bollhöfer and Rosman, 2000). The source of the contaminant $\mathrm{Pb}$ is probably not the Indian $\mathrm{Pb}$ ores because the use of Indian $\mathrm{Pb}$ ores was negligible in the countries around the Sumatra region (COMTRADE, 2009). The major source of the $\mathrm{Pb}$ in aerosols from Indonesia and Thailand was leaded gasoline during the sampling period (Bollhöfer and Rosman, 2000; Mukai et al., 1993). However, $\mathrm{Pb}$ from Thailand cannot explain the continuing increase of the $\mathrm{Pb} / \mathrm{Ca}$ ratios in the Sumatra coral because leaded gasoline was phased out in Thailand in the early 1990s. Thus, the 
dominant source of $\mathrm{Pb}$ that affected the western Sumatra region seems to be the leaded gasoline used in Indonesia, as leaded gasoline was popularly used until 2006 in this country (Figure 4.2).

The increasing pattern of the Sumatra coral $\mathrm{Pb} / \mathrm{Ca}$ does not exactly correspond to the trend of vehicle $\mathrm{Pb}$ emissions from Indonesia, though. Although there are periods when the amounts of $\mathrm{Pb}$ emissions are unknown, vehicle $\mathrm{Pb}$ emissions were larger in the early 1990s than in the early 2000s (Figure 4.2), which is not observed in the coral $\mathrm{Pb} / \mathrm{Ca}$ ratios (Figure 4.5). The variance of the surface seawater $\mathrm{Pb}$ might have been smoothened by upwelling occurring off Sumatra, and it is also possible that the decrease of the vehicle $\mathrm{Pb}$ emissions was compensated by $\mathrm{Pb}$ emissions from coal burning and other industrial sources from nearby countries (e.g. Indonesia, Malaysia), which increased rapidly after 1990s (Figure 4.3). However, influence of the coal-Pb inputs was probably small because coal $\mathrm{Pb}$ emissions from these countries were almost an order of magnitude smaller than vehicle $\mathrm{Pb}$ emissions (Figures 4.2 and 4.3), and the coral $\mathrm{Pb}$ isotope ratios do not increase to higher numbers, which would be the case if the coal-Pb inputs were significant.

\subsection{3. $\mathrm{Pb}$ in Jong Island coral and its potential sources}

Although the data fluctuate significantly, $\mathrm{Pb} / \mathrm{Ca}$ ratios are generally higher in 1980-2002 than those in 1960s and 1970s, and the $\mathrm{Pb} / \mathrm{Ca}$ ratios become lower in 20062010 (Figure 4.6). This trend might be partly ascribed to the input of Pb from Indonesia, particularly from vehicle exhausts, because vehicle $\mathrm{Pb}$ emissions from Indonesia increased until late 1990s, and large amount of $\mathrm{Pb}$ was emitted until leaded gasoline was 
phased out in 2006 (Figure 4.2). Vehicle Pb emissions from Singapore and Malaysia seem to have minimal impact on the $\mathrm{Pb}$ of the Jong Island coral because they start to decrease rapidly from late 1980s and 1990s and emit a small quantity of $\mathrm{Pb}$ compared to Indonesia's emissions (Figure 4.2). However, $\mathrm{Pb}$ isotope ratios of the Jong Island coral does not support the dominance of Indonesia's gasoline $\mathrm{Pb}$, because the coral $\mathrm{Pb}$ isotope ratios become higher in late 1980s (Figure 4.6), whereas Indonesian aerosol $\mathrm{Pb}$ has low isotope ratios (Bollhöfer and Rosman, 2000) (Figure 4.9). Therefore it seems likely that $\mathrm{Pb}$ from vehicle exhausts are not be the dominant source of $\mathrm{Pb}$ in this region, and there are other sources of $\mathrm{Pb}$ with high $\left({ }^{206} \mathrm{~Pb} /{ }^{207} \mathrm{~Pb}>\sim 1.18,{ }^{208} \mathrm{~Pb} /{ }^{207} \mathrm{~Pb}>\sim 2.47\right)$ isotope ratios.

There are many other industrial sources that could have contributed to the $\mathrm{Pb}$ in this region. For example, coal usage in power plants in Malaysia and Indonesia increased rapidly over the past two decades (Figure 4.2), and smelting of Pb-containing ores and manufacturing of $\mathrm{Pb}$-containing products would have also increased. In the triple-isotope plot, the Jong Island coral $\mathrm{Pb}$ falls in the range of the $\mathrm{Pb}$ in coals from China, Indonesia, and Australia, and the Pb ores from southern China and Malaysia (Figure 4.9). These are the coals and $\mathrm{Pb}$ ores that are mainly used in Singapore, Malaysia, and Indonesia - the countries around the Strait of Singapore. For example, during 1990-2010, Malaysia imported $67 \%$ of its coal from Indonesia and 24\% from Australia; Indonesia imported $37 \%$ of its coal from Australia and 35\% from China; and Singapore imported $40 \%$ of its $\mathrm{Pb}$ ores and $\mathrm{Pb}$ concentrates from Malaysia (COMTRADE, 2009), 73\% of unwrought $\mathrm{Pb}$ from China (UNEP, 2011). Moreover, there could be a supply of Pb emitted from southern China (from Chinese coal burning and $\mathrm{Pb}$ ore processing) that are transported 
long distances by northeasterly winds in winter, which was also suggested as a major source of $\mathrm{Pb}$ in the western Pacific and northern South China Sea regions (Inoue and Tanimizu, 2008). Chinese anthropogenic $\mathrm{Pb}$ emissions are so large (Figures 4.2 and 4.3) that the $\mathrm{Pb}$ concentrations in Chinese aerosols were found to be the highest among Northern Hemisphere cities (Bollhöfer and Rosman, 2001), and thus, even small fractional inputs of Chinese aerosols could have considerable impact on the $\mathrm{Pb}$ in the Jong Island region.

However, when we compare the $\mathrm{Pb}$ isotope ratios of the Jong Island coral to the aerosol $\mathrm{Pb}$ isotope ratios from Malaysia collected in 1995, and Indonesia in 1989 (Mukai et al., 1993) and 1995 (Bollhöfer and Rosman, 2000), Jong Island coral Pb isotope ratios are always higher than the aerosols for the corresponding years. Aerosol samples we collected in Singapore (July 2011-April 2012) also had lower Pb isotope ratios than the Jong Island coral, with averaged values of $(\mathrm{n}=17){ }^{206} \mathrm{~Pb} /{ }^{207} \mathrm{~Pb}=1.148 \pm 0.003,{ }^{208} \mathrm{~Pb} /{ }^{207} \mathrm{~Pb}$ $=2.111 \pm 0.003$ (Table 4.5). It has been known that surface seawaters are polluted with $\mathrm{Pb}$ mainly through aerosol deposition, but in the Jong Island region, local aerosol deposition does not seem to be the main pathway of the pollutant $\mathrm{Pb}$ to the surface ocean.

There is a possibility that the Malaysian, Indonesian, and Singaporean aerosols used in this study are affected by local sources and do not represent the overall isotope ratios of the $\mathrm{Pb}$ emitted from the continent. Mukai et al. (1993) show that $\mathrm{Pb}$ isotope ratios can vary significantly depending on collection site, e.g. Pb isotope ratios in aerosols collected from a site with heavy traffic $\left({ }^{206} \mathrm{~Pb} /{ }^{207} \mathrm{~Pb}=1.14\right)$ were different from those from a site with low traffic and other industries $\left({ }^{206} \mathrm{~Pb} /{ }^{207} \mathrm{~Pb}=1.10\right)$, although the 
two sites were only $\sim 10 \mathrm{~km}$ apart. We do not know where exactly the aerosol samples from Bollhöfer and Rosman (2000) were taken, but our Singapore aerosol samples were taken on the campus of National University of Singapore (NUS), far from the main industrial area. Moreover, Inoue and Tanimizu (2008) demonstrated that a coral collected in the sea off Hong Kong had an isotopic signature of the $\mathrm{Pb}$ transported from China, although they could not find the Chinese $\mathrm{Pb}$ signals in the aerosols that were collected in the city of Hong Kong, $\sim 30 \mathrm{~km}$ from the coral site, because the aerosols were influenced by city incinerators and road dust. Therefore, aerosol sampling covering a wider area, particularly the main industrial areas, is necessary before concluding that aerosols are not the major source of $\mathrm{Pb}$ in Jong Island region.

Seawater samples collected near the Jong Island in 2010 showed the $\mathrm{Pb}$ isotope ratios $\left({ }^{206} \mathrm{~Pb} /{ }^{207} \mathrm{~Pb}=1.190\right.$ and $\left.{ }^{208} \mathrm{~Pb} /{ }^{207} \mathrm{~Pb}=2.471\right)$ corresponding to the Jong Island coral. Thus, if aerosols are not the main source, the $\mathrm{Pb}$ with high isotope ratios might have been advectively transported to the Jong Island region from other seas. Seawater in the Strait of Singapore is a mixture of the waters from South China Sea, Java Sea, and northeastern Indian Ocean. $\mathrm{Pb}$ isotope ratios were analyzed in six surface samples collected from the eastern part of the South China Sea $\left(18-21^{\circ} \mathrm{N}\right.$ and $116-119^{\circ} \mathrm{W}$, collected in 2000$)$, and averaged values were ${ }^{206} \mathrm{~Pb} /{ }^{207} \mathrm{~Pb}=1.156 \pm 0.015,{ }^{208} \mathrm{~Pb} /{ }^{207} \mathrm{~Pb}=2.444 \pm 0.017$ (Table 4.4). No seawater data is available for the Java Sea, but a coral sample collected off Jakarta Bay, whose age is from 1998-2001, had the $\mathrm{Pb}$ isotope ratios of ${ }^{206} \mathrm{~Pb} /{ }^{207} \mathrm{~Pb}=1.158$ and ${ }^{208} \mathrm{~Pb} /{ }^{207} \mathrm{~Pb}=2.430$ (Inoue et al., 2006). Although we do not have direct information on the eastern Indian Ocean seawater $\mathrm{Pb}$, the $\mathrm{Pb}$ isotope ratios in the Bay of Bengal surface 
seawaters were ${ }^{206} \mathrm{~Pb} /{ }^{207} \mathrm{~Pb}=1.149$ and ${ }^{208} \mathrm{~Pb} /{ }^{207} \mathrm{~Pb}=2.431$ (station 2 from the Indian GEOTRACES cruise, see Chapter 5). Thus, seawaters in the South China Sea, Java Sea, and the northeastern Indian Ocean seem to have $\mathrm{Pb}$ isotope ratios that are too low to be the source of $\mathrm{Pb}$ in the Jong Island region.

The high $\mathrm{Pb}$ isotope ratios of the Jong Island region might be the result of the isotope exchange between seawater and riverine particles. Based on ${ }^{210} \mathrm{~Pb}$ studies, it has been known that most of the dissolved $\mathrm{Pb}$ in rivers is scavenged in estuaries (Turekian, 1977 and references therein). However, reversible exchange equilibrium may occur between the $\mathrm{Pb}$ isotopes in riverine particles and seawaters as suggested to occur for $\mathrm{Sr}$ and Nd isotopes (Jones et al., 2012a; 2012b; Oelkers et al., 2011; 2012), and the altered $\mathrm{Pb}$ isotope ratios may be transported offshore (details of this hypothesis are discussed in Chapter 5, section 5.4.5). There are many rivers in the Malay and Indochina Peninsula, Sumatra, and Borneo that run into the Malacca Strait and the southern South China Sea, or directly to the Strait of Singapore (e.g. Juhor River). Sediment discharges from the rivers in this region are particularly large because of mountainous terrain, erodible strata that are often impacted by deforestration and agriculture, and seasonally heavy rainfall (Douglas, 1996; Milliman and Meade, 1983; Milliman et al., 1987). For example, sediment discharge from Sumatra, Java, and Borneo only $\left(2.02 \times 10^{9} \mathrm{t} / \mathrm{yr}\right)$ accounts for $10-12 \%$ of the total sediment discharge to the global ocean (Milliman et al., 1999). Little is known about the $\mathrm{Pb}$ isotope ratios of the riverine particles of this region, but sediment samples and K-feldspar grains in the rivers of the Indochina Peninsula have been found to have high $\mathrm{Pb}$ isotope ratios $\left({ }^{206} \mathrm{~Pb} /{ }^{207} \mathrm{~Pb}>1.18,{ }^{208} \mathrm{~Pb} /{ }^{206} \mathrm{~Pb}>2.08\right)$ with ${ }^{208} \mathrm{~Pb}$ enrichment 
because of the Th-rich continental crust (Bodet and Schrärer, 2001; Millot et al., 2004). Thus, although seawater $\mathrm{Pb}$ isotope ratios were low initially in the Bay of Bengal, (northern) South China Sea, and Java Sea, they may have increased to higher values during the transport to the Strait of Singapore due to the isotope exchange with riverine particles.

There also could be sources of $\mathrm{Pb}$ that are directly injected to the Jong Island region. For example, scrapings from boat paints that leach out from transport vessels can contribute to the $\mathrm{Pb}$ in this region (Goh and Chou, 1997). The Strait of Singapore is one of the busiest shipping routes in the world, and Jong Island is in the vicinity (within $\sim 5 \mathrm{~km}$ ) of the Port of Singapore. This is supported by high $\mathrm{Pb}$ concentrations (420-624

pmol kg${ }^{-1}$ ) found in the seawaters collected near the Port of Singapore in January 2010. There are other industrial facilities near the Jong Island (see Figure 4.1C), e.g., Singapore's largest oil refineries are located on the Jurong and Bukom Islands, and Pulau Semakau Landfill is mainly being filled with ash produced from Singapore's four incineration plants. However, they are unlikely to be the main source of $\mathrm{Pb}$ to the Jong Island region because $\mathrm{Pb}$ content in crude oils is typically very low in the ppb range (Hurst, 2002), and $\mathrm{Pb}$ isotope ratios of the fly ash collected from Singapore's incineration facilities are too low $\left({ }^{206} \mathrm{~Pb} /{ }^{207} \mathrm{~Pb}=1.148 \pm 0.005 ;{ }^{208} \mathrm{~Pb} /{ }^{207} \mathrm{~Pb}=2.424 \pm 0.003\right.$, Mengli Chen's unpublished data).

\subsection{Conclusion}


This study provides preliminary data on the evolution of $\mathrm{Pb}$ concentrations and isotope ratios of the surface Indian Ocean over the past $\sim 50$ years, where such data has been unavailable in spite of the increasing anthropogenic $\mathrm{Pb}$ emissions from South and Southeast Asia. Corals collected from Chagos Archipelago, West Sumatra, and Strait of Singapore (Jong Island) exhibit different trends of $\mathrm{Pb} / \mathrm{Ca}$ and $\mathrm{Pb}$ isotope ratios, implying that the main sources and controlling processes of $\mathrm{Pb}$ are different in each region. Four conclusions are obtained from this study:

1. The central and eastern Indian Ocean seems to be contaminated from the mid 1970s, although this timing is not very obvious in Jong Island coral $\mathrm{Pb} / \mathrm{Ca}$ data due to high variability.

2. $\mathrm{Pb} / \mathrm{Ca}$ ratios in the Chagos coral increase drastically after $\sim 1985$, probably because of the inputs of $\mathrm{Pb}$ mainly from India's vehicle $\mathrm{Pb}$ emissions and coal burning. The changing $\mathrm{Pb}$ isotope ratios around 1985 could be because of changed market share of leaded gasoline or increased coal burning in India.

3. In the western Sumatra region, vehicle $\mathrm{Pb}$ emissions from Indonesia seem to be a major source of $\mathrm{Pb}$, but the $\mathrm{Pb} / \mathrm{Ca}$ ratios of Sumatra coral do not exactly follow Indonesia's vehicle $\mathrm{Pb}$ emission history. $\mathrm{Pb}$ from coal burning and other industrial sources, e.g. smelting, may have become an important source in recent years, and upwelling off Sumatra may have smoothen out the temporal variance of the surface seawater $\mathrm{Pb}$. 
4. In the Jong Island region, leaded gasoline combustions do not seem to be the major source of $\mathrm{Pb}$. Based on $\mathrm{Pb}$ isotope ratios, potential sources of $\mathrm{Pb}$ are likely the $\mathrm{Pb}$ from coal burning and other industrial processes that use southern Chinese and Malaysian $\mathrm{Pb}$ ores, but there can be other sources of $\mathrm{Pb}$ whose isotopic signals are unknown (thus unidentified in this study). However, a question arises as to how this anthropogenic $\mathrm{Pb}$ is delivered to the Jong Island region, because the $\mathrm{Pb}$ isotope ratios of the aerosols collected in the nearby cities are considerably lower than those in the Jong Island coral. This might be due to short-scale aerosol $\mathrm{Pb}$ isotopes variability, or there could be a supply of high $\mathrm{Pb}$ isotope ratios from river particles or from local sources that are close to the Jong Island.

The main sources of $\mathrm{Pb}$ in these regions could not be clearly identified because of the lack of data on the amounts and isotopic signatures of various $\mathrm{Pb}$ sources. Moreover, the isotope ratios of each $\mathrm{Pb}$ source vary temporally depending on where the $\mathrm{Pb}$ is imported, making source identification more difficult. Questions arising from this study can possibly be resolved by analyzing the $\mathrm{Pb}$ content and isotope ratios of various industrial $\mathrm{Pb}$ sources in South and Southeast Asia, as well as those in rivers and estuaries (both dissolved and particulate $\mathrm{Pb}$ ). Furthermore, analyzing corals with longer history (e.g. covering the period of leaded gasoline phase out in India), and analyzing additional elements in corals, e.g. $\mathrm{Cd} / \mathrm{Ca}$ as a tracer of upwelling in Sumatra coral and $\mathrm{Ba} / \mathrm{Ca}$ as a tracer of river inputs in Jong Island coral, will also provide useful information in identifying sources of the $\mathrm{Pb}$ in these regions. 


\section{References for Chapter 4.}

Afroz, R., M. N. Hassan, and N. A. Ibrahim (2003), Review of air pollution and health impacts in Malaysia, Environ. Res., 92(2), 71-77.

Balasubramanian, R., T. Victor, and R. Begum (1999), Impact of biomass burning on rainwater acidity and composition in Singapore, J Geophys Res-Atmos, 104(D21), 26881-26890.

Balasubramanian, R., S. Karthikeyan, J. Potter, O. Wurl, and C. Durville (2011), Chemical Characterization of aerosols in the equatorial atmosphere over the Indian Ocean, Atmos. Environ. doi: 10.1016/j.atmosenv.2011.10.066

Bacon, M. P., D. W. Spencer and P. G. Brewer (1976), Pb-210/Ra-226 and Po-210/Pb210 disequilibria in seawater and suspended particulate matter, Earth Planet. Sci. Lett., 32, 277-296.

Bodet, F., and U. Schärer (2001), Pb isotope systematics and time-integrated Th/U of SEAsian continental crust recorded by single K-feldspar grains in large rivers, Chem. Geol., 177(3-4), 265-285.

Bollhöfer, A., and K. J. R. Rosman (2000), Isotopic source signatures for atmospheric lead: The Southern Hemisphere, Geochim. Cosmochim. Ac., 64(19), 3251-3262.

Bollhöfer, A., and K. J. R. Rosman (2001), Isotopic source signatures for atmospheric lead: The Northern Hemisphere, Geochim Cosmochim Ac., 65(11), 1727-1740.

Chen, M., K. Murali, B. C. V. Khoo, J. Lou, and K. Kumar (2005), Circulation modelling in the Strait of Singapore, J. Coastal Res., 21(5), 960-972.

Chester, R., A. S. Berry, and K. J. T. Murphy (1991), The distributions of particulate atmospheric trace metals and mineral aerosols over the Indian Ocean, Mar. Chem., 34, 251-290.

COMTRADE (Commodity Trade Statistics Database), 2009. United Nations Statistics Division. Data are Available from: http://comtrade.un.org/db/default.aspx

Cooper, J. A., P. H. Reynolds, and J. R. Richards (1969), Double-spike calibration of the Broken Hill standard lead, Earth Planet. Sci. Lett., 6, 467-478.

Cummings, G. L. and J. R. Ricards (1975), Ore lead isotope ratios in a continuously changing earth, Earth Planet. Sci. Lett., 28, 155-171.

Desenfant, F., A. J. Veron, G. F. Camoin, and J. Nyberg (2006), Reconstruction of pollutant lead invasion into the tropical North Atlantic during the twentieth century, Coral Reefs, 25(3), 473-484.

Diaz-Somoano, M., M. E. Kylander, M. A. Lopez-Anton, I. Suarez-Ruiz, M. R. Martinez-Tarazona, M. Ferrat, B. Kober, and D. J. Weiss (2009), Stable Lead Isotope Compositions In Selected Coals From Around The World And Implications For Present Day Aerosol Source Tracing, Environ. Sci. Technol., 43(4), 1078-1085.

Dodge, R. E., and T. R. Gilbert (1984), Chronology of Lead Pollution Contained in Banded Coral Skeletons, Mar. Biol., 82(1), 9-13. 
Doe, B. R. (1970), Lead isotopes. Springer Verlag, Berlin, Heidelberg, New York.

Douglas, I. (1996), The impact of land-use changes, especially logging, shifting cultivation, mining and urbanization on sediment yields in humid tropical Southeast Asia: A review with special reference to Borneo, Proceedings of the Exeter Symposium, July, 1996, IAHS Publ. no.236, 463-471.

George, A. M. (1999), The George Foundation Project lead free: a study of lead poisoning in major cities, paper presented at International Conference on Lead Poisoing Prevention and Treatment, Bangalore, India, February 8-10.

Godfrey, J. S. (1996), The effect of the Indonesian throughflow on ocean circulation and heat exchange with the atmosphere: A review, J. Geophys. Res.-Oceans, 101(C5), 12217-12237.

Goh, B. P. L., and L. M. Chou (1997), Heavy metal levels in marine sediments of Singapore, Environ. Monit. Assess., 44(1-3), 67-80.

Grobler, S. R., L. S. Maresky, and T. J. V. Kotze (1992), Lead Reduction of Petrol and Blood Lead Concentrations of Athletes, Arch. Environ. Health, 47(2), 139-142.

Hilton, F. G. (2006), Poverty and pollution abatement: Evidence from lead phase-out, Ecological Economics, 56, 125-131.

Hirota, K. (2006), Review of Lead Phase Out for Air Quality Improvement in the Third World Cities, Journal of Studies in Regional Science, 36(2), 527-541.

Hosono, T., C. C. Su, R. Delinom, Y. Umezawa, T. Toyota, S. Kaneko, and M. Taniguchi (2011), Decline in heavy metal contamination in marine sediments in Jakarta Bay, Indonesia due to increasing environmental regulations, Estuar. Coast. Shelf S., 92(2), 297-306.

Hulme, M., T. J. Osborn, and T. C. Johns (1998), Precipitation sensitivity to global warming: Comparison of observations with HadCM2 simulations, Geophys. Res. Lett., 25(17), 3379-3382.

Hurst, R.W. (2002), Lead Isotopes as Age-Sensitive, Genetic Markers in Hydrocarbons: 2. Kerogens, Crude Oils, and Unleaded Gasoline, Env.Geosciences, 9(1), 1-7.

Inoue, M., and M. Tanimizu (2008), Anthropogenic lead inputs to the western Pacific during the 20th century, Sci. Total Environ., 406(1-2), 123-130.

Inoue, M., A. Hata, A. Suzuki, M. Nohara, N. Shikazono, W. W. S. Yim, W. S. Hantoro, D. H. Sun, and H. Kawahata (2006), Distribution and temporal changes of lead in the surface seawater in the western Pacific and adjacent seas derived from coral skeletons, Environ. Pollut., 144(3), 1045-1052.

Isdale, P. (1984), Fluorescent Bands in Massive Corals Record Centuries of Coastal Rainfall, Nature, 310(5978), 578-579.

Jones, M. T., C. R. Pearce, and E. H. Oelkers (2012a), An experimental study of the interaction of basaltic riverine particulate material and seawater, Geochim. Cosmochim. Ac., 77, 108-120. 
Jones, M. T., C. R. Pearce, C. Jeandel, S. R. Gislason, E. S. Eiriksdottir, V. Mavromatis, and E. H. Oelkers (2012b), Riverine particulate material dissoluton as a significant flux of strontium to the oceans, Earth Planet. Sc. Lett., 355-356, 51-59.

Kelly, A. E., M. K. Reuer, N. F. Goodkin, and E. A. Boyle (2009), Lead concentrations and isotopes in corals and water near Bermuda, 1780-2000, Earth Planet. Sc. Lett., 283(1-4), 93-100.

Kondo, A., E. Hamonangan, S. Soda, A. Kaga, Y. Inoue, M. Eguchi, and Y. Yasaka (2007), Impacts of converting from leaded to unleaded gasoline on ambient lead concentrations in Jakarta metropolitan area, J. Environ. Sci.-China, 19(6), 709713.

Lelieveld, J., et al. (2001), The Indian Ocean Experiment: Widespread air pollution from South and Southeast Asia, Science, 291(5506), 1031-1036.

Li, Q., H. G. Cheng, T. Zhou, C. Y. Lin, and S. Guo (2012), The estimated atmospheric lead emissions in China, 1990-2009, Atmos. Environ., 60, 1-8.

Liepert, B. G., J. Feichter, U. Lohmann, and E. Roeckner (2004), Can aerosols spin down the water cycle in a warmer and moister world?, Geophys. Res. Lett., 31(6).

Lough, J. M. (2011a), Measured coral luminescence as a freshwater proxy: comparison with visual indices and a potential age artifact, Coral Reefs, 30(1), 169-182.

Lough, J. M. (2011b), Great Barrier Reef coral luminescence reveals rainfall variability over northeastern Australia since the 17th century, Paleoceanography, 26.

Masto, R. E., L. C. Ram, V. A. Selvi, S. K. Jha, and N. K. Srivastava (2007), Soil contamination and human health risks in coal mining environs, Proceedings of the $1^{\text {st }}$ International Conference on Managing the Social and Environmental Consequences of Coal Mining in India, New Delhi, India.

Mathee, A., H. Rollin, Y. von Schirnding, J. Levin, and I. Naik (2006), Reductions in blood lead levels among school children following the introduction of unleaded petrol in South Africa, Environ. Res., 100(3), 319-322.

Meltzner, A. J., K. Sieh, H. W. Chiang, C. C. Shen, B. W. Suwargadi, D. H. Natawidjaja, B. E. Philibosian, R. W. Briggs, and J. Galetzka (2010), Coral evidence for earthquake recurrence and an A.D. 1390-1455 cluster at the south end of the 2004 Aceh-Andaman rupture, J. Geophys. Res.-Sol. Ea., 115.

Milliman, J. D., and R. H. Meade (1983), World-Wide Delivery of River Sediment to the Oceans, J. Geol., 91(1), 1-21.

Milliman, J. D., K. L. Farnsworth, and C. S. Albertin (1999), Flux and fate of fluvial sediments leaving large islands in the East Indies, J. Sea Res., 41(1-2), 97-107.

Milliman, J. D., Y. S. Qin, M. E. Ren, and Y. Saito (1987), Mans Influence on the Erosion and Transport of Sediment by Asian Rivers - the Yellow-River (Huanghe) Example, J. Geol., 95(6), 751-762.

Millot, R., C.-J. Allegre, J. Gaillardet and S. Roy (2004), Lead isotopic systematic of major river sediments: a new estimate of the $\mathrm{Pb}$ isotopic composition of the Upper Continental Crust, Chem. Geol., 203, 75-90. 
Mukai, H., N. Furuta, T. Fujii, Y. Ambe, K. Sakamoto, and Y. Hashimoto (1993), Characterization of Sources of Lead in the Urban Air of Asia Using Ratios of Stable Lead Isotopes, Environ. Sci. Technol., 27(7), 1347-1356.

Nozaki, Y., J. Thomson and K. K. Turekian (1976), The distribution of Pb-210 and Po210 in the surface waters of the Pacific Ocean, Earth Planet. Sci. Lett., 32, 304312.

Nriagu, J. O. (1979), Global Inventory of Natural and Anthropogenic Emissions of TraceMetals to the Atmosphere, Nature, 279(5712), 409-411.

Nriagu, J. O., and J. M. Pacyna (1988), Quantitative Assessment of Worldwide Contamination of Air, Water and Soils by Trace-Metals, Nature, 333(6169), 134139.

Nyberg, J., B. A. Malmgren, A. Winter, M. R. Jury, K. H. Kilbourne, and T. M. Quinn (2007), Low Atlantic hurricane activity in the 1970s and 1980s compared to the past 270 years, Nature, 447(7145), 698-701.

Oelkers, E. H., S. R. Gislason, E. S. Eiriksdottir, M. Jones, C. R. Pearce, and C. Jeandel (2011), The role of riverine particulate material on the global cycles of the elements, Appl Geochem, 26, S365-S369.

Oelkers, E. H., M. T. Jones, C. R. Pearce, C. Jeandel, E. S. Eiriksdottir, and S. R. Gislason (2012), Riverine particulate material dissolution in seawater and its implications for the global cycles of the elements, Comptes Rendus Geoscience, 344, 646-651.

Pfeiffer, M., W. C. Dullo, J. Zinke, and D. Garbe-Schonberg (2009), Three monthly coral $\mathrm{Sr} / \mathrm{Ca}$ records from the Chagos Archipelago covering the period of 1950-1995 AD: reproducibility and implications for quantitative reconstructions of sea surface temperature variations, Int. J. Earth Sci., 98(1), 53-66.

Potemra, J. T., and R. Lukas (1999), Seasonal to interannual modes of sea level variability in the western Pacific and eastern Indian Oceans, Geophys. Res. Lett., 26(3), 365-368.

Quadfasel, D., and G. R. Cresswell (1992), A Note on the Seasonal Variability of the South Java Current, J. Geophys. Res.-Oceans, 97(C3), 3685-3688.

Ramanathan, V., P. J. Crutzen, J. T. Kiehl, and D. Rosenfeld (2001a), Atmosphere Aerosols, climate, and the hydrological cycle, Science, 294(5549), 2119-2124.

Ramanathan, V., C. Chung, D. Kim, T. Bettge, L. Buja, J. T. Kiehl, W. M. Washington, Q. Fu, D. R. Sikka, and M. Wild (2005), Atmospheric brown clouds: Impacts on South Asian climate and hydrological cycle, P. Natl. Acad. Sci. USA, 102(15), 5326-5333.

Ramanathan, V., et al. (2001b), Indian Ocean Experiment: An integrated analysis of the climate forcing and effects of the great Indo-Asian haze, J. Geophys. Res.-Atmos., 106(D22), 28371-28398. 
Rejomon, G., P. K. D. Kumar, and N. Bahulayan (2010), Biogeochemistry of Lead in the Eastern Arabian Sea and Western Bay of Bengal, Environ. Forensics, 11(3), 223 236.

Reuer, M. K. (2002), Centennial-Scale Elemental and Isotopic Variability in the Tropical and Subtropical North Atlantic Ocean, Massachusetts Institute of Technology.

Rosenfeld, D. (2000), Suppression of rain and snow by urban and industrial air pollution, Science, 287(5459), 1793-1796.

Sangster, D. F., P. M. Outridge, and W. J. Davis (2000), Stable lead isotope characteristics of lead ore deposits of environmental significance, Environ. Rev., 8, 115-147.

Schott, F. A., M. Dengler, and R. Schoenefeldt (2002), The shallow overturning circulation of the Indian Ocean, Prog. Oceanogr., 53(1), 57-103.

Schott, F. A., S. P. Xie, and J. P. McCreary (2009), Indian Ocean Circulation and Climate Variability, Rev. Geophys., doi:10.1029/2007RG000245.

Scoffin, T. P., A. W. Tudhope, and B. E. Brown (1989), Fluorescent and Skeletal Density Banding in Porites-Lutea from Papua New-Guinea and Indonesia, Coral Reefs, 7(4), 169-178.

Shen, G. T., and E. A. Boyle (1987), Lead in Corals - Reconstruction of Historical Industrial Fluxes to the Surface Ocean, Earth Planet. Sc. Lett., 82(3-4), 289-304.

Sheppard, C. R. C., M. R. D. Seaward, R. Klaus, and J. M. W. Topp (1999), The Chagos Archipelago: an introduction, in Ecology of the Chagos Archipelago, edited by C. R. C. Sheppard and M. R. D. Seaward, pp. 1-20, The Linnean Society Occasional Publications, Westbury Academic and Scientific Publishing, Otley.

Shirahata, H., R. W. Elias, C. C. Patterson, and M. Koide (1980), Chronological Variations in Concentrations and Isotopic Compositions of Anthropogenic Atmospheric Lead in Sediments of a Remote Subalpine Pond, Geochim. Cosmochim. Ac., 44(2), 149-162.

Singapore Ministry of Environment and Water Resources, 1987-2000, annual report.

Singh, A. K., and M. Singh (2006), Lead decline in the Indian environment resulting from the petrol-lead phase-out programme, Sci. Total Environ., 368(2-3), 686-694.

Sprintall, J., J. Chong, F. Syamsudin, W. Morawitz, S. Hautala, N. Bray, and S. Wijffels (1999), Dynamics of the South Java Current in the Indo-Australian Basin, Geophys. Res. Lett., 26(16), 2493-2496.

Tandon, S. K. (1999), Some identified sources of lead in India, in Lead Poisoning Prevention and Treatment: Implementing a National Program in Developing Countries, edited by A. M. George, George Foundation, Bangalore, India.

Tomczak, M., and J. S. Godfrey (2003), Regional Oceanography: an Introduction, Daya Publishing House, Delhi.

Turekian, K. K. (1977), The fate of metals in the oceans, Geochim. Cosmochim. Ac., 41, 1139-1144. 
UNEP (2007), The global campaign to eliminate leaded gasoline: progress as of January 2007, edited, www.unep.org/pcfv/PDF/LeadReport.pdf.

UNEP (2011), Study on the possible effects on Human Health and the Environment in Asia and the Pacific of the trade of products containing Lead, Cadmium and Mercury

UNEP Chemical (1998), www.chem.unep.ch/pops/pdf/lead/toc.htm

Witt, M. L. I., A. R. Baker, and T. D. Jickells (2006), Atmospheric trace metals over the Atlantic and South Indian Oceans: Investigation of metal concentrations and lead isotope ratios in coastal and remote marine aerosols, Atmos. Environ., 40(28), 5435-5451.

Wurl, O., J. R. Potter, J. P. Obbard, and C. Durville (2006), Persistent organic pollutants in the equatorial atmosphere over the open Indian Ocean, Environ. Sci. Technol., 40(5), 1454-1461.

Xu, H. M., J. J. Cao, K. F. Ho, H. Ding, Y. M. Han, G. H. Wang, J. C. Chow, J. G. Watson, S. D. Khol, J. Qiang, and W. T. Li (2012), Lead concentrations in fine particulate matter after the phasing out of leaded gasoline in Xi'an, China, Atm. Env., 46, 217-224.

Zhu, L. M., L. D. Guo, Z. Y. Gao, G. A. Yin, B. Lee, F. Wang, and J. A. Xu (2010), Source and distribution of lead in the surface sediments from the South China Sea as derived from $\mathrm{Pb}$ isotopes, Mar. Pollut. Bull., 60(11), 2144-2153. 

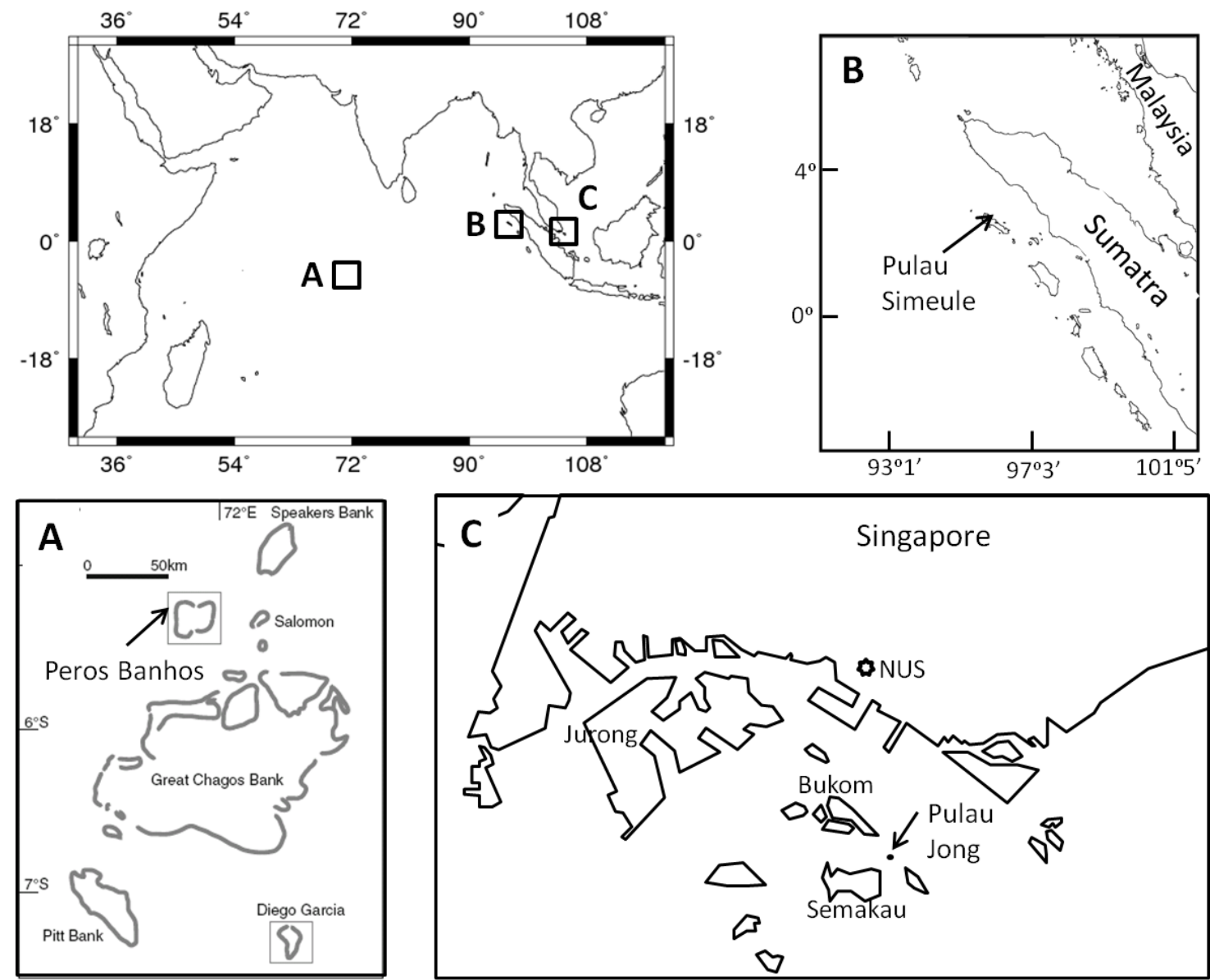

Figure 4.1 Map of the Indian Ocean and the locations where (A) Chagos, (B) Sumatra, and (C) Jong Island (Singapore Strait) corals were collected. 


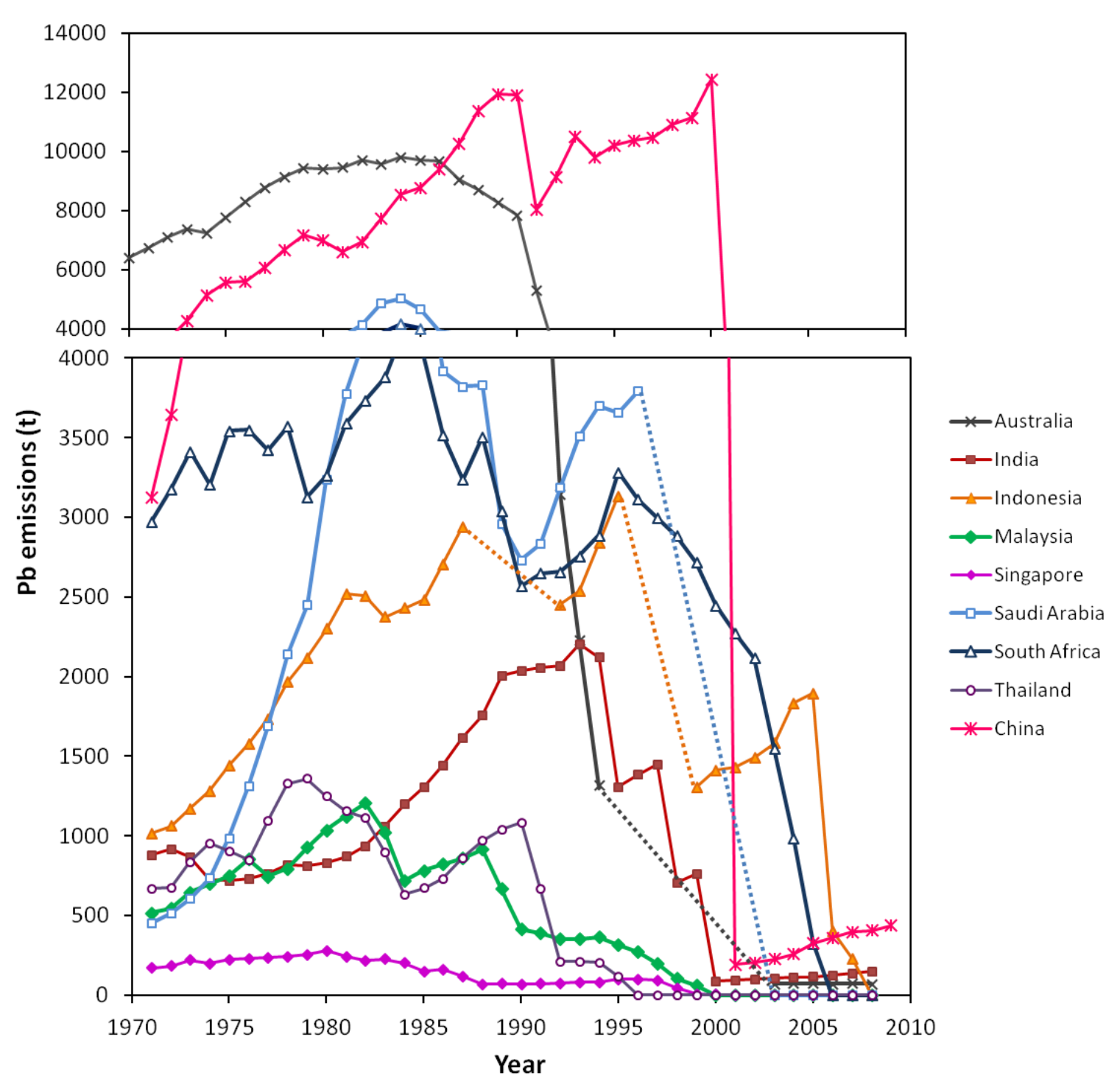

Figure 4.2 Historical $\mathrm{Pb}$ emissions (t) from vehicle gasoline combustion in the countries around the Indian Ocean. Dotted lines are for the years where data are unavailable. 


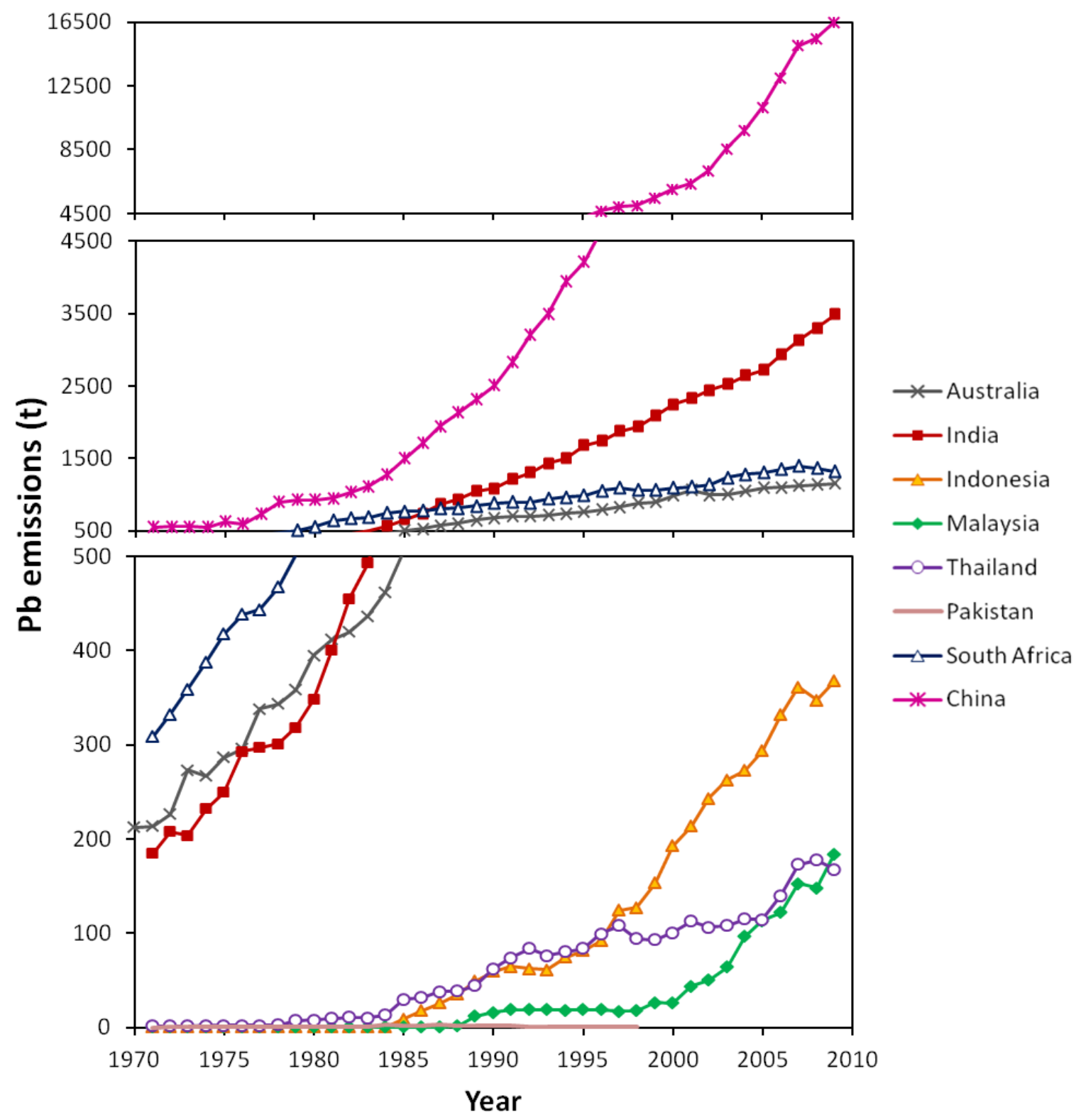

Figure 4.3 Historical $\mathrm{Pb}$ emissions from coal burning for electricity production. Saudi Arabia, Sri Lanka, and Singapore did not use coal to produce power during this period (1971-1999). Coal consumed by other industrial facilities and domestic use are not included. 

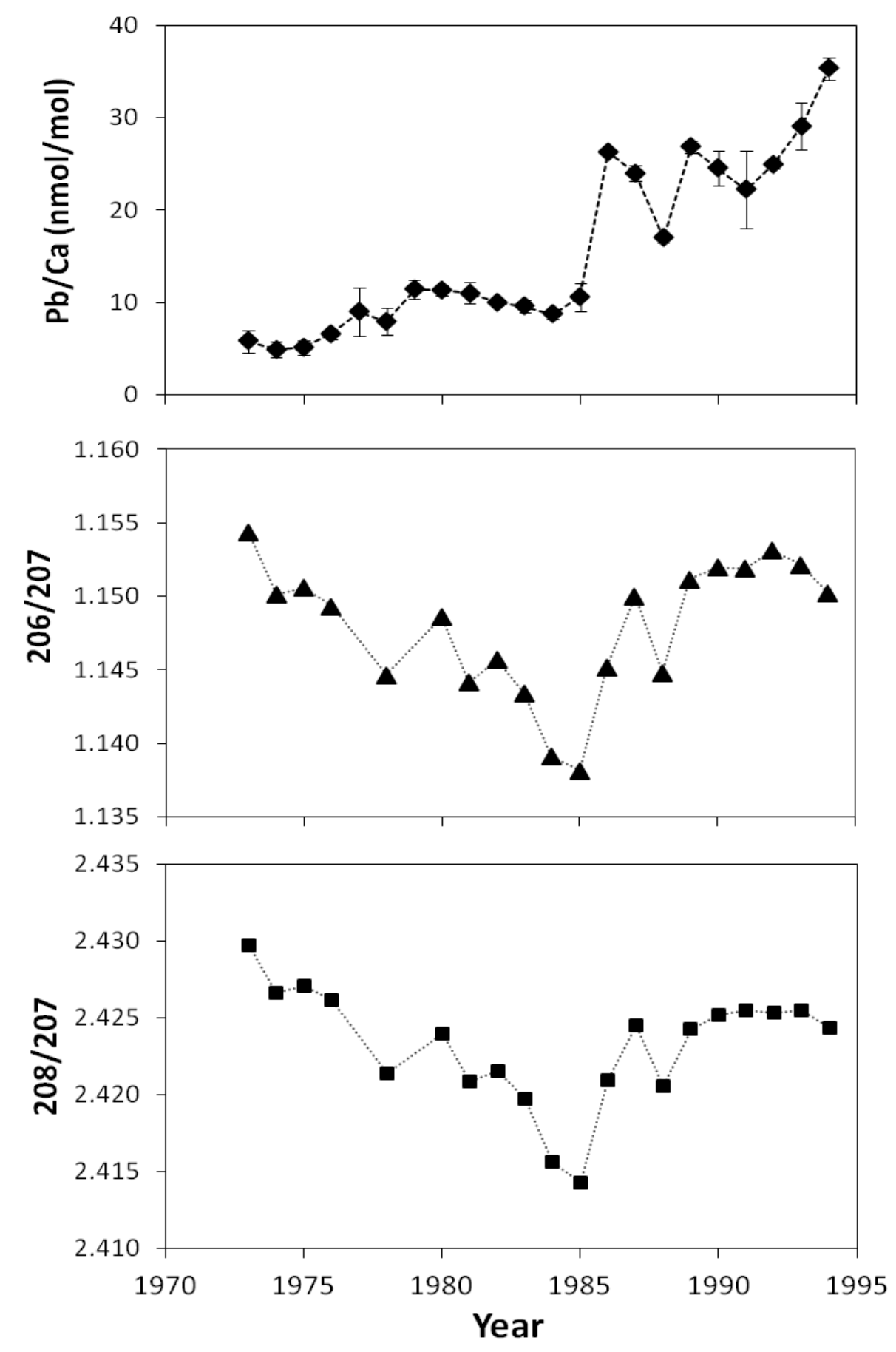

Figure 4.4 Time series of $\mathrm{Pb} / \mathrm{Ca},{ }^{206} \mathrm{~Pb} /{ }^{207} \mathrm{~Pb}$ and ${ }^{208} \mathrm{~Pb} /{ }^{207} \mathrm{~Pb}$ ratios in the Chagos coral. 

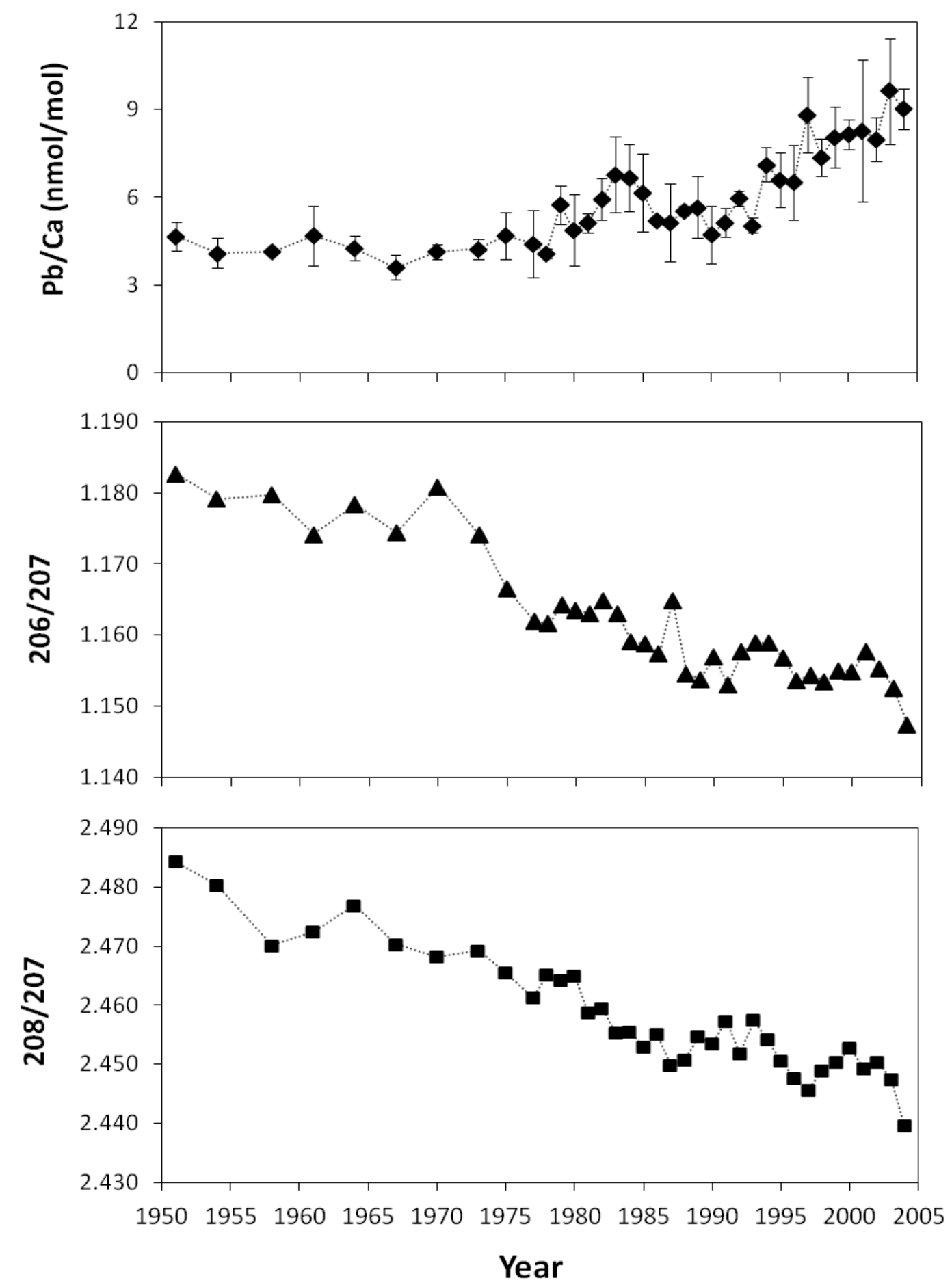

Figure 4.5 Time series of $\mathrm{Pb} / \mathrm{Ca},{ }^{206} \mathrm{~Pb} /{ }^{207} \mathrm{~Pb}$ and ${ }^{208} \mathrm{~Pb} /{ }^{207} \mathrm{~Pb}$ ratios in the Sumatra coral. 

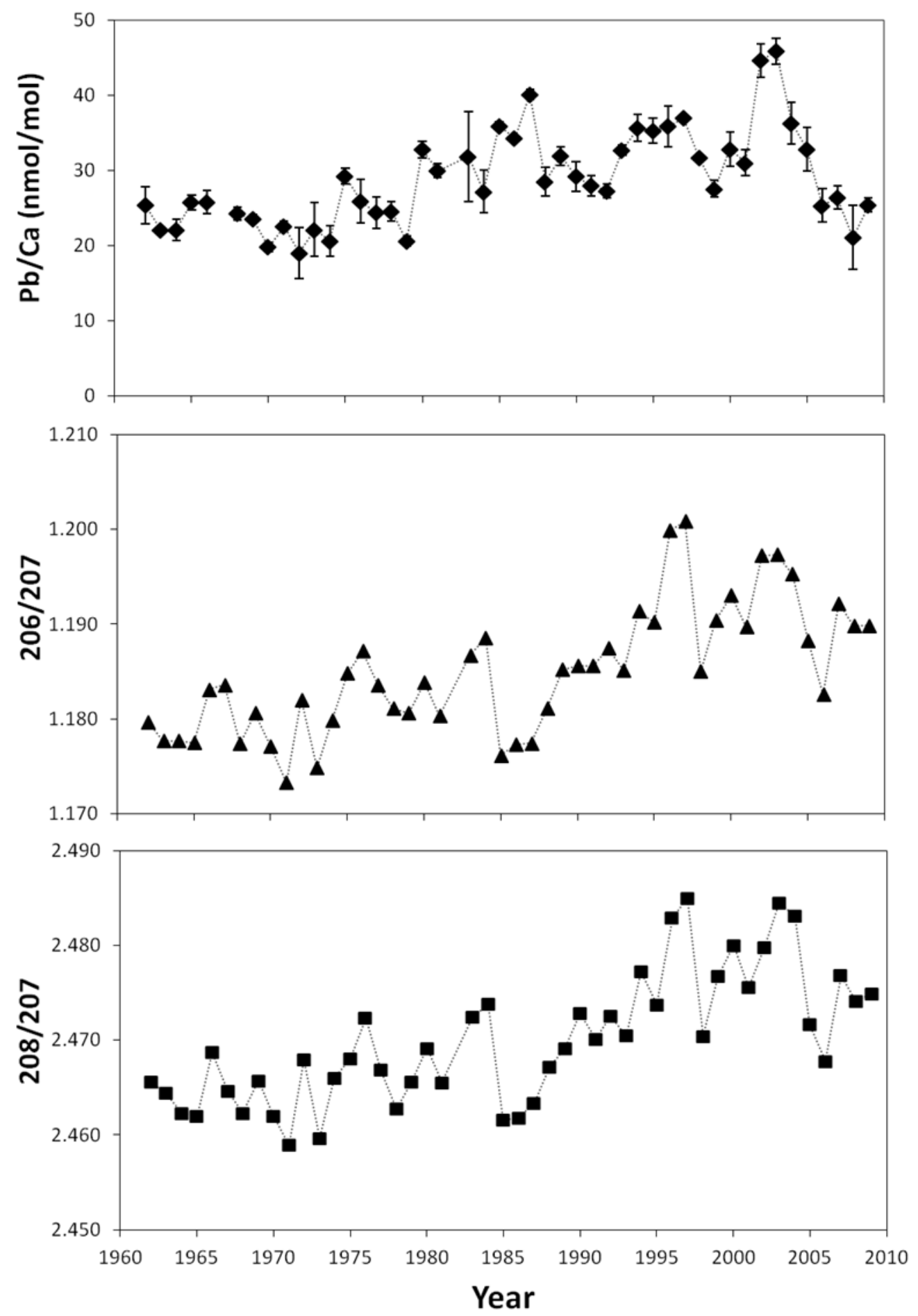

Figure 4.6 Time series of $\mathrm{Pb} / \mathrm{Ca},{ }^{206} \mathrm{~Pb} /{ }^{207} \mathrm{~Pb}$ and ${ }^{208} \mathrm{~Pb} /{ }^{207} \mathrm{~Pb}$ ratios in the Jong Island coral. 
(a)

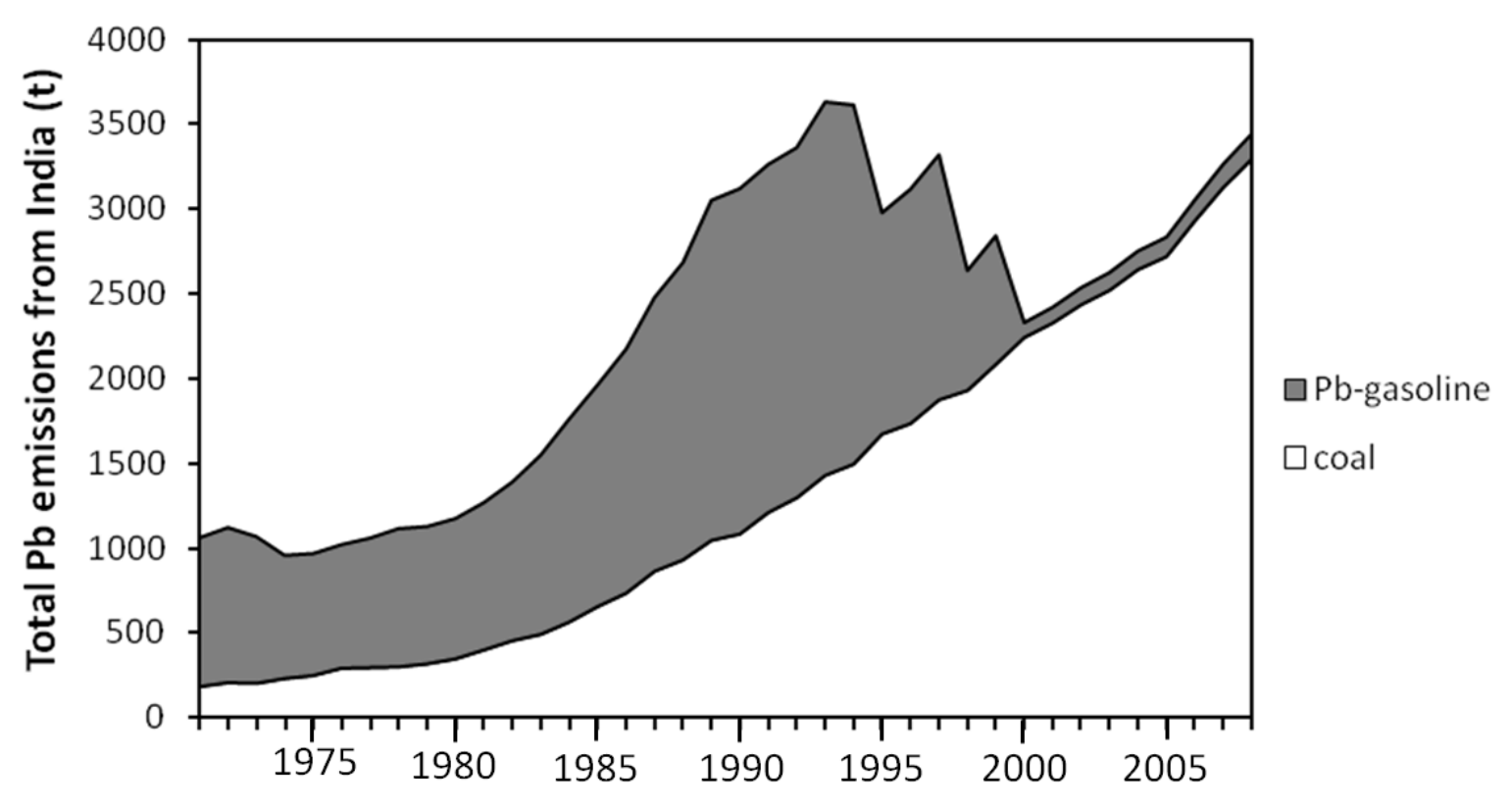

(b)

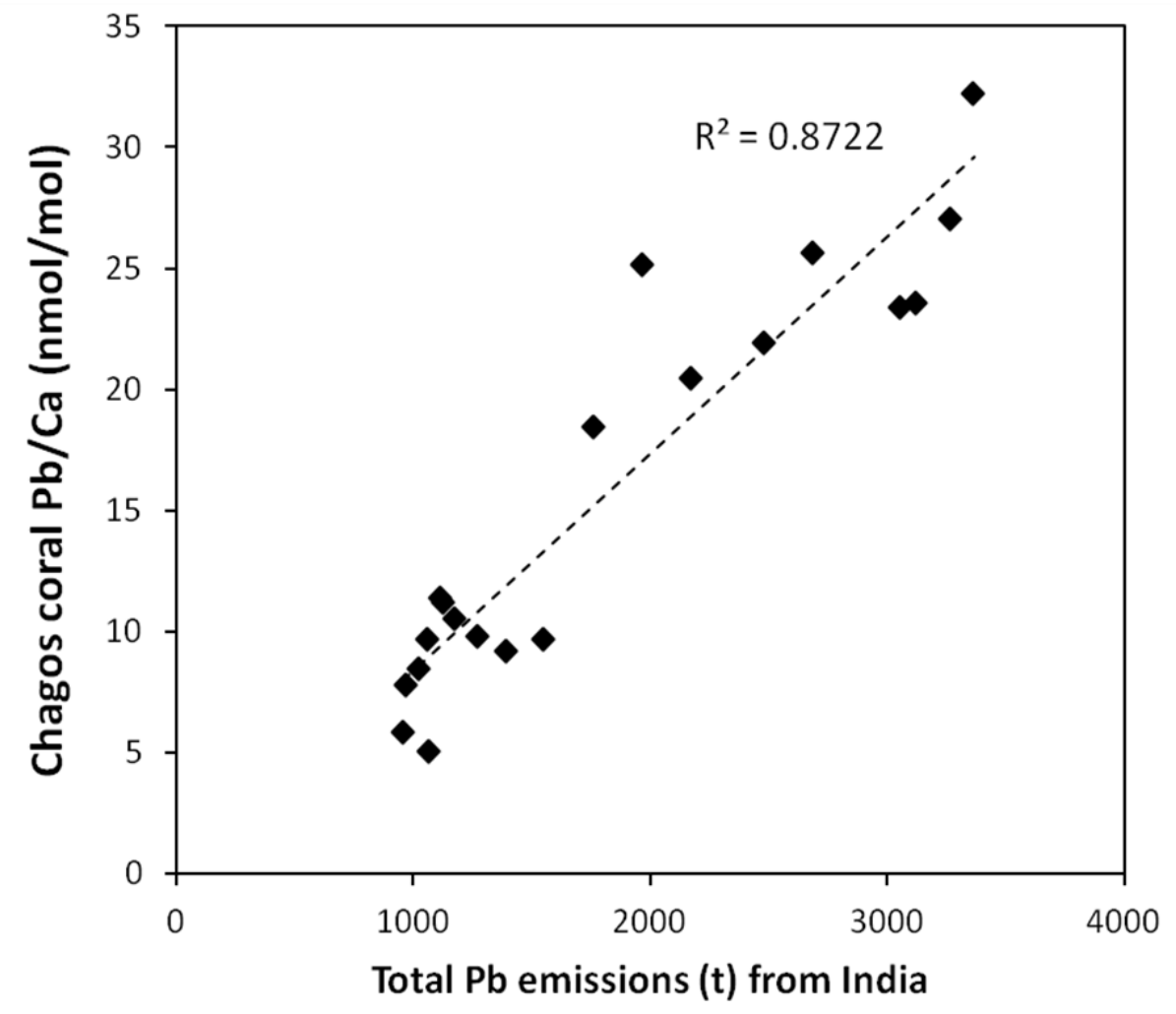

Figure 4.7 (a) Total $\mathrm{Pb}$ emissions from India, which is the sum of $\mathrm{Pb}$ emissions from vehicle gasoline combustion and coal burning, and (b) relationship between India's $\mathrm{Pb}$ emissions and the $\mathrm{Pb} / \mathrm{Ca}$ ratios in the Chagos coral with a 1.5-yr lag time. 


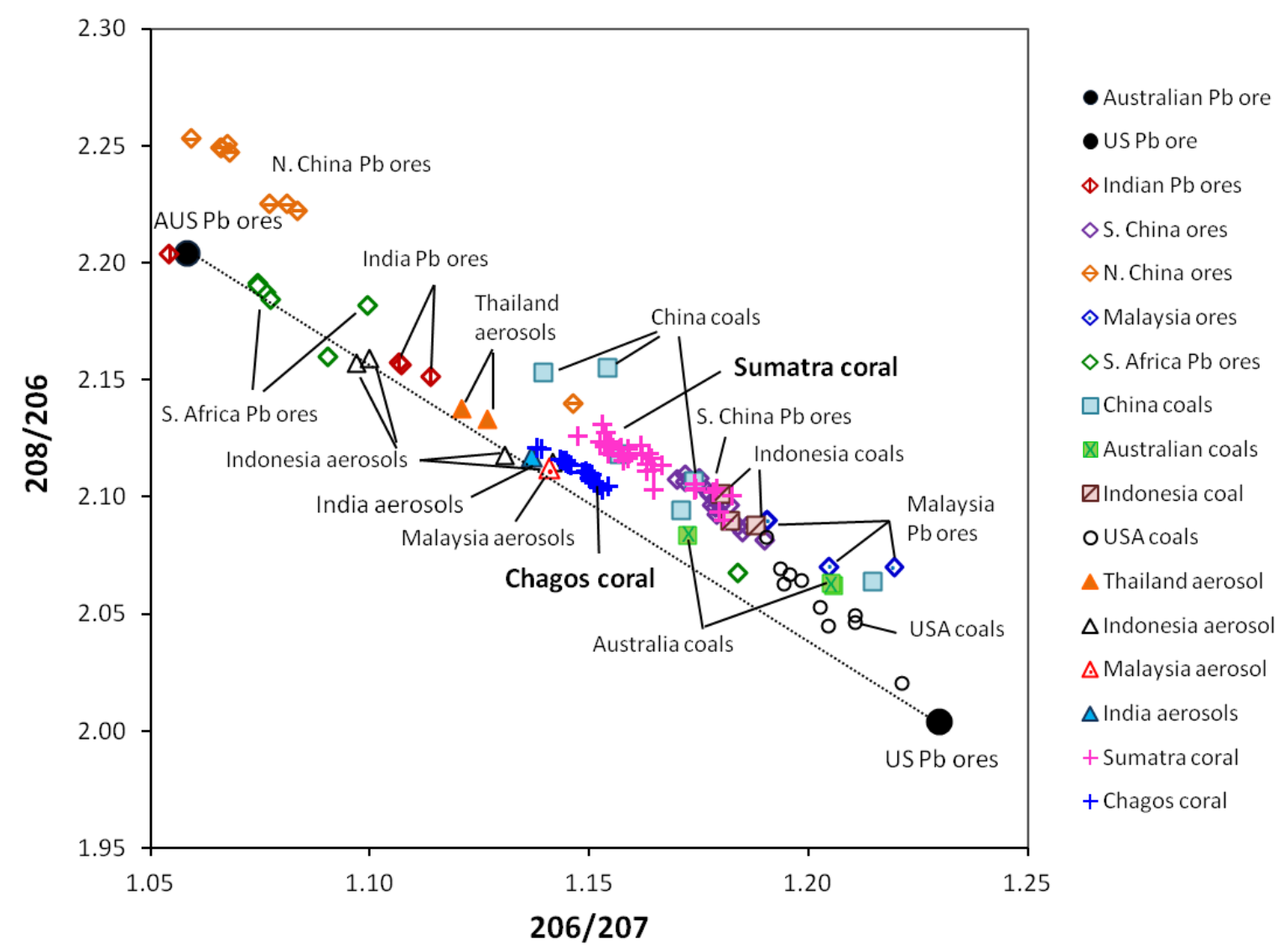

Figure 4.8 Triple isotope plot for the $\mathrm{Pb}$ in the Chagos and Sumatra corals in comparison with various $\mathrm{Pb}$ ores (Sangster et al., 2000; Inoue and Tanimizu, 2008 and references therein) and coals (Diaz-Somoano, 2009) and the aerosols collected from the countries in South and Southeast Asia (Bollhöfer and Rosman, 2000; 2001; Mukai et al., 1993). Black circles represent typical Australian (Broken Hill) type and US (Mississippy vally) type $\mathrm{Pb}$ ores used in alkyllead (Cooper et al., 1969; Doe, 1970; Cummings and Richards, 1975). 


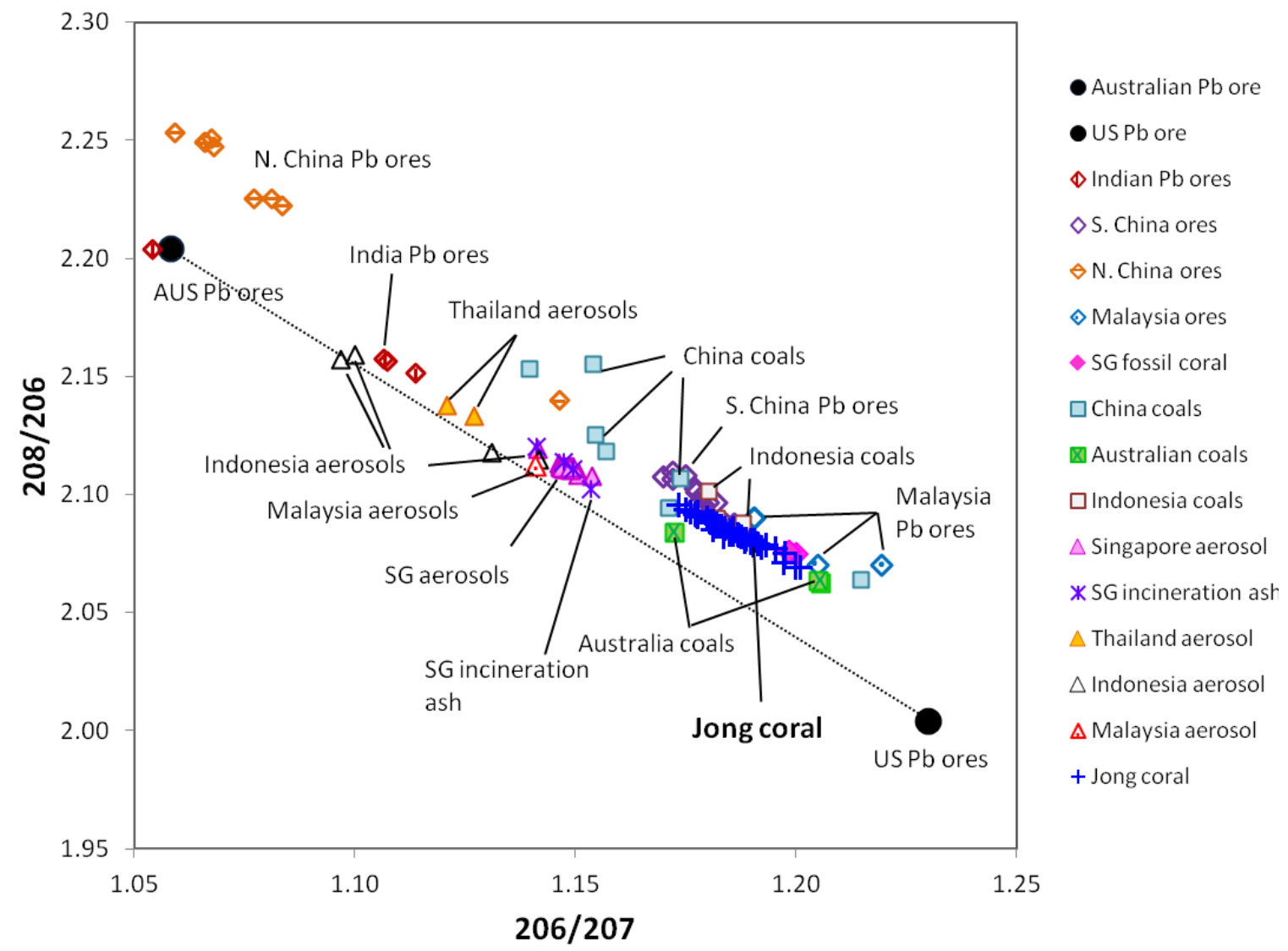

Figure 4.9 Triple isotope plot for the $\mathrm{Pb}$ in the Jong Island coral in comparison with various $\mathrm{Pb}$ ores, coals, and aerosols collected from the countries in Southeast Asia. References are same as Figure 4.8, and the $\mathrm{Pb}$ in Singapore aerosols and incineration ash are from this study. 
Table 4.1. $\mathrm{Pb} / \mathrm{Ca}(\mathrm{nmol} / \mathrm{mol}),{ }^{206} \mathrm{~Pb} /{ }^{207} \mathrm{~Pb},{ }^{208} \mathrm{~Pb} /{ }^{207} \mathrm{~Pb}$, and ${ }^{206} \mathrm{~Pb} /{ }^{204} \mathrm{~Pb}$ ratios in the $\mathrm{Chagos}$ coral. The $2 \sigma$ for $\mathrm{Pb} / \mathrm{Ca}$ represents the triplicates standard deviation, and $2 \sigma$ for $\mathrm{Pb}$ isotope ratios represent internal statistics for 20 , ten second integrations via MC-ICPMS.

\begin{tabular}{|c|c|c|c|c|c|c|c|c|}
\hline Year & $\mathbf{P b / C a}$ & $\mathbf{2 \sigma}$ & $\mathbf{2 0 6 / 2 0 7}$ & $\mathbf{2 \sigma}$ & $\mathbf{2 0 8 / 2 0 7}$ & $\mathbf{2 \sigma}$ & $\mathbf{2 0 6 / 2 0 4}$ & $\mathbf{2 \sigma}$ \\
\hline \hline 1994 & 35.30 & 1.18 & 1.1503 & 0.0001 & 2.4243 & 0.0002 & 18.01 & 0.01 \\
1993 & 29.07 & 2.51 & 1.1522 & 0.0002 & 2.4255 & 0.0004 & 18.08 & 0.01 \\
1992 & 24.98 & 0.54 & 1.1531 & 0.0001 & 2.4254 & 0.0002 & 18.06 & 0.01 \\
1991 & 22.21 & 4.22 & 1.1519 & 0.0001 & 2.4255 & 0.0003 & 18.04 & 0.01 \\
1990 & 24.52 & 1.91 & 1.1520 & 0.0002 & 2.4252 & 0.0004 & 18.07 & 0.01 \\
1989 & 26.81 & 0.66 & 1.1512 & 0.0001 & 2.4243 & 0.0003 & 18.01 & 0.01 \\
1988 & 16.98 & 0.50 & 1.1448 & 0.0001 & 2.4206 & 0.0002 & 17.96 & 0.01 \\
1987 & 23.97 & 0.82 & 1.1500 & 0.0002 & 2.4245 & 0.0003 & 18.00 & 0.01 \\
1986 & 26.30 & 0.00 & 1.1452 & 0.0002 & 2.4209 & 0.0004 & 17.92 & 0.01 \\
1985 & 10.60 & 1.51 & 1.1382 & 0.0003 & 2.4142 & 0.0004 & 17.84 & 0.02 \\
1984 & 8.75 & 0.52 & 1.1391 & 0.0003 & 2.4157 & 0.0005 & 17.86 & 0.02 \\
1983 & 9.58 & 0.68 & 1.1434 & 0.0003 & 2.4197 & 0.0004 & 17.89 & 0.02 \\
1982 & 9.98 & 0.32 & 1.1457 & 0.0002 & 2.4216 & 0.0003 & 17.93 & 0.01 \\
1981 & 11.02 & 1.15 & 1.1442 & 0.0002 & 2.4208 & 0.0002 & 17.87 & 0.02 \\
1980 & 11.31 & 0.60 & 1.1486 & 0.0002 & 2.4240 & 0.0003 & 17.93 & 0.02 \\
1979 & 11.40 & 1.05 & - & - & - & - & - & - \\
1978 & 7.94 & 1.48 & 1.1447 & 0.0002 & 2.4214 & 0.0004 & 17.94 & 0.02 \\
1977 & 8.98 & 2.62 & - & - & - & - & - & - \\
1976 & 6.58 & 0.57 & 1.1493 & 0.0004 & 2.4262 & 0.0005 & 18.01 & 0.03 \\
1975 & 5.13 & 0.78 & 1.1506 & 0.0003 & 2.4271 & 0.0006 & 18.01 & 0.02 \\
1974 & 4.94 & 0.85 & 1.1501 & 0.0002 & 2.4266 & 0.0006 & 18.01 & 0.02 \\
1973 & 5.82 & 1.20 & 1.1544 & 0.0002 & 2.4297 & 0.0003 & 18.09 & 0.02 \\
\hline
\end{tabular}


Table 4.2. $\mathrm{Pb} / \mathrm{Ca}(\mathrm{nmol} / \mathrm{mol}),{ }^{206} \mathrm{~Pb} /{ }^{207} \mathrm{~Pb},{ }^{208} \mathrm{~Pb} /{ }^{207} \mathrm{~Pb}$, and ${ }^{206} \mathrm{~Pb} /{ }^{204} \mathrm{~Pb}$ ratios in the Sumatra coral. The $2 \sigma$ standard deviations are same as Table 4.1.

\begin{tabular}{|c|c|c|c|c|c|c|c|c|}
\hline Year & $\mathrm{Pb} / \mathrm{Ca}$ & $2 \sigma$ & $206 / 207$ & $2 \sigma$ & $208 / 207$ & $2 \sigma$ & $206 / 204$ & $2 \sigma$ \\
\hline 2004 & 9.03 & 0.70 & 1.1474 & 0.0003 & 2.4396 & 0.0007 & 17.85 & 0.02 \\
\hline 2003 & 9.63 & 1.80 & 1.1526 & 0.0004 & 2.4475 & 0.0009 & 17.88 & 0.04 \\
\hline 2002 & 7.99 & 0.76 & 1.1553 & 0.0006 & 2.4504 & 0.0009 & 18.01 & 0.05 \\
\hline 2001 & 8.27 & 2.41 & 1.1578 & 0.0005 & 2.4493 & 0.0007 & 18.04 & 0.03 \\
\hline 2000 & 8.16 & 0.51 & 1.1549 & 0.0005 & 2.4527 & 0.0014 & 17.86 & 0.04 \\
\hline 1999 & 8.05 & 1.05 & 1.1550 & 0.0007 & 2.4503 & 0.0008 & 17.90 & 0.04 \\
\hline 1998 & 7.35 & 0.63 & 1.1535 & 0.0005 & 2.4490 & 0.0009 & 17.91 & 0.03 \\
\hline 1997 & 8.81 & 1.29 & 1.1544 & 0.0004 & 2.4457 & 0.0011 & 18.19 & 0.03 \\
\hline 1996 & 6.50 & 1.26 & 1.1536 & 0.0007 & 2.4476 & 0.0011 & 17.89 & 0.04 \\
\hline 1995 & 6.59 & 0.93 & 1.1568 & 0.0005 & 2.4506 & 0.0009 & 18.03 & 0.04 \\
\hline 1994 & 7.11 & 0.59 & 1.1589 & 0.0005 & 2.4541 & 0.0007 & 18.03 & 0.03 \\
\hline 1993 & 5.04 & 0.26 & 1.1589 & 0.0005 & 2.4575 & 0.0012 & 17.90 & 0.06 \\
\hline 1992 & 5.97 & 0.25 & 1.1577 & 0.0006 & 2.4518 & 0.0011 & 17.83 & 0.05 \\
\hline 1991 & 5.14 & 0.48 & 1.1530 & 0.0006 & 2.4574 & 0.0016 & 17.53 & 0.08 \\
\hline 1990 & 4.71 & 0.98 & 1.1569 & 0.0004 & 2.4535 & 0.0014 & 17.99 & 0.05 \\
\hline 1989 & 5.66 & 1.06 & 1.1538 & 0.0008 & 2.4547 & 0.0014 & 17.85 & 0.07 \\
\hline 1988 & 5.53 & 0.16 & 1.1545 & 0.0006 & 2.4507 & 0.0009 & 18.03 & 0.04 \\
\hline 1987 & 5.14 & 1.34 & 1.1648 & 0.0004 & 2.4498 & 0.0008 & 18.16 & 0.04 \\
\hline 1986 & 5.21 & 0.06 & 1.1574 & 0.0004 & 2.4552 & 0.0008 & 17.87 & 0.03 \\
\hline 1985 & 6.16 & 1.32 & 1.1588 & 0.0007 & 2.4530 & 0.0013 & 18.03 & 0.02 \\
\hline 1984 & 6.67 & 1.15 & 1.1590 & 0.0005 & 2.4555 & 0.0012 & 18.03 & 0.06 \\
\hline 1983 & 6.78 & 1.29 & 1.1631 & 0.0004 & 2.4553 & 0.0008 & 18.23 & 0.03 \\
\hline 1982 & 5.93 & 0.71 & 1.1649 & 0.0003 & 2.4595 & 0.0004 & 18.27 & 0.03 \\
\hline 1981 & 5.13 & 0.33 & 1.1630 & 0.0006 & 2.4587 & 0.0010 & 18.18 & 0.05 \\
\hline 1980 & 4.88 & 1.23 & 1.1636 & 0.0004 & 2.4650 & 0.0013 & 18.16 & 0.04 \\
\hline 1979 & 5.75 & 0.66 & 1.1642 & 0.0006 & 2.4642 & 0.0011 & 18.14 & 0.03 \\
\hline 1978 & 4.09 & 0.18 & 1.1617 & 0.0009 & 2.4651 & 0.0016 & 18.00 & 0.02 \\
\hline 1977 & 4.42 & 1.15 & 1.1620 & 0.0006 & 2.4613 & 0.0009 & 18.03 & 0.03 \\
\hline 1975 & 4.69 & 0.80 & 1.1665 & 0.0005 & 2.4655 & 0.0011 & 18.10 & 0.05 \\
\hline 1973 & 4.23 & 0.36 & 1.1741 & 0.0007 & 2.4693 & 0.0007 & 18.38 & 0.04 \\
\hline 1970 & 4.14 & 0.25 & 1.1809 & 0.0007 & 2.4683 & 0.0013 & 18.39 & 0.05 \\
\hline 1967 & 3.60 & 0.42 & 1.1744 & 0.0009 & 2.4703 & 0.0018 & 17.97 & 0.06 \\
\hline 1964 & 4.25 & 0.42 & 1.1783 & 0.0008 & 2.4769 & 0.0015 & 18.23 & 0.06 \\
\hline 1961 & 4.69 & 1.02 & 1.1742 & 0.0008 & 2.4725 & 0.0015 & 18.33 & 0.03 \\
\hline 1958 & 4.15 & 0.04 & 1.1797 & 0.0005 & 2.4701 & 0.0005 & 18.56 & 0.03 \\
\hline 1954 & 4.09 & 0.51 & 1.1791 & 0.0006 & 2.4804 & 0.0011 & 18.46 & 0.03 \\
\hline
\end{tabular}


Table 4.2 (continued)

\begin{tabular}{|c|c|c|c|c|c|c|c|c|}
\hline Year & $\mathbf{P b} / \mathbf{C a}$ & $\mathbf{2 \sigma}$ & $\mathbf{2 0 6 / 2 0 7}$ & $\mathbf{2 \sigma}$ & $\mathbf{2 0 8 / 2 0 7}$ & $\mathbf{2 \sigma}$ & $\mathbf{2 0 6 / 2 0 4}$ & $\mathbf{2 \sigma}$ \\
\hline \hline 1951 & 4.67 & 0.49 & 1.1827 & 0.0008 & 2.4843 & 0.0014 & 18.41 & 0.04 \\
\hline
\end{tabular}


Table 4.3 $\mathrm{Pb} / \mathrm{Ca}$ (nmol/mol), ${ }^{206} \mathrm{~Pb} /{ }^{207} \mathrm{~Pb},{ }^{208} \mathrm{~Pb} /{ }^{207} \mathrm{~Pb}$, and ${ }^{206} \mathrm{~Pb} /{ }^{204} \mathrm{~Pb}$ ratios in the Jong Island coral. The $2 \sigma$ standard deviations are same as Table 4.1.

\begin{tabular}{|c|c|c|c|c|c|c|c|c|}
\hline Year & $\mathrm{Pb} / \mathrm{Ca}$ & $2 \sigma$ & $206 / 207$ & $2 \sigma$ & $208 / 207$ & $2 \sigma$ & $206 / 204$ & $2 \sigma$ \\
\hline 2009 & 25.41 & 0.91 & 1.1899 & 0.0002 & 2.4749 & 0.0004 & 18.82 & 0.02 \\
\hline 2008 & 21.06 & 4.27 & 1.1898 & 0.0003 & 2.4741 & 0.0005 & 18.69 & 0.01 \\
\hline 2007 & 26.41 & 1.58 & 1.1922 & 0.0002 & 2.4768 & 0.0003 & 18.70 & 0.02 \\
\hline 2006 & 25.34 & 2.21 & 1.1826 & 0.0002 & 2.4678 & 0.0001 & 18.63 & 0.01 \\
\hline 2005 & 32.87 & 2.90 & 1.1882 & 0.0002 & 2.4717 & 0.0003 & 18.64 & 0.01 \\
\hline 2004 & 36.29 & 2.75 & 1.1953 & 0.0001 & 2.4831 & 0.0002 & 18.77 & 0.01 \\
\hline 2003 & 45.86 & 1.74 & 1.1973 & 0.0001 & 2.4845 & 0.0002 & 18.84 & 0.01 \\
\hline 2002 & 44.62 & 2.28 & 1.1972 & 0.0001 & 2.4798 & 0.0002 & 18.79 & 0.01 \\
\hline 2001 & 31.01 & 1.75 & 1.1897 & 0.0001 & 2.4756 & 0.0003 & 18.70 & 0.01 \\
\hline 2000 & 32.86 & 2.27 & 1.1931 & 0.0001 & 2.4800 & 0.0002 & 18.72 & 0.01 \\
\hline 1999 & 27.55 & 1.08 & 1.1904 & 0.0002 & 2.4768 & 0.0004 & 18.73 & 0.01 \\
\hline 1998 & 31.68 & 0.13 & 1.1850 & 0.0001 & 2.4704 & 0.0002 & 18.59 & 0.01 \\
\hline 1997 & 37.01 & - & 1.2009 & 0.0000 & 2.4850 & 0.0002 & 18.86 & 0.01 \\
\hline 1996 & 35.87 & 2.76 & 1.1999 & 0.0001 & 2.4829 & 0.0002 & - & - \\
\hline 1995 & 35.26 & 1.68 & 1.1902 & 0.0001 & 2.4737 & 0.0003 & 18.61 & 0.01 \\
\hline 1994 & 35.67 & 1.82 & 1.1914 & 0.0001 & 2.4773 & 0.0001 & 18.68 & 0.02 \\
\hline 1993 & 32.70 & 0.74 & 1.1851 & 0.0001 & 2.4705 & 0.0001 & 18.60 & 0.01 \\
\hline 1992 & 27.29 & 0.88 & 1.1875 & 0.0001 & 2.4726 & 0.0004 & 18.65 & 0.02 \\
\hline 1991 & 27.95 & 1.40 & 1.1856 & 0.0002 & 2.4702 & 0.0002 & 18.61 & 0.01 \\
\hline 1990 & 29.18 & 1.97 & 1.1856 & 0.0002 & 2.4728 & 0.0003 & 18.68 & 0.01 \\
\hline 1989 & 31.93 & 1.20 & 1.1852 & 0.0001 & 2.4691 & 0.0002 & 18.62 & 0.01 \\
\hline 1988 & 28.53 & 1.94 & 1.1811 & 0.0001 & 2.4672 & 0.0002 & 18.56 & 0.02 \\
\hline 1987 & 40.12 & 0.73 & 1.1774 & 0.0001 & 2.4634 & 0.0002 & 18.49 & 0.01 \\
\hline 1986 & 34.27 & 0.15 & 1.1773 & 0.0001 & 2.4618 & 0.0001 & 18.42 & 0.00 \\
\hline 1985 & 35.97 & 0.48 & 1.1762 & 0.0001 & 2.4616 & 0.0002 & 18.50 & 0.01 \\
\hline 1984 & 27.18 & 2.82 & 1.1886 & 0.0001 & 2.4738 & 0.0002 & 18.67 & 0.01 \\
\hline 1983 & 31.85 & 5.97 & 1.1867 & 0.0001 & 2.4724 & 0.0003 & 18.64 & 0.01 \\
\hline 1981 & 29.96 & 0.94 & 1.1804 & 0.0001 & 2.4656 & 0.0004 & 18.56 & 0.00 \\
\hline 1980 & 32.76 & 1.15 & 1.1839 & 0.0001 & 2.4692 & 0.0002 & 18.57 & 0.01 \\
\hline 1979 & 20.56 & 0.68 & 1.1806 & 0.0002 & 2.4656 & 0.0004 & 18.55 & 0.01 \\
\hline 1978 & 24.57 & 1.33 & 1.1811 & 0.0001 & 2.4627 & 0.0003 & 18.58 & 0.01 \\
\hline 1977 & 24.39 & 2.11 & 1.1835 & 0.0002 & 2.4669 & 0.0004 & 18.63 & 0.02 \\
\hline 1976 & 25.91 & 2.85 & 1.1871 & 0.0002 & 2.4724 & 0.0004 & 18.70 & 0.01 \\
\hline 1975 & 29.20 & 1.05 & 1.1848 & 0.0001 & 2.4680 & 0.0003 & 18.63 & 0.01 \\
\hline 1974 & 20.65 & 2.03 & 1.1798 & 0.0001 & 2.4660 & 0.0003 & 18.57 & 0.01 \\
\hline
\end{tabular}


Table 4.3 (continued)

\begin{tabular}{|c|c|c|c|c|c|c|c|c|}
\hline Year & Pb/Ca & $\mathbf{2 \sigma}$ & $\mathbf{2 0 6 / 2 0 7}$ & $\mathbf{2 \sigma}$ & $\mathbf{2 0 8 / 2 0 7}$ & $\mathbf{2 \sigma}$ & $\mathbf{2 0 6 / 2 0 4}$ & $\mathbf{2 \sigma}$ \\
\hline \hline 1973 & 22.10 & 3.58 & 1.1749 & 0.0002 & 2.4597 & 0.0003 & 18.49 & 0.01 \\
1972 & 19.01 & 3.39 & 1.1820 & 0.0002 & 2.4679 & 0.0004 & 18.55 & 0.01 \\
1971 & 22.57 & 0.66 & 1.1733 & 0.0001 & 2.4589 & 0.0003 & 18.41 & 0.02 \\
1970 & 19.79 & 0.61 & 1.1771 & 0.0002 & 2.4620 & 0.0003 & 18.49 & 0.01 \\
1969 & 23.55 & 0.56 & 1.1807 & 0.0001 & 2.4657 & 0.0002 & 18.49 & 0.01 \\
1968 & 24.28 & 0.87 & 1.1774 & 0.0001 & 2.4623 & 0.0003 & 18.43 & 0.01 \\
1967 & - & - & 1.1836 & 0.0001 & 2.4646 & 0.0003 & 18.58 & 0.01 \\
1966 & 25.79 & 1.52 & 1.1831 & 0.0001 & 2.4687 & 0.0002 & 18.57 & 0.01 \\
1965 & 25.72 & 0.96 & 1.1775 & 0.0002 & 2.4620 & 0.0004 & 18.47 & 0.01 \\
1964 & 22.13 & 1.42 & 1.1777 & 0.0002 & 2.4623 & 0.0004 & 18.48 & 0.02 \\
1963 & 22.03 & 0.36 & 1.1777 & 0.0002 & 2.4644 & 0.0003 & 18.52 & 0.01 \\
1962 & 25.36 & 2.44 & 1.1797 & 0.0001 & 2.4656 & 0.0003 & 18.53 & 0.02 \\
\hline
\end{tabular}


Table 4.4 $\mathrm{Pb}$ isotope ratios in seawater collected from South China Sea in March, 2000. The $2 \sigma$ represents internal statistics for 20 , ten second integrations via MC-ICP-MS.

\begin{tabular}{|c|c|c|c|c|c|c|c|c|}
\hline Cast & depth & location & $206 / 207$ & $2 \sigma$ & $208 / 207$ & $2 \sigma$ & $206 / 204$ & $2 \sigma$ \\
\hline \hline T1 & surface & $21^{\circ} 50^{\prime} \mathrm{N}$, & 1.1619 & 0.0002 & 2.4468 & 0.0003 & 18.335 & 0.041 \\
S1 & $10 \mathrm{~m}$ & $19^{\circ} 20^{\prime} \mathrm{W}$ & 1.1630 & 0.0001 & 2.4517 & 0.0002 & 18.349 & 0.011 \\
$\mathrm{~S} 1$ & $20 \mathrm{~m}$ & & 1.1632 & 0.0001 & 2.4512 & 0.0002 & 18.260 & 0.023 \\
$\mathrm{~S} 1$ & $40 \mathrm{~m}$ & & 1.1625 & 0.0002 & 2.4538 & 0.0003 & 18.189 & 0.020 \\
& & $20^{\circ} 19^{\prime} \mathrm{N}$, & 1.1619 & 0.0003 & 2.4472 & 0.0004 & 18.161 & 0.043 \\
T3 & surface & $118^{\circ} 08^{\prime} \mathrm{W}$ & & & & & & \\
& & $18^{\circ} 48^{\prime} \mathrm{N}$, & \multirow{2}{*}{1.1256} & 0.0000 & 2.4103 & 0.0001 & - & - \\
T5 & surface & $116^{\circ} 47^{\prime} \mathrm{W}$ & & & & & & \\
\hline
\end{tabular}

Table 4.5 $\mathrm{Pb}$ isotope ratios in aerosols collected on the campus of National University of Singapore in 2011-2012. The $2 \sigma$ represents internal statistics for 20 , ten second integrations via MC-ICP-MS.

\begin{tabular}{|c|l|c|c|c|c|c|c|}
\hline Year & Sampling period & $206 / 207$ & $2 \sigma$ & $208 / 207$ & $2 \sigma$ & $206 / 204$ & $2 \sigma$ \\
\hline \hline \multirow{5}{*}{2011} & Jul 27-29 & 1.1415 & 0.0001 & 2.4192 & 0.0001 & 18.312 & 0.009 \\
& Aug 3-7 & 1.1508 & 0.0000 & 2.4267 & 0.0001 & 18.462 & 0.041 \\
& Aug 7-14 & 1.1489 & 0.0001 & 2.4267 & 0.0001 & 18.558 & 0.009 \\
& Aug 14-23 & 1.1496 & 0.0001 & 2.4268 & 0.0001 & 18.671 & 0.008 \\
& Aug 23-Sep 16 & 1.1488 & 0.0001 & 2.4265 & 0.0001 & - & - \\
& Sep 16-Oct 1 & 1.1481 & 0.0000 & 2.4245 & 0.0001 & - & - \\
& Oct 1-14 & 1.1462 & 0.0001 & 2.4223 & 0.0002 & 18.066 & 0.010 \\
& Oct 14-Nov 1 & 1.1467 & 0.0000 & 2.4213 & 0.0001 & 18.886 & 0.021 \\
& Nov 1-16 & 1.1478 & 0.0001 & 2.4236 & 0.0001 & - & - \\
& Nov 16-Dec 15 & 1.1467 & 0.0001 & 2.4221 & 0.0001 & 18.326 & 0.011 \\
& Dec 16-Jan 2 & 1.1539 & 0.0003 & 2.4319 & 0.0005 & 17.977 & 0.023 \\
& Jan 16-18 & 1.1480 & 0.0003 & 2.4228 & 0.0004 & 17.876 & 0.030 \\
& Feb 2-7 & 1.1496 & 0.0001 & 2.4276 & 0.0001 & 18.487 & 0.009 \\
& Feb 16-21 & 1.1507 & 0.0001 & 2.4257 & 0.0001 & 18.339 & 0.012 \\
Mar 4-9 & 1.1474 & 0.0001 & 2.4216 & 0.0001 & 18.397 & 0.010 \\
& Mar 22-27 & 1.1491 & 0.0000 & 2.4248 & 0.0002 & 18.388 & 0.006 \\
& Apr 5-10 & 1.1469 & 0.0001 & 2.4214 & 0.0002 & 18.297 & 0.010 \\
& Apr 12-17 & 1.1486 & 0.0001 & 2.4247 & 0.0002 & 18.024 & 0.013 \\
\hline
\end{tabular}


Table 4.6 $\mathrm{Pb}$ emissions (tonne) from leaded gasoline combustions in India, Indonesia (Indo), Malaysia (Malay), Singapore (SG), Sri Lanka (SL), Thailand (Thai), Australia (Aus), South Africa, Saudi Arabia (SA), China.

\begin{tabular}{|c|c|c|c|c|c|c|c|c|c|c|}
\hline Year & India & Indo & Malay & SG & SL & Thai & Aus & S.Africa & SA & China \\
\hline $\begin{array}{l}1965 \\
1966 \\
1967 \\
1968 \\
1969 \\
1970\end{array}$ & & & & & & & $\begin{array}{l}4870 \\
5060 \\
5337 \\
5649 \\
6043 \\
6403\end{array}$ & & & \\
\hline 1971 & 878 & 1016 & 517 & 170 & 70 & 667 & 6735 & 2970 & 452 & 3126 \\
\hline 1972 & 916 & 1062 & 545 & 184 & 82 & 675 & 7126 & 3175 & 512 & 3647 \\
\hline 1973 & 867 & 1171 & 645 & 221 & 78 & 837 & 7384 & 3413 & 604 & 4277 \\
\hline 1974 & 727 & 1284 & 697 & 200 & 63 & 954 & 7256 & 3207 & 738 & 5159 \\
\hline 1975 & 720 & 1444 & 749 & 223 & 57 & 904 & 7773 & 3542 & 987 & 5565 \\
\hline 1976 & 730 & 1577 & 854 & 232 & 64 & 849 & 8314 & 3549 & 1313 & 5607 \\
\hline 1977 & 764 & 1735 & 744 & 234 & 67 & 1093 & 8771 & 3420 & 1689 & 6073 \\
\hline 1978 & 816 & 1966 & 795 & 240 & 78 & 1329 & 9151 & 3571 & 2140 & 6693 \\
\hline 1979 & 811 & 2118 & 927 & 256 & 67 & 1359 & 9456 & 3128 & 2452 & 7172 \\
\hline 1980 & 828 & 2300 & 1037 & 279 & 78 & 1248 & 9417 & 3263 & 3236 & 6996 \\
\hline 1981 & 870 & 2517 & 1123 & 241 & 78 & 1155 & 9459 & 3590 & 3777 & 6612 \\
\hline 1982 & 937 & 2508 & 1207 & 217 & 82 & 1116 & 9719 & 3734 & 4147 & 6945 \\
\hline 1983 & 1058 & 2374 & 1018 & 227 & 93 & 898 & 9575 & 3880 & 4874 & 7749 \\
\hline 1984 & 1199 & 2430 & 719 & 202 & 103 & 634 & 9796 & 4179 & 5030 & 8535 \\
\hline 1985 & 1308 & 2482 & 781 & 148 & 105 & 673 & 9722 & 4017 & 4679 & 8784 \\
\hline 1986 & 1441 & 2707 & 821 & 164 & 113 & 730 & 9663 & 3513 & 3915 & 9421 \\
\hline 1987 & 1616 & 2940 & 858 & 120 & 121 & 862 & 9032 & 3236 & 3820 & 10287 \\
\hline 1988 & 1755 & $\mathrm{n} / \mathrm{a}$ & 914 & 69 & 136 & 970 & 8708 & 3504 & 3829 & 11374 \\
\hline 1989 & 2008 & $\mathrm{n} / \mathrm{a}$ & 667 & 72 & 112 & 1039 & 8281 & 3041 & 2961 & 11955 \\
\hline 1990 & 2039 & $\mathrm{n} / \mathrm{a}$ & 414 & 67 & 73 & 1083 & 7831 & 2568 & 2732 & 11915 \\
\hline 1991 & 2055 & $\mathrm{n} / \mathrm{a}$ & 389 & 71 & 65 & 669 & 5311 & 2646 & 2835 & 8050 \\
\hline 1992 & 2068 & 2454 & 350 & 77 & 68 & 212 & 3142 & 2658 & 3185 & 9144 \\
\hline 1993 & 2205 & 2540 & 354 & 80 & 71 & 210 & 2231 & 2757 & 3507 & 10522 \\
\hline 1994 & 2120 & 2842 & 363 & 83 & 75 & 206 & 1317 & 2886 & 3699 & 9825 \\
\hline 1995 & 1307 & 3132 & 315 & 98 & 44 & 117 & $\mathrm{n} / \mathrm{a}$ & 3282 & 3656 & 10200 \\
\hline 1996 & 1384 & $\mathrm{n} / \mathrm{a}$ & 273 & 100 & 47 & 0 & $\mathrm{n} / \mathrm{a}$ & 3110 & 3791 & 10371 \\
\hline 1997 & 1448 & $\mathrm{n} / \mathrm{a}$ & 196 & 95 & 46 & 0 & $\mathrm{n} / \mathrm{a}$ & 2996 & $\mathrm{n} / \mathrm{a}$ & 10466 \\
\hline 1998 & 708 & $\mathrm{n} / \mathrm{a}$ & 103 & 45 & 48 & 0 & $\mathrm{n} / \mathrm{a}$ & 2882 & $\mathrm{n} / \mathrm{a}$ & 10901 \\
\hline 1999 & 760 & 1308 & 60 & 6 & 42 & 0 & $\mathrm{n} / \mathrm{a}$ & 2716 & $\mathrm{n} / \mathrm{a}$ & 11153 \\
\hline 2000 & 88 & 1411 & 0 & 4 & 35 & 0 & $\mathrm{n} / \mathrm{a}$ & 2447 & $\mathrm{n} / \mathrm{a}$ & 12430 \\
\hline 2001 & 94 & 1430 & 0 & 2 & 31 & 0 & $\mathrm{n} / \mathrm{a}$ & 2269 & $\mathrm{n} / \mathrm{a}$ & 192 \\
\hline 2002 & 101 & 1490 & 0 & 0 & 0 & 0 & $\mathrm{n} / \mathrm{a}$ & 2114 & $\mathrm{n} / \mathrm{a}$ & 203 \\
\hline 2003 & 105 & 1582 & 0 & 0 & 0 & 0 & 71 & 1549 & 0 & 227 \\
\hline 2004 & 110 & 1834 & 0 & 0 & 0 & 0 & 73 & 986 & 0 & 258 \\
\hline 2005 & 115 & 1896 & 0 & 0 & 0 & 0 & 75 & 325 & 0 & 326 \\
\hline
\end{tabular}


Table 4.6 (continued)

\begin{tabular}{|c|c|c|c|c|c|c|c|c|c|c|}
\hline Year & India & Indo & Malay & SG & SL & Thai & Aus & S.Africa & SA & China \\
\hline \hline 2006 & 124 & 404 & 0 & 0 & 0 & 0 & 71 & 0 & 0 & 359 \\
2007 & 138 & 229 & 0 & 0 & 0 & 0 & 72 & 0 & 0 & 399 \\
2008 & 150 & 0 & 0 & 0 & 0 & 0 & 71 & 0 & 0 & 407 \\
\hline
\end{tabular}


Table 4.7 $\mathrm{Pb}$ emissions (tonne) from coal burning for electricity production in India, Indonesia (Indo), Malaysia (Malay), Thailand (Thai), Australia (Aus), South Africa, Pakistan (P), China.

\begin{tabular}{|c|c|c|c|c|c|c|c|c|}
\hline Year & India & Indo & Malay & Thai & Aus & S.Africa & $\mathbf{P}$ & China \\
\hline 1965 & & & & & 134 & & & \\
\hline 1966 & & & & & 154 & & & \\
\hline 1967 & & & & & 167 & & & \\
\hline 1968 & & & & & 181 & & & \\
\hline 1969 & & & & & 197 & & & \\
\hline 1970 & & & & & 212 & & & \\
\hline 1971 & 184 & 0 & 0 & 2 & 213 & 309 & 1 & 552 \\
\hline 1972 & 208 & 0 & 0 & 2 & 226 & 332 & 1 & 553 \\
\hline 1973 & 204 & 0 & 0 & 1 & 273 & 359 & 0 & 553 \\
\hline 1974 & 232 & 0 & 0 & 2 & 267 & 388 & 1 & 548 \\
\hline 1975 & 250 & 0 & 0 & 2 & 287 & 418 & 0 & 626 \\
\hline 1976 & 293 & 0 & 0 & 2 & 296 & 438 & 0 & 591 \\
\hline 1977 & 297 & 0 & 0 & 2 & 338 & 444 & 0 & 726 \\
\hline 1978 & 301 & 0 & 0 & 3 & 344 & 467 & 0 & 898 \\
\hline 1979 & 319 & 0 & 0 & 7 & 358 & 501 & 0 & 926 \\
\hline 1980 & 348 & 0 & 0 & 8 & 395 & 554 & 0 & 929 \\
\hline 1981 & 400 & 0 & 0 & 9 & 412 & 634 & 0 & 948 \\
\hline 1982 & 455 & 0 & 0 & 11 & 420 & 668 & 0 & 1032 \\
\hline 1983 & 493 & 0 & 0 & 10 & 437 & 682 & 0 & 1114 \\
\hline 1984 & 566 & 0 & 0 & 13 & 462 & 740 & 0 & 1268 \\
\hline 1985 & 657 & 9 & 0 & 30 & 506 & 766 & 0 & 1494 \\
\hline 1986 & 735 & 18 & 0 & 31 & 526 & 770 & 0 & 1714 \\
\hline 1987 & 865 & 26 & 0 & 38 & 570 & 808 & 0 & 1942 \\
\hline 1988 & 932 & 35 & 1 & 38 & 601 & 810 & 0 & 2135 \\
\hline 1989 & 1047 & 49 & 12 & 45 & 643 & 840 & 0 & 2312 \\
\hline 1990 & 1085 & 60 & 16 & 63 & 674 & 883 & 0 & 2506 \\
\hline 1991 & 1212 & 65 & 19 & 74 & 695 & 890 & 0 & 2827 \\
\hline 1992 & 1298 & 62 & 19 & 84 & 703 & 886 & 0 & 3209 \\
\hline 1993 & 1430 & 61 & 19 & 76 & 713 & 939 & 0 & 3493 \\
\hline 1994 & 1497 & 74 & 18 & 80 & 738 & 962 & 0 & 3937 \\
\hline 1995 & 1675 & 81 & 19 & 84 & 756 & 987 & 2 & 4214 \\
\hline 1996 & 1737 & 92 & 19 & 99 & 793 & 1055 & 2 & 4665 \\
\hline 1997 & 1876 & 124 & 17 & 108 & 827 & 1092 & 2 & 4911 \\
\hline 1998 & 1932 & 127 & 18 & 94 & 881 & 1062 & 3 & 5003 \\
\hline 1999 & 2086 & 154 & 26 & 93 & 897 & 1057 & 2 & 5459 \\
\hline 2000 & 2244 & 192 & 26 & 101 & 986 & 1095 & 1 & 6013 \\
\hline 2001 & 2330 & 213 & 44 & 113 & 1057 & 1105 & 2 & 6352 \\
\hline 2002 & 2438 & 243 & 50 & 106 & 993 & 1138 & 1 & 7197 \\
\hline 2003 & 2523 & 263 & 64 & 108 & 996 & 1232 & 1 & 8579 \\
\hline 2004 & 2646 & 273 & 97 & 115 & 1043 & 1281 & 1 & 9701 \\
\hline 2005 & 2722 & 293 & 113 & 115 & 1092 & 1297 & 1 & 11162 \\
\hline
\end{tabular}


Table 4.7 (continued)

\begin{tabular}{|c|c|c|c|c|c|c|c|c|}
\hline Year & India & Indo & Malay & Thai & Aus & S.Africa & P & China \\
\hline \hline 2006 & 2933 & 332 & 122 & 140 & 1100 & 1345 & 1 & 13026 \\
2007 & 3132 & 361 & 153 & 173 & 1119 & 1397 & 1 & 15034 \\
2008 & 3298 & 348 & 148 & 178 & 1137 & 1363 & 1 & 15473 \\
\hline
\end{tabular}




\title{
Chapter 5
}

\section{Distribution of $\mathrm{Pb}$ and $\mathrm{Pb}$ isotopes in the Indian Ocean}

\begin{abstract}
$\mathrm{Pb}$ and $\mathrm{Pb}$ isotopes in the modern ocean have been altered significantly by anthropogenic $\mathrm{Pb}$ inputs over the past century. Most studies on the anthropogenic $\mathrm{Pb}$ in the ocean have focused on the North Atlantic and North Pacific Oceans, however, and the impact of anthropogenic $\mathrm{Pb}$ inputs to the Indian Ocean and the processes controlling the distribution of $\mathrm{Pb}$ in the Indian Ocean are poorly known. This study presents the $\mathrm{Pb}$ and $\mathrm{Pb}$ isotope composition $\left({ }^{206} \mathrm{~Pb} /{ }^{207} \mathrm{~Pb},{ }^{208} \mathrm{~Pb} /{ }^{207} \mathrm{~Pb}\right)$ of 11 deep stations from the Indian Ocean, from the Bay of Bengal and Arabian Sea to the Southern Ocean. The study shows that $\mathrm{Pb}$ in the upper Indian Ocean (particularly in the northern Indian Ocean) is largely perturbed by the anthropogenic $\mathrm{Pb}$ from Africa, the Middle East, South/Southeast Asia, and Australia. The $\mathrm{Pb}$ isotope ratios of the Indian Ocean water column are controlled by water mass distributions and the evolving isotope ratios of the anthropogenic $\mathrm{Pb}$ as dominant $\mathrm{Pb}$ emission sources change. The $\mathrm{Pb}$ isotope ratios in the Arabian Sea are lower than those in the Bay of Bengal, which might be the result of the $\mathrm{Pb}$ inputs from different
\end{abstract}


anthropogenic sources and $\mathrm{Pb}$ isotope exchange with particles and/or sediments of the Arabian Sea boundaries.

\subsection{Introduction}

Anthropogenic $\mathrm{Pb}$ emissions have contaminated the Atlantic Ocean (Boyle et al., 1986; Schaule and Patterson, 1983; Wu and Boyle, 1997a) and Pacific oceans (Flegal and Patterson, 1983; Flegal et al., 1986; Schaule and Patterson, 1981), as well as the Southern Ocean (Flegal et al., 1993; Westerlund and Ohman, 1991), altering Pb concentrations and isotope composition of these oceans. The influence of anthropogenic $\mathrm{Pb}$ inputs to the Indian Ocean is unknown, however, because reliable data on the $\mathrm{Pb}$ in the Indian Ocean have been absent. A few earlier works attempted to measure $\mathrm{Pb}$ in the Indian Ocean, but because of contamination during sampling, what they found was either a measure of the sampling contamination or concentrations close to the detection limit (e.g. Danielsson, 1980, Morley et al. 1993). With the first Indian Ocean GEOTRACES cruise undertaken by Japan, and now with advanced water sampling techniques, we acquired a chance to fill the gap in our knowledge.

The Indian Ocean is surrounded by rapidly developing countries - countries in Africa, Arabian Peninsula, South and Southeast Asia. However, environmental regulations in these countries are often not as stringent as in more developed countries, resulting in rapidly rising $\mathrm{Pb}$ emissions. For example, leaded gasoline, which was phased out in North America and western Europe in the late 1970s and 1980s, was used in many 
of these countries until the late 1990s and mid-2000s (Senior, 2006; UNEP, 2007). Moreover, $\mathrm{Pb}$ is emitted by other industrial activities such as mining, smelting, and coal combustion, which might be as important as leaded gasoline consumption in $\mathrm{Pb}$ emissions from this region (Nriagu et al., 1996a; Nriagu et al., 1996b). Pb isotope ratios measured from aerosols collected from major cities around the Indian Ocean were found to have significantly lower isotopic ratios $\left({ }^{206} \mathrm{~Pb} /{ }^{207} \mathrm{~Pb}=1.067-1.053,{ }^{208} \mathrm{~Pb} /{ }^{207} \mathrm{~Pb}=2.340\right.$ 2.433) (Bollhöfer and Rosman, 2000; 2001) than natural $\mathrm{Pb}$ found in the ferromanganese deposits in the Indian Ocean basins $\left({ }^{206} \mathrm{~Pb} /{ }^{207} \mathrm{~Pb}=1.203 \pm 0.005,{ }^{208} \mathrm{~Pb} /{ }^{207} \mathrm{~Pb}=\right.$ 2.489 \pm 0.008 ) (Vlastelic et al., 2001). Thus, anthropogenic $\mathrm{Pb}$ in the Indian Ocean water column would be discernible by $\mathrm{Pb}$ isotope ratios as well as from higher $\mathrm{Pb}$ concentrations.

In order to understand the distribution of $\mathrm{Pb}$ in the Indian Ocean, we need to understand the prevailing wind directions over the Indian Ocean, as $\mathrm{Pb}$ is mainly transported to the ocean by aerosols. In the southern Indian Ocean (south of $10^{\circ} \mathrm{S}$ ), the southeast trades are relatively steady, with their northern edge shifting northward during northern hemisphere summer and fall. North of $10^{\circ} \mathrm{S}$, the prevailing wind directions vary with the monsoons; the wind mainly blows from northeast during winter monsoon (December-March) and from southwest during summer monsoon (June-September). As a result of Ekman transport produced by southwesterly winds, strong upwelling occurs along the coast of Somalia and Arabia and near the tip of India during summer monsoon. Near the equator, winds have an easterly component only during the late winter/early 
spring and a westerly component during both intermonsoons (Schott et al., 2009;

Tomczak and Godfrey, 2003).

Another important process that controls the distribution of $\mathrm{Pb}$ in the ocean is ocean circulation. The Indian Ocean has a unique circulation system differing from the Atlantic and the Pacific Oceans because it is bounded to the north by the Asian continent (Schott et al., 2002; 2009). The surface circulation of the southern India Ocean is characterized by the westward flowing South Equatorial Current (SEC) that is mostly fed by the Indonesia Throughflow (ITF) water, and the subtropical gyre between around 20$40^{\circ} \mathrm{S}$. In the northern Indian Ocean, surface circulation is dependent on the monsoon cycle. During the summer monsoon, the strong SEC and East African Coastal Current (EACC) supply water to the northward flowing Somali Current (SC), and the eastward flows (Equatorial Countercurrent, ECC, and Southwest Monsoon Current, SMC) dominate the northern Indian Ocean, bringing Arabian Sea water into the Bay of Bengal. During winter monsoon, the SC flows southward, and with EACC, it feeds the eastward flowing ECC. North of the ECC, the Northeast Monsoon Current (NMC) flows westward, carrying fresher Bay of Bengal water into the Arabian Sea.

The thermocline of the Indian Ocean is ventilated mostly from the south through Indian Central Water (ICW). The ICW is formed with water subducted in the Subtropical Convergence $\left(30-40^{\circ} \mathrm{S}\right)$, and more dominantly, with denser Subantarctic Mode Water (SAMW), which is formed by deep winter convection in the southeast part of the Indian Ocean, immediately north of the Subantarctic Front (SAF) (Fine, 1993; Karstensen and Tomczak, 1997; Karstensen and Quadfasel, 2002; McCartney, 1982). Below SAMW is 
the Antarctic Intermediate Water (AAIW) that enters from the southwest Indian Ocean carried by the Circumpolar Current (Fine, 1993; Fine et al., 2008; Toole and Warren, 1993; Warren, 1981). Both SAMW and AAIW flow equatorward following the subtropical gyre, entering the northern Indian Ocean along the western boundary (west of $70^{\circ} \mathrm{E}$ ) off the African coast (Wyrtki, 1973; You and Tomczak, 1993). Other than southorigin waters, Persian Gulf Water (PGW), Red Sea Water (RSW), and the Indonesia Throughflow (ITF) feed a small percentage of the thermocline and intermediate water of the Indian Ocean, but their influence is confined in the Arabian Sea (PGW, RSW) and the eastern equatorial region (ITF) (You, 1998; You and Tomczak, 1993).

Abyssal waters of the Indian Ocean are occupied by Antarctic Bottom water (AABW) with two significant flows, one originated from the Weddell Sea and filling the western basins of the Indian Ocean and the other from the Adelie Land coast/Ross Sea and filling the eastern basins (Gordon and Tchernia, 1972; Mantyla and Reid, 1983; 1995). Both waters flow northward, and in the northern basin, they gradually upwell to form the overlying Indian Deep Water (IDW), which occupies the depths between AAIW and $\mathrm{AABW}$. Unlike AAIW and AABW, IDW is not formed in the Southern Ocean. Rather, it is a fraction of NADW carried from the Atlantic sector that is mixed with upper Circumpolar Deep Water along the path to the Indian Ocean (Tomczak and Godfrey, 2003).

In this chapter, accurate and precise $\mathrm{Pb}$ concentration and $\mathrm{Pb}$ isotope ratios of the Indian Ocean are reported for the first time. The data covers a few stations in the northern Indian Ocean and a section in the western Indian Ocean along $\sim 45^{\circ} \mathrm{W}$ (Figure 5.1). More 
GEOTRACES cruises will be launched in the near future, which will have more coverage on the central and eastern parts of the Indian Ocean.

\subsection{Materials and Method}

Thanks to K. Norisuye, T. Gamo, and H. Obata, samples were obtained during the Japanese Indian Ocean GEOTRACES cruise (KH09-5, November to December 2010), which covered 13 stations from the Bay of Bengal, Arabian Sea, to the Antarctic Circumpolar water $\left(60^{\circ} \mathrm{S}\right)$. Seawater samples for $\mathrm{Pb}$ analysis were collected from 11 stations (Figure 5.1) using a CTD carousel with an Epoxy-coated Al frame and Tefloncoated Niskin-X bottles (General Oceanics, 12L-type), which were thoroughly cleaned by soaking in 1.5\% Extran MA01 (EMD milipore), $0.1 \mathrm{M} \mathrm{HCl}$, and high-purity water. Upon retrieval, Niskin-X bottles were transferred into a clean "bubble", where clean air is introduced through HEPA filter units, and seawater samples were pressure-filtered through $0.2 \mu \mathrm{m}$-size capsule filters (Pall Scientific, AcroPak 200). Filtered samples were acidified to $\mathrm{pH} 2.0$ on board with clean $\mathrm{HCl}$ and shipped to MIT for the analysis.

At MIT, $\mathrm{Pb}$ concentrations were measured in triplicate by Yolanda EchegoyenSanz, using the ID-ICPMS technique after purification and preconcentration with NTA resin, as described in Chapter 2 (Lee et al, 2011). Samples for Pb isotope analysis were prepared by the double $\mathrm{Mg}(\mathrm{OH})_{2}$ precipitation method described by Reuer et al. (2003) as modified by Boyle et al. (2012). Depending on the Pb concentrations in each sample, 270-550 $\mathrm{ml}$ of sample was poured into a clean 1-L polyethylene separatory funnel. A small amount of vapor-distilled ammonia solution was added to form $\mathrm{Mg}(\mathrm{OH})_{2}$ 
precipitate, and the next day, the settled precipitate was drawn off into clean $50 \mathrm{~mL}$ polypropylene centrifuge tubes, centrifuged, and the supernatant siphoned off. The precipitate was then re-dissolved in high-purity $6 \mathrm{M} \mathrm{HCl}$, and a few drops of ammonia solution was added again to repeat the $\mathrm{Mg}(\mathrm{OH})_{2}$ precipitation. The amount of ammonia added to the samples for the first and second precipitation was determined empirically to produce a $\mathrm{Mg}(\mathrm{OH})_{2}$ precipitate that scavenges $\mathrm{Pb}$ nearly quantitatively ( $\mathrm{Wu}$ and Boyle, 1997b), but minimizing the precipitate so as to make the final purification work in a single step. The final wet $\mathrm{Mg}(\mathrm{OH})_{2}$ precipitate was usually less than $100 \mu \mathrm{l}$ in volume, and it was dissolved in high-purity $1.1 \mathrm{M} \mathrm{HBr}$ for the $\mathrm{HCl}-\mathrm{HBr}$ anion exchange column separation.

As described in Boyle et al. (2012), $\mathrm{Si}(\mathrm{OH})_{4}$ scavenged during $\mathrm{Mg}(\mathrm{OH})_{2}$ precipitation tends to precipitate as a thick gel if the amount of $\mathrm{HBr}$ added to the final precipitate is insufficient, and this gel clogs the anion columns during the purification procedure. This problem occurred for high-Si samples, e.g. deep samples and samples from station 14 . For most of the samples, this problem was resolved by adjusting the volume of $1.1 \mathrm{M} \mathrm{HBr}(0.8$ to $2.8 \mathrm{ml})$ added to the samples to avoid the precipitation of the gel. However, for some samples, the silica gel was not dissolved completely even after increasing the volume of $\mathrm{HBr}$. In that case, we centrifuged the vials to settle the silica gel to the bottom and carefully loaded the $\mathrm{HBr}$ solution only to the columns. This may lower the recovery efficiency of the procedure as some $\mathrm{Pb}$ is trapped in the silica gel. However, the loss of $\mathrm{Pb}$ does not seem to affect the resulted $\mathrm{Pb}$ isotope ratios (i.e., little fractionation occurs by $\mathrm{Pb}$ entrapment in the silica gel) given that 1) duplicates of a few 
samples processed with different amount of $\mathrm{HBr}$ (different amount of silica gel) gave identical results, and 2) the $\mathrm{Pb}$ isotope ratios of the samples processed with silica gel were consistent with samples from immediately above and below in the water column that were processed without silica gel formation.

The samples dissolved in $1.1 \mathrm{M} \mathrm{HBr}$ were purified by passing through columns packed with EIChrome anion-exchange resin. The purified samples were dried on a hotplate in a clean fume hood, and then re-dissolved in $0.2 \mathrm{M} \mathrm{HNO}_{3}$ immediately before isotope analysis using a GV/Micromass Isoprobe MC-ICP-MS. The details of the instrumental setting and data corrections are described in the method section of Chapter 3 and in Appendix I.

\subsection{Results}

\subsubsection{Hydrography}

T-S diagrams for all stations are shown in Figure 5.2. At the stations in the Arabian Sea (St. 5-7), Arabian Sea High Salinity Water (ASHSW) is observed at shallow depths $(<100 \mathrm{~m})$ at density $\left(\sigma_{\mathrm{t}}\right) 23.5-24 \mathrm{~kg} \mathrm{~m}^{-3}$, which becomes weaker at station 8 . At the northernmost station (station 5), North Arabian Sea High Salinity Water (NASHSW) appears right below ASHSW at $\sigma_{\mathrm{t}}$ near $25 \mathrm{~kg} \mathrm{~m}^{-3}$, and Persian Gulf Water (PGW) is also observed at $\sigma_{\mathrm{t}}$ around $26.5 \mathrm{~kg} \mathrm{~m}^{-3}$ by increased salinities between $200-300 \mathrm{~m}$. The NASHSW and PGW are not observed in other stations, as it is known in the literature to occur only in the northern part of the Arabian Sea $\left(>18{ }^{\circ} \mathrm{N}\right)$ (Banse and Postel, 2009; Prasad et al., 2001; Premchand, 1982; Shetye et al., 1994). Red Sea Water (RSW) is 
found at all stations in the Arabian Sea by high salinity at $\sigma_{\mathrm{t}} 27-27.2 \mathrm{~kg} \mathrm{~m}^{-3}$, appearing in depth range 500-700m. Station 2 in the Bay of Bengal shows low salinity waters at shallow depths, reflecting the influence of Bay of Bengal water (BBW). At station 3, which is located near the Equator, the T-S diagram forms a straight line with uniform salinity around 35 showing the presence of Indonesian throughflow (ITF). The ITF enters the Indian Ocean through the Australasian Mediterranean Sea centering at $\sim 10^{\circ} \mathrm{S}$, and thus, ITF is also observed at station 9 , which is located at $5^{\circ} \mathrm{S}$. In the southern Indian Ocean (stations 10-12), thermocline water $\left(\sigma_{\mathrm{t}}=26-27 \mathrm{~kg} \mathrm{~m}^{-3}\right)$ is occupied by ICW, and below ICW appears AAIW at depths 1000-1500m, showing low salinity. The depth range below AAIW to about $3800 \mathrm{~m}$ is occupied by Indian Deep Water (IDW), characterized by a deep salinity maximum. Antarctic Bottom Water (AABW) appears at the bottom of the southern Indian Ocean.

\subsubsection{Distribution of $\mathrm{Pb}$ concentrations}

At all stations except station $14, \mathrm{~Pb}$ concentrations are high at the surface, gradually decrease to $\sim 1500 \mathrm{~m}$ depth, and are uniform below $\sim 1500 \mathrm{~m}$ ranging between 5$10 \mathrm{pmol} \mathrm{kg}^{-1}$ (Figure 5.3, see table 5.1 for data). This was the pattern seen in the North Atlantic and North Pacific Oceans decades ago due to high anthropogenic $\mathrm{Pb}$ inputs into the surface (by aerosol deposition) and removal by particle scavenging at depths (Schaule and Patterson, 1981; 1983). ${ }^{210} \mathrm{~Pb}$ studies in the Indian Ocean showed net scavenging of ${ }^{210} \mathrm{~Pb}$ in the water column and more extensive ${ }^{210} \mathrm{~Pb}$ deficit in the deep water toward the north and other oceanic margins (e.g. Mid-Indian Ridge) because of boundary scavenging 
(Cochran et al., 1983; Chung, 1987). Thus, it is likely that low deep water $\mathrm{Pb}$ concentrations in the northern Indian Ocean (Bay of Bengal and Arabian Sea) are the result of enhanced $\mathrm{Pb}$ removal near oceanic boundaries. $\mathrm{Pb}$ concentrations as low as $\sim 2$ pmol kg ${ }^{-1}$ are found below $4500 \mathrm{~m}$ at stations 7 and 8 . Surface $\mathrm{Pb}$ concentrations range in 21-82 $\mathrm{pmol} \mathrm{kg}^{-1}$, higher in the northern Indian Ocean than in the southern Indian Ocean because the northern Indian Ocean is proximate to and surrounded by $\mathrm{Pb}$ emitting continents. The $\mathrm{Pb}$ concentrations in the northern Indian Ocean $\left(53-82 \mathrm{pmol} \mathrm{kg}^{-1}\right)$ are higher than those observed in the present-day Atlantic (20-30 $\mathrm{pmol} \mathrm{kg}^{-1}$ ) (Lee et al., 2011 and MIT unpublished data), North Pacific (23-52 $\mathrm{pmol} \mathrm{kg}^{-1}$ ) (Boyle et al., 2005; Gallon et al., 2011; Wu et al., 2010; Zubrick et al., 2012), and South Pacific Oceans (4-20 pmol $\mathrm{kg}^{-1}$ ) (Flegal and Patterson, 1983 and MIT unpublished data), because of large anthropogenic $\mathrm{Pb}$ inputs and weak ventilation from the northern Indian Ocean. For the surface of the southwestern Indian Ocean, Morley et al. (1993) reported Pb concentrations ranging 0.01-0.04 nM (sampled in 1986). Although these values are close to their detection limit, the results are generally comparable to the $\mathrm{Pb}$ concentrations we measured from the southern Indian Ocean. At station $14, \mathrm{~Pb}$ concentrations are between $3.8-8.9 \mathrm{pmol} \mathrm{kg}^{-1}$ at all depths, except in $150-200 \mathrm{~m}$ depth range where $\mathrm{Pb}$ is around 12 pmol kg ${ }^{-1}$.

\subsubsection{Distribution of $\mathrm{Pb}$ isotopes}

Both in the northern and southern Indian Ocean, lower $\mathrm{Pb}$ isotope ratios $\left({ }^{206} \mathrm{~Pb} /{ }^{207} \mathrm{~Pb}<1.16,{ }^{208} \mathrm{~Pb} /{ }^{207} \mathrm{~Pb}<2.435\right)$ appear in the upper water column $(<1500 \mathrm{~m})$ 
where increased $\mathrm{Pb}$ concentrations are found (Figure 5.3), implying that the low $\mathrm{Pb}$ isotope ratios are the result of anthropogenic $\mathrm{Pb}$ inputs as represented by urban aerosols (Bollhöfer and Rosman, 2000; 2001). On the other hand, the southernmost station (St. 14) appears to be least affected by anthropogenic $\mathrm{Pb}$ given the distinctively high $\mathrm{Pb}$ isotopic ratios $\left({ }^{206} \mathrm{~Pb} /{ }^{207} \mathrm{~Pb}=1.17-1.19 ;{ }^{208} \mathrm{~Pb} /{ }^{207} \mathrm{~Pb}=2.44-2.46\right)$, although it might be possible that the $\mathrm{Pb}$ transported from the North Atlantic Ocean (Figure 1.3) by NADW may contribute to the high lead isotope ratios. Overall, $\mathrm{Pb}$ isotope distributions of the Indian Ocean water column are set by the mixing of anthropogenic $\mathrm{Pb}$ inputs from above and the less contaminated water flowing from south to north in deep layers. When plotted on the triple isotope plot, all the $\mathrm{Pb}$ from the Indian Ocean water column fall on to the mixing line of the aerosols collected from the major cities around the Indian Ocean and the deep waters from station 14 (Figure 5.4). The northward flowing deep water can be clearly seen in the meridional transect of $\mathrm{Pb}$ isotope ratios (Figure 5.3), where high $\mathrm{Pb}$ isotope ratios are carried northward from station 14 by $\mathrm{AABW}$ and IDW, and the isotope ratios decrease along the path due to the mixing with overlying waters that are affected by anthropogenic $\mathrm{Pb}$. Thus, when looking at the vertical distribution, $\mathrm{Pb}$ isotope ratios are generally low at the surface and increase with depth at all stations. A few anomalous features appear in the thermocline water, which will be discussed in the following section. For instance, at stations 5-7, both $\mathrm{Pb}$ isotope ratios show a slight maximum (reaching 1.145-1.15 in ${ }^{206} \mathrm{~Pb} /{ }^{207} \mathrm{~Pb}$ and $\sim 2.43$ in ${ }^{208} \mathrm{~Pb} /{ }^{207} \mathrm{~Pb}$ ) in the depth range $100-200 \mathrm{~m}$ (Figure 5.6), and at stations $10-12, \mathrm{~Pb}$ isotope ratios exhibit a minimum at $600-800 \mathrm{~m}$ and the 
isotope ratio at these depths are almost uniform, ${ }^{206} \mathrm{~Pb} /{ }^{207} \mathrm{~Pb}=\sim 1.142$ and ${ }^{208} \mathrm{~Pb} /{ }^{207} \mathrm{~Pb}=$ $\sim 2.418$ (Figure 5.5).

\subsection{Discussion}

5.4.1. $\mathrm{Pb}$ concentrations and the phase-out of leaded gasoline

The vertical distribution of $\mathrm{Pb}$ concentrations in the water column reflects changes in the amount of $\mathrm{Pb}$ getting into the surface ocean, although it is also controlled by other factors, e.g., particle scavenging and ventilation. For instance, in the surface North Atlantic Ocean, the highest $\mathrm{Pb}$ concentration appeared in 1975 and decreased subsequently after phase out of leaded gasoline in US and western Europe (e.g., Shen and Boyle, 1987; Boyle et al., 1994; Wu et al. 1997a). As a result of this change, and also because of surface water ventilation, subsurface $\mathrm{Pb}$ concentration maxima appears in the thermocline of the North Atlantic Ocean (e.g., Schaule and Patterson, 1983; Boyle et al., 1986). Leaded gasoline was phased out late in Africa, the Middle East, and South/Southeast Asia in late1990s through mid-2000s, several years to a decade earlier than our sample collection in 2009. However, instead of a subsurface maximum, $\mathrm{Pb}$ concentrations in the Indian Ocean show the highest values at the surface. The lack of subsurface maximum is partly due to the weak ventilation from the northern Indian Ocean, which is more contaminated with $\mathrm{Pb}$ than the southern Indian Ocean, but it also implies that the $\mathrm{Pb}$ inputs to the Indian Ocean from other sources are still large even after leaded gasoline was phased out. $\mathrm{Pb}$ concentrations in the southwestern Indian Ocean that are similar to those measured in 1986 (Morley et al., 1993) also demonstrates that the 
phase out of leaded gasoline has not decreased the $\mathrm{Pb}$ inputs to the Indian Ocean significantly. Bollhöfer and Rosman (2000) estimated that even in 1995, when leaded gasoline was in use, $\mathrm{Pb}$ from other industrial activities account for $\sim 60 \%$ of $\mathrm{Pb}$ emissions from Southern Africa in 1995, and these sources probably have increased with rapid industrial development in this region.

\subsection{2. $\mathrm{Pb}$ in the Southern Ocean (station 14)}

The $\mathrm{Pb}$ concentrations at station 14 are low in the entire water column without a prominent surface maximum. This result is comparable to the $\mathrm{Pb}$ distributions found in the Weddell Sea (Sanũdo-Wilhelmy et al., 2002; Westerlund and Ohman, 1991), near the Antarctic peninsula (Flegal et al., 1993), in the Atlantic-sector Southern Ocean (Boye et al., 2012), and the Subantarctic water near Australia (Ellwood, 2008). The lack of surface maximum and low concentrations indicate that this area receives significantly low anthropogenic $\mathrm{Pb}$ due to its remote location, and the $\mathrm{Pb}$ is effectively scavenged by particles in this highly productive region.

The $\mathrm{Pb}$ isotope ratios in the station 14 are much higher than all the other stations, consistent with the premise of low anthropogenic $\mathrm{Pb}$ inputs to this area. However, these ratios are still lower than the natural $\mathrm{Pb}$ isotopic ratios found in the ferromanganese nodules in the Indian Ocean basin (Vlastelic et al., 2001), implying the impact of some anthropogenic $\mathrm{Pb}$, particularly in the upper layers where $\mathrm{Pb}$ isotope ratios are lower. The triple-isotope plot also shows the combined effect of anthropogenic $\mathrm{Pb}$ and natural $\mathrm{Pb}$ to the $\mathrm{Pb}$ in station 14 (Figure 5.4). Similar relationships between South American 
anthropogenic $\mathrm{Pb}$ and natural $\mathrm{Pb}$ were found in the Weddell Sea (Flegal et al., 1993; Sanũdo-Wilhelmy et al., 2002), and the natural sources of $\mathrm{Pb}$ are suggested as volcanic emissions (e.g. Mount Erebus), aeolian dust from South America, and ice-rafted sediment (Flegal et al., 1993).

\subsection{3. $\mathrm{Pb}$ isotopes in the southern Indian Ocean SAMW}

At the stations 10, 11, and 12, minimum $\mathrm{Pb}$ isotope ratios appear at $600-800 \mathrm{~m}$ depth (Figure 5.5). The minimum isotope ratios are ${ }^{206} \mathrm{~Pb} /{ }^{207} \mathrm{~Pb}=\sim 1.142$ and ${ }^{208} \mathrm{~Pb} /{ }^{207} \mathrm{~Pb}$ $=\sim 2.418$, and almost identical in the three stations. This isotopic minimum seems to be associated with the water mass at density ranges $26.5-27.0 \mathrm{~kg} \mathrm{~m}^{-3}$, which is known as Subantarctic Mode Water (SAMW) (McCartney, 1977; 1982). The SAMW has been identified by temperature and salinity that are nearly homogeneous vertically and horizontally, defining a minimum of potential vorticity (Hanawa and Talley, 2001; McCarthy and Talley, 1999; McCartney, 1977; 1982). Due to its active renewal during formation, high CFCs (Fine, 1993; Fine et al., 2008) and high dissolved oxygen concentrations (McCartney, 1982) have been also found in the SAMW. In our data set, SAMW can be recognized by the pycnostad on a density-depth plot and the increased oxygen concentrations (Figure 5.5), and this water overlaps with the layers where the minimum $\mathrm{Pb}$ isotope ratios appear. There are a few locations in the Southern Hemisphere where SAMW is formed, and the SAMW of the Indian Ocean is formed in the southeast part of the Indian Ocean (approximately $80^{\circ}-130^{\circ} \mathrm{E}, 43^{\circ}-48^{\circ} \mathrm{S}$ ), which then flows northward into the subrtopical gyre as a part of the ICW (Fine, 1993; Karstensen and 
Tomczak, 1997; Sallee et al., 2006). The SAMW formation zone is located downwind of southern Africa as westerly winds dominate over this region. However, based on $\mathrm{Pb}$ isotope ratios of the aerosols collected on board, Witt et al. (2006) demonstrated that at least for $\mathrm{Pb}$, Australian sources dominate over the southern African sources in the central and eastern part of the southern Indian Ocean, probably because of the proximity to Australia and larger anthropogenic $\mathrm{Pb}$ emissions from Australia than southern Africa (Figure. 4.2 in Chapter 4). $\mathrm{Pb}$ isotope ratios of the aerosols collected in Australia and southern Africa in 1990s were low with ${ }^{206} \mathrm{~Pb} /{ }^{207} \mathrm{~Pb}=1.060-1.110$ and ${ }^{208} \mathrm{~Pb} /{ }^{207} \mathrm{~Pb}=$ 2.335-2.365, because of the use of alkyllead manufactured mainly from Australian (Broken Hill) type Pb, and was supplied from the U.K. (Bollhöfer and Rosman, 2000) (Figure 5.4). Thus, regardless of the exact provenance of $\mathrm{Pb}$, it is likely that the SAMW was formed at the region of low $\mathrm{Pb}$ isotope ratios, and the low $\mathrm{Pb}$ isotopic signal was carried northward by SAMW, resulting in the minimum $\mathrm{Pb}$ isotopic ratios observed in the lower thermocline of stations 10-12. At these locations (St. 10-12), SAMW was found to have pCFC-12 age of 8-12 years $\left(\sigma_{\mathrm{t}}=26.7 \mathrm{~kg} \mathrm{~m}^{-3}\right)$, i.e. the water was formed at the surface 8-12 years ago (Fine et al., 2008). This coincides with the period when Australia and southern Africa were still using leaded gasoline, and thus supports our hypothesis. The SAMW and the associated low $\mathrm{Pb}$ isotope ratios leaves a weak imprint upon the $\mathrm{Pb}$ isotope distribution at station 9 as the upper water column of this station is influenced by the ITF, but slightly low $\mathrm{Pb}$ isotope ratios and slightly increased oxygen concentration at $\sim 400 \mathrm{~m}$ depth could be a trace of SAMW. 
The increase in $\mathrm{Pb}$ isotope ratios below SAMW can be justified by mixing with the less contaminated deep waters originating from the south, as previously described. However, the increase of $\mathrm{Pb}$ isotopes toward surface above the SAMW needs an explanation. The waters shallower than the SAMW are formed at lower latitudes (20$40^{\circ} \mathrm{S}$ ) and are much younger than SAMW (Fine et al., 2008). The increase of Pb isotope ratios in this layer is probably related to the evolution of anthropogenic $\mathrm{Pb}$ sources in Africa and Australia. As the use of leaded gasoline diminished (or was phased out), smelting and coal burning came to dominate the lead emissions from these countries (Witt et al., 2006; 2010) (also see Figure 4.3 in Chapter 4). Coals generally have high $\mathrm{Pb}$ isotopic ratios (e.g. ${ }^{206} \mathrm{~Pb} /{ }^{207} \mathrm{~Pb}$ around 1.2) due to their high $\mathrm{U}$ and $\mathrm{Th}$ contents, and South African coals have a very high isotopic ratio (avg. ${ }^{206} \mathrm{~Pb} /{ }^{207} \mathrm{~Pb}=\sim 1.22$ ) compared to coals from other regions (Diaz-Somoano et al., 2009; Farmer et al., 1999). Pb from the major Namibian $\mathrm{Pb}$ mine at Tsumeb also has higher $\mathrm{Pb}$ isotope ratios than leaded gasoline sources (Bollhöfer and Rosman, 2000), and the uranium and gold mines in Australia and South Africa emit $\mathrm{Pb}$ with a ${ }^{206} \mathrm{~Pb} /{ }^{207} \mathrm{~Pb}$ ratio as high as 2.88 (Chiaradia et al., 1997; Honeybun et al., 2003). Thus, isotope ratios of the Pb emitted from Africa and Australia probably have increased recently while dominating $\mathrm{Pb}$ emission sources changed, and this could have resulted in the increase of the $\mathrm{Pb}$ isotope ratios in shallow Indian Ocean waters. We do not have direct evidence showing the evolution of $\mathrm{Pb}$ isotopes in the surface Indian Ocean, but aerosols collected from South African cities (Bollhöfer and Rosman, 2000) and marine aerosols collected near South Africa (Witt et 
al., 2006; 2010) from 1995 to 2008 show the expected increase in Pb isotope ratios (Figure 5.7).

5.4.4. $\mathrm{Pb}$ isotopes in the northwestern Indian Ocean (Arabian Sea)

As observed in the southern Indian Ocean, a minimum of $\mathrm{Pb}$ isotope ratios also appears at stations 5-8 at density layers $26.9-27.0 \mathrm{~kg} \mathrm{~m}^{-3}$, but with a smaller magnitude (Figure 5.6). As the thermocline water of the northern Indian Ocean is mostly ventilated from the south (Fine et al., 2008; Tomczak and Godfrey, 2003; Wyrtki, 1971; You and Tomczak, 1993), it is likely that this $\mathrm{Pb}$ isotope minimum is an extended feature of that seen in the southern Indian Ocean, which enters the northern Indian Ocean along the western boundary of the Indian Ocean (and thus not appearing at station 9). The isotope ratios at the minimum increase northward as the south-origin water mass is diluted along the path (e.g. minimum ${ }^{206} \mathrm{~Pb} /{ }^{207} \mathrm{~Pb}=1.144$ at station 8 increases to 1.148 at station 5 ).

Above this minimum, a subsurface maximum of the $\mathrm{Pb}$ isotope ratio appears between 100-200m depth, where $\sigma_{\mathrm{t}}=26-26.4 \mathrm{~kg} \mathrm{~m}^{-3}$ (Figure 5.6). This subsurface maximum only appears in the northern Indian Ocean, and the maximum values are higher at the northern stations (e.g. ${ }^{206} \mathrm{~Pb} /{ }^{207} \mathrm{~Pb}=1.15$ at station 5) than the south $(1.144$ at station 8), implying that higher $\mathrm{Pb}$ isotope ratios are introduced from the north. On the $\mathrm{T}$ $\mathrm{S}$ diagram, it seems that salinity is slightly elevated at this density layer, but no particular water mass has been documented for this layer of the Arabian Sea. Water masses that are known to be ventilated from the northern Arabian Sea are either too shallow (e.g. ASHSW at $\sigma_{\mathrm{t}}=\sim 24 \mathrm{~kg} \mathrm{~m}^{-3}$ and NASHSW at $\sigma_{\mathrm{t}}=\sim 25 \mathrm{~kg} \mathrm{~m}^{-3}$ ) (Kumar and Prasad, 1999; 
Prasad and Ikeda, 2001) or too deep (e.g. PGW at $\sigma_{\mathrm{t}}=\sim 26.5 \mathrm{~kg} \mathrm{~m}^{-3}, \mathrm{RSW} \sigma_{\mathrm{t}}=\sim 27.1 \mathrm{~kg}$ $\mathrm{m}^{-3}$ ) (Prasad et al., 2001; Shetye et al., 1994), and hence we cannot identify the origin of the maximum $\mathrm{Pb}$ isotope ratios.

In the upper $100 \mathrm{~m}$, on top of the maximum $\mathrm{Pb}$ isotopes, the isotope ratios decrease sharply again, exhibiting the lowest ratios at the surface (Figure 5.6). Different water masses are delivered to the upper Arabian Sea during the summer and winter monsoons; during the summer monsoons, the water from the equator is delivered to the northern Arabian Sea by the Somali Current along the west coast, and during the winter monsoons, Bay of Bengal water enters the Arabian Sea from the southeast (Schott et al., 2009; Tomczak and Godfrey, 2003). However, because the surface Pb isotope ratios near the Equator (station 9) and the Bay of Bengal (station 2) are higher than observed in the Arabian Sea, it is more likely that the low isotope ratio $\mathrm{Pb}$ was directly introduced to the surface of the Arabian Sea rather than horizontally advected from other regions of the Indian Ocean. It is surprising to find the lowest $\mathrm{Pb}$ isotope ratios at the surface as we expect the isotope ratios of the anthropogenic $\mathrm{Pb}$ would increase as other $\mathrm{Pb}$ sources come to play more important role than leaded gasoline. There could be some $\mathrm{Pb}$ with low isotope ratios from leaded gasoline combustion that was deposited on land and re-emitted, or other $\mathrm{Pb}$ sources with low isotope ratios may exist that are not recognized yet. As the baseline study is severely limited on the $\mathrm{Pb}$ isotope compositions of various $\mathrm{Pb}$ emitting sources and aerosols, we cannot identify the source of the low $\mathrm{Pb}$ isotope ratios until more data is collected. 


\subsection{5. $\mathrm{Pb}$ isotopes in the Bay of Bengal}

One profile was obtained from the Bay of Bengal (station 2). Pb concentrations in the Bay of Bengal were almost identical to those in the Arabian Sea (Figure 5.8), with a surface maximum at $\sim 76 \mathrm{pmol} \mathrm{kg}^{-1}$ and gradual decrease with depth until reaching to the almost constant $\mathrm{Pb}$ concentrations $\left(5-7 \mathrm{pmol} \mathrm{kg}^{-1}\right)$ below $\sim 2000 \mathrm{~m}$. The vertical distribution of $\mathrm{Pb}$ isotope ratios in the Bay of Bengal was similar to that of the Arabian Sea, with a minimum at the surface and subsurface maximum at $100 \mathrm{~m}$ and increasing values below. The isotope ratios, however, were higher in the Bay of Bengal than in the Arabian Sea by 0.005-0.01 for both ratios (Figure 5.8), suggesting that the Bay of Bengal and the Arabian Sea were influenced by different sources of $\mathrm{Pb}$. These sources could include anthropogenic inputs, advected water mass features, and/or exchange with particles, and the potential influence of these sources are discussed in the following paragraphs.

The observed isotope offset between the Bay of Bengal and the Arabian Sea is likely due in part to differences in anthropogenic inputs. As the prevailing winds switch between southwesterlies and northeasterlies, the Bay of Bengal likely receives more aerosols from China and southeast Asia than the Arabian Sea. Chinese city aerosols collected in mid 1990s have higher $\mathrm{Pb}$ isotope ratios than those from India and northern Africa (Bollhöfer and Rosman, 2001), and $\mathrm{Pb}$ isotope ratios from Chinese aerosols further increased after the phase out of leaded gasoline around 2000 (Cheng and $\mathrm{Hu}$, 2010 and references therein). However, if the isotope offset was caused by differences in atmospheric anthropogenic $\mathrm{Pb}$ inputs only, the largest offset should appear at the surface 
and in the upper water column above $\sim 1500 \mathrm{~m}$, where $\mathrm{Pb}$ concentrations are increased due to anthropogenic $\mathrm{Pb}$ inputs. Comparing $\mathrm{Pb}$ isotopes at station 2 to the stations at similar latitudes (stations 6 and 7), the offset is slightly larger in the upper water column, but a significant offset still appears in the deep water column. When compared to station 5, the offset is almost uniform throughout the entire water column (Figure 5.8). Thus, this offset cannot be explained by the different provenance of anthropogenic $\mathrm{Pb}$ alone.

Different $\mathrm{Pb}$ isotope ratios might have been advected to the Arabian Sea and Bay of Bengal from the south, as the bottom waters of the Arabian Sea originate in the Weddell Sea and those of the Bay of Bengal originate in the Adelie Land coast/Ross Sea (Gordon and Tchernia, 1972; Mantyla and Reid, 1983; 1995). This seems unlikely because the $\mathrm{Pb}$ isotope ratios of the stations 9 and 3, which are located in the south of Arabian Sea and Bay of Bengal, respectively, are similar (Figure 5.8). If the Weddell Sea and Ross Sea source waters carried different isotope signatures, this should be evident at these upstream stations as well. There is, however, another pathway for the Antarctic Bottom water to reach the Bay of Bengal. West Australian Basin deep water, which also originates in the Adelie Land coast/Ross Sea spreads to the Bay of Bengal from the southeast, in the north of the Ninety East Ridge (Mantyla and Reid, 1995). While the $\mathrm{Pb}$ isotope ratios of the West Australian Basin deep water are not well characterized, the distribution of $\mathrm{Pb}$ isotope ratios of $\mathrm{Fe}-\mathrm{Mn}$ deposits in the Indian Ocean basins suggests that the $\mathrm{Pb}$ isotope signals carried by southern waters must either be lost before entering the northern Indian Ocean, or else be completely overwhelmed by sources within the N- 
Indian Ocean (Vlastélic et al., 2001). Thus, deep water advection is less likely the reason of the observed isotope offset.

Given the $\mathrm{Pb}$ isotope ratios in deep waters of the Bay of Bengal that are similar to the stations 3 and 9, and the lower values observed in the deep Arabian Sea, there must be an external input of low-isotope-ratio $\mathrm{Pb}$ to the deep Arabian Sea. Exchange between dissolved and particulate species has been suggested to influence the isotopic distributions of other particle reactive elements such as Nd (Lacan and Jeandel, 2005; Jeandel et al., 1998; Amakawa et al., 2000). This exchange can occur along ocean boundaries by reacting with the sediments on the continental shelf and slope (Lacan and Jeandel, 2005; Jeandel et al., 1998; Amakawa et al., 2000) and with river particles and sediments (Oelkers, 2012; Singh et al., 2012), and also in the water column by reacting with sinking biogenic particles (Grasse et al., 2012). This isotope exchange could occur without a significant change in the dissolved $\mathrm{Nd}$ concentrations in seawater, as the $\mathrm{Nd}$ fluxes liberated from particles are matched by concurrent precipitation of Nd-bearing secondary phases (Oelkers et al., 2012), although the detailed processes of the exchange remain unclear. $\mathrm{Pb}$ has higher affinity to particles than $\mathrm{Nd}$, but similar processes may influence the distribution of $\mathrm{Pb}$ isotopes in the Arabian Sea.

Stations 5 and 6 in the northern Arabian Sea are characterized by higher particle concentrations (higher turbidity) than station 2 in the Bay of Bengal (Figure 5.9), with peaks at around $250 \mathrm{~m}$ and $1000 \mathrm{~m}$ depth. They could be biogenic particles produced in situ, as the Arabian Sea is one of the most biologically productive ocean regions (Ryther and Menzel, 1965). They also could be the particles derived directly from the Indus River, 
which discharges $100 \mathrm{Mt}$ of sediments annually (Milliman and Meade, 1983), and the resuspended sediments that were exported from the wide (up to $\sim 500 \mathrm{~km}$ ) continental shelf and slope of the eastern Arabian Sea. These sediments are composed of organic matter deposited from the overlying water column and detrital materials from the Indus River and the hinterland (Kessarkar et al., 2003; Nath et al., 1997). High particle concentrations of the Arabian Sea result in net scavenging of $\mathrm{Pb}$ in the water column, as seen in the low $\mathrm{Pb}$ concentrations in deep layers (Figures 5.3 and 5.8). Even so, reversible exchange may occur between dissolved and particulate $\mathrm{Pb}$, while particles releasing the upper-ocean or terrestrial $\mathrm{Pb}$ isotope signal into seawater depending on the origin of the particles. Our hypothesis is consistent with the isotopic equilibrium between dissolved and suspended particulate $\mathrm{Pb}$ in the water column near Bermuda reported by Sherrell and Boyle (1992), although lithogenic particles contribute less than $20 \%$ of the particles at this location (Sherrell and Boyle, 1992b) and detailed process of the exchange may be different from what occurs in the Arabian Sea.

Otherwise, isotope exchange may occur at oceanic boundaries, continental shelf and slope, or deep-sea floor (Indus Fan), and the altered $\mathrm{Pb}$ isotope signals may be advected to the central Arabian Sea. Edmond et al. (1979) reported a nutrient-rich benthic layer in the Arabian Sea, which is the result of intense respiration and dissolution occurring in the benthic sediments of the continental shelf and slope (Broecker et al., 1980). The Fe and Mn oxidation-reduction cycling involved in these benthic processes has been suggested to produce a sink for particle-reactive elements (boundary scavenging) (Spencer et al., 1981). However, even though the boundary processes are a sink for 
elemental $\mathrm{Pb}$, they may allow the $\mathrm{Pb}$ isotope exchange between seawater and benthic particles by accelerating the $\mathrm{Pb}$-release from particles and re-precipitation of $\mathrm{Pb}$ containing particles.

If dissolved-particulate $\mathrm{Pb}$ isotope exchange occurs in the Arabian Sea, this could explain the low $\mathrm{Pb}$ isotope ratios in the Arabian Sea when the reacting particles and sediments have low $\mathrm{Pb}$ isotope ratios (e.g. ${ }^{206} \mathrm{~Pb} /{ }^{207} \mathrm{~Pb}<1.165$ ). Biogenic particles are likely to contain the $\mathrm{Pb}$ isotope signatures of the upper Arabian Sea, where the isotope ratios are as low as $1.145\left({ }^{206} \mathrm{~Pb} /{ }^{207} \mathrm{~Pb}\right)$. Lithogenic particles may have higher isotope ratios, for example, the Indus River drains the Himalayas, whose source rocks (noncontaminated) contain ${ }^{206} \mathrm{~Pb} /{ }^{207} \mathrm{~Pb}$ higher than 1.2 (Scharer, 1984; Scharer et al., 1986). However, it is possible that the lithogenic particles are contaminated with anthropogenic $\mathrm{Pb}$ in downstream areas and have low isotope ratios.

$\mathrm{Pb}$ isotope exchange might occur in the Bay of Bengal as well. The Bay of Bengal has narrower continental shelf off the eastern coast of India, but particle discharges from the Ganges-Brahmaputra (G-B) (1670 Mt $\mathrm{yr}^{-1}$, Milliman and Meade, 1983) are larger than the Indus River, forming the Bengal Fan that extends $\sim 8{ }^{\circ} \mathrm{S}$ (Nath et al., 1989). Intense respiration and dissolution also occur in the benthic sediments of the Bay of Bengal, resulting in the nutrient-rich deep water (Broecket et al., 1980) and boundary scavenging of $\mathrm{Pb}$ (Cochran et al., 1983). It is possible that the effect of $\mathrm{Pb}$ isotope exchange was not observed at station 2 because station 2 is not as close to the river mouth and the continental margin as stations $5-8$, which is also probably the reason why the particle densities in station 2 are lower than stations 5 and 6 (Figure 5.9). It is also 
possible that the altered benthic $\mathrm{Pb}$ isotope signals were erased by the West Australian Basin deep water. Otherwise, the $\mathrm{Pb}$ isotope ratios of the particles and sediments in the Bay of Bengal may not be as low as those in the Arabian Sea, so the particle-seawater interaction does not decrease the $\mathrm{Pb}$ isotope ratios of the waters in the Bay of Bengal.

\subsection{Conclusions}

The $\mathrm{Pb}$ concentrations and $\mathrm{Pb}$ isotope compositions of the Indian Ocean demonstrate the importance of anthropogenic input and hydrography on the modern Indian Ocean $\mathrm{Pb}$ distribution. Six conclusions are obtained from these observations:

1. $\mathrm{Pb}$ concentrations are elevated in the upper water column, with a surface maximum and a decrease with depth, and surface $\mathrm{Pb}$ concentrations of the (northern) Indian Ocean are higher than present-day Atlantic and Pacific oceans. This implies that the Indian Ocean receives large surface $\mathrm{Pb}$ inputs because of the late phase-out of leaded gasoline and increased $\mathrm{Pb}$ emissions from other industrial sources in the countries surrounding the Indian Ocean.

2. $\mathrm{Pb}$ isotope ratios $\left({ }^{206} \mathrm{~Pb} /{ }^{207} \mathrm{~Pb}\right.$ and $\left.{ }^{208} \mathrm{~Pb} /{ }^{207} \mathrm{~Pb}\right)$ of the Indian Ocean are controlled by mixing of anthropogenic $\mathrm{Pb}$ with low isotope ratios that is introduced from above, and the $\mathrm{Pb}$ with high isotope ratios that is carried northward in deep layers from the Southern Ocean. As shown in the high $\mathrm{Pb}$ isotope ratios, the water in the Southern Ocean is less contaminated, but is still under the influence of the anthropogenic $\mathrm{Pb}$ despite its remote location. 
3. The minimum of $\mathrm{Pb}$ isotope ratios occurring at $600-800 \mathrm{~m}$ depth of the southern Indian Ocean (stations 10-12) and at 400-600m depth of the southern Arabian Sea (stations 5-8) seems to be associated with the SAMW that is formed in the southeast Indian Ocean and advected northward. The low $\mathrm{Pb}$ isotope ratios are probably due to inputs of $\mathrm{Pb}$ from Australia (and southern Africa) to the SAMW formation region, which had low isotope ratios when the SAMW was formed.

4. An increase of $\mathrm{Pb}$ isotope ratios from SAMW to the surface is probably because of the temporal evolution of the anthropogenic $\mathrm{Pb}$ isotope ratios toward higher values, which is the result of increased coal burning and mining and decreased use of leaded gasoline. This, in addition to the $\mathrm{Pb}$ concentration distributions described in summary 1 , corroborates our conclusion that $\mathrm{Pb}$ emissions other than from leaded gasoline combustion are becoming more important in the India Ocean region.

5. In the northern Indian Ocean (most prominently in Arabian Sea), there is a surface minimum and subsurface maximum of $\mathrm{Pb}$ isotopes. These features seem to be related to the $\mathrm{Pb}$ inputs of characteristic isotope ratios from the atmosphere or advected from the northern Arabian Sea. However, because of the lack of data on the $\mathrm{Pb}$ isotope ratios of the recent emission sources around the northern Indian Ocean, we could not identify the sources of these features.

6. $\mathrm{Pb}$ isotope ratios in the Bay of Bengal are higher than the Arabian Sea, whereas $\mathrm{Pb}$ concentrations are similar. The difference may be partly because each ocean receives anthropogenic $\mathrm{Pb}$ inputs from different sources, and also might be the result of the $\mathrm{Pb}$ isotope exchange between dissolved and particulate species in the Arabian Sea. 
This study reports the first reliable $\mathrm{Pb}$ data from the Indian Ocean and provides baseline knowledge on the Indian Ocean $\mathrm{Pb}$ and $\mathrm{Pb}$ isotope distribution. The study shows a potential of using $\mathrm{Pb}$ isotope ratios to trace the sources and pathways of time-dependent elements and water circulation in the Indian Ocean. For instance, an anomalous $\mathrm{Pb}$ isotope minimum may possibly be used as a tracer of the SAMW in the Indian Ocean thermocline. Additional water column observations and studies on the history and isotope composition of $\mathrm{Pb}$ emitted from surrounding regions will further facilitate the utility of $\mathrm{Pb}$ isotopes. Moreover, our hypothesis about the particle-seawater $\mathrm{Pb}$ isotope exchange in the Arabian Sea (and Bay of Bengal) needs to be verified by batch experiments and field observations. 


\section{References for Chapter 5}

Amakawa, H., D. A. Alibo, and Y. Nozaki (2000), Nd isotopic composition and REE pattern in the surface waters of the easter Indian Ocean and its adjacent seas, Geochim. Comochim. Ac., 64(10), 1715-1727.

Banse, K., and J. R. Postel (2009), Wintertime Convection and Ventilation of the Upper Pycnocline in the Northernmost Arabian Sea, Geophys. Monogr. Ser., 185, 87-117.

Bollhöfer, A., and K. J. R. Rosman (2000), Isotopic source signatures for atmospheric lead: The Southern Hemisphere, Geochim. Cosmochim. Ac., 64(19), 3251-3262.

Bollhöfer, A., and K. J. R. Rosman (2001), Isotopic source signatures for atmospheric lead: The Northern Hemisphere, Geochim. Cosmochim. Ac., 65(11), 1727-1740.

Boye, M., B. D. Wake, P. L. Garcia, J. Bown, A. R. Baker, and E. P. Achterberg (2012), Distributions of dissolved trace metals $(\mathrm{Cd}, \mathrm{Cu}, \mathrm{Mn}, \mathrm{Pb}, \mathrm{Ag})$ in the southeastern Atlantic and the Southern Ocean, Biogeosciences, 9(8), 3231-3246.

Boyle, E. A., R. M. Sherrel, and M. P. Bacon (1994), Lead Variability in the Western North-Atlantic Ocean and Central Greenland Ice - Implications for the Search for Decadel Trends in Anthropogenic Emissions, Geochim. Cosmochim. Ac., 58(15), 3227-3238.

Boyle, E. A., S. D. Chapnick, G. T. Shen, and M. P. Bacon (1986), Temporal Variability of Lead in the Western North-Atlantic, J. Geophys. Res.-Oceans, 91(C7), 85738593.

Boyle, E. A., B. A. Bergquist, R. A. Kayser, and N. Mahowald (2005), Iron, Manganese, and lead at Hawaii Ocean Time-series station ALOHA: Temporal variability and an intermediate water hydrothermal plume, Geochim. Cosmochim. Acta, 69(4), 933952.

Boyle, E. A., et al. (2012), GEOTRACES IC1 (BATS) contamination-prone trace element isotopes $\mathrm{Cd}, \mathrm{Fe}, \mathrm{Pb}, \mathrm{Zn}, \mathrm{Cu}$, and $\mathrm{Mo}$ intercalibration, Limnol. Oceanogr.Meth., 10, 653-665.

Broecker, W., R. Toggweiler, and T. Takahashi (1980), The Bay of Bengal - a major nutrient source for the deep Indian Ocean, Earth Planet. Sci. Lett., 49, 506-512.

Cheng, H. F., and Y. A. Hu (2010), Lead (Pb) isotopic fingerprinting and its applications in lead pollution studies in China: A review, Environ. Pollut., 158(5), 1134-1146.

Chiaradia, M., B. E. Chenhall, A. M. Depers, B. L. Gulson, and B. G. Jones (1997), Identification of historical lead sources in roof dusts and recent lake sediments from an industrialized area: indications from lead isotopes, Sci. Total Environ., 205(2-3), $107-128$.

Chung, Y. (1987), ${ }^{210} \mathrm{~Pb}$ in the western Indian Ocean: distribution, disequilibrium, and partitioning between dissolved and particulate phases, Earth Planet. Sc. Lett., 85, $28-40$.

Cochran, J. K., M. P. Bacon, S. Krishnaswami, and K. K. Turekian (1983), ${ }^{210}$ Po and ${ }^{210} \mathrm{~Pb}$ distributions in the central and eastern Indian Ocean, Earth Planet. Sc. Lett., 65, 433-452.

Cooper, J. A., P. H. Reynolds, and J. R. Richards (1969), Double-Spike Calibration of Broken Hill Standard Lead, Earth Planet. Sc. Lett., 6(6), 467-478. 
Cumming, G. L., and J. R. Richards (1975), Ore Lead Isotope Ratios in a Continuously Changing Earth, Earth Planet. Sc. Lett, 28(2), 155-171.

Danielsson, L. G. (1980), Cadmium, Cobalt, Copper, Iron, Lead, Nickel and Zinc in Indian-Ocean Water, Mar. Chem., 8(3), 199-215.

Diaz-Somoano, M., M. E. Kylander, M. A. Lopez-Anton, I. Suarez-Ruiz, M. R. Martinez-Tarazona, M. Ferrat, B. Kober, and D. J. Weiss (2009), Stable Lead Isotope Compositions In Selected Coals From Around The World And Implications For Present Day Aerosol Source Tracing, Environ. Sci. Technol., 43(4), 1078-1085.

Edmond, J., S. Jacobs, A. Gordon, A. Mantyla, and R. Weiss (1979), Water column anomalies in dissolved silica over opaline pelagic sediments and the origin of the deep silica maximum, J. Geophys. Res., 84(C12), 7809-7826.

Ellwood, M. J. (2008), Wintertime trace metal (Zn, Cu, Ni, Cd, Pb and Co) and nutrient distributions in the Subantarctic Zone between 40-52 degrees S; 155-160 degrees E, Mar. Chem., 112(1-2), 107-117.

Farmer, J. G., L. J. Eades, and M. C. Graham (1999), The lead content and isotopic composition of British coals and their implications for past and present releases of lead to the UK environment, Environ. Geochem. Hlth., 21(3), 257-272.

Fine, R. A. (1993), Circulation of Antarctic Intermediate Water in the South IndianOcean, Deep-Sea Res. Pt. I, 40(10), 2021-2042.

Fine, R. A., W. M. Smethie, J. L. Bullister, M. Rhein, D. H. Min, M. J. Warner, A. Poisson, and R. F. Weiss (2008), Decadal ventilation and mixing of Indian Ocean waters, Deep-Sea Res. Pt. I, 55(1), 20-37.

Flegal, A. R., and C. C. Patterson (1983), Vertical Concentration Profiles of Lead in the Central Pacific at 15-Degrees-N and 20-Degrees-S, Earth Planet. Sc. Lett., 64(1), 19-32.

Flegal, A. R., H. Maring, and S. Niemeyer (1993), Anthropogenic Lead in Antarctic SeaWater, Nature, 365(6443), 242-244.

Flegal, A. R., K. Itoh, C. C. Patterson, and C. S. Wong (1986), Vertical Profile of Lead Isotopic Compositions in the Northeast Pacific, Nature, 321(6071), 689-690.

Gallon, C., M. A. Ranville, C. H. Conaway, W. M. Landing, C. S. Buck, P. L. Morton, and A. R. Flegal (2011), Asian Industrial Lead Inputs to the North Pacific Evidenced by Lead Concentrations and Isotopic Compositions in Surface Waters and Aerosols, Environ. Sci. Technol., 45(23), 9874-9882.

Gordon, A. L., and P. L. Tchernia (1972), Waters of the continental margin off Adelie Coast, Antarctica, in Antarctic Oceanography II: The Australizn-New Zealand Sector, Antarct. Res. Ser., edited by E. Hayes, pp. 59-69, AGU, Washington, D.C.

Grasse, P., T. Stichel, R. Stumpf, L. Stramma, and M. Frank (2012), The distribution of neodymium isotopes and concentrations in the Eastern Equatorial Pacific: Water mass advection versus particle exchange, Earth Planet. Sci. Lett., 353-354, 198-207.

Hanawa, K., and L. D. Talley (2001), Mode waters, in Ocean Circulation and Climate, edited by G. Siedler, J. Church and J. Gould, Academic Press, New York.

Honeybun, R., A. F. Bollhofer, and K. J. R. Rosman (2003), Atmospheric transport of radiogenic lead in the vicinity of Ranger uranium mine determined using lead 
isotope ratios in dust deposited on acacia leaves, edited, Department of the Environment and Heritage, Australian Government.

Jeandel, C., D. Thouron, and M. Fieux (1998), Concentrations and isotopic compositions of neodymium in the eastern Indian Ocean and Indonesian straits, Geochim. Cosmochim. Ac., 62, 2597-2607.

Karstensen, J., and M. Tomczak (1997), Ventilation processes and water mass ages in the thermocline of the southeast Indian Ocean, Geophys. Res. Lett., 24(22), 2777-2780.

Karstensen, J., and D. Quadfasel (2002), Water subducted into the Indian Ocean subtropical gyre, Deep-Sea Res. Pt. II, 49(7-8), 1441-1457.

Kessarkar, P. M., V. P. Rao, S. M. Ahmad, and G. A. Babu (2003), Clay minerals and Sr$\mathrm{Nd}$ isotopes of the sediments along the western margin of India and their implication for sediment provenance, Mar. Geol., 202, 55-69.

Kumar, S. P., and T. G. Prasad (1999), Formation and spreading of Arabian Sea highsalinity water mass, J. Geophys. Res.-Oceans, 104(C1), 1455-1464.

Lacan, F. and C. Jeandel (2005), Neodymium isotopes as a new tool for quantifying exchange fluxes at the continent-ocean interface, Geophys. Res. Lett., 31, L14306.

Lee, J. M., E. A. Boyle, Y. Echegoyen-Sanz, J. N. Fitzsimmons, R. F. Zhang, and R. A. Kayser (2011), Analysis of trace metals $(\mathrm{Cu}, \mathrm{Cd}, \mathrm{Pb}$, and $\mathrm{Fe})$ in seawater using single batch nitrilotriacetate resin extraction and isotope dilution inductively coupled plasma mass spectrometry, Anal. Chim. Acta, 686(1-2), 93-101.

Mantyla, A. W., and J. L. Reid (1983), Abyssal Characteristics of the World Ocean Waters, Deep-Sea Res., 30(8), 805-833.

Mantyla, A. W., and J. L. Reid (1995), On the Origins of Deep and Bottom Waters of the Indian-Ocean, J. Geophys. Res.-Oceans, 100(C2), 2417-2439.

McCarthy, M. C., and L. D. Talley (1999), Three-dimensional isoneutral potential vorticity structure in the Indian Ocean, J. Geophys. Res.-Oceans, 104(C6), 1325113267.

McCartney, M. S. (1977), Subantarctic Mode Water, Deep-Sea Res., 24, 103-119.

McCartney, M. S. (1982), The subtropical recirculation of mode waters, J. Mar. Res., 40, 427-464.

Milliman, J. D., and R. H. Meade (1983), World-Wide Delivery of River Sediment to the Oceans, J Geol, 91(1), 1-21.

Morley, N. H., P. J. Statham, and J. D. Burton (1993), Dissolved Trace-Metals in the Southwestern Indian-Ocean, Deep-Sea Res. Pt. I, 40(5), 1043-1062.

Nath, B. N., M. Bau, B. R. Rao, and C. M. Rao (1997), Trace and rare earth elemental variation in Arabian Sea sediments through a transect across the oxygen minimum zone, Geochim. Cosmochim. Ac., 61, 2375-2388.

Nath, B. N., V. P. Rao, and K. P. Becker (1989), Geochemical Evidence of Terrigenous Influence in Deep-Sea Sediments up to 8-Degrees-S in the Central Indian Basin, Mar. Geol., 87(2-4), 301-313.

Nriagu, J. O., M. L. Blankson, and K. Ocran (1996a), Childhood lead poisoning in Africa: A growing public health problem, Sci. Total Environ., 181(2), 93-100.

Nriagu, J. O., C. Jinabhai, R. Naidoo, and A. Coutsoudis (1996b), Atmospheric lead pollution in KwaZulu/Natal, South Africa, Sci. Total Environ., 191(1-2), 69-76. 
Oelkers, E. H., M. T. Jones, C. R. Pearce, C. Jeandel, E. S. Eiriksdottir, and S. R. Gislason (2012), Riverine particulate material dissolution in seawater and its implications for the global cycles of the elements, Comptes Rendus Geoscience, 344, 646-651.

Prasad, T. G., and M. Ikeda (2001), Spring evolution of Arabian Sea High in the Indian Ocean, J. Geophys. Res.-Oceans, 106(C12), 31085-31098.

Prasad, T. G., M. Ikeda, and S. P. Kumar (2001), Seasonal spreading of the Persian Gulf Water mass in the Arabian Sea, J. Geophys. Res.-Oceans, 106(C8), 17059-17071.

Premchand, K. (1982), Spreading and Mixing of the Persian Gulf Water in the Northern Arabian Sea, Indian J. Mar. Sci., 11(4), 321-326.

Reuer, M. K., E. A. Boyle, and B. C. Grant (2003), Lead isotope analysis of marine carbonates and seawater by multiple collector ICP-MS, Chem. Geol., 200, 137-153.

Ryther, J. H. and D. W. Menzel (1965), On the production, composition, and distribution of organic matter in the Arabian Sea, Deep Sea Res., 12, 199-209.

Sallee, J. B., N. Wienders, K. Speer, and R. Morrow (2006), Formation of subantarctic mode water in the southeastern Indian Ocean, Ocean Dynam., 56(5-6), 525-542.

Sanudo-Wilhelmy, S. A., K. A. Olsen, J. M. Scelfo, T. D. Foster, and A. R. Flegal (2002), Trace metal distributions off the Antarctic Peninsula in the Weddell Sea, Mar. Chem., 77(2-3), 157-170.

Scharer, U. (1984), The Effect of Initial Th-230 Disequilibrium on Young U-Pb Ages the Makalu Case, Himalaya, Earth Planet. Sc. Lett., 67(2), 191-204.

Scharer, U., R. H. Xu, and C. J. Allegre (1986), U-(Th)-Pb Systematics and Ages of Himalayan Leukogranites, South Tibet, Earth Planet. Sc. Lett., 77(1), 35-48.

Schaule, B. K., and C. C. Patterson (1981), Lead Concentrations in the Northeast Pacific - Evidence for Global Anthropogenic Perturbations, Earth Planet. Sc. Lett., 54(1), 97-116.

Schaule, B. K., and C. C. Patterson (1983), Perturbations of the natural lead profile in the Sargasso Sea by industrial lead, in Trace Metals in Sea Water, edited by C. S. Wong, pp. 487-504, Plenum, New York.

Schott, F. A., M. Dengler, and R. Schoenefeldt (2002), The shallow overturning circulation of the Indian Ocean, Prog. Oceanogr., 53(1), 57-103.

Schott, F. A., S. P. Xie, and J. P. McCreary (2009), Indian Ocean Circulation and Climate Variability, Rev. Geophys., 47.

Senior, K. (2006), Africa bans lead in gasoline, Frontiers in Ecology and the Environment, 4(1), 7-7.

Shen, G. T., and E. A. Boyle (1987), Lead in Corals - Reconstruction of Historical Industrial Fluxes to the Surface Ocean, Earth Planet. Sc. Lett., 82(3-4), 289-304.

Sherrell, R. M., and E. A. Boyle (1992a), Isotopic Equilibration between Dissolved and Suspended Particulate Lead in the Atlantic-Ocean - Evidence from Pb-210 and Stable Pb Isotopes, J. Geophys. Res.-Oceans, 97(C7), 11257-11268.

Sherrell, R. M., and E. A. Boyle (1992b), The Trace-Metal Composition of Suspended Particles in the Oceanic Water Column near Bermuda, Earth Planet. Sc. Lett., 111(1), 155-174. 
Shetye, S. R., A. D. Gouveia, and S. S. C. Shenoi (1994), Circulation and Water Masses of the Arabian Sea, P. Indian. Acad. Sci.-Earth, 103(2), 107-123.

Singh, S. P., S. K. Singh, V. Goswami, R. Bhushan, and V. K. Rai (2012), Spatial distribution of dissolved neodymium and $\varepsilon N d$ in the Bay of Bengal: Role of particulate matter and mixing of water masses, Geochim. Cosmochim. Ac., 94, 3856.

Spencer, D. W., M. P. Bacon and P. G. Brewer (1981), Models of the distribution of ${ }^{210} \mathrm{~Pb}$ in a section across the North Equatorial Atlantic Ocean, J. Mar. Res. 29, 119138.

Tomczak, M., and J. S. Godfrey (2003), Regional Oceanography: an Introduction, Daya Publishing House, Delhi.

Toole, J. M., and B. A. Warren (1993), A Hydrographic Section across the Subtropical South Indian-Ocean, Deep-Sea Res. Pt. I, 40(10), 1973-2019.

UNEP (2007), The global campaign to eliminate leaded gasoline: progress as of January 2007, edited, www.unep.org/pcfv/PDF/LeadReport.pdf.

Vlastelic, I., W. Abouchami, S. J. G. Galer, and A. W. Hofmann (2001), Geographic control on $\mathrm{Pb}$ isotope distribution and sources in Indian Ocean Fe-Mn deposits, Geochim. Cosmochim. Ac., 65(23), 4303-4319.

Warren, B. A. (1981), Transindian Hydrographic Section at Lat 18-Degrees-S - Property Distributions and Circulation in the South Indian-Ocean, Deep-Sea Res., 28(8), 759-788.

Westerlund, S., and P. Ohman (1991), Cadmium, Copper, Cobalt, Nickel, Lead, and Zinc in the Water Column of the Weddell Sea, Antarctica, Geochim. Cosmochim. Ac., 55(8), 2127-2146.

Witt, M. L. I., A. R. Baker, and T. D. Jickells (2006), Atmospheric trace metals over the Atlantic and South Indian Oceans: Investigation of metal concentrations and lead isotope ratios in coastal and remote marine aerosols, Atmos. Environ., 40(28), 5435-5451.

Witt, M. L. I., T. A. Mather, A. R. Baker, J. C. M. De Hoog, and D. M. Pyle (2010), Atmospheric trace metals over the south-west Indian Ocean: Total gaseous mercury, aerosol trace metal concentrations and lead isotope ratios, Mar. Chem., 121(1-4), 2 16.

Wu, J. F., and E. A. Boyle (1997a), Lead in the western North Atlantic Ocean: Completed response to leaded gasoline phaseout, Geochim. Cosmochim. Ac., 61(15), 3279-3283.

Wu, J. F., and E. A. Boyle (1997b), Low blank preconcentration technique for the determination of lead, copper, and cadmium in small-volume seawater samples by isotope dilution ICPMS, Anal. Chem., 69(13), 2464-2470.

Wu, J. F., R. Rember, M. B. Jin, E. A. Boyle, and A. R. Flegal (2010), Isotopic evidence for the source of lead in the North Pacific abyssal water, Geochim. Cosmochim. Ac., 74(16), 4629-4638.

Wyrtki, K. (1971), Oceanographic atlas of the International Indian Ocean Expedition, National Science Foundation. 
Wyrtki, K. (1973), Physical oceanography of the Indian Ocean, in The biology of the Indian Ocean, edited by B. Zeitzschel, pp. 18-36, Springer-Verlag, Berlin.

You, Y. Z. (1998), Intermediate water circulation and ventilation of the Indian Ocean derived from water-mass contributions, J. Mar. Res., 56(5), 1029-1067.

You, Y. Z., and M. Tomczak (1993), Thermocline Circulation and Ventilation in the Indian-Ocean Derived from Water Mass Analysis, Deep-Sea Res. Pt. I, 40(1), 13-56.

Zubrick, C. M., P. L. Morton, C. Gallon, A. M. Shiller, W. M. Landing, and A. R. Flegal (2012), Intercalibration of $\mathrm{Cd}$ and $\mathrm{Pb}$ concentration measurements in the northwest Pacific Ocean, Limnol. Oceanogr.-Meth., 10, 270-277. 


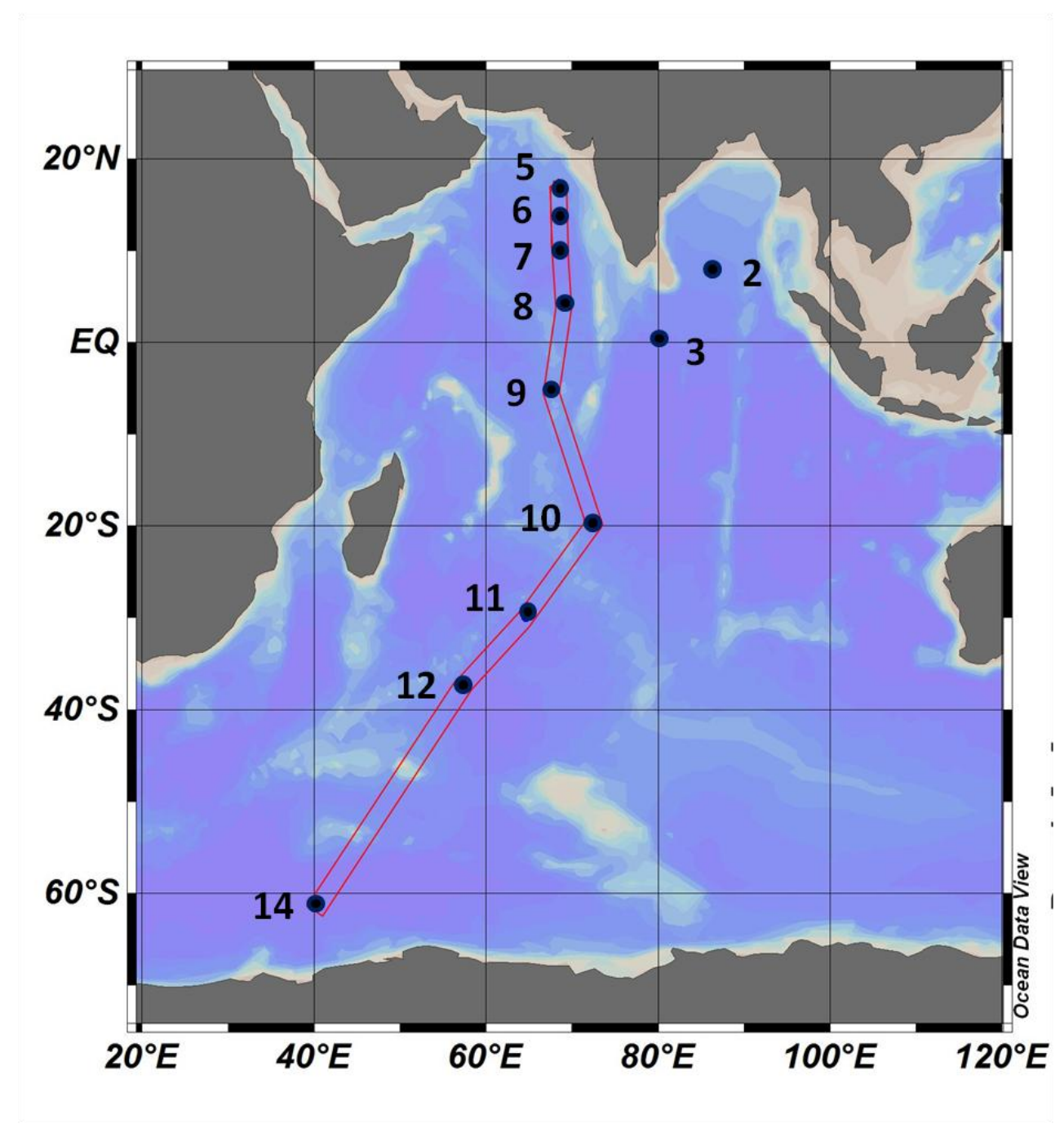

Figure 5.1 Map of sampling stations. Transect line for Figure 3 is shown in red. 

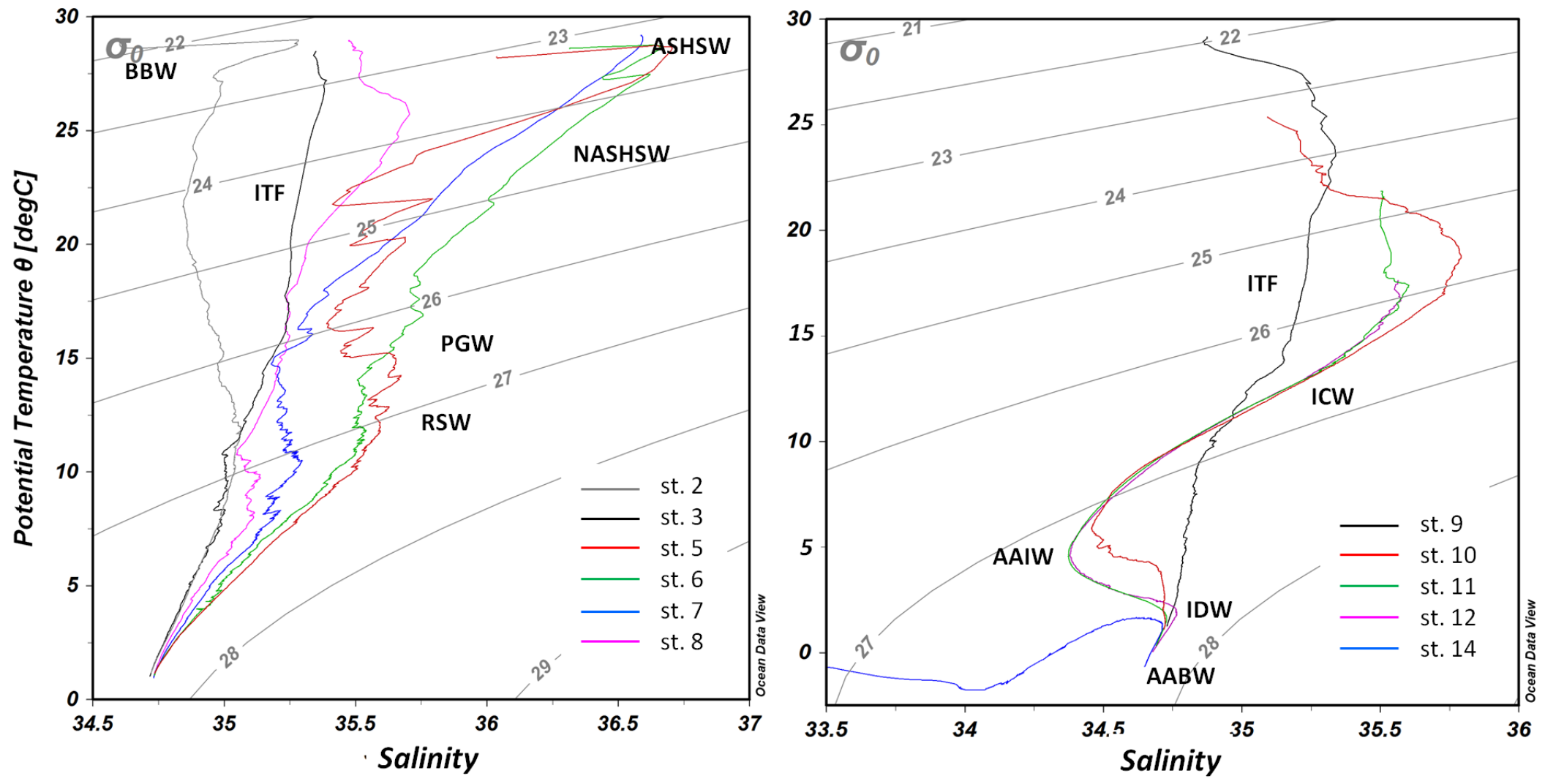

Figure 5.2 T-S diagram of the stations in the northern (left) and southern Indian Oceans (right). 


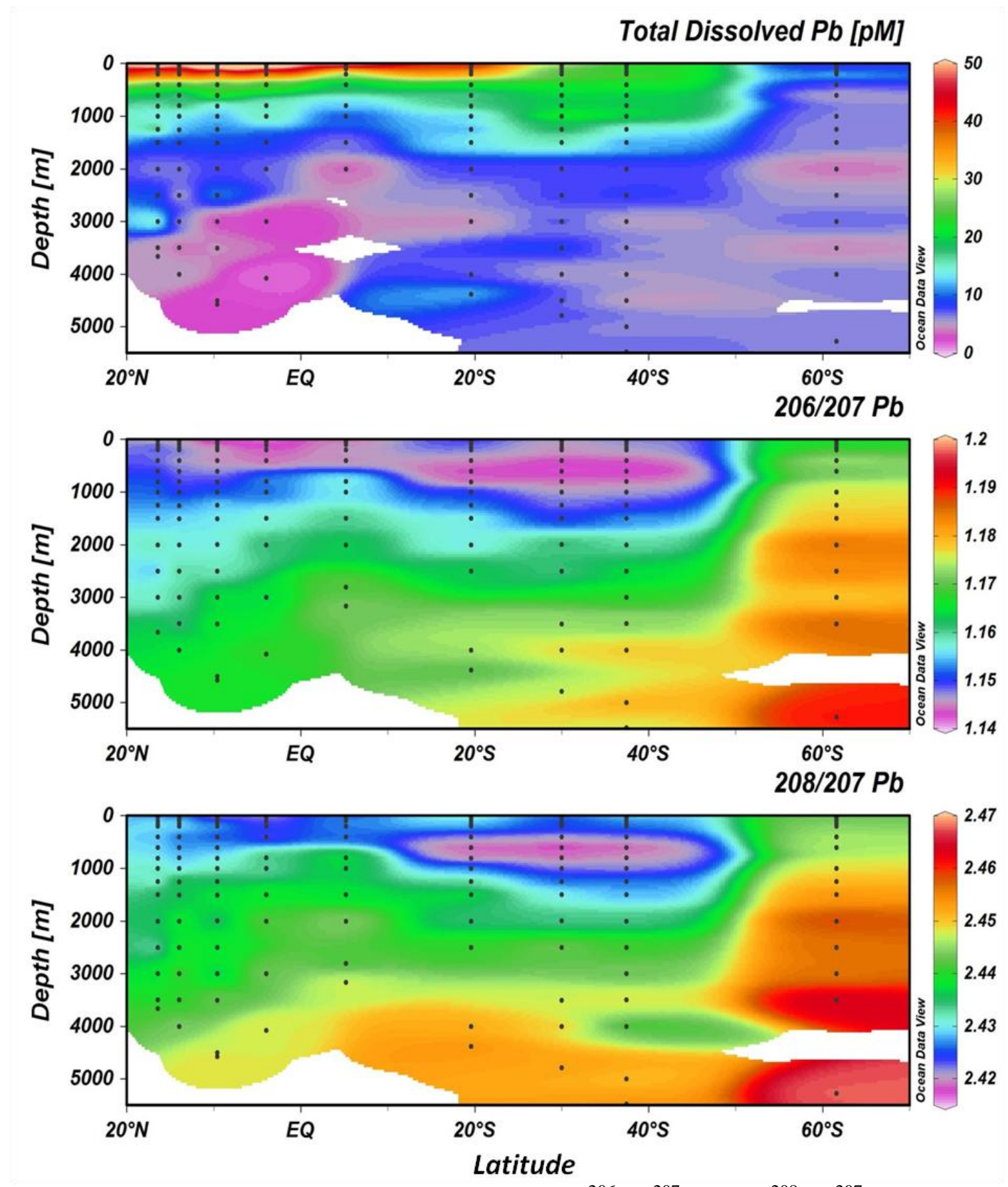

Figure 5.3 Transect of dissolved $\mathrm{Pb}$ concentrations, ${ }^{206} \mathrm{~Pb} /{ }^{207} \mathrm{~Pb}$, and ${ }^{208} \mathrm{~Pb} /{ }^{207} \mathrm{~Pb}$ ratios from stations 5 to 14 . Black dots show the sampling locations. 


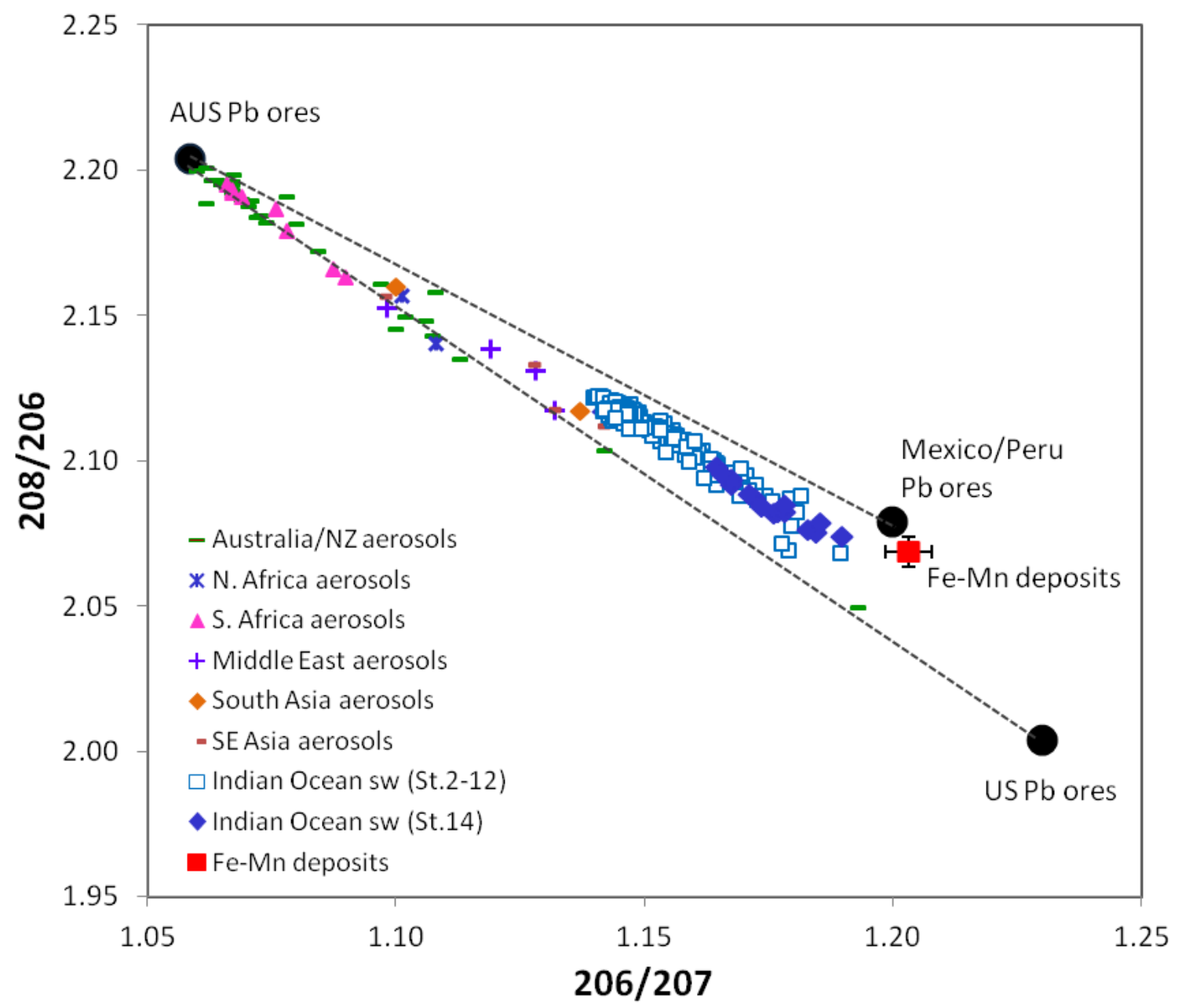

Figure 5.4 Triple isotope plot for the $\mathrm{Pb}$ in the Indian Ocean seawater and the aerosols collected from the major cities in Australia/New Zealand, Africa, Middle East, South and Southeast Asia (Bollhöfer and Rosman, 2000; 2001). Plotted together are the average of the $\mathrm{Pb}$ in Fe-Mn deposits in the Indian Ocean basins (Vlastelic et al., 2001), and the $\mathrm{Pb}$ in Australian (Broken Hill type), U.S. (Mississippi valley type), and Peruvian/Mexican Pb ores (Broken Hill) (Cooper et al., 1969; Doe, 1970; Cummings and Richards, 1975), which were used for alkyllead production. 


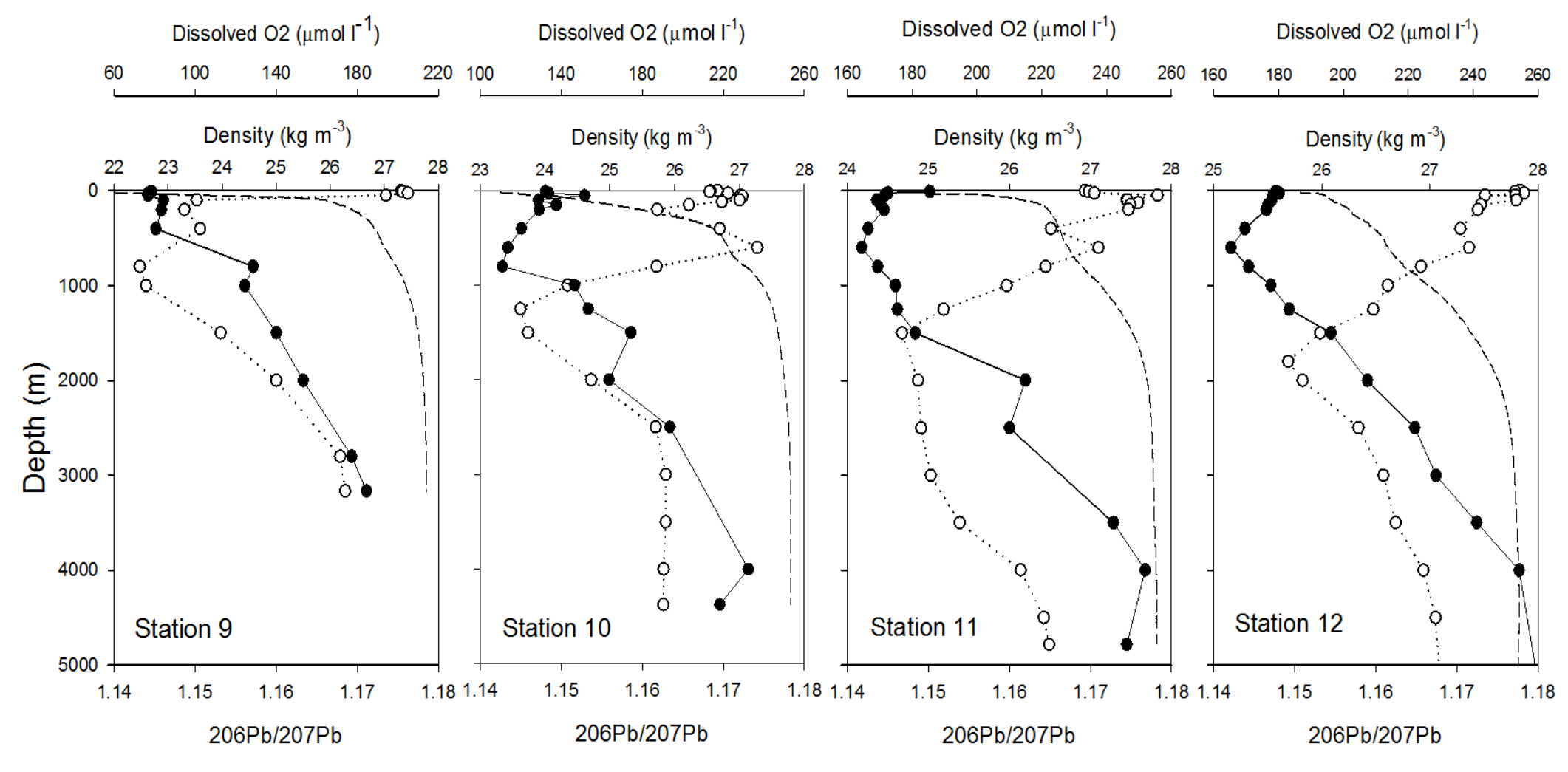

Figure 5.5 ${ }^{206} \mathrm{~Pb} /{ }^{207} \mathrm{~Pb}(\bullet)$, dissolved $\mathrm{O}_{2}$ concentration $(\circ)$, and density (dashed line) profiles of the southern Indian Ocean (stations 9-12). Note that dissolved $\mathrm{O}_{2}$ concentrations decrease northward. Waters with low densities $\left(<24 \mathrm{~kg} \mathrm{~m}^{-3}\right)$ appear in the shallow depths of the stations at lower latitudes (stations 9 and 10). 


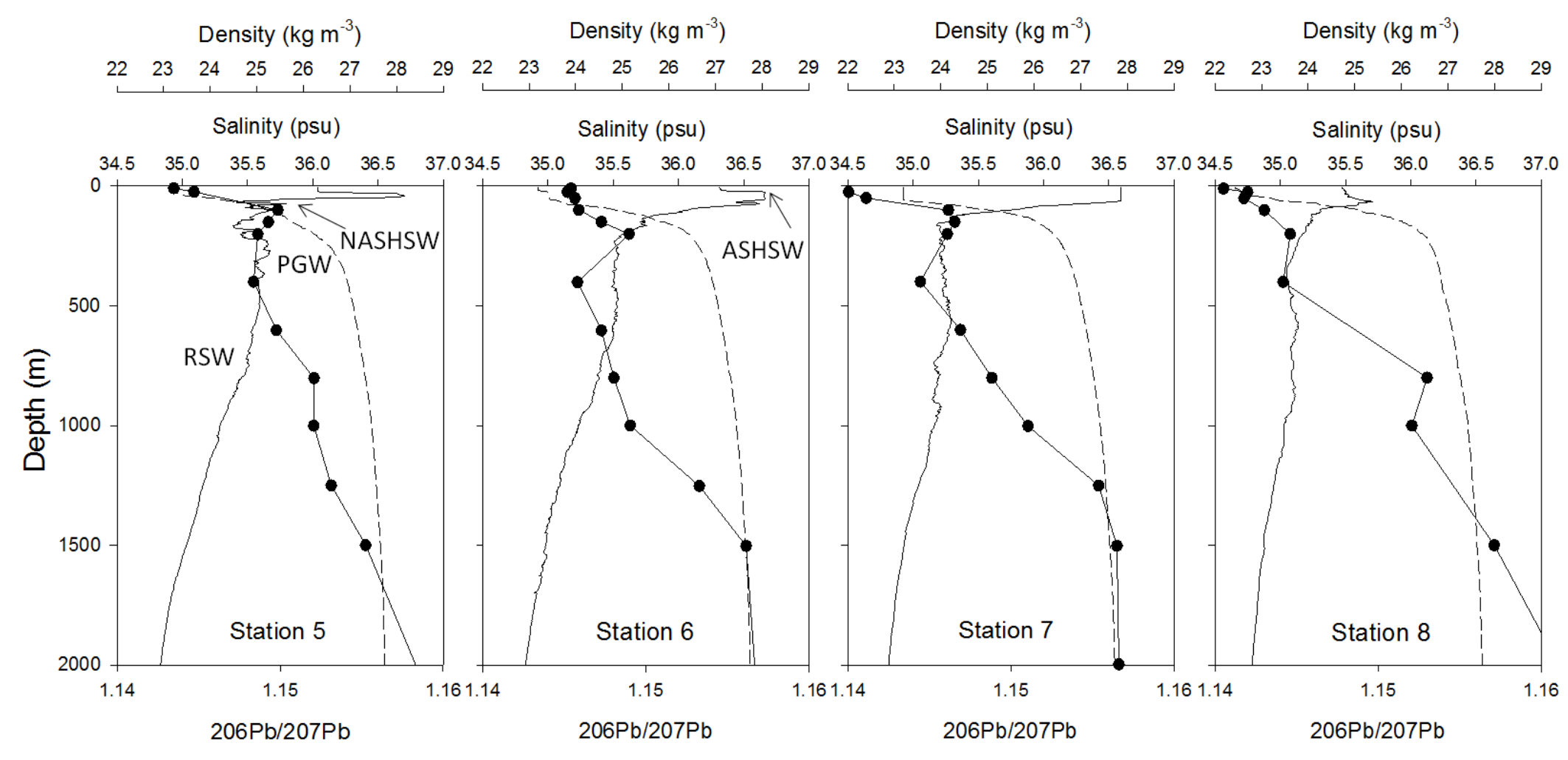

Figure 5.6 ${ }^{206} \mathrm{~Pb} /{ }^{207} \mathrm{~Pb}(\bullet)$, salinity (solid line), and density (dashed line) profiles of the northern Indian Ocean upper water column (stations 5-8). 


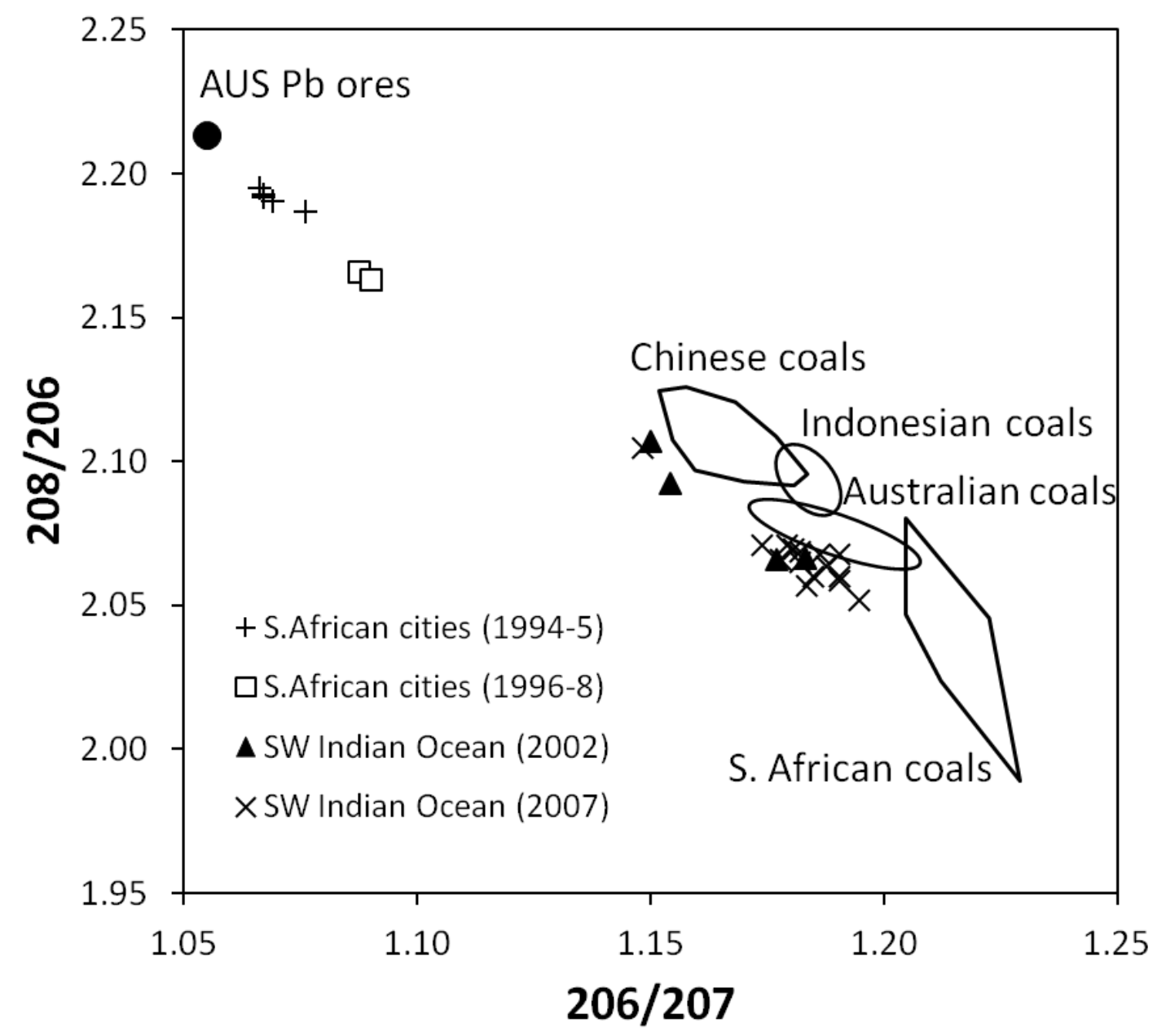

Figure 5.7 $\mathrm{Pb}$ isotope composition of coals from countries around the Indian Ocean (Diaz-Somoano et al., 2009), aerosols collected from southern African cities in 1994-5 and 1996-8 (Bollhöfer and Rosman, 2000), and marine aerosols collected near southern Africa in 2002 (Witt et al., 2006) and 2007 (Witt et al., 2010). 


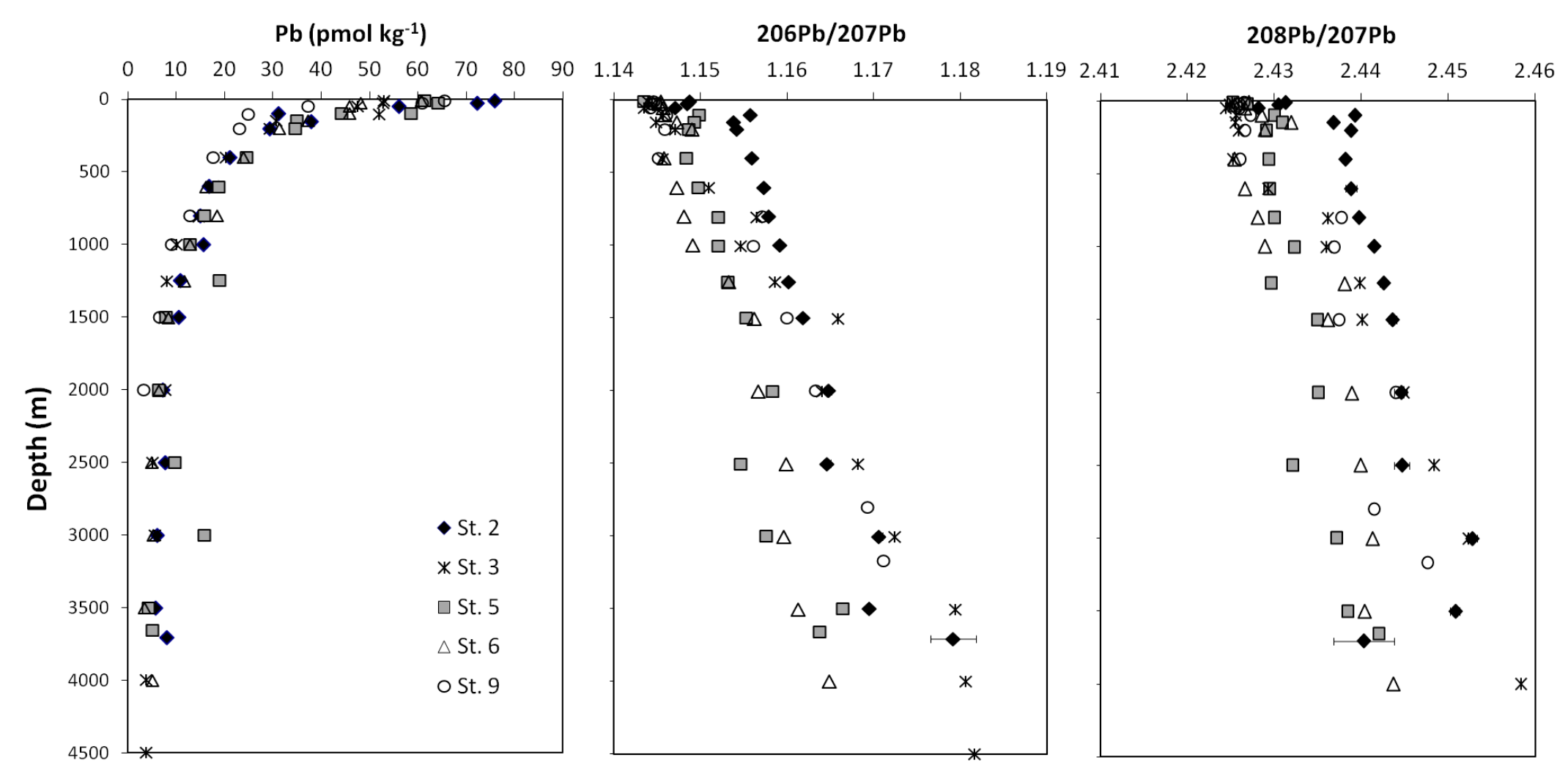

Figure 5.8 Profiles of dissolved $\mathrm{Pb}$ concentration and isotope ratios from the Bay of Bengal (St.2) in comparison with those from the Arabian Sea (St. 5 and 6). Stations 3 and 9 are located at the south of the Bay of Bengal and Arabian Sea, respectively. 


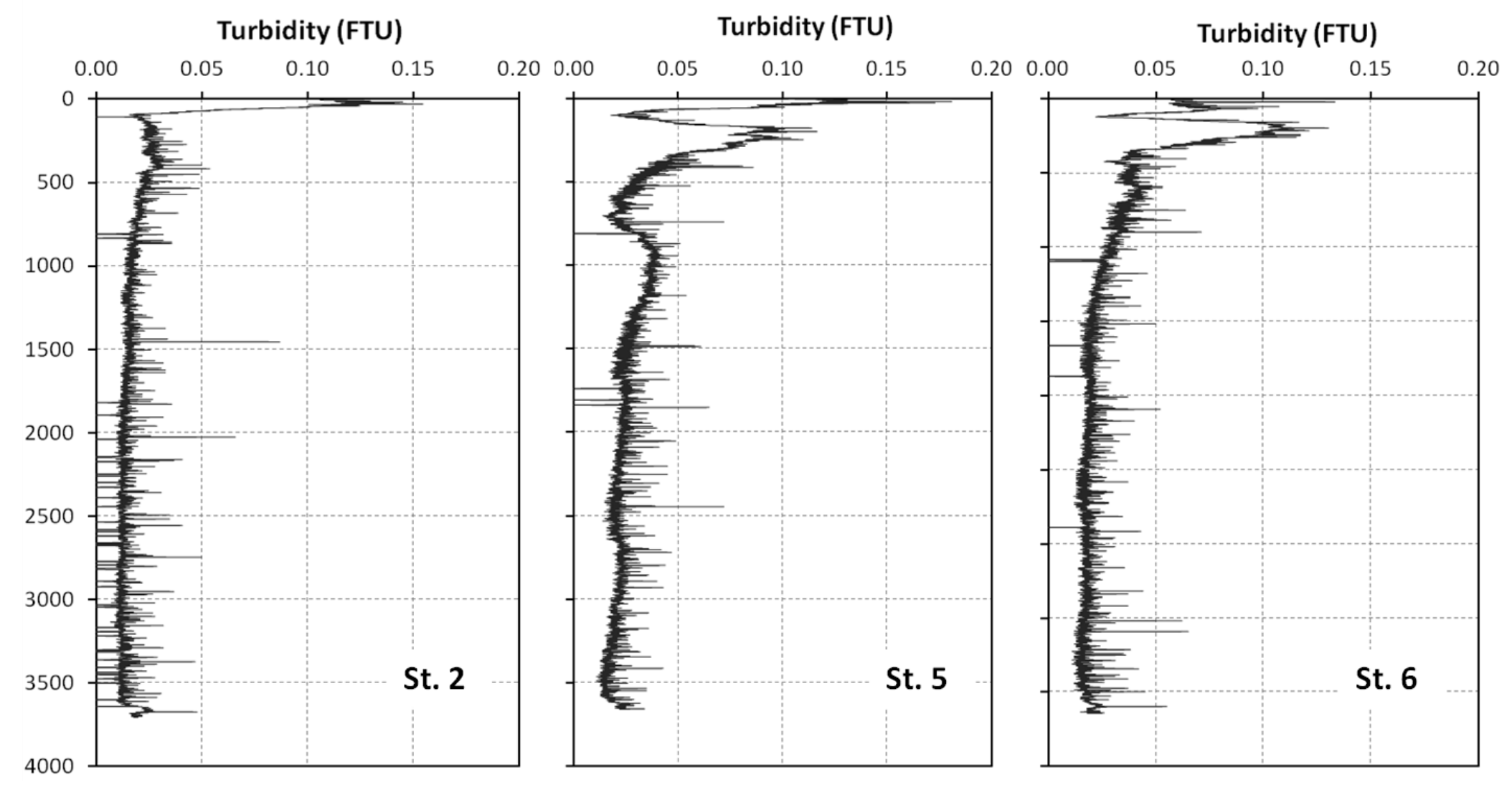

Figure 5.9 Turbidity (FTU) of station 2 (Bay of Bengal), and stations 5 and 6 (Arabian Sea). 
Table 5.1 Sampling locations of the Japanese Indian GEOTRACES cruise (KH09-5) with water column depth (m), salinity (psu), temperature $\left({ }^{\circ} \mathrm{C}\right)$, and $\sigma_{\theta}\left(\mathrm{kg} \mathrm{m}^{-3}\right)$.

\begin{tabular}{|c|c|c|c|c|c|c|c|}
\hline Depth & Salinity & Temp. & $\sigma_{\theta}$ & Depth & Salinity & Temp. & $\boldsymbol{\sigma}_{\theta}$ \\
\hline \multicolumn{4}{|c|}{ Station $2\left(0^{\circ} 31.10^{\prime} \mathrm{N}, 8^{\circ} 01.55^{\prime} \mathrm{E}\right)$} & \multicolumn{4}{|c|}{ Station $5\left(16^{\circ} 44.58^{\prime} \mathrm{N}, 6^{\circ} 59.72^{\prime} \mathrm{E}\right)$} \\
\hline 11 & 28.84 & 34.62 & 21.83 & 10 & 28.13 & 35.90 & 23.03 \\
\hline 26 & 28.71 & 34.67 & 21.92 & 25 & 28.27 & 36.11 & 23.14 \\
\hline 51 & 28.26 & 35.23 & 22.49 & 100 & 19.88 & 35.68 & 25.32 \\
\hline 100 & 21.31 & 34.85 & 24.31 & 151 & 17.02 & 35.54 & 25.94 \\
\hline 151 & 16.64 & 34.94 & 25.57 & 201 & 15.35 & 35.48 & 26.28 \\
\hline 200 & 14.57 & 35.00 & 26.08 & 400 & 12.78 & 35.63 & 26.94 \\
\hline 401 & 10.74 & 35.04 & 26.87 & 602 & 11.17 & 35.53 & 27.18 \\
\hline 601 & 9.20 & 35.02 & 27.12 & 803 & 9.87 & 35.45 & 27.35 \\
\hline 801 & 7.90 & 34.98 & 27.29 & 1001 & 8.44 & 35.31 & 27.48 \\
\hline 1000 & 6.82 & 34.94 & 27.42 & 1250 & 6.92 & 35.16 & 27.58 \\
\hline 1250 & 5.72 & 34.90 & 27.53 & 1501 & 5.47 & 35.03 & 27.67 \\
\hline 1500 & 4.57 & 34.85 & 27.63 & 2001 & 3.18 & 34.84 & 27.77 \\
\hline 2000 & 2.88 & 34.79 & 27.75 & 2501 & 2.25 & 34.78 & 27.80 \\
\hline 2501 & 2.14 & 34.75 & 27.79 & 3000 & 1.84 & 34.75 & 27.82 \\
\hline 3001 & 1.74 & 34.74 & 27.81 & 3500 & 1.72 & 34.74 & 27.82 \\
\hline 3501 & 1.48 & 34.72 & 27.82 & 3658 & 1.71 & 34.74 & 27.82 \\
\hline \multirow[t]{2}{*}{3706} & 1.44 & 34.72 & 27.82 & & & & \\
\hline & & & & \multicolumn{4}{|c|}{ Station $6\left(14^{\circ} 00.12^{\prime} \mathrm{N}, 68^{\circ} 59.45^{\prime} \mathrm{E}\right)$} \\
\hline \multicolumn{4}{|c|}{ Station $3\left(00^{\circ} 00.34^{\prime} \mathrm{S}, 8^{\circ} 00.38^{\prime} \mathrm{E}\right)$} & 10 & 28.53 & 36.32 & 23.21 \\
\hline 11 & 28.36 & 35.36 & 22.55 & 26 & 28.71 & 36.66 & 23.41 \\
\hline 26 & 28.36 & 35.36 & 22.55 & 51 & 28.28 & 36.61 & 23.52 \\
\hline 51 & 28.21 & 35.41 & 22.64 & 100 & 22.32 & 36.03 & 24.92 \\
\hline 101 & 27.93 & 35.42 & 22.74 & 150 & 18.36 & 35.75 & 25.77 \\
\hline 150 & 16.50 & 35.23 & 25.82 & 201 & 15.84 & 35.72 & 26.35 \\
\hline 203 & 13.75 & 35.14 & 26.36 & 402 & 12.33 & 35.48 & 26.92 \\
\hline 402 & 10.77 & 35.01 & 26.84 & 603 & 11.17 & 35.51 & 27.16 \\
\hline 601 & 9.41 & 35.01 & 27.08 & 801 & 9.62 & 35.39 & 27.35 \\
\hline 807 & 7.79 & 34.99 & 27.32 & 1000 & 7.91 & 35.21 & 27.48 \\
\hline 1001 & 6.47 & 34.93 & 27.46 & 1253 & 6.50 & 35.09 & 27.58 \\
\hline 1251 & 5.21 & 34.87 & 27.57 & 1503 & 5.14 & 34.98 & 27.67 \\
\hline 1503 & 4.19 & 34.83 & 27.65 & 2003 & 3.11 & 34.83 & 27.77 \\
\hline 2001 & 2.58 & 34.77 & 27.76 & 2502 & 2.21 & 34.77 & 27.80 \\
\hline 2501 & 2.03 & 34.75 & 27.79 & 3000 & 1.82 & 34.75 & 27.82 \\
\hline 3003 & 1.72 & 34.73 & 27.81 & 3500 & 1.72 & 34.74 & 27.82 \\
\hline 3501 & 1.50 & 34.73 & 27.82 & 4000 & 1.71 & 34.74 & 27.82 \\
\hline 4000 & 1.40 & 34.72 & 27.83 & & & & \\
\hline 4501 & 1.41 & 34.72 & 27.83 & & & & \\
\hline
\end{tabular}


Table 5.1 (continued)

\begin{tabular}{|c|c|c|c|c|c|c|c|}
\hline Depth & Salinity & Temp. & $\sigma_{\theta}$ & Depth & Salinity & Temp. & $\sigma_{\theta}$ \\
\hline \multicolumn{4}{|c|}{ Station $7\left(09^{\circ} 59.88^{\prime} \mathrm{N}, 68^{\circ} 44.79^{\prime} \mathrm{E}\right)$} & \multicolumn{4}{|c|}{ 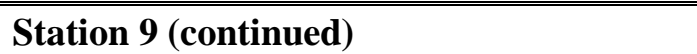 } \\
\hline 10 & 29.07 & 36.54 & 23.20 & 101 & 15.53 & 35.19 & 26.01 \\
\hline 26 & 29.09 & 36.55 & 23.20 & 202 & 12.65 & 35.03 & 26.50 \\
\hline 51 & 28.96 & 36.59 & 23.28 & 401 & 10.13 & 34.88 & 26.85 \\
\hline 101 & 18.45 & 35.42 & 25.49 & 801 & 7.52 & 34.83 & 27.23 \\
\hline 150 & 15.94 & 35.30 & 26.00 & 1001 & 6.09 & 34.80 & 27.40 \\
\hline 201 & 13.76 & 35.22 & 26.42 & 1500 & 3.92 & 34.78 & 27.64 \\
\hline 400 & 11.43 & 35.24 & 26.90 & 2000 & 2.71 & 34.76 & 27.74 \\
\hline 602 & 10.27 & 35.28 & 27.14 & 2801 & 1.79 & 34.73 & 27.80 \\
\hline 802 & 8.70 & 35.16 & 27.31 & 3166 & 1.71 & 34.73 & 27.81 \\
\hline 1003 & 7.93 & 35.17 & 27.44 & & & & \\
\hline 1251 & 6.46 & 35.05 & 27.56 & \multicolumn{4}{|c|}{ Station $10\left(19^{\circ} 59.63^{\prime} \mathrm{S}, 72^{\circ} 32.67^{\prime} \mathrm{E}\right)$} \\
\hline 1503 & 5.08 & 34.94 & 27.64 & 11 & 25.38 & 35.13 & 23.33 \\
\hline 1998 & 3.11 & 34.82 & 27.76 & 25 & 24.97 & 35.19 & 23.50 \\
\hline 2501 & 2.19 & 34.77 & 27.80 & 52 & 23.13 & 35.23 & 24.08 \\
\hline 3003 & 1.81 & 34.74 & 27.81 & 100 & 21.60 & 35.37 & 24.62 \\
\hline 3501 & 1.71 & 34.74 & 27.82 & 151 & 20.66 & 35.67 & 25.11 \\
\hline 4004 & 1.69 & 34.73 & 27.82 & 201 & 19.49 & 35.77 & 25.50 \\
\hline 4500 & 1.70 & 34.73 & 27.82 & 403 & 12.82 & 35.21 & 26.61 \\
\hline \multirow[t]{2}{*}{4570} & 1.71 & 34.73 & 27.82 & 601 & 9.56 & 34.73 & 26.83 \\
\hline & & & & 802 & 6.28 & 34.47 & 27.11 \\
\hline \multicolumn{4}{|c|}{ Station $8\left(04^{\circ} 00.83^{\prime} \mathrm{N}, 69^{\circ} 00.42^{\prime} \mathrm{E}\right)$} & 1001 & 4.65 & 34.53 & 27.36 \\
\hline 11 & 28.93 & 35.47 & 22.44 & 1251 & 4.32 & 34.66 & 27.50 \\
\hline 26 & 28.67 & 35.49 & 22.55 & 1501 & 3.80 & 34.71 & 27.60 \\
\hline 51 & 28.29 & 35.52 & 22.70 & 2001 & 2.64 & 34.72 & 27.71 \\
\hline 102 & 20.17 & 35.32 & 24.97 & 2500 & 1.87 & 34.72 & 27.78 \\
\hline 200 & 13.23 & 35.17 & 26.49 & 3001 & 1.57 & 34.72 & 27.80 \\
\hline 401 & 10.85 & 35.07 & 26.87 & 3502 & 1.42 & 34.72 & 27.82 \\
\hline 801 & 8.62 & 35.09 & 27.27 & 4002 & 1.43 & 34.72 & 27.82 \\
\hline 1001 & 7.09 & 35.02 & 27.44 & 4377 & 1.46 & 34.72 & 27.82 \\
\hline 1501 & 4.62 & 34.87 & 27.64 & & & & \\
\hline 2002 & 2.81 & 34.79 & 27.76 & \multicolumn{4}{|c|}{ Station $11\left(30^{\circ} 00.02^{\prime} \mathrm{S}, 64^{\circ} 59.93^{\prime} \mathrm{E}\right)$} \\
\hline 3001 & 1.79 & 34.74 & 27.81 & 10 & 21.10 & 35.52 & 24.87 \\
\hline \multirow[t]{2}{*}{4074} & 1.72 & 34.74 & 27.82 & 25 & 20.52 & 35.50 & 25.01 \\
\hline & & & & 50 & 17.56 & 35.58 & 25.83 \\
\hline \multicolumn{4}{|c|}{ Station $9\left(05^{\circ} 16.01^{\prime} \mathrm{S}, 67^{\circ} 54.25^{\prime} \mathrm{E}\right)$} & 100 & 15.21 & 35.46 & 26.28 \\
\hline 10 & 29.07 & 34.89 & 21.96 & 151 & 14.37 & 35.39 & 26.42 \\
\hline 25 & 28.51 & 34.92 & 22.17 & 200 & 13.91 & 35.36 & 26.49 \\
\hline 50 & 25.12 & 35.29 & 23.53 & 400 & 12.45 & 35.15 & 26.63 \\
\hline
\end{tabular}


Table 5.1 (continued)

\begin{tabular}{|c|c|c|c|c|c|c|c|}
\hline Depth & Salinity & Temp. & $\sigma_{\theta}$ & Depth & Salinit & Temp. & $\sigma_{\theta}$ \\
\hline \multicolumn{4}{|c|}{ "Station 11 (continued) } & \multicolumn{4}{|c|}{ Station 12 (continued) } \\
\hline 600 & 11.19 & 34.95 & 26.72 & 3001 & 2.0 & 34.8 & 27.84 \\
\hline 801 & 8.66 & 34.63 & 26.90 & 3499 & 1.4 & 34.7 & 27.80 \\
\hline 1001 & 5.58 & 34.40 & 27.14 & 4000 & 0.6 & 34.7 & 27.86 \\
\hline 1251 & 3.75 & 34.42 & 27.36 & 4501 & 0.5 & 34.7 & 27.86 \\
\hline 1500 & 3.05 & 34.54 & 27.53 & 5000 & 0.5 & 34.7 & 27.87 \\
\hline 1999 & 2.33 & 34.69 & 27.71 & 5474 & 0.5 & 34.7 & 27.87 \\
\hline 2501 & 1.99 & 34.73 & 27.78 & & & & \\
\hline 3001 & 1.73 & 34.73 & 27.80 & \multicolumn{4}{|c|}{ Station $14\left(61^{\circ} 59.95, \mathrm{~S}, 40^{\circ} 05.98^{\prime} \mathrm{E}\right)$} \\
\hline 3501 & 1.46 & 34.72 & 27.82 & 9 & -0.31 & 33.35 & 26.79 \\
\hline 4000 & 0.91 & 34.70 & 27.84 & 25 & -1.38 & 33.83 & 27.22 \\
\hline 4500 & 0.72 & 34.69 & 27.84 & 51 & -1.72 & 34.02 & 27.39 \\
\hline \multirow[t]{2}{*}{4782} & 0.72 & 34.69 & 27.85 & 100 & -1.10 & 34.18 & 27.50 \\
\hline & & & & 149 & 1.15 & 34.51 & 27.65 \\
\hline \multicolumn{4}{|c|}{ Station $12\left(37^{\circ} 45.15^{\prime} \mathrm{S}, 57^{\circ} 37.13^{\prime} \mathrm{E}\right)$} & 201 & 1.46 & 34.60 & 27.70 \\
\hline 10 & 17.8 & 35.6 & 25.79 & 399 & 1.48 & 34.69 & 27.77 \\
\hline 26 & 17.2 & 35.6 & 25.93 & 600 & 1.34 & 34.71 & 27.80 \\
\hline 50 & 16.6 & 35.5 & 26.00 & 1000 & 0.96 & 34.71 & 27.83 \\
\hline 100 & 16.3 & 35.5 & 26.07 & 1250 & 0.78 & 34.70 & 27.83 \\
\hline 151 & 15.9 & 35.5 & 26.17 & 1501 & 0.62 & 34.70 & 27.84 \\
\hline 200 & 15.4 & 35.5 & 26.28 & 2000 & 0.37 & 34.68 & 27.84 \\
\hline 401 & 13.7 & 35.3 & 26.50 & 2500 & 0.18 & 34.67 & 27.85 \\
\hline 600 & 12.2 & 35.1 & 26.65 & 2999 & 0.03 & 34.67 & 27.86 \\
\hline 800 & 9.9 & 34.8 & 26.83 & 3501 & -0.09 & 34.66 & 27.86 \\
\hline 1000 & 7.7 & 34.6 & 27.02 & 4001 & -0.16 & 34.66 & 27.86 \\
\hline 1251 & 4.7 & 34.4 & 27.25 & 4500 & -0.22 & 34.65 & 27.86 \\
\hline 1501 & 3.5 & 34.4 & 27.37 & 5000 & -0.24 & 34.65 & 27.86 \\
\hline 2001 & 2.7 & 34.6 & 27.61 & 5272 & -0.25 & 34.65 & 27.86 \\
\hline 2499 & 2.4 & 34.8 & 27.80 & & & & \\
\hline
\end{tabular}


Table 5.2 $\mathrm{Pb}$ concentration and $\mathrm{Pb}$ isotope results from the Japanese Indian GEOGRACES cruise (KH09-5). Sampling stations and depths (m) are same as Table 5.1. $\mathrm{Pb}$ concentrations are pmol kg${ }^{-1}$ and $2 \sigma$ represents the standard deviation of triplicate measurements. The $2 \sigma$ for $\mathrm{Pb}$ isotopes are internal statistics of 20 , ten seconds integrations via MC-ICP-MS. (* indicates samples possibly contaminated)

\begin{tabular}{|c|c|c|c|c|c|c|c|c|}
\hline Depth & {$[\mathbf{P b}]$} & $2 \sigma$ & $206 / 207$ & $2 \sigma$ & $208 / 207$ & $2 \sigma$ & $206 / 204$ & $2 \sigma$ \\
\hline \multicolumn{9}{|c|}{ Station 2} \\
\hline 11 & 75.93 & 1.16 & 1.1488 & 0.0001 & 2.4313 & 0.0002 & 18.24 & 0.01 \\
\hline 26 & 72.20 & 1.39 & 1.1485 & 0.0001 & 2.4304 & 0.0001 & 17.89 & 0.01 \\
\hline 51 & 56.10 & 1.15 & 1.1479 & 0.0001 & 2.4281 & 0.0002 & 17.91 & 0.01 \\
\hline 100 & 31.20 & 0.57 & 1.1558 & 0.0001 & 2.4392 & 0.0002 & 18.00 & 0.01 \\
\hline 151 & 38.00 & 0.70 & 1.1538 & 0.0000 & 2.4368 & 0.0001 & 18.17 & 0.01 \\
\hline 200 & 29.35 & 0.21 & 1.1541 & 0.0001 & 2.4388 & 0.0003 & 18.04 & 0.01 \\
\hline 401 & 21.15 & 0.07 & 1.1559 & 0.0001 & 2.4382 & 0.0002 & 18.00 & 0.01 \\
\hline 601 & 16.83 & 0.25 & 1.1573 & 0.0004 & 2.4388 & 0.0006 & 18.14 & 0.02 \\
\hline 801 & 15.07 & 1.19 & 1.1579 & 0.0001 & 2.4397 & 0.0002 & 18.07 & 0.01 \\
\hline 1000 & 15.60 & 4.10 & 1.1592 & 0.0001 & 2.4415 & 0.0002 & 18.35 & 0.01 \\
\hline 1250 & 10.93 & 0.57 & 1.1601 & 0.0002 & 2.4425 & 0.0004 & 18.21 & 0.01 \\
\hline 1500 & 10.50 & 0.28 & 1.1618 & 0.0002 & 2.4436 & 0.0004 & 18.25 & 0.01 \\
\hline 2000 & 7.23 & 1.15 & 1.1647 & 0.0004 & 2.4445 & 0.0007 & 18.32 & 0.04 \\
\hline 2501 & 7.67 & 0.25 & 1.1646 & 0.0004 & 2.4446 & 0.0009 & 18.27 & 0.03 \\
\hline 3001 & 6.07 & 0.21 & 1.1706 & 0.0004 & 2.4527 & 0.0006 & 18.40 & 0.03 \\
\hline 3501 & 5.75 & 0.35 & 1.1695 & 0.0003 & 2.4508 & 0.0006 & 18.32 & 0.03 \\
\hline 3706 & 8.05 & 0.35 & 1.1792 & 0.0027 & 2.4403 & 0.0035 & 18.16 & 0.16 \\
\hline \multicolumn{9}{|c|}{ Station 3} \\
\hline 11 & 53.03 & 1.32 & 1.1439 & 0.0001 & 2.4251 & 0.0001 & 17.84 & 0.01 \\
\hline 26 & 52.80 & 0.28 & 1.1444 & 0.0001 & 2.4248 & 0.0001 & 17.80 & 0.01 \\
\hline 51 & 47.43 & 1.14 & 1.1435 & 0.0001 & 2.4244 & 0.0002 & 17.84 & 0.01 \\
\hline 101 & 51.90 & 0.26 & 1.1457 & 0.0001 & 2.4255 & 0.0002 & 18.10 & 0.01 \\
\hline 150 & 30.67 & 1.58 & 1.1449 & 0.0001 & 2.4255 & 0.0001 & 17.98 & 0.00 \\
\hline 203 & 29.33 & 0.96 & 1.1471 & 0.0001 & 2.4259 & 0.0002 & 17.83 & 0.01 \\
\hline 402 & 20.25 & 0.35 & 1.1456 & 0.0002 & 2.4252 & 0.0007 & 17.91 & 0.05 \\
\hline 601 & 17.63 & 1.56 & 1.1510 & 0.0010 & 2.4293 & 0.0018 & 18.18 & 0.05 \\
\hline 807 & 14.60 & 0.17 & 1.1564 & 0.0005 & 2.4361 & 0.0008 & 18.30 & 0.03 \\
\hline 1001 & 9.97 & 0.25 & 1.1546 & 0.0002 & 2.4360 & 0.0002 & 18.10 & 0.01 \\
\hline 1251 & 8.10 & 0.28 & 1.1586 & 0.0002 & 2.4398 & 0.0006 & 18.23 & 0.01 \\
\hline 1503 & 7.60 & 0.46 & 1.1658 & 0.0012 & 2.4401 & 0.0019 & 18.37 & 0.04 \\
\hline 2001 & 7.70 & 0.57 & 1.1640 & 0.0004 & 2.4448 & 0.0006 & 18.29 & 0.02 \\
\hline 2501 & 5.05 & 1.63 & 1.1682 & 0.0007 & 2.4483 & 0.0009 & 18.34 & 0.04 \\
\hline
\end{tabular}


Table 5.2 (continued)

\begin{tabular}{|c|c|c|c|c|c|c|c|c|}
\hline Depth & {$[\mathbf{P b}]$} & $2 \sigma$ & $206 / 207$ & $2 \sigma$ & $208 / 207$ & $2 \sigma$ & $206 / 204$ & $2 \sigma$ \\
\hline \multicolumn{9}{|c|}{ Station 3 (continued) } \\
\hline 3003 & 5.55 & 0.21 & 1.1724 & 0.0003 & 2.4523 & 0.0005 & 18.38 & 0.03 \\
\hline 3501 & 4.65 & 0.07 & 1.1794 & 0.0005 & 2.4614 & 0.0008 & 18.63 & 0.02 \\
\hline 4000 & 3.70 & 0.78 & 1.1807 & 0.0010 & 2.4583 & 0.0019 & 18.54 & 0.05 \\
\hline 4501 & 3.77 & 0.93 & 1.1816 & 0.0004 & 2.4672 & 0.0014 & 18.58 & 0.04 \\
\hline 4730 & 7.03 & 1.40 & 1.1895 & 0.0014 & 2.4603 & 0.0039 & 18.51 & 0.07 \\
\hline \multicolumn{9}{|c|}{ Station 5} \\
\hline 10 & 61.45 & 2.62 & 1.1435 & 0.0001 & 2.4252 & 0.0001 & 17.76 & 0.01 \\
\hline 25 & 64.15 & 2.90 & 1.1447 & 0.0001 & 2.4269 & 0.0002 & 17.78 & 0.01 \\
\hline 100 & 44.23 & 6.24 & 1.1499 & 0.0001 & 2.4300 & 0.0002 & 17.99 & 0.01 \\
\hline 151 & 34.93 & 0.70 & 1.1493 & 0.0001 & 2.4309 & 0.0002 & 17.68 & 0.00 \\
\hline 201 & 34.67 & 1.53 & 1.1486 & 0.0001 & 2.4291 & 0.0001 & 17.58 & 0.01 \\
\hline 400 & 24.55 & 0.21 & 1.1484 & 0.0001 & 2.4293 & 0.0002 & 17.58 & 0.02 \\
\hline 602 & 18.87 & 0.93 & 1.1498 & 0.0002 & 2.4295 & 0.0004 & 17.99 & 0.02 \\
\hline 803 & 15.87 & 0.95 & 1.1521 & 0.0003 & 2.4300 & 0.0004 & 18.04 & 0.01 \\
\hline 1001 & 12.85 & 3.46 & 1.1521 & 0.0002 & 2.4323 & 0.0003 & 18.06 & 0.01 \\
\hline 1250 & 18.95 & 0.64 & 1.1531 & 0.0002 & 2.4296 & 0.0003 & 18.01 & 0.02 \\
\hline 1501 & 7.88 & 0.59 & 1.1552 & 0.0004 & 2.4349 & 0.0005 & 18.15 & 0.02 \\
\hline 2001 & 6.45 & 0.78 & 1.1583 & 0.0003 & 2.4350 & 0.0005 & 18.03 & 0.06 \\
\hline 2501 & 9.70 & 0.71 & 1.1546 & 0.0001 & 2.4321 & 0.0003 & 18.08 & 0.03 \\
\hline 3000 & 15.80 & 0.99 & 1.1576 & 0.0002 & 2.4372 & 0.0003 & 18.13 & 0.01 \\
\hline 3500 & 4.30 & 0.42 & 1.1664 & 0.0015 & 2.4385 & 0.0030 & 18.40 & 0.09 \\
\hline 3658 & 5.08 & 0.42 & 1.1637 & 0.0003 & 2.4420 & 0.0004 & 18.26 & 0.02 \\
\hline \multicolumn{9}{|c|}{ Station 6} \\
\hline 10 & 60.67 & 0.50 & 1.1454 & 0.0002 & 2.4270 & 0.0004 & 18.42 & 0.04 \\
\hline 26 & 48.22 & 1.42 & 1.1452 & 0.0002 & 2.4254 & 0.0003 & 17.91 & 0.01 \\
\hline 51 & 45.93 & 1.29 & 1.1457 & 0.0001 & 2.4266 & 0.0001 & 17.81 & 0.01 \\
\hline 100 & 45.81 & 0.72 & 1.1459 & 0.0003 & 2.4285 & 0.0004 & 19.64 & 0.04 \\
\hline 150 & 37.23 & 0.77 & 1.1473 & 0.0005 & 2.4319 & 0.0009 & 19.80 & 0.04 \\
\hline 201 & 31.31 & 0.81 & 1.1490 & 0.0001 & 2.4288 & 0.0001 & 17.75 & 0.01 \\
\hline 402 & 23.90 & 0.58 & 1.1458 & 0.0001 & 2.4254 & 0.0003 & 17.95 & 0.02 \\
\hline 603 & 16.11 & 1.18 & 1.1473 & 0.0002 & 2.4266 & 0.0003 & 17.98 & 0.02 \\
\hline 801 & 18.39 & 0.54 & 1.1480 & 0.0004 & 2.4280 & 0.0003 & 18.04 & 0.03 \\
\hline 1000 & 12.91 & 0.27 & 1.1491 & 0.0001 & 2.4289 & 0.0002 & 17.94 & 0.02 \\
\hline 1253 & 11.68 & 1.06 & 1.1533 & 0.0004 & 2.4381 & 0.0010 & 18.01 & 0.07 \\
\hline 1503 & 8.34 & 1.34 & 1.1562 & 0.0002 & 2.4361 & 0.0004 & 18.15 & 0.02 \\
\hline 2003 & 6.39 & - & 1.1567 & 0.0005 & 2.4389 & 0.0006 & 18.68 & 0.25 \\
\hline
\end{tabular}


Table 5.2 (continued)

\begin{tabular}{|c|c|c|c|c|c|c|c|c|}
\hline Depth & {$[\mathbf{P b}]$} & $2 \sigma$ & $206 / 207$ & $2 \sigma$ & $208 / 207$ & $2 \sigma$ & $206 / 204$ & $2 \sigma$ \\
\hline \multicolumn{9}{|c|}{ Station 6 (continued) } \\
\hline 2502 & 4.93 & 0.68 & 1.1598 & 0.0006 & 2.4399 & 0.0011 & 18.24 & 0.04 \\
\hline 3000 & 5.22 & 0.57 & 1.1596 & 0.0001 & 2.4413 & 0.0004 & 18.21 & 0.02 \\
\hline 3500 & 3.44 & 0.39 & 1.1612 & 0.0006 & 2.4403 & 0.0008 & 18.24 & 0.03 \\
\hline 4000 & 5.02 & 0.43 & 1.1649 & 0.0004 & 2.4437 & 0.0007 & 18.28 & 0.02 \\
\hline \multicolumn{9}{|c|}{ Station 7} \\
\hline 10 & 82.39 & 0.14 & 1.1398 & 0.0001 & 2.4188 & 0.0001 & 17.66 & 0.01 \\
\hline 26 & 82.45 & 2.01 & 1.1401 & 0.0001 & 2.4192 & 0.0002 & 17.40 & 0.01 \\
\hline 51 & 68.72 & 3.19 & 1.1411 & 0.0002 & 2.4216 & 0.0003 & 18.26 & 0.07 \\
\hline 101 & 43.47 & 1.90 & 1.1462 & 0.0002 & 2.4273 & 0.0004 & 17.87 & 0.11 \\
\hline 150 & 32.13 & - & 1.1466 & 0.0003 & 2.4286 & 0.0004 & 17.65 & 0.05 \\
\hline 201 & 29.45 & 1.24 & 1.1461 & 0.0004 & 2.4280 & 0.0007 & 18.47 & 0.07 \\
\hline 400 & 23.13 & 1.40 & 1.1445 & 0.0003 & 2.4251 & 0.0005 & 18.60 & 0.02 \\
\hline 602 & 24.11 & 1.86 & 1.1469 & 0.0001 & 2.4272 & 0.0003 & 17.96 & 0.01 \\
\hline 802 & 13.08 & 0.11 & 1.1488 & 0.0002 & 2.4299 & 0.0004 & 18.01 & 0.01 \\
\hline 1003 & 11.63 & 1.11 & 1.1511 & 0.0003 & 2.4312 & 0.0004 & 18.04 & 0.02 \\
\hline 1251 & 10.87 & 0.70 & 1.1554 & 0.0006 & 2.4359 & 0.0011 & 18.17 & 0.04 \\
\hline 1503 & 8.91 & 1.54 & 1.1565 & 0.0003 & 2.4379 & 0.0003 & 18.17 & 0.01 \\
\hline 1998 & 7.56 & 1.84 & 1.1566 & 0.0005 & 2.4353 & 0.0006 & 18.03 & 0.04 \\
\hline 2501 & 10.57 & 0.67 & 1.1584 & 0.0005 & 2.4385 & 0.0008 & 18.10 & 0.05 \\
\hline 3003 & 2.60 & 0.25 & 1.1633 & 0.0023 & 2.4358 & 0.0024 & 17.89 & 0.22 \\
\hline 3501 & 4.22 & 0.60 & 1.1654 & 0.0008 & 2.4426 & 0.0031 & 17.77 & 0.06 \\
\hline 4004 & $6.00 *$ & 1.50 & $1.1560 *$ & 0.0013 & $2.4284^{*}$ & 0.0022 & $17.72 *$ & 0.08 \\
\hline 4500 & 2.13 & 0.39 & 1.1663 & 0.0007 & 2.4460 & 0.0007 & 18.51 & 0.11 \\
\hline 4570 & 2.53 & 0.15 & 1.1665 & 0.0011 & 2.4499 & 0.0018 & 18.41 & 0.26 \\
\hline \multicolumn{9}{|c|}{ Station 8} \\
\hline 11 & 66.93 & 2.47 & 1.1405 & 0.0002 & 2.4205 & 0.0003 & 18.13 & 0.15 \\
\hline 26 & 52.97 & 1.12 & 1.1420 & 0.0001 & 2.4222 & 0.0002 & 17.81 & 0.02 \\
\hline 51 & 49.00 & 0.43 & 1.1418 & 0.0001 & 2.4225 & 0.0002 & 17.96 & 0.08 \\
\hline 102 & 46.10 & 2.75 & 1.1430 & 0.0001 & 2.4229 & 0.0003 & 17.79 & 0.12 \\
\hline 200 & 31.00 & 3.72 & 1.1446 & 0.0002 & 2.4242 & 0.0003 & 17.54 & 0.02 \\
\hline 401 & 22.62 & 2.40 & 1.1442 & 0.0002 & 2.4233 & 0.0005 & 17.78 & 0.07 \\
\hline 801 & 15.29 & 2.12 & 1.1530 & 0.0004 & 2.4339 & 0.0006 & 18.12 & 0.02 \\
\hline 1001 & 15.54 & 2.37 & 1.1521 & 0.0002 & 2.4331 & 0.0003 & 18.08 & 0.01 \\
\hline 1501 & 8.66 & 0.92 & 1.1571 & 0.0004 & 2.4384 & 0.0006 & 18.20 & 0.02 \\
\hline 2002 & 6.81 & 0.85 & 1.1611 & 0.0005 & 2.4419 & 0.0005 & 18.29 & 0.03 \\
\hline 3001 & 2.30 & 0.21 & 1.1642 & 0.0009 & 2.4431 & 0.0011 & 18.11 & 0.16 \\
\hline
\end{tabular}


Table 5.2 (continued)

\begin{tabular}{|c|c|c|c|c|c|c|c|c|}
\hline Depth & {$[\mathbf{P b}]$} & $2 \sigma$ & $206 / 207$ & $2 \sigma$ & $208 / 207$ & $2 \sigma$ & $206 / 204$ & $2 \sigma$ \\
\hline \multicolumn{9}{|c|}{ Station 8 (continued) } \\
\hline 4074 & 1.55 & 0.30 & 1.1674 & 0.0004 & 2.4480 & 0.0007 & 18.43 & 0.12 \\
\hline \multicolumn{9}{|c|}{ Station 9} \\
\hline 10 & 65.44 & 5.24 & 1.1446 & 0.0001 & 2.4265 & 0.0001 & 17.97 & 0.01 \\
\hline 25 & 60.89 & 1.41 & 1.1443 & 0.0001 & 2.4259 & 0.0002 & 17.84 & 0.01 \\
\hline 50 & 37.36 & 0.86 & 1.1442 & 0.0001 & 2.4260 & 0.0002 & 17.87 & 0.01 \\
\hline 101 & 24.93 & 0.41 & 1.1461 & 0.0001 & 2.4272 & 0.0002 & 17.92 & 0.02 \\
\hline 202 & 23.06 & 0.88 & 1.1458 & 0.0001 & 2.4266 & 0.0001 & 17.89 & 0.02 \\
\hline 401 & 17.63 & 2.72 & 1.1452 & 0.0002 & 2.4260 & 0.0004 & 17.90 & 0.01 \\
\hline 801 & 12.89 & 1.07 & 1.1571 & 0.0002 & 2.4377 & 0.0005 & 18.01 & 0.18 \\
\hline 1001 & 8.98 & 2.36 & 1.1561 & 0.0001 & 2.4369 & 0.0002 & 18.01 & 0.00 \\
\hline 1500 & 6.53 & 1.41 & 1.1600 & 0.0003 & 2.4374 & 0.0005 & 18.16 & 0.06 \\
\hline 2000 & 3.35 & 0.88 & 1.1633 & 0.0006 & 2.4439 & 0.0010 & 18.23 & 0.02 \\
\hline 2801 & - & - & 1.1693 & 0.0010 & 2.4414 & 0.0010 & 18.16 & 0.13 \\
\hline 3166 & - & - & 1.1711 & 0.0009 & 2.4476 & 0.0012 & 18.34 & 0.04 \\
\hline \multicolumn{9}{|c|}{ Station 10} \\
\hline 11 & 42.10 & 1.13 & 1.1481 & 0.0001 & 2.4304 & 0.0001 & 18.01 & 0.02 \\
\hline 25 & 43.57 & 2.03 & 1.1485 & 0.0000 & 2.4298 & 0.0003 & 18.01 & 0.02 \\
\hline 52 & 45.15 & 1.20 & 1.1529 & 0.0005 & 2.4343 & 0.0007 & 18.15 & 0.03 \\
\hline 100 & 43.10 & 1.70 & 1.1472 & 0.0004 & 2.4290 & 0.0005 & 18.01 & 0.01 \\
\hline 151 & 34.30 & 0.71 & 1.1494 & 0.0002 & 2.4292 & 0.0003 & 18.06 & 0.01 \\
\hline 201 & 33.70 & 0.85 & 1.1473 & 0.0002 & 2.4270 & 0.0004 & 17.99 & 0.01 \\
\hline 403 & 20.54 & 1.11 & 1.1451 & 0.0004 & 2.4214 & 0.0008 & 18.02 & 0.02 \\
\hline 601 & 16.05 & 0.21 & 1.1434 & 0.0002 & 2.4182 & 0.0005 & 17.89 & 0.01 \\
\hline 802 & 16.95 & 0.21 & 1.1427 & 0.0002 & 2.4178 & 0.0004 & 17.91 & 0.02 \\
\hline 1001 & 11.03 & 0.21 & 1.1516 & 0.0003 & 2.4283 & 0.0005 & 18.05 & 0.01 \\
\hline 1251 & 10.75 & 1.06 & 1.1533 & 0.0003 & 2.4340 & 0.0007 & 18.09 & 0.03 \\
\hline 1501 & 13.35 & 2.03 & 1.1586 & 0.0003 & 2.4389 & 0.0004 & 18.28 & 0.04 \\
\hline 2001 & 7.40 & 0.57 & 1.1559 & 0.0004 & 2.4345 & 0.0005 & 17.98 & 0.19 \\
\hline 2500 & 5.55 & 1.63 & 1.1634 & 0.0004 & 2.4404 & 0.0009 & 18.30 & 0.02 \\
\hline 3001 & 4.00 & 1.59 & 1.1610 & 0.0007 & 2.4332 & 0.0011 & 18.03 & 0.15 \\
\hline 3502 & $12.10 *$ & - & $1.1539 *$ & 0.0005 & $2.4323^{*}$ & 0.0007 & $18.03^{*}$ & 0.01 \\
\hline 4002 & 7.30 & 1.56 & 1.1731 & 0.0004 & 2.4519 & 0.0013 & 17.20 & 0.22 \\
\hline 4377 & $12.00 *$ & 1.98 & $1.1696^{*}$ & 0.0011 & $2.4534 *$ & 0.0008 & $18.23^{*}$ & 0.09 \\
\hline \multicolumn{9}{|c|}{ Station 11} \\
\hline 10 & 28.82 & 1.56 & 1.1502 & 0.0002 & 2.4286 & 0.0003 & 18.13 & 0.03 \\
\hline
\end{tabular}


Table 5.2 (continued)

\begin{tabular}{|c|c|c|c|c|c|c|c|c|}
\hline Depth & {$[\mathbf{P b}]$} & $2 \sigma$ & $206 / 207$ & $2 \sigma$ & $208 / 207$ & $2 \sigma$ & $206 / 204$ & $2 \sigma$ \\
\hline \multicolumn{9}{|c|}{ Station 11 (continued) } \\
\hline 25 & 33.26 & 1.02 & 1.1450 & 0.0002 & 2.4254 & 0.0004 & 17.95 & 0.02 \\
\hline 50 & 23.81 & 1.26 & 1.1446 & 0.0002 & 2.4234 & 0.0003 & 17.96 & 0.01 \\
\hline 100 & 23.70 & 2.19 & 1.1436 & 0.0002 & 2.4223 & 0.0005 & 17.95 & 0.02 \\
\hline 151 & 22.85 & 1.25 & 1.1441 & 0.0002 & 2.4231 & 0.0003 & 17.95 & 0.01 \\
\hline 200 & 22.80 & 1.05 & 1.1445 & 0.0002 & 2.4240 & 0.0004 & 17.95 & 0.01 \\
\hline 400 & 21.33 & 0.45 & 1.1426 & 0.0002 & 2.4202 & 0.0002 & 17.94 & 0.01 \\
\hline 600 & 20.18 & & 1.1418 & 0.0003 & 2.4171 & 0.0005 & 17.90 & 0.02 \\
\hline 801 & 19.76 & 0.12 & 1.1438 & 0.0004 & 2.4180 & 0.0005 & 17.95 & 0.05 \\
\hline 1001 & 24.67 & 6.03 & 1.1459 & 0.0005 & 2.4213 & 0.0011 & 17.92 & 0.02 \\
\hline 1251 & 21.00 & 3.19 & 1.1462 & 0.0005 & 2.4250 & 0.0008 & 17.98 & 0.03 \\
\hline 1500 & 16.71 & 1.99 & 1.1484 & 0.0001 & 2.4305 & 0.0009 & 18.09 & 0.03 \\
\hline 1999 & 7.21 & 0.33 & 1.1620 & 0.0006 & 2.4334 & 0.0011 & 18.13 & 0.09 \\
\hline 2501 & 7.67 & 2.85 & 1.1600 & 0.0006 & 2.4438 & 0.0013 & 18.27 & 0.06 \\
\hline 3001 & 7.69 & 3.19 & $1.1545^{*}$ & 0.0006 & $2.4292 *$ & 0.0013 & $17.97 *$ & 0.07 \\
\hline 3501 & 9.38 & 0.17 & 1.1728 & 0.0004 & 2.4474 & 0.0009 & 18.55 & 0.09 \\
\hline 4000 & 5.17 & 1.37 & 1.1768 & 0.0009 & 2.4505 & 0.0009 & 18.52 & 0.07 \\
\hline 4500 & 7.22 & 0.33 & $1.1659 *$ & 0.0006 & $2.4436^{*}$ & 0.0012 & $18.26^{*}$ & 0.05 \\
\hline 4782 & 7.30 & 2.21 & 1.1745 & 0.0014 & 2.4526 & 0.0019 & 18.43 & 0.07 \\
\hline \multicolumn{9}{|c|}{ Station 12} \\
\hline 10 & 21.31 & 3.06 & 1.1477 & 0.0002 & 2.4303 & 0.0005 & 18.04 & 0.03 \\
\hline 26 & 25.87 & 1.41 & 1.1481 & 0.0003 & 2.4295 & 0.0006 & 18.00 & 0.02 \\
\hline 50 & 20.64 & 0.72 & 1.1473 & 0.0003 & 2.4285 & 0.0003 & 17.99 & 0.02 \\
\hline 100 & 20.01 & 1.14 & 1.1472 & 0.0002 & 2.4275 & 0.0003 & 18.00 & 0.02 \\
\hline 151 & 20.91 & 1.64 & 1.1467 & 0.0002 & 2.4272 & 0.0003 & 17.99 & 0.02 \\
\hline 200 & 25.40 & 3.03 & 1.1465 & 0.0002 & 2.4260 & 0.0003 & 17.96 & 0.02 \\
\hline 401 & 22.10 & 3.96 & 1.1438 & 0.0002 & 2.4221 & 0.0005 & 17.95 & 0.02 \\
\hline 600 & 19.30 & 2.63 & 1.1421 & 0.0003 & 2.4184 & 0.0004 & 17.90 & 0.02 \\
\hline 800 & 19.01 & 0.89 & 1.1443 & 0.0003 & 2.4198 & 0.0004 & 17.97 & 0.04 \\
\hline 1000 & 19.95 & 1.77 & 1.1470 & 0.0005 & 2.4214 & 0.0006 & 17.99 & 0.02 \\
\hline 1251 & 11.75 & 1.57 & 1.1493 & 0.0006 & 2.4265 & 0.0009 & 18.07 & 0.04 \\
\hline 1501 & 10.25 & 0.17 & 1.1545 & 0.0004 & 2.4278 & 0.0010 & 18.20 & 0.03 \\
\hline 2001 & 7.56 & 0.61 & 1.1590 & 0.0003 & 2.4336 & 0.0008 & 18.13 & 0.04 \\
\hline 2499 & 8.15 & 3.04 & 1.1648 & 0.0006 & 2.4406 & 0.0009 & 18.23 & 0.04 \\
\hline 3001 & 4.54 & 2.78 & 1.1674 & 0.0004 & 2.4431 & 0.0005 & 18.30 & 0.06 \\
\hline 3499 & 5.25 & 3.47 & 1.1725 & 0.0005 & 2.4482 & 0.0005 & 18.47 & 0.07 \\
\hline 4000 & 5.42 & 0.72 & 1.1777 & 0.0011 & 2.4396 & 0.0033 & 18.10 & 0.24 \\
\hline 4501 & 4.06 & - & $1.1609 *$ & 0.0004 & $2.4370^{*}$ & 0.0005 & $18.21^{*}$ & 0.06 \\
\hline
\end{tabular}


Table 5.2 (continued)

\begin{tabular}{|ccccccccc|}
\hline Depth & [Pb] & $\mathbf{2 \sigma}$ & $\mathbf{2 0 6 / 2 0 7}$ & $\mathbf{2 \sigma}$ & $\mathbf{2 0 8} / \mathbf{2 0 7}$ & $\mathbf{2 \sigma}$ & $\mathbf{2 0 6 / 2 0 4}$ & $\mathbf{2 \sigma}$ \\
\hline \hline \multicolumn{2}{|c}{ Station 12 (continued) } & & & & & & & \\
5000 & 6.09 & 0.86 & 1.1797 & 0.0012 & 2.4508 & 0.0021 & 18.46 & 0.08 \\
5474 & 6.84 & 1.35 & 1.1759 & 0.0013 & 2.4532 & 0.0025 & 18.40 & 0.11 \\
& & & & & & & & \\
Station 14 & & & & & & & & \\
9 & 7.23 & 0.70 & 1.1676 & 0.0009 & 2.4422 & 0.0013 & 18.56 & 0.07 \\
25 & 8.14 & 2.41 & 1.1676 & 0.0004 & 2.4437 & 0.0010 & 18.32 & 0.04 \\
51 & 8.94 & 1.80 & 1.1645 & 0.0007 & 2.4430 & 0.0011 & 18.30 & 0.06 \\
100 & 6.03 & 0.16 & 1.1675 & 0.0002 & 2.4443 & 0.0004 & 18.37 & 0.04 \\
149 & 11.74 & 0.97 & 1.1656 & 0.0003 & 2.4422 & 0.0006 & 18.28 & 0.01 \\
201 & 12.55 & 0.94 & 1.1723 & 0.0007 & 2.4467 & 0.0013 & 18.56 & 0.06 \\
399 & 7.35 & 2.28 & 1.1736 & 0.0004 & 2.4460 & 0.0009 & 18.46 & 0.05 \\
600 & 5.17 & 1.51 & 1.1712 & 0.0003 & 2.4461 & 0.0006 & 18.42 & 0.04 \\
1000 & 6.30 & 0.46 & 1.1761 & 0.0005 & 2.4483 & 0.0008 & 18.49 & 0.03 \\
1250 & 5.92 & 0.82 & 1.1768 & 0.0009 & 2.4506 & 0.0011 & 18.43 & 0.03 \\
1501 & 6.18 & 1.69 & 1.1783 & 0.0008 & 2.4538 & 0.0013 & 18.52 & 0.05 \\
2000 & 3.78 & 1.19 & 1.1845 & 0.0015 & 2.4583 & 0.0021 & 18.72 & 0.05 \\
2500 & 5.49 & 4.43 & 1.1829 & 0.0015 & 2.4563 & 0.0026 & 18.62 & 0.08 \\
2999 & 6.70 & 0.22 & 1.1781 & 0.0006 & 2.4561 & 0.0009 & 18.68 & 0.18 \\
3501 & 4.31 & 1.53 & 1.1853 & 0.0013 & 2.4637 & 0.0019 & 18.51 & 0.07 \\
4001 & 6.05 & 1.06 & 1.1944 & 0.0007 & 2.4761 & 0.0010 & 18.78 & 0.07 \\
4500 & $32.43 *$ & 3.23 & $1.1424 *$ & 0.0004 & $2.4213 *$ & 0.0006 & $17.76 *$ & 0.02 \\
5000 & 6.85 & 0.59 & $1.1590^{*}$ & 0.0006 & $2.4372 *$ & 0.0014 & $17.99 *$ & 0.05 \\
5272 & 6.19 & 1.66 & 1.1897 & 0.0009 & 2.4676 & 0.0025 & 18.68 & 0.06 \\
\hline
\end{tabular}




\section{Appendix I. Pb isotopes measurement via MC-ICP-MS}

$\mathrm{Pb}$ isotope ratios in corals and sweaters were measured with multiple collector ICP-MS (Micromass/GV IsoProbe). Data processing and corrections were performed as described in Reuer et al. (2003), which includes eliminating the isobaric interferences of ${ }^{204} \mathrm{Hg}$, exponential "beta" mass fractionation correction normalized with a ${ }^{205} \mathrm{Tl} /{ }^{203} \mathrm{Tl}$ spike and with renormalization to NIST SRM-981, and a tailing correction derived from a curve fit to ${ }^{209} \mathrm{Bi}$ at half-mass intervals. Three modifications were made to the Reuer et al.'s method.

First, Reuer et al. used dilute high-purity nitric acid to correct for instrumental hardware blanks using the on-peak zero correction. However, Kelly et al. (2009) observed that an on-peak acid blank does not fully compensate for $\mathrm{Pb}$ coming off the instrumental hardware because ion-laden samples with $0.2-0.6 \mathrm{~V}$ signal of $\mathrm{Tl}$ and $\mathrm{Pb}$ ablate more $\mathrm{Pb}$ off of the hardware (cones, hexapole tips) than the high purity acid used in the on-peak zero correction. Therefore, in addition to the nitric acid, we also used nitric acid spiked with the same amount of $\mathrm{Tl}$ that was added to samples and the $\mathrm{Pb}$ isotope standards. We ran these two acid solutions $\left(\mathrm{HNO}_{3}, \mathrm{HNO}_{3}+\mathrm{Tl}\right)$ at the beginning and the end of each session, and also after every 8-10 samples during the session. The measurements of the $0.2 \mathrm{M} \mathrm{HNO}_{3}+\mathrm{Tl}$ will include the actual $\mathrm{Pb}$ blank in the $\mathrm{Tl}$ solution and enhanced ablation blanks. Thus, on-peak zero corrections for ${ }^{204} \mathrm{Hg}$ and all $\mathrm{Pb}$ isotope signals were made by subtracting $\mathrm{HNO}_{3}+\mathrm{Tl}$ signals from sample signals, and the 
corrections for ${ }^{203} \mathrm{Tl}$ and ${ }^{205} \mathrm{Tl}$ signals were made by subtracting the $0.2 \mathrm{M} \mathrm{HNO}_{3}$ signals from sample signals. Technically, the $\mathrm{HNO}_{3}+\mathrm{Tl}$ measurements will also include $\mathrm{Tl}$ tails, and thus, the tails onto the $\mathrm{Pb}$ isotopes from $\mathrm{Tl}$ spikes should be corrected by subtracting the $0.2 \mathrm{M} \mathrm{HNO}_{3}+\mathrm{Tl}$ signals from sample signals. However, we recently found that $\mathrm{Tl}$ sensitivity is enhanced in samples beyond standards in pure $\mathrm{HNO}_{3}+\mathrm{Tl}$ for unknown reasons, which means that the $\mathrm{HNO}_{3}+\mathrm{Tl}$ measurements underestimate the $\mathrm{Tl}$ tails on $\mathrm{Pb}$ isotopes. Thus, we make the tail correction for the $\mathrm{Tl}$ spikes using measured $\mathrm{Tl}$ signals and tailing correction factors determined using ${ }^{209} \mathrm{Bi}$. This will slightly overcorrect the tails since both the Tl blank and actual sample blank tails are being subtracted, but this uncertainty is probably lower than the other uncertainties we have.

Second modification was made on the ${ }^{204} \mathrm{~Pb}$ signal measurement. Reuer et al. (2003) measured all $\mathrm{Pb}$ isotopes using Faraday cups. In this study, ${ }^{204} \mathrm{~Pb}$ was measured with an ion-counting Daly detector with the WARP (Wide Aperture Retarding Potential) filter, while all other isotopes were measured on Faraday cups. The Daly detector has lower instrumental noise than Faraday cups, and the WARP filter reduces tailing signals from neighboring peaks, both of which are beneficial for ${ }^{204} \mathrm{~Pb}$ measurements because of its low abundance (low signal intensities) surrounded by larger ${ }^{203} \mathrm{Tl}$ and ${ }^{205} \mathrm{Tl}$ peaks. The deadtime of the Daly detector was determined by analyzing ${ }^{206} \mathrm{~Pb} /{ }^{204} \mathrm{~Pb}$ ratios in the $\mathrm{Pb}$ isotope standard solutions, while changing the strength of ${ }^{204} \mathrm{~Pb}$ ion beams by dilution with pure acid. A deadtime of 50ns was determined from a regression line between measured ${ }^{206} \mathrm{~Pb} /{ }^{204} \mathrm{~Pb}$ ratios and ${ }^{204} \mathrm{~Pb}$ counts, and was applied to correct the measured ${ }^{206} \mathrm{~Pb} /{ }^{204} \mathrm{~Pb}$ ratios using this equation: 


$$
R_{\text {true }}=\frac{R_{\text {measured }}}{\left(1+\text { deadtime } * c p s_{\text {measured }}\right)} * \text { CounterEfficiency }
$$

where $\mathrm{R}_{\text {true }}$ and $\mathrm{R}_{\text {measured }}$ are true and measured ${ }^{206} \mathrm{~Pb} /{ }^{204} \mathrm{~Pb}$ ratios, respectively, and $\mathrm{cps}_{\text {measured }}$ is measured ${ }^{204} \mathrm{~Pb}$ counts. During these measurements, the manufacturers successor company (IsotopX) discovered that their Daly detectors of our generation sometimes recorded electronic "reflections" in the circuit and overcounted signals in a non-reproducible manner (Isotopx technical note T11010). There is no technical fix for this problem and hence our ${ }^{206} \mathrm{~Pb} /{ }^{204} \mathrm{~Pb}$ ratios are not as good as they would have been using newer IsotopX Daly detectors which eliminate this problem. Moreover, we also observed that counter efficiency of the Daly detector drifts very slightly during a single day's run. To correct for this drift, we ran our in-lab Pb isotope standard (BAB3deg, with $\mathrm{a}^{206} \mathrm{~Pb} /{ }^{204} \mathrm{~Pb}$ isotopic ratio determined using Faraday cups at a lower dilution) every 3-5 samples and normalized the deadtime-corrected sample ${ }^{206} \mathrm{~Pb} /{ }^{204} \mathrm{~Pb}$ ratios for variations in the counter efficiency.

Finally, procedural column blanks were determined by analyzing 1-3 column blanks every $18-25$ samples. To obtain representative column blanks, we averaged ${ }^{208} \mathrm{~Pb}$ signal intensities of the column blanks measured over a period of time, grouped depending on the batch of reagents and resins used for column purification, excluding single runs where the column blank was contaminated. The isotope ratio of the column blanks could not be accurately determined due to low signal intensity $\left(10^{-3}-10^{-4} \mathrm{~V}\right)$. Thus, we assumed that if any $\mathrm{Pb}$ was added to the sample during column procedure, the $\mathrm{Pb}$ would have the isotope ratio of $\mathrm{Pb}$ typically used in U.S., which is approximated by our 
internal lab standard BAB3deg $\left({ }^{206} \mathrm{~Pb} /{ }^{207} \mathrm{~Pb}=1.0919 \pm 0.0016 ;{ }^{208} \mathrm{~Pb} /{ }^{207} \mathrm{~Pb}=\right.$ $\left.2.4739 \pm 0.0007 ;{ }^{206} \mathrm{~Pb} /{ }^{204} \mathrm{~Pb}=18.718 \pm 0.014\right)$, and subtracted the averaged values from the sample data based on the ${ }^{208} \mathrm{~Pb}$ signal intensity of the column blanks. These column blanks were 3-8 picograms of $\mathrm{Pb}$ for coral samples, and 7-16 picograms for seawater samples. The correction for the procedural column blanks made only slight differences to the final data relative to the raw data.

\section{References for Appendix I}

Kelly, A. E., M. K. Reuer, N. F. Goodkin, and E. A. Boyle (2009), Lead concentrations and isotopes in corals and water near Bermuda, 1780-2000, Earth Planet.Sc.Lett., 283(1-4), 93-100.

Reuer, M. K., E. A. Boyle, and B. C. Grant (2003), Lead isotope analysis of marine carbonates and seawater by multiple collector ICP-MS, Chem. Geol., 200, 137-153. 